\title{
Assessment and Learning
}

\section{A conversational exploration of the relationship between the assessment of managers and their learning}

\author{
A thesis submitted for the degree of Doctor of Philosophy \\ by \\ Laurence Solkin
}

Division of Human Learning, Brunel University

September 1998 


\section{Contents}

Abstract

Overview

\section{Part 1 The research process}

Chapter 1 An examination of my personal motives and subsequent learning

Chapter 2 An introduction to the research and its purposes.

Part 2 Management learning and assessment centres

Chapter 3 A consideration of assessment centres and supporting literature

Chapter 4 An overview of the assessment centre process used in the LFCDA and the related research project.

$\begin{array}{lll}\text { Chapter } 5 & \text { Research on assessment centres ( } 7 \text { case studies) } & 70\end{array}$

Case A

80

Case B

Case C

Case D

Case E

Chapter 6 Findings and conclusions on assessment centres and management learning.180

\section{Part 3 Management learning and NVQs}

Chapter 7 A consideration of NVQ assessment and supporting literature 202

Chapter 8 An overview of the assessment process and the management standards 206

$\begin{array}{lll}\text { Chapter } 9 & \text { Research on NVQs candidates (5 case studies) } & 221\end{array}$

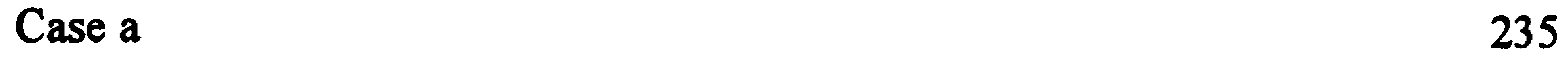

Case b 255

$\begin{array}{ll}\text { Case c } & 266\end{array}$

Case d 283

$\begin{array}{ll}\text { Case e } & 295\end{array}$

Chapter $10 \quad$ Research on NVQs assessors (survey results and subsequent discussions) 301

Chapter $11 \quad$ Findings and conclusions on NVQs and management learning 317

\section{Part 4 General conclusions.}

Chapter 12 General conclusions in respect of assessment and learning. 


\section{Appendices}

Appendix A

Appendix A1 LDCDA rank structure

Appendix A2 Extract from Operational Training Strategy

Appendix A3 Extract from "Towards 2000" LFCDA and Culture Change

Appendix B Assessment Centre Materials.

Appendix C Extracts from MCI Standards 


\begin{abstract}
Brunel University, Uxbridge

Division of Human Learning

Author: Laurence Solkin

Title: $\quad$ Assessment and Learning, A conversational exploration of the relationship between the assessment of managers and their learning
\end{abstract}

Year 1998

Degree Doctor of Philosophy

This research seeks to explore the relationship between formal assessment methods used within organisations and the subsequent learning of managers. The managers who participated in this study are all employees of the London Fire Brigade and the assessment that they undertook were administered as part of the selection and development activities provided by that organisation. The purpose of the research was to examine how being assessed affected their learning and the methodology used was that of action research. Two forms of assessment were administered those of the management assessment or development centre and those of the national vocational qualification system (NVQs). The research is based on two parallel sets of case studies with managers who participated in the different assessment activities.

The initial absence of any clear positive learning, as a product of being assessed, gave rise to a broader consideration of the relationship between assessment and personal learning. This examination culminated in the development of personally oriented tools that were used to interpret assessment data and to assist in the management of individuals' learning. The results are considered in the context of current literature and practice regarding assessment, and conclusions are made in relation to improving the learning outcomes of assessment processes. The issues of learner involvement and learner's control over the learning process are discussed and integrated within the conclusions and the adoption of a more humanistic approach based on self organisation recommended.

Finally, the research considers the methodology required for studies of the quality of human learning and the need for learner participation on the research process itself. 


\section{Acknowledgements}

To Sharon, without whom none of this would ever have been possible.

To Alex, Dominic and Ben, my sons, for keeping it all in perspective.

To my colleagues in the London Fire Brigade and particularly those who participated and supported this research

To my peers, and fellow inmates, at CSHL, whose insights and personal examples gave me inspiration, particularly to Myra Wilson

To my supervisors and mentors Sheila Harri-Augstein and Laurie Thomas. 


\section{Overview}

This research is about learning and assessment. It derives from two studies of how managers learn and how their learning may be affected or influenced by the experience of an assessment process. The two studies focus on different assessment processes. Although the two assessment processes are very different, as are the research participants, the data derived is remarkably similar, as a result of which I have chosen to present the research as parallel studies.

I have presented the research in four parts:-

Part 1 deals with general research issues, encompassing Chapters 1 and 2. It seeks to explain how the research came about from both a professional and personal standpoint.

Part 2 which includes Chapters 3 to 6 deals specifically with assessment centres and examines the relationship between assessment (or development) centres and management learning. Beginning with claims made within the literature, giving details of the actual process as conducted within the LFCDA, it presents the research conducted with assessment centre participants and the conclusions based on that research.

Part 3 examines the use of National Vocational Qualifications. It includes Chapters 7 to 11 and explores the relationship between the use of National Vocational Qualifications and management learning. The structure of part 3 is broadly similar to that of part 2, commencing with a literature review, giving details of the actual process as conducted within the LFCDA, presenting the research conducted with assessment centre participants and the conclusions based on that research. Part 3 also includes an additional chapter covering research conducted with assessors.

Part 4 provides general conclusions concerning learning and my role as a researcher. Chapters 12 and 13 examine the similarities between the two studies in relation to self 
managed or self organised learning and how conducting the research has influenced my own learning as a researcher, a manager and a designer of assessment systems. 


\section{Chapter 1 A personal account of undertaking a PhD}

\subsection{Introduction}

This $\mathrm{PhD}$ is about human learning. Its focus is the learning of managers as a result of some form of assessment. In addition, however, it is about my own learning and changes in my view of how research can be undertaken. Completing a PhD has been described as a "liminal journey". In this light the document submitted at the end of the journey - the dissertation itself - can be seen as an indication of an arrival at some new understanding or knowledge. My own view is that the research undertaken as part of this dissertation represents only part of a much longer life journey in which this particular meandering can be seen as an excursion, or perhaps, more hopefully an expedition, into a particular area of human learning. In this sense, my personal commentary is a reflective account of my travels on the way to completing this piece of work. In it I intend to explain how and why the research came about. In doing so, I also hope to explain why, despite all my efforts to the contrary, I still consider it to be in some ways, incomplete. It is an account of part of a journey, not always in a straight line, often having to overcome organisational and methodological barriers. In presenting it as I do, I have become more aware of its limitations and sought to justify what I see as its shortcomings. I ask the readers forbearance if the account sometimes appears confused or unduly complex - to some extent this is a matter of style. Much, however, of the apparent complexity derives from a developing understanding of the subject of learning. The research is not seamless but many stranded, both methods and underlying themes emerge and are developed as the project progressed. It is not realistice to describe these as if they were planned or intended and, for this reason, I have tried to explain how they came about .

\subsection{Initial interests - the beginning of a journey towards a PHD}

To some extent denoting any beginning (or for that matter any ending) is simply a matter of convenience. I registered for this degree many years ago. During this time my interest, and thus the focus of my research, has changed. When I began my research I was fully employed in the management of training. Having drifted into local government, I had made a specific 
career choice in relation to personnel work and gained a relevant professional qualification through evening classes. I secured a professional personnel role in training and commenced a Master's course with the hope of finding a more intellectually challenging and thus satisfying approach to my day to day activities. This academic background, together with several years practical experience, brought me to the London Fire Brigade and a Principal Officer's position managing training. At the time of registration I was thus relatively successful in my chosen career but intellectually (and to an extent professionally) frustrated. Training provided a steady income and a source of day to day job satisfaction but little intellectual challenge. As my career progressed, so I spent less time in training and more in guiding and developing others, evaluating their work (in particular training proposals and course outlines) and assessing and selecting consultants. All of this could be undertaken without any real common understanding of how training actually worked on anything more sophisticated than a purely practical level.

Initially I was concerned to discover something more substantial about the domain in which I worked - something which might justify its existence and explain its apparent success. My review of the literature, however, provided little in the way of comfort or enlightenment. As a profession, training was (and probably still is) dominated by people who are interpersonally adept, reasonable planners and managers of their own output, but singularly lacking in any understanding of what they do or why they do it. Their writing on the subject of training is sometimes painfully close to treating is as some distant cousin of religion, by way of cookery, based on second and third hand sociology. Too much paper and ink seemed to be related to the role of the trainer and little or none to the learner. Apart from downright mechanism (the use of overhead projectors and room layout) the major texts tended to concentrate on the relationship between the expert and his, or her, flock of receptive minds. Within the genre of training writing, the cook book approach of useful techniques was clearly dominant and the consideration of leaming or the learner relatively absent. When learning was considered, the approaches cited were often crudely behaviourist - suitable perhaps for rats but of limited value to someone who was errant enough to consider the people being trained as equals.

I therefore came to my present research, largely, though not exclusively as a result of my 
dissatisfaction with the dominant ideology of training. My concern was that organisational training i.e. organisational learning supported or managed by trainers, was reliant on a implicit theory of learning which prioritised the role of the external agent - i.e. the trainer . My intention or purpose, at that time, was to discover an alternative approach to the management of human learning, one that could be based on a more realistic model of learning but at the same time one which had practical application. My approach was structured as follows:-

- to examine this myth through the writings of its principal exponents

to reveal the inadequacy of the concept and,

using a Rogerian model, to suggest that training as an activity needed to consider the individual as an active participant in the learning process.

My view of conducting research at that time was about providing evidence which could discredit or undermine current notions about the trainer as the principal agent of learning. In this context, research itself was conceived of a simple process of gathering evidence from subjects to support a given assertion or hypothesis.

Looking back, from what is now a great distance, it appears that this initial aim or purpose was to substitute one form of expert model - that of the trainer, with that of another - the disillusioned trainer. Although the latter may have suggested more scope for the learner to take an active part in their learning, it still relegated them to the role of a subject, or someone who provided data, and their learning to that of an object of my studies. In this sense, the power relationship between learner and researcher or expert had not really changed. The creation of a new ideology of joint learning, or partnerships in learning, continued to look for its support to a research methodology practised on people rather than with them. All that had changed was the substitution of my researcher's control over learners in a research programme (which I would design and manage) for the earlier assumption of control over learners by trainers in a training course. I can still see aspects of the process which were 
practised on the learner, without any real sharing of information, let alone trying to establish common purpose.

\subsection{From training to assessment}

My early research into the area of organisational training sought to identify key components of the existing practitioners' model. My review of the literature revealed a rather disappointing selection of elements all based on an essentially tutor centred system. The significance of other factors or variables was either marginalised or excluded completely, as was the role of the learner in many writer's summaries of training. The absence of the learner proved problematic to the construction of a general taxonomy of training, since, by omission, most practitioners were indicating that the learner, and by inference learning itself, were of secondary importance to the process and in some instances even the technology of teaching/training. As such, learning became implicit. Learning was assumed to occur without any real evidence being provided or mechanism explained. At its most basic levels the dominant practitioners' model of training suggested that the learner played a subordinate role to that of the trainer and that the activity (of training) was largely, if not exclusively, concerned with the trainers relationship to the domain and the technology of teaching. The learner appeared seldom and then in the guise of a passive receptacle. This approach, or pattern of approaches, severely limited the use of any taxonomy in the investigation of self organised or leamer centred leaming. Leaming needs were identified or defined by the trainer. Learning methods were specified and controlled by the trainer. Evaluation consisted largely of the trainer being capable of demonstrating overall levels of change. Without seeking to be unduly cynical, the whole edifice gave the appearance of something constructed by, and for the benefit of, trainers. At the same time, the absence of evaluation as something more than an afterthought, guided me towards a more practical area of research - one in which the individual was being considered, albeit as someone who needed to demonstrate a particular level of performance.

If the evaluation of training is often superficial in both design and outcomes, the assessment of individual performance, by contrast, is often more specific and rigorous. This is 
particularly true in its treatment of data and individuals. Trainers may be allowed to justify themselves by their style of teaching; learners on the other hand, and learners in high risk environments, in particular, must demonstrate their skills and abilities in more precise and demanding conditions. The notion of assessment as a possible avenue for examining learning seemed to suggest a less didactic starting point for my studies. I became interested in the idea that an assessment process could influence individual learning. This view was extended when I began to realise that assessment and training systems often operated in isolation. To the extent that learners were often focused on results, rather than teaching content, a possibility existed that development could take place without, and even in opposition to, formal training or teaching.

In 1992 I was asked to assist colleagues at the recruit firefighter training school in a review of assessment procedures. The recruit course (then undertaken over 20 weeks) had developed over a considerable period of time and was a combination of quasi legislative requirements (a basic 12 week course which formed the basis of all firefighter training in the UK) and more specific needs related to operational practice (or in one or two instances the needs of the organisation as perceived by the senior officer in charge). The course structure was based on a syllabus which determined content and approach but not outcomes. The assessment system based itself on a separate set of documents which related to the job requirements themselves, although even these were sometimes recognised to be out of date. Most importantly, the syllabus and the assessment system, though of similar design had no specific linkage and what was actually being assessed could not be directly related to the components of the course.

Rather than follow the traditional "systematic trainer's" route of redefining needs in order to redesign the course (and then fitting it to the assessment system), I decided to investigate what might be the more coherent of the design and evaluation processes, and chose to look in more detail at the assessment. With the aid of a specially commissioned video, I asked two senior assessors to firstly describe what was taking place (i.e. to label the various tasks or components) and then to indicate their success/failure criteria. The outcome of this process was two sets of personal constructs both based on the same activity and both indicative of the 
actual criteria being used. Although a nominal (four point) scale existed, the elicitation of criteria revealed an underlying judgemental system based on personal constructs. As construct systems the criteria could be examined in more detail and exchanged between different assessors. The first point, noticed by both assessors, was a discrepancy between a largely mechanistic process, based on compliance with rules and regulations, and a specific aspect of the task which required what they termed as "judgement". At first the two criteria seemed very different, yet both assessors individually, and later, collectively, agreed that judgement was a key component of the task. It was not specified in the assessment guidance, nor was it specifically dealt with on the course, yet both assessors saw it as essential to effective operational performance.

This preliminary research, which is not reported fully here, threw up a number of significant pointers which were to lead to a radical review of my overall research programme. Firstly, it indicated a more suitable area of research in terms of learning - that of assessment. In as much as organisational assessment is often more rigorous than the design or delivery of training, the former may be taken as a clearer indicator of the organisation's required outcomes. Secondly, the method of ascertaining organisational outcomes used in this particular case could equally well be used on an individual learner basis, that is to say, just as assessors had views of how to assess and what criteria to use, so individual learners may also have views as to what they consider significant in terms of work or career related learning and these may, or may not, concur with the organisation itself. Finally, if we are to examine the effectiveness of learning, both the individual and the organisation need to be taken into account and some mechanism needs to be created to allow the two to communicate these different needs.

\subsection{What is learning ?}

At the same time that I was conducting these initial studies of assessment, I was looking for a framework within which individual learning could be examined. One of the most difficult tasks confronting me was to identify an approach to learning which actually recognised and valued the learner as an active participant in the learning process. One of the many 
unanswered questions in the literature about training relates to the nature of learning itself. Too often assumptions are made which imply that learning is a simple additive or acquisitive process - new knowledge either overwrites or extends existing knowledge, new understanding either amends or adds to the old. By implication, new is better than old, and more is better than less. Whilst such a model may well be useful for juvenile education, it suggests that existing or "old" understanding is of little value and thus that which existed before is of less importance than the message now being delivered by the trainer. Such a model not only emphasises the role and dominance of the trainer, but fundamentally rejects the notion of the learner as an active participant.

My concern was to identify a model or approach to learning which at least recognised some equivalence between leamer and trainer and, preferably, one which identified the significance of the former as an active participant in the process. The notion of self organised learning developed by Laurie Thomas and Sheila Harri Augstein (1.) (Harri-Augstein and Thomas 1991) seemed to provide such a possibility. The model of self organised learning contributed two key aspects to my research.

The first contribution was the notion of self organisation - a cybernetic process of self regulation based on the consideration of purpose, strategy and outcomes followed by a process of review and reflection. Purpose recognises that human activity of any form encompasses a degree of intentionality. Strategies are methods of achieving purposes, although they are often initially expressed as purposes in themselves, strategies define the actions which purposeful individuals take to achieve their objectives. Outcomes include a range of hard and soft data about the result of strategies, these can be specific achievements or personal impressions, and self organised learning is about a range of outcomes being examined. Review and reflection consist of examining, or recalling, outcomes in relation to strategies, considering the effectiveness of strategies in relation to purposes and if necessary seeking to redefine purpose. This is not too dissimilar from Argyris's double loop learning (2.) (Argyris 1994) in that it seeks to examine purpose as well as strategy.

Self organised learning or SOL can also be configured hierarchically to give different levels 
of learning conversation - the immediate learning domain, the broader person or life domain and a learning to learn conversation which is about how change takes place. Perhaps most significant of all however, from the perspective of learning, is the definition given to the process itself as "the conversational construction of personally significant, relevant and viable meaning" (3.) (Harri-Augstein and Thomas 1991)

If the first contribution of SOL was a means of recognising the learner as the key figure in the learning process, the second major contribution of SOL lay in its approach to research methodology and the concept of a conversational paradigm. At first, this tended to be peripheral to the value placed on learning. As the research progressed, however, it became obvious that examining learning could not be meaningfully undertaken from the position of an observer. To examine learning one had to converse with the learner and, as a consequence, the results of the research emerged from learning focused conversations. The conversational methodology represents both a means of exchanging meaning and, by representing meaning back to participants, an opportunity to create or construct new meanings. It is therefore, both a learning tool and, when used here simultaneously, a research tool. The development of my approach to research is explained below. It must, however, be pointed out that the concept of conversational research was not immediately apparent to me and that a considerable shift took place between my initial research focus and the research presented.

\subsection{The search for an appropriate methodology}

The modern study of learning, particularly management learning, has been dominated by the science of psychology. Earlier epistemological considerations have given way to a research paradigm based on a positivist model of the world as measurable objects. In this context the researcher is seen to stand apart, not only from the source of his, or her, information (research subjects), but also from the results of any investigation. The outcome of research is thus perceived as an objective (value free) contribution to the world of objective or scientific knowledge. Failure to stand apart in this way is seen as a corrupting influence in as much as the researcher has sacrificed their objectivity. Criticisms such as "contamination" or worse "subjectivity" are levelled against those who fail to pursue this dogma. At best their research 
is considered exploratory or preliminary - meaning that it has yet to conform to the requirements of the dominant ideology in science. At worst it is considered as heresy unscientific and hence unacceptable in polite academic circles. To admit to any form of subjectivity does not imply simply going beyond the current positivist paradigm, it explicitly goes against it. For this reason many researchers who find themselves driven to the consideration of the subject as an active participant have also derived for themselves the title of new paradigm researchers.

Reason and Rowan make the point that the dominant world view within science is fragmentary, it separates the researcher from the research subject, the expert from the object of study (Reason and Rowan 1981) (4.). Part of this new paradigm is about recognising subjectivity by allowing or promoting the participation of others. Equally significant, however, is the recognition of research as a creative act of the individual researcher recognising the relationship between the knower and that which is known. Thus a critical element in participative research, of any form, is the role of the researcher as someone who both gathers and interprets information and ultimately makes conclusions about what they perceive to be going on. To this extent even the most participatory research project contains some element in which the researcher seeks to make sense of both his, or her, own and some other persons understandings.

Reason and Rowan describe this as a self reflexive process in as much as our understanding of that which is known is made conscious to us through the process of considering how and why we consider ourselves to know it (Reason and Rowan 1981) (5.). Thomas and Augstein take this approach a stage further when they suggest that reflectivity needs to take account not only of ourselves but also of others interpretations i.e. that the researcher can only become fully aware though a process of conversation either internally (through the creation of reflective record) or externally though interaction or conversation with others. The notion of a conversational paradigm thus extends beyond individual or group self definition into an active process of defining self in relation or relations to others through the process of conversation or exchange of meaning. This is an important distinction to bear in mind, not only in considering how the researcher conducts research with others, but also how and why 
research findings are represented. A purely, or exclusively, self reflexive paradigm would feel no need to communicate its findings beyond itself and may remain unconcerned as to examining if, or how, such reports were interpreted. A conversational approach, by way of contrast, would interest itself not only in self representation i.e. representing the subjectivity from which it derived, but also a consideration of how that subjectivity was being interpreted by other paradigms. Whereas new paradign research sees itself as in conflict or even competition with the fragmentary eurocentric epistemology of modern science (in some ways a contender for the title of dominant paradigm in the revolutionary contest described by Kuhn (Kuhn 1962) (6.), Thomas and Augstein (7.) perceive themselves as operating between paradigms, or possibly above them. The idea of a conversational paradigm carries within it the notion that understandings can be conveyed between existing or competing paradigms - it predicates a plurality of understandings rather than either the monist structures suggested by Kuhn or the primordial or postrevolutionary chaos envisaged by Reason. It also suggests an equally radical but, potentially, less violent change process, based not on how scientists (as a community) view themselves and their work, but on how people generally could view their knowledge. It is predicated on Kelly's (8.) notion of "the personal scientist" rather than the professional or academic model (Kelly 1955).

Subjective reality is not, seamless or unified (in some religious or mystical sense) but actually multi layered, partial and hence immensely complex. Subjectivity as self definition, Harre (9) points out, has its limitations both ontologically and practically (Harre 1995). In a world defined by social as well as physical forces, interpretations of reality by either the researcher or research participants need to be compared to existing understandings of the world. The conversational methodology offers the opportunity to explore relationships within and between groups and individuals and to examine sense-making in a social context. It encourages the formulation and exchange of these subjective perceptions as well as personal reflection.

In addition to the methodological concerns (examined above) the notion of participation was also influenced by the notion of availability and willingness of research participants and the scheduling of assessment activities. This is not a piece of collective research and it would be 
inaccurate to describe the participants as co-researchers. Their interests are not necessarily identical to mine, although we have cooperated in the programme we have done so for different reasons and this particular outcome (a written account of the process) is mine alone. The combination of a participative methodology, the perceived needs of the participants in terms of their own learning, and the timing of specific assessment events has meant that research interviews have been conducted at very different times in different contexts.

Although the focus of the research has been on the impact of assessment, on some occasions research was conducted before an assessment, on others prior to a decision being known, on others before feedback, and on others only after detailed performance feedback was provided. This has a significant impact of the view of the assessment process manifested by the participant and therefore on their perceived learning needs and plans.

\subsection{The problem of evidence}

One of the emerging features of my research has been a transformation in the way in which research evidence has been collected and utilised. The early work on a taxonomy of training, together with much of the review of the literature concerning assessment, has centred on the absence of evidence. The fact that the learner seldom appears in research on learning is both obvious and problematic. Obvious, in the sense that the learner exists by implication, and whose character can often be inferred from what is written, but problematic, in the sense that the absence of direct and specific evidence makes it difficult to test some of the assumptions made. In the case of assessment centres it is far too easy to point to the lack of specific information concerning the learner. At the same time it is almostimpossible to demonstrate that some form of learning is actually not taking place. Whilst the absence of evidence cannot be relied upon as the evidence of absence, that fact that the literature does not even indicate a place to look makes such research difficult. It would be easy to conduct research on human leaming (as an outcome of assessment) and find that no appropriate evidence can be unearthed, but does this prove that it is not happening? It may indicate that the researcher is simply looking in the wrong place, or using the wrong tools.

The missing references to learning in training literature, the assumptive nature of learning 
implied by literature on assessment and the obvious gaps between the formal systems and a person's own judgements of learning are not in themselves evidence of learning. Rather they are indications of where learning may take place but in which the relevant conditions have not been identified. Just as the absence of evidence is not evidence of absence, so the apparent poverty of training and assessment systems is not an adequate explanation of how learning could be encouraged. Mine is not a barren academic approach to the study of human behaviour, it implies a willingness to change what is discovered and improve the position of the client - in this case the individual learner. Rather than demonstrate the absence of evidence, much of this research consists of the creation or development of learning which can then be used as positive evidence of how personally significant learning can be achieved.

This research is thus partially self fulfilling, in as much as, it seeks to generate evidence about human or social phenomena from the results of its own activities. Without research it is unlikely that there would be any evidence, or at least any evidence in the sense that positivist science has traditionally sought it - pure and unsullied by human (particularly researcher) contamination. The evidence which I seek to present is a product of my actions as a researcher together with those of the learner themselves. It is not exclusively my own but is a shared product. At the same time I have chosen to write it up in a way which the learner perhaps would not recognise and have done so for the purpose of presenting it as research evidence.

\subsection{A model of action research}

Kurt Lewin (10) created the concept of Action Research as a means within which social problems could be explored and solutions implemented (Lewin 1946). Action research was very much about problem solving and tended to take as its starting point the definition, by the researcher of an issue to examine or problem to be solved. Action research was hailed as a progressive movement in social sciences because it offered the opportunity to deliver relevant and valued solutions in the form of a range of welfare and social programmes. Marxism contrasts the traditional nineteenth century view of bourgeois science as an explanatory process with the notion of science as a change process. To some extent Lewin's Action Research recognises and takes account for the idea of change albeit within given parameters 
(limited solutions to generally limited problems). Modern psychology, on the other hand, as a peculiarly twentieth century science has, in technical terms at least, progressed from the notion of explanation to that of prediction and it is thus predictive science which dominates the psychology of assessment.

I wish to return science to an explanatory or exploratory process about change. To this extent, I wish to use explanation and exploration as an opportunity to encourage reflection and personal change. I see the researcher as a change agent, in collaboration with the research participant, and in negotiation about the outcome and the strategies to be pursued. In this study action research is not controlled by the researcher but rather guided by the researcher's skills and the conversation between researcher and participant. Different purposes, and therefore different strategies, are negotiated within an overall framework of improving the quality of individual learning. As the research progresses new purposes are identified and built in to the process itself. As new data appears, so this influences the direction taken with each participant, and as new processes are developed these are utilised to enhance the learning of individuals, and thereby provide additional data. This research is about using explanation as a means of encouraging or enabling personally meaningful change, it is also about the exchange of meaning and explanations to improve and enhance our understanding of ourselves and the domain in which we work.

\subsection{Methodology and Presentation}

Studies of human learning generally appear in two forms. Research into learning or teaching programmes tends to be represented in literature on education. The main approach is that of sociology and social psychology - such studies tend to focus on general factors and treat learners as uniform beings. On the other hand, studies in psychology, particularly occupational psychology, tend to follow a more traditional physical science route and whilst considering individual differences are often too keen to reduce these to impersonal data.

Within my own area the fields of research design, and therefore presentation, are dominated by the experimental or quasi experimental approach. In writing up my results I have tended to replicate the latter although I have not followed a traditional experimental method. 


\subsubsection{The Experimental Design}

Because the presentation of data follows the experimental approach, it is, perhaps, useful to define those characteristics of the traditional or physical science paradigm, before considering the significant differences in the way in which my own research proceeded.

Traditionally, research begins with the posing of a question or hypothesis. This is generally formulated from an examination of existing published research and the hypothesis is suggested by previous studies. Often, previous studies will have raised questions which may have been only partially or even inadequately answered. At least this is the impression given by the completed research publication. It may well be that the question is formulated before the literature study and that the purpose of the study is either to refine (or indeed give academic credibility to) the hypothesis.

Following the generation of a hypothesis, the researcher turns to the development of a methodology. Often, this too is derived from the available literature, and may even be determined by the nature of the hypothesis and the favoured current approach or conventional research wisdom. Having determined general methodology, the next step is the identification or determination of research data, the so called operationalisation of variables. This process consists of identifying those factors which contribute to the study and the mechanisms by which such data can be collected. In organisational and occupational psychology this normally consists of defining the means by which variables are to be measured.

Data is collected, measures taken and statistical analysis conducted. Often the scientific nature of the study is confirmed not by the results but by the level and sophistication of the statistical analysis. One could even argue that, within some disciplines, the pursuit of statistical methods has been given primacy over the research matter to the extent that the technique is seen as more valid or significant than the resultant conclusions. This is not always the case, however, the statistical method is often dictated by the nature and volume of the data used. Conclusions which flow from this analysis are thus traceable back to the data, which, in turn are related directly to the hypothesis or question posed. 
In itself, the traditional method is scientifically valid. Even where the presentation of research suggests a certain naivete, the process provides a coherent structured approach to the augmentation of public knowledge. What is often missing, however, is the part played by the researcher. Whilst it may be acceptable for researchers working in the physical world to avoid considering their own personal contribution to the research process, for psychologists, or others studying human beings, such an omission represents a serious flaw. Not only does the researcher play a key role in determining the nature of the study, his, or her, purposes and strategies will inevitably influence the results, not least by the interaction between researcher and research participants.

\subsubsection{An Emergent Methodology}

The research process used in these studies is presented in a traditional manner which, at first, sight may give the impression of a quasi experimental approach. In reality, however, the approach was much less structured than the presentation and the latter is a product of a later deliberate design stage. The methodology used can best be described as emergent. Emergent in the sense that both data and hypotheses emerged from the process at different times with different participants (although quite often new data and new hypotheses emerged at the same time) and the results were used to determine further progress in undertaking the research.

The two literature surveys provided some useful consideration of the assessment processes but did not generate a specific hypothesis which could be tested. Indeed, as the surveys themselves indicate, the subject of learning is often conspicuous by its absence. Assessment centre literature in particular is problematic in this respect. Rather than have specific hypotheses to test, the research addresses the issue of learning more generally.

Similarly, the experimental design is inappropriate to research which was generated from a very different perspective. Multiple hypotheses, existing within broad framework, were given focus not by the literature, but by the data as it emerged. The research participants themselves brought purposes of their own to the research and with them came direction. The idea of emergent methods is based on deriving and applying methods to the research process as they 
became necessary or useful. Action research is not simply about applying research methods to problems but also about deriving new methods from the requirements of the problem itself.

The development of interactive research techniques is a key element in the process and, without some explanation, the case studies themselves may appear as incoherent or even irrational. At first my hypotheses related to the effect of the assessment process or event on the learning of individual candidates. As such, the research methods used tended to look for change in the form of changes to proposed development. The lack of change indicated in the assessment centre studies suggested not only that this hypothesis about learning was difficult to sustain, but also that the research methodology was unlikely to find any real evidence of personal significant learning.

Of course critics will raise the problem of contamination, which is inevitable in any process which recognises subjective data as valid. Similarly, some may point to the poor operationalisation of variables. This is a fair criticism. If by operationalisation, however, we mean the standardisation or reduction in data necessary for measurement, then it must be pointed out that action research is not directed towards measurement but towards effective outcomes. My purpose in presenting this research is to examine learning from the perspective of the learners. If, at times, it appears that I am getting too close to my subjects, it is precisely because they are not subjects but particpants. I make no pretense of being objective - we are all participants. There may be different roles and responsibilities (and differences in power and status) but conducting action research means that all particpate in the process.

\subsection{Conclusions.}

I have tried to represent my research as a journey. This introduction represents my personal map. It seeks to trace the rather tortuous route I have travelled and, in doing so, explain some of the desisions taken and directions followed. It indicates themes or currents which run through the research but are not always immediately apparent. Above all, it seeks to explain that the place in which I started is very different from where I am now and the interests and motives which initiated the project have developed, and been developed, through my 
interaction with other learners. 


\section{Chapter 2 How the research came about}

\subsection{The Background}

The last two decades have seen a consistent decline in the popularity of conventional teaching and training for the provision of management skills. This is particularly true in relation to organisational or in-house training. Structured training is not seen as having delivered the necessary skills in the workplace. The combination of high costs (in terms of absence from work), coupled with perceived low relevance has encouraged organisations to examine other options for encouraging learning at work. Generally speaking, there has not simply been a replacement of training by some other form of development but rather a broader movement to diversify learning activities. Despite its apparent unpopularity training has not been replaced, but rather a range of "new" activities provided to supplement existing learning. Within this broad framework, considerable anticipation, if not actual consideration, relates to the use of assessment as a vehicle for self development. Occasionally the idea of assessment emerges from some body of extant literature on self development (such as some of the self assessment procedures suggested by Pedlar (1) (Pedlar, Burgoyne and Boydell 1995). More frequently, however, the notion of development seems to be attached to assessment processes as an inevitable, or implicit, consequence. This research seeks to examine how assessment actually influences development and looks in details at the relationship between the two activities.

The research is located within the London Fire Brigade which is a constituent of the London Fire and Civil Defence Authority or LFCDA. For the purposes of this study the terms LFCDA, Authority, London Fire and Civil Defence Authority and Brigade are used interchangeably, although strictly speaking the latter is a purely operational entity. The London Fire Brigade was created in the late nineteenth century as a uniformed, and hence disciplined, public service responsible for fire suppression (firefighting) in central London. Expanded in 1965 to cover Greater London it is currently responsible for both fire suppression and fire safety across the metropolis. Since the abolition of the GLC in 1986, the Brigade has become part of a statutory fire authority - the London Fire and Civil Defence Authority - made up of councillors from all 33 London local authorities. Although part of 
local government for over ninety years the Brigade, maintains its own quite distinct "culture", based partially on a re-interpretation of Royal Navy rules and regulations but also derived from the nature of its principal activity (firefighting). Power relationships within the organisation are significant and although it displays features of a bureaucratic organisation (rules and regulations etc), there is a thriving informal culture of networks and personal relationships, which is seen as having greater influence over promotion and appointment. Historically, the organisation has relied on formal course methods for the provision of organisational and individual learning within which external providers (principally the Fire Service College) have been responsible for the training of managers. External learning of this type has not been linked to job activities or necessarily job performance and the application in the workplace of such skills and knowledge, which may have been provided, has never been effectively evaluated.

During the early 1990's the LFCDA began to experience a number of organisational changes. Some of these were led internally by a new Chief Executive in the, then, fashionable, charismatic mould. Others were imposed externally, as a result of operational failures, including the tragic death of two firefighters. The latter event resulted in the issue of a statutory improvement notice by the Health and Safety Executive which required the Brigade to identify occupational standards or competences for its operational workforce based on the principles used to develop national vocational qualifications. The former gave rise to a number of visionary documents and a much smaller number of actual projects, one of which was a proposal to introduce a coherent and objective system for the recruitment and promotion of operational personnel. As an organisation, the Brigade consists of over 5,000 uniformed personnel organised in 10 ranks. Because there is only one entry level - that of Firefighter, the Chief Fire Officer was able to link the idea of competences or performance standards, which had to be achieved by personnel, to the notion of improving the quality of people entering and rising within the service. The resultant operational training strategy (Appendix A2) therefore rested on two distinct pillars:-

i. Improving the quality of personnel being promoted, through the use of more objective 
measures - essentially assessment centres - and,

ii. Ensuring that personnel were trained and developed to meet the requirements of the job, as expressed in occupational standards or competences.

Both systems relied heavily on assessment and, as will be considered in this research, carry with them a strong bias towards individual self development. Thus it came about that an organisation traditionally dependent upon external course provision for the development of its managers saw assessment as the means to break away from the constraints imposed by syllabus and teaching styles and reinvent itself as a "learning organisation".

\subsection{Assessment within the LFCDA}

Although there was some use of assessment centres at Principal Officer level within the LFCDA, the normal method of selection consisted of a semi structured interview preceded by some form of short listing, based either on application forms or a combination of application forms and psychometric (reasoning) tests. The use of tests had become commonplace and was seen as an objective and cost effective method of assessment. The LFCDA was, and still is unusual for an organisation of its size and status (public sector) in having no effective appraisal system. The assessment of manager's performance was thus likely to be sporadic, incoherent and, in the eyes of many staff, arbitrary. In many ways, therefore, the proposed introduction of coherent assessment came as a welcome sign of progress within the LFCDA, most significantly as an alternative to the subjectivity of interviews and management perceptions.

NVQ assessment was first introduced on a pilot basis as part of a qualification programme for managers. NVQ level 4 (MCI management standard M1) and NVQ level 5 (MCI management standard M2), (2) were offered through sponsored study to a pilot group of 12 officers across the Authority. The pilot was intended to examine the extent to which these qualifications were of relevance to LFCDA staff and to identify the resources required to complete and assess such qualifications. This programme was offered as an alternative to 
existing course based programmes such as the Diploma in Management Studies (DMS) and the Certificate in Management Studies (CMS) and staff expressing an interest in the latter were recommended to become part of the pilot programme. (Summaries of the standards are included in Appendix C)

"Assessment centres" were first introduced in the LFCDA for selection to a junior officer development programme. Successful candidates were offered a standard course designed around NVQ competences. This approach is one of several combinations of assessment and development available for assessment centre use and was seen as appropriate to more junior staff. At more senior levels, despite the use of the term development centre, the emphasis of the activity was selection and the option of a standard development programme was rejected in favour of an implicit model of personal development. My research focussed on this latter type of assessment and examined its use in selecting (or not selecting) staff for Principal Officer posts.

\subsection{How the data was collected}

The research presented here is a product of organisational requirements, personal interests and academic structure. Initially $I$ had intended to focus on assessors and assessees or candidates across both assessment centres and NVQs in sufficient numbers to undertake some sort of comparative validation. It soon became evident that, in the case of the NVQ pilot, the numbers would be too small to undertake this form of research and my attention shifted to a more individualistic process using case studies. (The assessor survey is indicative of the type of research I had hoped to conduct).The role of researcher was later combined with that of informal coach and, as the case studies progressed, so the research focused more on the needs of the participants than the organisation itself.

The assessment centre research was driven in its initial stages by organisational insecurity and the need to provide an indication of participant views on the process. Later, when the process was officially sanctioned by the Chief Fire Officer (in the form of using the data to make decisions) the views of the participants became irrelevant and the research unnecessary. 
As official support was withdrawn, so the research process became less overt. Whilst never being formally supressed, the research effectively became a series of partnerships between myself and the restearch participants.

The structure of the two sets of studies is broadly similar and follows a traditional pattern.

Parts 2 and 3 consist of

i. a literature review which examines the claims made for a relationship between assessment and learning,

ii. an overview of the assessment process within the LFCDA and how the research relates to it.

iii. The research data itself and, finally,

iv a set of conclusions based on the data.

In terms of content, the two sets of research represent significantly different approaches to learning. Assessment centre research is dominated by the assessment process itself since this event is seen as having an effect on learning. In the NVQ research the assessment forms part of a broader system, within which both learning and assessment are allocated a role. To some extent therefore, the investigation of assessment centres tends to be event based, whereas that of NVQs tends to examine events in the context of a broader process. In both sets of research the key issue is learning and, as the research progresses, so it is the learning issue which dominates both the methodology and the results.

The choice of research activities is both opportunistic and planned. Opportunistic, to the extent that the assessment activities were being undertaken within the organisation. Planned, to the extent that the initial focus on assessment per se within the assessment centre research was supplemented by a broader consideration of assessment as an activity within a 
performance management system within NVQs. A further stage would have been to examine the use of asessment in a less formal context such as appraisal. Unfortunaltely, however, this opportunity does not exist as the LFCDA continues to operate management development without any appraisal of performance. Although other assessment systems exist and assessment activities occur within the LFCDA, these tend to be course related and, as such, simply reiterate the model of teaching/learning implicit in a pedagogical aproach. My interests were in the use of assessment outside a teaching environment.

\subsection{Conducting research within the LFCDA}

I have dealt with my own personal research programme and the learning context in which it takes place. This also needs to be seen within an organisational context for research which could at times be supportive and at others openly hostile. Although The LFB has a commitment to becoming a "Leaming Organisation" (see Appendix A3) it remains a considerable distance from such a description. The Brigade is superficially a structured bureaucracy with clear and sometimes excessive rules and proscriptions. At an informal level, however, the organisation can best be described as a power culture (Handy 1985) in which distance from the Chief Fire Officer is the key to explaining decision making. Formal roles exist, as do prescribed methods and procedures. These should not be confused, however, with the application of rules, which is often arbitrary and capricious.

It would be easy to suggest that original research does not exist within the LFCDA. To the extent that it publishes very little information about itself, other than images of its own effectiveness, this might be accurate. On the other hand, research, in the sense of a deliberate process of gathering information, does take place. Leaving aside research on fires as physical phenomena, research in the London Fire Brigade tends to be both purposeful and focused. Data is firstly gathered to support existing positions. This is done both formally (mostly by external consultants) and informally as part of management decision making. Assumptions are then confirmed by rational enquiry (rather than challenged by alternative data collection or interpretation). Finally, conclusions in the form of endorsements or other self 
congratulatory statements are made.

We encounter the paradox of apparent rationality (the physical science model) underpinning a decision making process which relies on predetermined power relationships, which seem at best partial, but are probably also very arbitrary. Research is outcome based and focuses on specific predetermined sets of objectives. It either supports a position, in which case it is viewed positively, or it is received negatively, in which case it is often perceived as irrelevent or methodologically flawed. The idea of independent, let alone subjective, research does not form part of the learning ideology of the London Fire Brigade. In order to undertake research within the LFCDA it is necessary to fulfill the organisation's own need for self sustaining information. Thus, at times, my own research has been disguised behind an approved organisational requirement. In validating organisational strategies and programmes I have also been concerned to find alterative clients and sponsors. In this context, the research presented consists of several very different sets of negotiations over content and purpose. The result is several distinct individual research projects described here as case studies and grouped in terms of their source assessment activity. Each one highlights different client needs and, to a certain extent, different responses, within a common treatment or format.

At times the organisation has been supportive and has demanded information. In the most part, however, the absence of criticism (i.e. the suppression of contrary data, comment or interpretation) has been taken as confirming the validity of the strategy being pursued. On occasions, however, support has been withdrawn and barriers deliberately created, particularly when the direction was perceived as irrelevant or the potential conclusions to be reached dangerous to existing policies. 
Chapter 3 Management Development and the use of Assessment/Development

\section{Centres}

\subsection{The Assessment Centre Methodology}

The notion of an assessment centre (or development centre) often conjures up an image of a physical location to which people arrive, are assessed, and from which they subsequently depart. In fact, although assessment centres often operate from a fixed location, and may indeed sometimes give candidates the impression of being some sort of human processing plant, the term is used to denote any assessment activity which uses "multiple observers, multiple sources of information and specifically defined objective dimensions of performance (all of which are designed to add to the objectivity of the process) " (1.) (Moses 1977) This operational definition is important as both objectivity and perceived accuracy are key elements in the structure of the assessment centre methodology and have contributed to much of its attractiveness to large organisations. The history of assessment centres seems to indicate that they came about initially in goverment and the military (2) (Vernon 1962) and subsequently migrated to large civilian organisations such as the American communications company AT\&T. Their main purpose in these contexts was to select large numbers of people for standardised roles in which the possession of previous academic achievement was not necessarily seen as relevant to future performance. Standardised roles and generic job descriptions allowed the use of standardised procedures and the assessment centre was created by combining a range of previously isolated selection and assessment techniques including interviews, psychometric tests and exercises or simulations of the job itself. The precise point of origin (whether it be the Royal Navy, the US military, the British War Office Selection Board or even the leaderless group exercises of the German Wehrmacht) is of relatively little interest today as these early prototypes have now spread far beyond their initial applications. What remains, however, is a commitment to the idea of multiplicity of assessment techniques and assessors and, in a continuing concem (sometimes almost obsessional) with the idea of standardisation and objectivity.

It is beyond the scope of this study to examine in detail the claims made on behalf of the 
assessment centre save to note that these are not the sole source of its support. Much has been made of the scientific basis of the assessment centre methodology. Stewart \& Stewart, go so far as to claim that "The success of the assessment implementation rests heavily on a welldocumented and well-reported research base. It relies on a very successful blend of research, organisational needs and practice." (3). (Stewart, \& Stewart, 1981). On the other hand a large scale meta analysis by Hunter and Hunter (Hunter and Hunter 1984) (4) failed to discover precisely what is being assessed or to account for the continued use of what can be a very costly assessment process. This suggests that the perception of objectivity may be more common amongst managers themselves than among psychologists. Dodd (Dodd 1977) (5) indicates another significant component in the use of the methodology when he noted greater support for assessment measures in assessors than other non-involved managers (as indicated by attitude surveys of both groups towards assessment centres). It may well be that involvement by managers in the assessment process is as significant an attraction as the scientific evidence upon which the methodology is based. Schmitt et al.s(6) comment that "Assessment centres work when they are operationalised as they were intended" (Schmitt 1984) which is particularly significant in this context of development, as it suggests the need for congruence between the purpose and the content of the assessment process. This, in turn, raises the question as to what is the purpose of the assessment or development centre and, perhaps more precisely for this research, what are the developmental outcomes being sought?

The term development centre has come into use to signify a type of assessment centre which has some developmental or learning outcome. Blinkhorn (7) makes the point "One distinction that is worth making because it is commonly confused is between assessment centres and development centres. In the first of these the emphasis tends to be on choosing amongst candidates, or making decisions about streaming or tracking of candidates, whereas in the second the individual's development needs and potential are more the focus of attention, so that output is an individual development plan. This distinction can be very important for the motivation of the candidate and the impact of the process in the particular culture of the organisation. However, the activities involved for all concerned-assessors and candidates alike - have a great deal in common whichever style of process is used, and the term assessment centre tends to be used generically for both" (Blinkhorn, my italics). In practice 
the two terms tend to be used interchangeable and the precise description of the assessment process is often described as "developmental" more as a means of encouraging participation (or minimising employee concerns) rather than to denote any significant difference in approach or any specific commitment to development itself. For the purposes of this research, the term assessment centre has been used, although this is not the one used within the organisation concerned. In truth, either description would suffice. From the point of view of previous research, little that has been written about the assessment centre cannot as easily, and equally appropriately, be applied to the development centre (and vice versa).

\subsection{What is being measured in a management assessment centre}

One of the first issues to be contended with in assessing managers, whatever the form of assessment, is the sheer number and variety of classification systems available. Measuring managerial skills or attributes predicates some system of definition by which these elements can be identified. Stewart and Stewart refer to a range of such systems in use including "leadership factors" (Bowers and Seashore), "Assessment Dimensions" (Katz and Kahn) and "supervisory functions" (Kahn) all of which have been employed in the search for adequate descriptions of management behaviour. They conclude that this is " a set of notoriously elusive entities". For assessment centres this issue can be particularly difficult.

Generally speaking an assessment or development centre concerns itself with measuring things that can be shown to be predictive of future job performance. Mayo (8) refers to this as the measurement of potential and argues that "Potential is about the ability to do a different job with different requirements at some time in the future. It is nothing to do with being the most outstanding performer in the current job" (Mayo p 164). Identifying suitable measures is therefore about isolating predictive factors and this must form part of the design process in any assessment centre. Stewart, A. \& Stewart, V.(9) refer to the identification of such measures as part of the "diagnostic stage" of the assessment design process, the three objectives of which are :-

"to obtain, in objective behavioural terms a statement of those characteristics which:- 
a. "differentiates the manager who is perceived as effective at a given level (and perhaps in a given function) from the manager who is perceived as ineffective at the same level and function..."

b. "which are strongly associated with perceived effectiveness at a given level ..."

c. "which are strongly associated with perceived ineffectiveness at a given level ..."

(Stewart and Stewart 1991) These job performance characteristics are then translated into a combination of observable assessment centre behaviours termed an assessment dimension. The relationship between job performance and assessment centre performance is thus mediated by a set of common factors (or a dimension). Such “dimensions", however, are notoriously difficult to sustain, as they tend to exist most obviously within the assessment process and are often much less tangible in the more complex real performance of a manager. Klimoski et al (10) argue that "it is just not possible to establish assessment centres as valid measures of constructs" Klimoski, R. \& Brickner 1987, p 256). More recently the term dimension has been replaced by that of "competency" and an attempt has been made to introduce a more robust link between jobs and the assessment process. A competency, or a group of competencies, is a construct designed to link performance in the workplace to something that can be assessed elsewhere (primarily though not exclusively in an assessment centre). The term can be used equally well to denote a skill, knowledge or a general orientation to work and can subsume personality factors including attitudinal elements, reasoning abilities or intelligence together with organisation specific pieces of knowledge. Boyatzis's (11) model (which is typical of the competency approach) has three principal components - the function/demands of the job, the organisation (its environment and culture) and the individual's competencies. He defines "Effective performance of a job is the attainment of specific results (i.e. outcomes) required by the job through specific actions while maintaining or being consistent with policies, procedures and conditions of the organisational environment" (Boyatzis, 1982, p 12). The relationship between the job the organisation and the individual is further explored in as much as effective outcomes occur "when the responsibilities of the job to produce the desired result require the demonstration of specific actions, the individual draws from his or her inner resources the capability to 
respond" (p 12). "A job competency is an underlying characteristic of a person (my italics) which results in effective and/or superior performance in a job" (p 21).

Although the model in use may not always be that of Boyatzis, the structure of a competency and its purpose within the assessment centre process, remains essentially the same i.e. that of a job related, but person specific, performance predictor. One clear advantage of this terminology over the more discrete psychological dimensions which had preceded it has been the flexibility or even fluidity which a competency definition provides. According to Hoogstreima (12) "Competencies can be motives, traits, self concepts, attitudes or values, content knowledge or behavioural skills, any individual characteristic that can be measured or counted reliably and that can be shown to differentiate significantly between superior and average performers, or between effective and ineffective performers" (Hoogstreima 1994, p 28). Once again there is a process of analysis which in this case is clearly person centred with the objective "..to identify the operant thoughts and behaviour causally related to these successful outcomes". This is followed by an assessment on the basis that ... "The best predictor of what a person can and will do is what he or she spontaneously thinks or does in an unstructured situation - or has done in similar past situations" (p 26). She distinguishes from the more traditional job based approach and suggests that "The essence of the competence assessment approach to job analysis is that it studies the people who do the job well and defines the job in terms of the characteristics and behaviours of these people rather than taking the traditional approach of analysing the elements of the job" (p 27)

The adoption of a competency based approach has enabled organisations to determine their own set or sets of requirements and to design assessment processes based on a perception of their own needs. Whilst some have argued that these competencies may lack any real construct validity, it is often their face validity which attracts employers. The openness of the system can also be portrayed as attractive to candidates as "The assessment centre offers a way to test probable performance more directly and provides an escape from the tyranny of credentialism".(ref) Bray sees assessment centres as overcoming problems relating to specific backgrounds and experience. He points out that, whilst "..you can hardly escape from your bio-data, you can perform to the best of your ability in an assessment centre"(13) (Bray 


\subsection{How is it being measured?}

The use of competency systems may not have entirely overcome the problem of measurement although the operationalisation of these measures is normally much less contentious. The dominant concern here is, once again, with objectivity and this is a key feature of any assessment centre design regardless of the purpose to which information is later put.

(Consideration of this area makes up well over half of the published research on assessment centres and, if we exclude the use of psychometric testing, is probably the single most significant component of personnel selection research). As Moses (Moses 1977) points out "An assessment centre can be defined as a sophisticated rating process which is designed to minimise as many forms of potential rater bias as possible" (14) "multiple observers, multiple sources of information and specifically defined objective dimensions of performance all add to the objectivity of the process" (p 5) A great deal of importance is therefore attached to assessor training because.... "the quality of the judge is of great importance. The assessor must be able to assimilate a great deal of information rapidly, must be relatively free of personal biases, and must be perceived by his or her organisation as an effective individual. This last factor is of great importance in terms of how the results of the program are used" (Moses). Assessor training is an integral element in the assessment process and great stress is placed on the consistency of measurement and the avoidance of "effects" or errors such as "halos" or "horns" (positive and negative perceptions). The focus of this training is to produce a consistent common set of measurements or assessments based on similar evidence but across different assessors.

The issue of reliability, however, is not simply on of reducing inter-rater error. It may also be a function of the relationship between dimensions or competencies and the assessment component or exercise. The issue of measurement dynamics is of interest here because research suggests that what is being measured may not in fact be the competence, but rather a more complex set of behaviours present in an exercise.. Robertson et al (15) argue, on the basis of low dimension reliability across exercises, that exercises are not true measures of 
underlying traits but simply a measure of exercise performance (Robertson et al 1987). This is particularly important to decision making. Klimoski, R. \& Brickner, M. (16) conclude that "it is just not possible to establish assessment centres as valid measures of constructs" (Klimoski, R. \& Brickner, M. 1987, p 256) by which they mean predetermined constructs or competencies. They suggest that, if prediction in selection is all that is required, an actuarial (or points based) approach works better than individual dimensions. This actuarial approach creates overall scores rather than individual competency or even exercise scores and this has significant implications for feedback and development.

In contrast a more detailed, dimension by dimension, approach is advocated by Hinrichs and Haanpera (17) who argue that "when assessment evaluations are used for individual placement and development, rather than actuarial and selection decision making, it becomes more important to ensure that all of the individual components are being measured reliably... the data can then be used for meaningful feedback to the individual for self development purposes or for differential placement decisions" (Hinrichs, J.R. \& Haanpera 1976, p 33) "this calls for an internal consistency reliability model within each characteristic" (p 33) "As assessment centres become more and more used for development and/or placement purposes it becomes especially important to improve their measurement dynamics" (p 39). Different sorts of competencies may still require different forms of assessment and measurement Lewis (18) for example, refers to the identification of interpersonal attributes such as sociability as a "clinical judgement" (Lewis 1985, p 53) rather than a measurement of any sort. The assessment and measurement processes, however, are of greatest significance when one consider how the results of the process are to be used.

\subsection{What are the results?}

For the purposes of this chapter the results of an assessment centre are discussed in terms of those outcomes which are actually planned or anticipated by the process itself. These can be labelled the intended results. As will be seen later, the actual results can be more varied than those intended and, whilst these have sometimes been referred to a by-products, it is the unintended, or unexpected, outcomes which may have greatest impact on the individual 
candidate as a leamer.

For the most part the result of an assessment centre is some form of management decision which concerns either the appointment to a job or role and/or the placement of a candidate or group of candidates (depending on whether the candidates are mainly external or internal to the organisation). The decision itself requires data from the centre to be processed and, depending upon the desired decision, this is normally presented in a single or a series of weighted scores. The notion of providing some feedback to the candidate as part of the decision making process appears to have been very much an afterthought. Slivinski \& Bourgeois (19) refer to poverty of feedback in many traditional assessment centres "Historically, it seems that feedback procedures usually have been developed as an afterthought, with little consideration being given to follow up in terms of effectiveness of the feedback procedures" (Slivinski \& Bourgeois 1977, p 159) Feltham (20) noted lack of feedback in use of Assessment Centres in US fire departments. Although feedback sessions were included in the design of the assessment process these had a mean length of one hour and a mode of only 30 minutes. He considered that this provided insufficient time for detailed behavioural feedback and scarcely enough time to explain the assessment results (Feltham 1987). Byham (21) recommended that "more attention should be given what is to be done with the detailed amount of performance data generated by the assessment centre. Such data provide an excellent basis for personal development". (Byham 1977, p 57) but failed to provide aclear indication of how this should be undertaken or how development would take place.

The idea of a development centre suggests quite specific developmental outcomes and Boehm \& Hoyle (22) express this in terms of a partnership approach "Both the organisation and the individual are considered malleable. While employees are expected to modify their goals to mesh better with those of the organisation, organisations are expected to respond to the needs of their employees. The organisation is no longer the sole instigator of the development process and the definer of process goals but rather a partner in the enterprise where joint positive outcomes re defined and worked toward" (Boehm \& Hoyle, 1977 p 205). Not all writers view this as a partnership Gill (23) expresses the decision making process 
exclusively from the point of view of the employer "the important questions [for development centres] are to what relative extent are these skills trainable, what kinds of individuals (in terms of motivation, knowledge, personality, intelligence and specific attitudes) are likely to be most trainable in each and, finally, what are the most appropriate and cost effective training methods for individuals and for different management skills" (Gill 1982, p 146). The concept of trainability is echoed by Hoogstreima (24) who suggests that "Competencies differ in the extent to which they can be taught. Content knowledge and behavioural skills are easiest to teach. Altering attitudes and values is harder. While changing motives and traits is possible, the process is lengthy, difficult and expensive. From a cost-effectiveness viewpoint, the rule is to hire for core motivation and trait characteristics and then develop knowledge and skills" (Hoogstreima, 1994, p 29-30). These latter two writers would both claim to be involved in the design of development centres, yet, as we can see, the notion of development is very much circumscribed by what the organisation is prepared to support.

These differences in scope are not the only variations within the development centre genre. Boehm \& Hoyle (25) also distinguish between identification and diagnostic strategies asserting that "An identification program is intended to provide a means for selecting potential managers early in their careers, rather than assessing candidates for immediate promotion. Diagnostically oriented development programs, on the other hand, focus on the development of weak areas identified in the assessment. Unlike the identification programs, diagnostic ones do not necessarily have upward mobility of the individual as one of their eventual goals. One strategy calls for placing a person in an assignment that meshes with strengths, as identified in the assessment, in order to provide the individual with the opportunity to learn technical and job administration skills needed for advancement. On the other hand, the development-of-weaknesses strategy, would place the individual in an assignment where an opportunity exists to develop a weak area in the management skills area. Similar differences exist in the type of training that would be considered developmental and the criteria that would be used to evaluate the programs' effectiveness" (Boehm \& Hoyle, 1977 p 214) Thus even explicit, developmental programmes can seek to provide different developmental outcomes. 
When it comes to the candidate and their learning, writers often tend either to refer to what could, or should, happen (hypothetical learning) or generalise from studies of managers (which assumes that the activity of assessing is essentially similar to that of being assessed.) Byham, (26) is typical of the former, whilst he suggests that "participation in the exercise may be a learning experience per se and may provide personal insights into managerial competence, feedback on results... may clarify developmental needs" (Byham, 1982, p 146) he is also clear that "No evidence has been published that assessment centres develop self insights or lead to management development although learning and training principles would suggest that these programmes should lead to management development" ( $p$ 161) Storey and Sisson (27) suggest that "..good assessment practice is often recognised by the candidates themselves, and can be a motivating factor in its own right" (Storey and Sisson, 1982, p 167). No clear indication is given as to how this good practice is to be evaluated by the candidate or what the candidate will be motivated to do. Similarly Boehm (28) suggests that "Participants must do something with the information they obtain, feedback must be detailed, behaviourally specific and if possible related to organisational structure and job demands" (Boehm, 1988, p 42)but fails to indicate what sort of decisions the candidate will make or how they will change their behaviour. Greatrex and Philips (29) suggest a more participative approach to assessment " in terms of self development the key point is to maximise opportunities for individuals to assess their own competency level, compare to other sources, and then to develop their own training and development plan..." (Greatrex and Philips, 1989, p 39) and this view is supported by Robertson and Makin (30), who suggest the use of self assessment as a means to constructive dialogue within a centre. Neither writer can however point to any significant research to support their suggestions. Even Boyatzis (31), assigns assessment a supporting role within a more oriented training approach. Although three of his six stages could be related to the impact of assessment viz:-

1. Recognition of the competency.

2. Understanding of the competency and how it relates to management effectiveness.

3. Self assessment or instrumented feedback on the competency.

the other three all require additional training . Boyatzis' learning process involves other 
factors, most notably a week of feedback, guidance and counselling to establish a specific competency learning plan.

\subsection{Research on Actual Learning}

Research on actual learning or developmental outcomes (as opposed to implied learning) is rather limited and somewhat surprisingly tends to focus on the assessor rather than directly on the candidate. Two factors emerge in this research :-

- firstly, the effect of providing a framework within which to describe management activities and skills - this is referred to as the impact on managerial literacy, and

- secondly, the effect of assessment itself i.e. the process of data gathering and judging people against the criteria.

Imada et al (32) suggest that assessors acquire a vocabulary to use when talking about personal development to their subordinates...often they learn from other observers about the standards and expectations of the organisation in a very immediate way" (Imada, 1988, p 8) a point confirmed by Glaze (33) writing about the experience of a single company (Cadbury's) "...the most fundamental effect of the use of assessment centres has been their contribution to the behavioural literacy of our managers." within which he included "the observing, recording, classifying and evaluating of behavioural data", together with the provision of more specific feedback (Glaze 1992, p45).

Byham, (34) suggests a number of possible influences on assessors "By participating in assessment centre exercises themselves, by reading information on alternative solutions furnished in the printed assessor training material, and by observing practice, subjects and relating the practice subjects' behaviour to their own behaviour, assessors gain self awareness into their abilities." He suggests that " they (assessors) realised that as a result of participating in a centre, they (assessors) were not as good as they though they were in managerial areas... They are more likely to put the proper weight on the results in terms of 
selection, and they are more apt to take meaningful action in terms of development" (Byham 1977, p 93) He argues that this change is a result of the actual assessment process "The managers in an assessor training programme feel the weight of their responsibilities to the candidates and at the same time are often confused by a myriad of new administrative details and jargon. This increases their anxiety making them more highly motivated learners" ( $p$ 123)

The earlier study on assessor training Byham, and Thoreson (35) referred to the process perceived re-evaluation of skills by assessors as a product of the training programme rather than the assessment process and noted that "Manager's perceptions of their own skills go down markedly between the beginning and end of an assessor training program" (Byham, and Thornton, 1976, p 341). Byham (36) suggests that both training and actual assessment contribute equally to the learning "development comes through both training and experience as an assessor. It is unlikely that training alone would result in significant development" (Byham1977, p 50)

Direct studies of assessment and candidate learning are even more scarce Mayer's (37) study of feedback examined the effects of normative comparisons on self esteem and perceived threats to self esteem. He concluded that "negative feedback which focuses on comparing an individual with others would be expected to have negative feedback" (Mayer 1980, p 294) On the other hand Fletcher's (38) research which directly focused on decision impact suggests a limited time span for these effects. Fletcher evaluated the effects of an assessment centre within a bank which was designed to measure potential and was used to select for an accelerated promotion/development scheme. He used pre centre, immediate post centre, and 6 month follow up questionnaires of self esteem. He concluded that effects of assessment on self esteem are short lived and suggests that there is a short period of no more than six months which provides a suitable learning opportunity. His recommendations favour the rapid feedback of results (Fletcher 1991) Timing and timescales provide a further problem for identifying the impact of assessment as Jacobs (39) points out "people perform successfully at different times for different reasons and under different sets of circumstances. They are able to choose to some extent how they achieve their goals. Another problem with 
assessment centres is that learning is likely to take place throughout the duration of the event. Certain individuals while not performing well on the day may learn a great deal from it. As a consequence they actually begin to perform better at work" (Jacobs, 1989, p 33)

According to some authors the impact of assessment is not simply a product of the feedback process but may in fact be related to the assessment itself. Schmitt (40) investigated the effects of an assessment centre on self perceived performance (measured against the Assessment centre dimensions) using a pre, immediate post and six month follow up finding. They found that "significant changes in self perceptions do occur as a result of performance in the assessment centre even in the absence of feedback" (Schmitt et al, 1986, p 334) i.e. as a result of the performance itself and that "changes in self assessment tended to be consistent with the nature of the exercises and the dimensions rated" ( $p$ 334). This process of assessment may not be positive, as George and Smith note (41) "the assessment centre significantly reduced the level of self-assessed performance in much the same way that realistic job previews have been shown to reduce initial job expectations". Whilst the "receiving of new information encourages a re-assessment of personal ability" (George and Smith 1991) it may not necessarily provide a motive to learn or change

One of the very few direct studies of assessment impact by Robertson et al.(42) make the point that previous studies have examined consequences of assessment centre failure on candidates. In contrast, he identifies three effects or components of the response - cognitive, affective and behavioural [know, feel, do ?]. His results suggest that "self esteem and psychological health appear to be unrelated [unaffected] by selection decision" however, career stage is an important variable, as is centre design and procedure. (Robertson et al 1991)

\subsection{Potential Learning Outcomes and a Provisional Learning Model}

In summary, assessment or development centres are sophisticated systems for assessing individual potential. Their use has been primarily geared to selecting people (either for appointment or for training) based on some measurement of that potential. The use of the term development in this context often refers to a later stage in the process rather than a 
feature of the assessment itself. Where writers have chosen to examine learning they have often focused on the assessor rather than the person being assessed and, in the case of the latter, there is far greater speculation about learning than hard evidence. Those studies which do exist suggest that assessment can also have a negative impact on self esteem, but fail to relate this directly to any meaningful learning or change.

If we are going to try to identify learning within assessment our starting point must be the candidate. As Huck (43) points out "Future research must be designed to systematically investigate the effects of the assessment process on the assessee - attitude, self esteem, motivation and career planning" (Huck, 1973, p 210). In this context it may be useful to step outside the assessment centre methodology to consider research on other forms of assessment and to examine ways in which learning is explained.

Wexley (44), identifies a number of characteristics for effective appraisal interviews including participation, in particular - "the employee's sense of significance". He claims that "the more the employee is satisfied with the appraisal process the more likely performance improvement goals will be accepted and met" (Wexley, 1986, p 169). This suggestion, that the process of assessment is being evaluated by the candidate, raises the question of what criteria are in use. Landy and Farr (45) suggest that this idea of candidate validity is also part of a perception of procedural justice or fairness. They claim that perceptions of appraisal "fairness" on the part of the appraisee are not linked to the individual outcome of the system for that person but the process involved. The authors dispute the argument that people view faimess as a product of their own assessment and suggest that the conduct of the process is more influential in determining perceived fairness. This distinction between personal outcome and procedural faimess is important since it suggests that the decision need not be the sole outcome for the candidate - he, or she, will also have views on the way in which the assessment was conducted and perhaps even about the measures used.

The idea of providing or encouraging self knowledge, which seems to be alluded to by some assessment centre authors, can be found in a number of publications most notably within the movement towards management self development Pedler, Burgoyne, and Boydell, (46) 
contend that "whatever each of us does is affected by our own view of our job or role or our values, feelings, strengths, weaknesses and a host of personal factors. To keep a relatively high degree of self control, the manager must be aware of these self-attributes and the part they play in influencing action. The successful manager therefore needs skills of introspection" (Pedler, Burgoyne, and Boydell 1978, p 30) This knowledge or information needs to be seen in the light of a candidate based decision making process. Career development work such as that of Schein (47) examines the use of career anchors..."as the individual acquires further and further job experience he learns about himself: his strengths and weaknesses, his needs and desires, and most of all, wether he holds a particular orientation or inclination in terms of the work he undertakes...(he) develops a particular occupational self concept" (Schein, 1980, p 48). Informed career choice is based on - $\quad$ self perceived talents and abilities - $\quad$ self perceived motives and needs - $\quad$ self perceived attitudes and values

Information from assessment or development centres can thus be examined within a context of conscious career planning.

Nemerroff and Wexley (48) considering the role of feedback in appraisal identified three main behavioural characteristics which have a significant effect on subordinate attitudes towards the feedback process. These are ..."supportive behaviour by the manager , an invitation to participate and an invitation to set goals to improve performance (problem solving rather than individually focused on strengths and weaknesses)".(Nemerroff and Wexley1979)

In conclusion current assessment and development centre literature can be said to suggest areas for further research rather than to be capable of generating specific learning related hypotheses. An examination of candidate learning has to take account of the following three factors the idea that the candidate evaluates the process, and that this from part of their response to it 
- the notion that development centre information is used by the candidate within their own career and development plan, and finally,

- the ability or opportunity of the candidate and the organisation to set specific developmental goals

An adequate examination of all of these is part of the necessary study of candidate learning. In order to gain insights into these processes it is necessary to elicit from the candidate their own perceptions or constructs of the assessment process and work with them in the use of the information provided. 


\section{Chapter 4 The Divisional Commander Development Centre.}

\subsection{The context}

The London Fire Brigade consists of just under 6,000 operational or uniformed personnel organised into 10 hierarchical ranks from Firefighter to Chief Fire Officer. All operational personnel enter as recruit firefighters and progress through the ranks by a series of examinations (at junior levels) and promotion interviews.

\subsubsection{Context for leaning}

Historically the London Fire Brigade has been heavily reliant for its learning upon formal courses, both internally and externally provided. The largest supplier of training is the Fire Service College, whose contract with the LFCDA is worth in the region of $£ 1$ million per year. The key component of this provision is the so called "progression system" - a range of structured courses designed around the rank system. Allocation of course places to junior staff is by means of rank i.e all rank holders are required to attend courses regardless of their experience or individual needs. Entrance to higher courses relies on subjective assessment by line managers, as the LFCDA still has no formal appraisal system for the identification training needs. The sole exception to this rather crude system of training allocation is the selection process for the Brigade Command Course which is run by the Home Office and for which an assessment centre, modelled on the Civil Service Selection Board (CISB) is used. The purpose of this assessment is selection to a course and little direct performance feedback is provided for participants. Other forms of learning such as mentoring, coaching or action learning are almost unknown in terms of support by LFCDA, although they are sometimes referred to as possibilities. Similarly, while it is often mentioned in relation to development programmes, there is no real understanding of personal learning or what this might entail.

\subsubsection{Assessment Context}

Since 1986 the system of promotion has developed to include psychometric testing as well as 
written application and formal interview. Between 1992 and 1994 assessment for the rank of Assistant Chief Fire Officer also included some additional selection tools (mostly off the shelf exercises). One strand of the operational training strategy developed in 1994 included measures to ensure that suitable staff were identified for promotion by the use of assessment centres. Formal assessment of performance for the purpose of promotion was thus introduced (at four levels) within the organisation for the first time. Although some experience of running assessment centres had been gained at ACO level these activities had been largely bought in. The aim of the LFB in setting up an Occupational Psychology Unit was to provide in-house expertise to design and support large scale assessment activities. The first product of the in house team was an assessment process for junior officers, elements of which (such as the use of personality testing) were developed and extended in the Divisional Commander process. The Divisional Commander assessment process from which this research derives was initially designed as a stop gap measure for the selection of Assistant Chief Fire Officers (very much in the way that external consultants had been used previously) Its use for Divisional Commanders, however, gave the assessment process much wider exposure and provided the first real opportunity for research into learning.

\subsection{The Assessment Process}

The assessment centre method was used to select for the post or role of Divisional Commander. Which exists at the rank of Senior Divisional Officer. (See appendix Al for rank structure) At the time of running the centre there were 16 such posts in the London Fire Brigade of which 7 were vacant. Applicants for the post came from the next two ranks down (Divisional Officer I and Divisional Officer III respectively) applicants from the lower rank group were short listed provided that they had undertaken a period of temporary duty at the higher rank. This was the first time that the assessment centre approach had been adopted for this rank group and al though the title Divisional Commander Development Centre (DCDC) was used, the main purpose of the process, in the eyes of both the London Fire Brigade and the candidates, was that of selection for promotion. 
The design of the centre was exercise based $i$.e. it did not rely on or relate to any public system of explicit management competencies (although it could be argued that the process certainly reflected a number of implicit competencies in the area of interpersonal and analytic skills). The assessment process was created without detailed job analysis and based itself on a broad understanding of a senior managers role. The assessment process was initially designed for the assessment of officers to the rank of Assistant Chief Officer (where it once again went by the title of a development centre) and was applied without significant modification to the selection of Senior Divisional Officers on the basis that the same core areas were of relevance to both groups i.e. to all holders of a Principal Officer rank. The process consisted of a number of elements, some externally available, but the majority home grown job samples (details of the actual materials are included in Appendix B)

\subsection{The Design}

The assessment centre consisted of several discrete components offered on two separate days.

\subsubsection{Day 1 testing}

\section{a. Reasoning Tests}

A battery of three tests were administered and scored. The tests used were the Abstract, Verbal and Numerical tests from ASE's Graduate and Managerial Aptitude (GMA) series. Similar tests had been used on other assessment processes, notably that for Divisional Officers and most candidates were familiar with testing if not with the use of a non verbal (abstract measure). The choice of the GMA was based on the availability of a non verbal reasoning component and sought to extend the range of data available. Prior experience of test use in the London Fire Brigade had indicated a discrepancy between scores on verbal and numerical reasoning tests. The abstract reasoning component was seen as a means of examining reasoning without reliance upon numeracy or literacy skills. All test scores were normed against a broad composite norm of managers and the three individual scores combined to produce a single measure of reasoning ability (or general intelligence) 


\section{b. Personality measure}

A customised form of ASE's Business Personality Inventory was administered. This form used 9 of the initial 11 scales and 88 of the 129 questions. Questions were removed where they related to non relevant areas (such as commercial risk taking) and where they may have been seen as intrusive (e.g. sleep patterns or problems). A number of questions were also edited to remove ambiguities and possible local misinterpretations (in relation to Brigade use of technical terms). The resultant scores were normed against a fire service sample $(n>180)$ and the resultant normed scale scores compared to an "expectations" grid. The "expectations" grid provided a perceived achievement or effectiveness score against each scale and allowed an overall effectiveness rating to be produced based on how more senior managers viewed the possession of certain traits. Although not strictly profiling, the method used tended to favour mid range responses at the expense of extremes and could be accused of promoting a certain degree of blandness under the guise of balance. Personality testing of this type had not been used before and although a previous exercise at a more senior level had used 16pf the results were not translated into a score. The score itself was expressed as a percentage figure and indicated the extent to which the candidates expressed preferred style was seen as effective. Alternatively the scores could be seen to represent distance from organisational norms or expectations.

\subsubsection{Day 2 Exercises based on job samples}

\section{a. In tray exercise}

A job sample was created in relation to the preparation of a report concerning various options for a fire station renewal. The exercise consisted of the identification of key information and the creation of a proposal based on a series of pair-wise comparisons between different important factors. This was a new type of exercise for the London Fire Brigade and its length (4 hours) with a certain degree of complexity was meant to simulate actual file information. This was scored against a standardised key to produce an overall percentage score. 


\section{b. Group exercise}

Although this was based on a simulation of a management task, the context was general local authority rather than fire service. The design was for a cooperative leaderless exercise of the type common to many assessment centres. Candidates were given a range of information relating to budget options and asked to prioritise the various proposals . Each candidate was observed by two more senior assessors (each assessor in turn assessing two candidates) against a six criterion scoring sheet focused on interpersonal skills. Each criterion was scored on a five point scale, anchored at either end. Overall percentage scores were computed by summing scores from both assessors.

\section{c. Presentation exercise}

The presentation exercise paralleled the written exercise and was derived from the selection criteria. Candidates were asked to make a 20 minute presentation about themselves and their experience in relation to a specific selection criterion to three asessors. The presentations were assessed by three assessors against a five criterion score sheet focused on presentation delivery. Each criterion was scored on a five point scale, anchored at either end. Overall percentage scores were computed by summing criterion scores from three assessors.

\section{d. Command interview}

This consisted of a low fidelity simulation of a specific type of incident which the successful candidates would be responsible for. The simulation was presented verbally by one assessor, whilst the second assessor asked questions about how the candidate would prepare and implement a plan. Both assessors were more senior uniformed officers. This type of simulation was completely new to the London Fire Brigade and does not resemble any other form of interview process used by the Fire Service. This interview was scored on a single unanchored five point scale and scores below 3 were seen as failures (later this procedure would be used to prevent the candidate progressing to the second stage interviews). The 
significance of this exercise lay both in its relevance to the key purpose of the operational officer (command) and in its scoring. Whilst management provided the largest component of the job in terms of time, command was seen as the most critical as it was, and still is, the activity which distinguishes fire officers from their non uniformed peers. As such it not only provided them with clear link to their original career choice as a firefighter but also to a key factor in determining and maintaining their organisational identity. Although details of other exercise weightings were kept confidential, all candidates were aware that this exercise produced yes or no decisions and that failure would limit their chances of promotion.

\section{f. Written exercise}

In addition to attending the assessment day candidates also submitted a pre-prepared written script. The written exercise was largely derived from the pre-existing application form system and candidates were asked to write about themselves and their experience in relation to a specific selection criterion. The written scripts were than marked blind by three assessors against a five criterion score sheet focused on written communication. Each criterion was scored on a five point scale, anchored at either end. Overall percentage scores were computed by summing criterion scores from three assessors.

\subsection{Delivery}

A total of 34 applicants were assessed over a period of four months. The initial testing session (ability and personality) was followed by a three month delay during which an organisational restructuring was agreed but not implemented. The next stage, consisting of an assessment centre day was run in groups of six to eight over a period of two weeks and included all exercises with the exception of the written exercise which was submitted in advance.

\subsection{Scoring}

Candidates were not made aware of the scoring or decision making process with the exception of the command interview. Following completion of the assessment process, 
percentile scores from the reasoning tests were combined with weighted percentage scores from all the other exercises (with the exception of the commend interview) to create an overall score. Initially it was intended that all candidates would undertake a further interview stage after the assessment centre process had been completed. However, before this second stage commenced, and shortly after I had begun my research, a decision was made to use the assessment centre scores as a means of shortlisting for the second stage. Candidates were thus identified for a further stage based on command interview score of 3 or more and a combined assessment centre score of 50 or more. The successful performers were then subject to a further stage consisting of two further interviews, one with the Chef Fire Officer. The content and impact of the latter interviews are not considered within this study as they represented elements of a pre-existing assessment system for which a review was not seen to be necessary.

\subsection{Feedback}

Initial decision feedback was provided to unsuccessful candidates once the first cut decision was made - this consisted of a summary score only. Subsequent face to face feedback based on exercise scores was provided to all candidates over a period of some four months. No development plans were agreed or proposed during this process, although "needs" were discussed with candidates individually.

\subsection{The research process.}

Having been responsible for a significant part of the assessment centre design (particularly the work samples used in the in tray and group exercise), I was asked to carry out an evaluation of the process. The research process began when the assessment centre delivery was completed. It was initiated as a means of evaluating the assessment centre using candidate perceptions, and in particular gaining information about the different components. Originally, it was intended to interview all candidates and to follow this up with a survey of assessors. However, as the process of assessment was modified, (a decision was made to use the assessment centre as a means of reducing numbers before the final interview stage) so the 
research focus changed, from assessment to learning and, later, from evaluation to actual support. The research process continued through, and sometimes despite, the feedback provided, and, although unsupported officially, served to assist candidates to organise and manage their own development. The evaluation process which had enabled the research, although never formally suspended or completed, was allowed to disappear through lack of resources or support. The questions it could have raised were conveniently buried.

My official or sanctioned role as a researcher was curtailed when the decision was made to advise candidates of the results of the assessment centre. From this point onwards it was no longer possible to identify any effects of attending the assessment centre as distinct from the overwhelming impact of the decision (particularly to those who had failed). The evaluation process was no longer relevant to the organisation as decisions had already been made.

Whilst it may have been of interest to have some information from candidates, the necessary validation had been secured by the decision to progress (without further research). From this point on the priorities of the organisation and those of the candidates were clearly different. That of the former was essentially the promotion of the successful - development was of little significance. The candidates, on the other hand, had varying views on their development. In some cases, development was secondary to the impending promotion. In other cases the candidates remained confused by their assessments and needed help to plan and manage their own development. As the organisation focused on selection, I chose to focus on development and with it the purposes of the candidates. The research became a joint project between myself and the participants focused on their development needs rather than solely the effects of the assessment process. 


\section{Chapter 5 The assessment centre case studies}

\subsection{Introduction}

The case studies and, to an extent, the case study methodology, came about as a result of the data (or lack of data) generated. As such, their structure is by no means uniform. Certain minor presentational changes have been made to enable them to be considered collectively as a single (although varied) process. The common core of the research evidence is based on four distinct sets of information which are common to all (but one) of the studies - the exception being provided as an indication of how the process was frustrated in the case of one participant. The four sets of data or main stages in the research process are as follows:-

i. Initial development intentions which focus on immediate pre and post attendance development plans.

ii. Participants' own perceptions of their assessment centre performance and linked job performance. This examines perceptions of performance in the context of both the specific development centre components or exercises and related aspects of normal or day to day job performance.

iii. The development of personal constructs and the reinterpretation of performance. This elicits the participant's own view of successful performance in the work domain and maps this back on the development centre process. It also reviews the participants' own performance against their own personal constructs.

iv. Represents subsequent use of the constructs in self development. This illustrates the uses and potential uses of the construct system in self development as both a system for assessing developmental needs and, through the process of exchange, a means of enhancing both performance and mutual understanding of the domain.

For the purposes of presentation the four components are presented as separate sequential 
stages.

Stage 1 was based on a simple open questionnaire to elicit pre and post centre development intentions. The terms, bridges and barriers were included to examine the extent to which development intentions could be achieved by the participant and what additional information or support was required. The questionnaire was followed by an open discussion with each participant on the identification of development needs and the choice of development strategies.

Stage 2 used self perceptions of performance and was generated in response to discussions with participants A and B. It sought to focus attention on the assessment centre performance since, at the time, this appeared to be a significant variable in minimising the effect of attending the centre on participants' development plans. The discussion focused on the use of a simple ratings grid from 1 to 10 (not effective to effective) across the different components of the exercise. This grid is presented as a table in a standardised format. Table S 1 provides an example of the initial grid. Subsequent tables are numbered A 1 etc.

Table S 1

\begin{tabular}{|c|c|c|c|}
\hline Conponent: & : & 等: & :difference: : \\
\hline Overall CDC: ::::: & 7 & 6 & 1 \\
\hline : & 8 & 6 & 2 \\
\hline : namerical: & 6 & 7 & -1 \\
\hline
\end{tabular}

Key to scores $-10=$ most effective, $0=$ least effective.

Self represents self perceived performance in assessment centre, group mean represents perceived mean performance of peer group in assessment centre (difference is calculated from self-group and represents positive or negative performance in relation to group mean)

The later adoption of a second parallel rating process (stage $2 \mathrm{a}$ ) for linked job components was derived from participant $\mathrm{B}$ to examine the relationship between assessment centre and 
job performance. This data is also presented in tabular form using a standard system of labelling. Table S 2 provides an example and subsequent tables are labelled A 2 etc according to the participant's identifying letter.

\section{Table S 2}

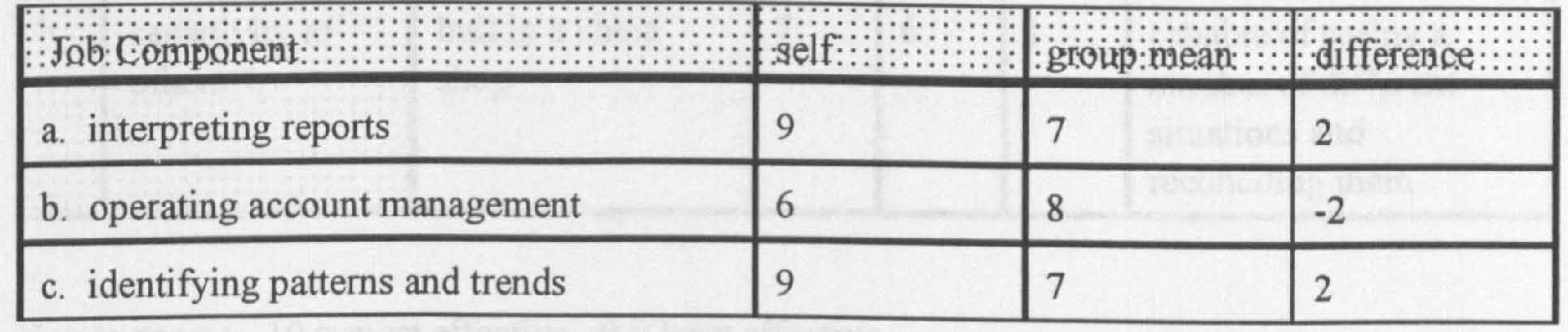

Key to scores $10=$ most effective, $0=$ least effective.

Self represents self perceived performance in job, group mean represents perceived mean performance of peer group in job activities (difference is calculated from self-group and represents positive or negative performance in relation to group mean)

Stage 3 consists of a version of the repertory grid process which was derived to compare workplace performance and assessment centre performances using a single set of scales. The derivation of the instrument is described more fully in details of participant $\mathrm{C}$. Table $\mathrm{S} 3$ represents the resultant personal construct grid. 
Table S 3

\begin{tabular}{|c|c|c|c|c|c|c|}
\hline & Quadities: : : & negative : & sele: & mèan: & diffe: & :positive ::::::::: \\
\hline a & andyouplaty & can read & 8 & 7 & 1 & $\begin{array}{l}\text { can undertake multiple } \\
\text { tasks }\end{array}$ \\
\hline$\dddot{a}$ & o & $\begin{array}{l}\text { bull in a china } \\
\text { shop }\end{array}$ & 7 & 6 & 1 & $\begin{array}{l}\text { capable of seeing a } \\
\text { number of different } \\
\text { situations and } \\
\text { reconciling them }\end{array}$ \\
\hline
\end{tabular}

Key to scores $-10=$ most effective, $0=$ least effective.

Self represents self perceived performance in terms of construct, group mean represents perceived mean performance of peer group in relation to construct (difference is calculated from self-group and represents positive or negative performance in relation to group mean)

Stage 3 also contains a remapping of the constructs back on to the assessment centre in terms of strength of coverage. This was developed for participant $\mathrm{D}$ as a means of decoding feedback information as it became available and incidentally provides a more specific participant oriented evaluation of the assessment centre process. Table S 4 provides an example of this data.

Table S 4

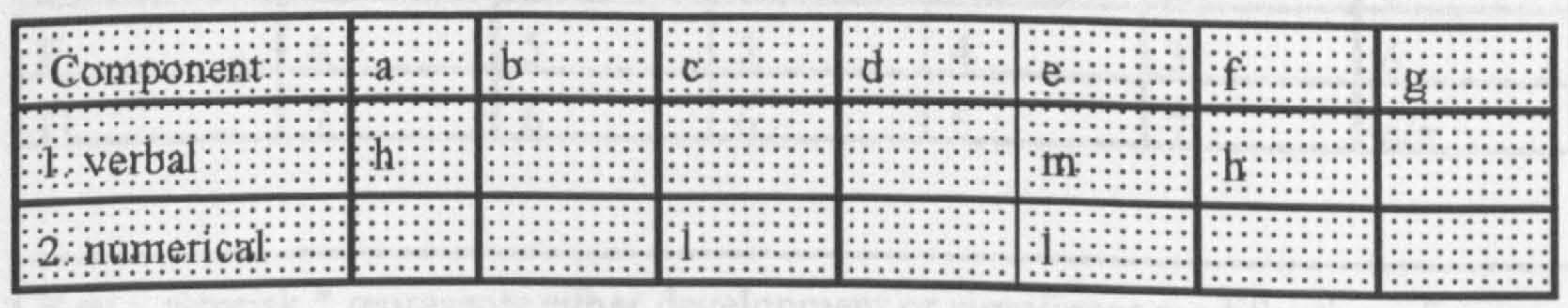

Stage 4 represents the continued use, modification and extension of the constructs as a means of eliciting further feedback for development and includes the exchange of constructs as a 
developmental tool (stage 4 a). Table S 5 presents an example of the way in which the remapping data is presented in this chapter.

Key: $\mathbf{H}$ represents strong relationship between construct and assessment component $M$ represents medium relationship between construct and assessment component $L$ represents weak relationship between construct and assessment component blank cells indicate no perceived relationship between construct and assessment component

\section{Table S 5}

Although the cases are presented in chronological sequence beginning with the first participant and the stages were conducted sequentially within each case, the actual development and delivery of different stages for each participant took place at different times i.e certain research processes were developed with a subsequent participant and then applied to an early participant. Listed below is the chronology of development and use of different research tools.

Table S5 Chronology of case studies and development of methodology.

\begin{tabular}{|l|l|l|l|l|l|l|l|}
\hline Darticioant & stage & stage 2 & stage 2a & stage 3 & stage 3a & stage 4 & stage 4a \\
\hline A & $1^{*}$ & 7 & 7 & 6 & 5 & 2 & n/a \\
\hline B & 2 & 2 & $1^{*}$ & 7 & 6 & $1^{*}$ & $1^{*}$ \\
\hline C & 3 & $1^{*}$ & 2 & $1^{*}$ & 4 & 3 & 2 \\
\hline D & 4 & 3 & 3 & 3 & $1^{*}-$ & 4 & 3 \\
\hline E & 5 & 4 & 4 & 2 & 2 & 5 & 4 \\
\hline F & 6 & 5 & 5 & 4 & 3 & 6 & 5 \\
\hline G & 7 & 6 & 6 & 5 & 7 & n/a & n/a \\
\hline
\end{tabular}

Key : asterisk * represents either development or significant modification of a research instrument/process. Subsequent plain numbers represent sequential usage of a specific process, $1=$ first use, 2 second etc. 


\subsection{Participant A}

Participant A was a substantive Divisional Officer who had been identified for temporary promotion to Divisional Commander (Senior Divisional Officer) prior to the running of the assessment centre. At the time of the first interview he was undertaking a principal officer role and had recently completed the centre but not received any feedback nor had decisions been made regarding his progress.

\section{Stage I}

a. pre centre development needs

- A general broadening of senior management skills especially strategic management.

- Greater operational awareness and experience via extensive exposure

b. pre centre development plans or strategies

The participant was scheduled for attendance on the Home Office Brigade Command Course for potential Chief Fire Officers which would assist in the broadening, albeit in a specific Fire Service context.

The issue of operational exposure was seen to be experiential and he sought greater operational responsibilities following promotion to the rank of Senior Divisional Officer
c. post centre development needs

A general broadening of senior management skills especially strategic management. The participant linked this to one of the exercises on decision making - the in tray exercise.

d. post centre development plans or strategies 
The Brigade Command Course was seen as an appropriate vehicle for his development needs in as much as it related to his career as a fire officer - other development , as a manager generally, was considered but not seen as a particular priority at this time.

e. Bridges and barriers

- No significant barriers were identified, whilst the place on a Brigade Command Course was seen as a substantial bridge.

\section{f. Review}

Participant A's analysis of needs derived from a long term view of his career to date and future expectations. His assessment of his own performance was at this stage "reasonably favourable" and although the availability of assessment centre data was seen as potentially useful, he had no clear views on its usage, other than as additional material to consider when planning his own development. The apparent lack of impact of the centre was not seen as problematic by the participant. Although he considered the process valid, in that it was a distinct improvement in terms of objectivity, he was not particularly interested in either the design of the centre or its possible use as a leaming event. To some extent, development planning was predicated by attendance on a formal training course, which, itself, had been determined by the use of another assessment centre, supplemented by the experience he hoped to gain in post following promotion. Further development was of interest but not a particular concern and certainly not a matter of urgency for this participant. Contingency planning in the event of not being promoted was not a significant issue for this participant- he had already achieved some measure of assessment centre success in another context. To this extent prior performance in a similar context may well have insulated this participant from any major assessment centre attendance effects. The participant was able to link the assessment centre into his own development needs and plan without any significant modification to his plans. At this point assessment centre attendance cannot be perceived to 
have had any significant impact on developmental planning.

\section{Stage 2}

The apparent lack of impact of attending the assessment centre seemed to derive from a relatively positive view of performance i.e. the participant's view of his performance suggested that he had "little to worry about" in terms of the assessment centre components. The obvious contrast with participant $\mathrm{C}$ (see below) suggested the area of self perception of performance was worth further examination. I therefore designed the second stage to examine the extent to which perceived performance may have acted as an intermediate variable and administered (first to participant $\mathrm{C}$ then participants $\mathrm{A}$ and $\mathrm{B}$ )

\section{Table A 1 Participant A self perceived assessment centre performance}

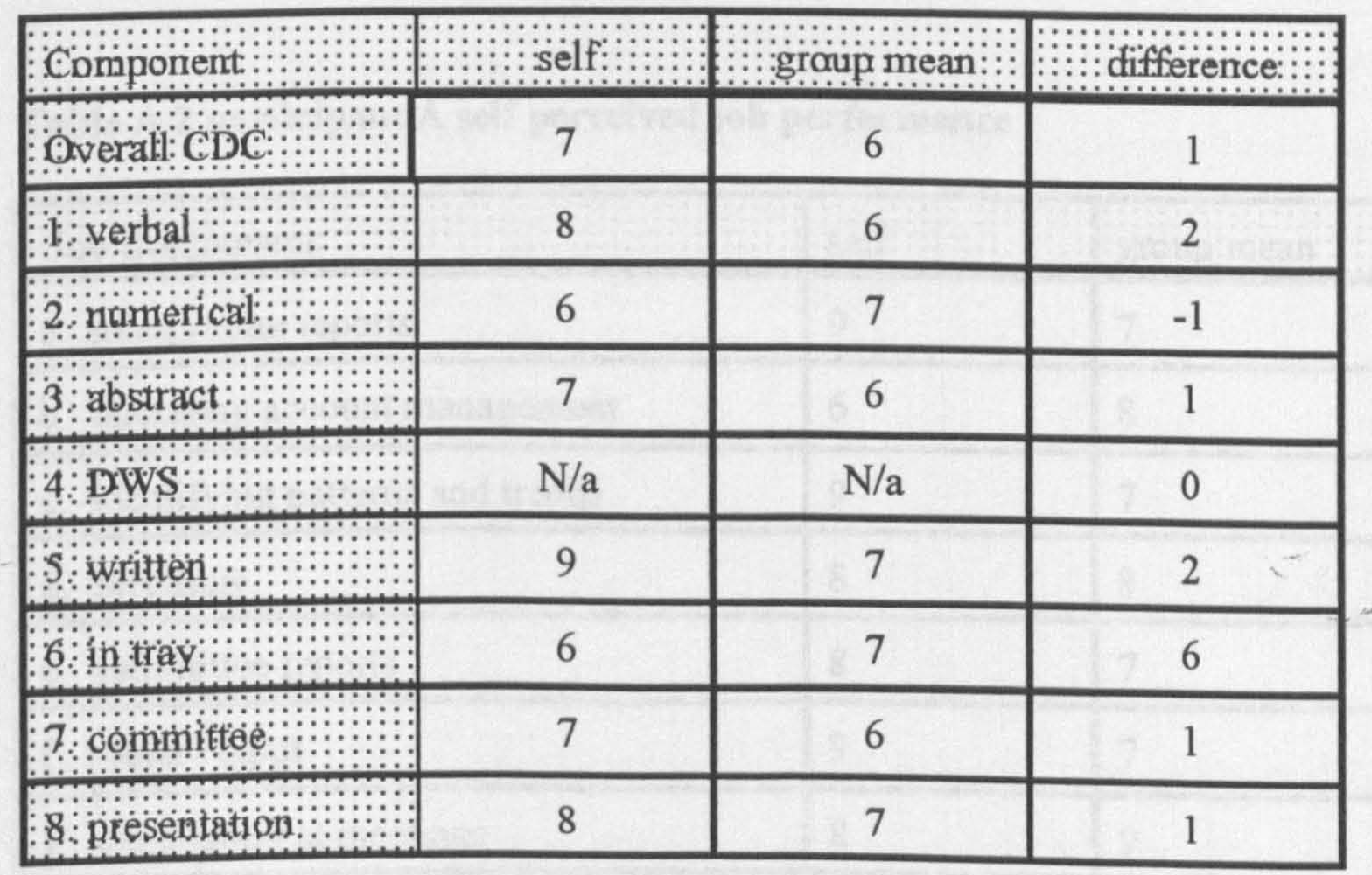

With the exception of one relatively minor component, participant A's more detailed view of his performance concurs with his overall view of his assessment centre performance and supports the idea that self perceived performance may be more significant in terms of impact 
than simple attendance. This suggests that the candidate is not a passive figure in the assessment process but one who evaluates his or her own performance.

In general, therefore, where needs were confirmed by the centre, these could be seen as a product of the external job related view of performance. Where needs were identified outside the centre but not within, these were maintained. The centre identified no new needs, and, to the extent that it failed to confirm existing needs, was seen as partial or, in this particular case, unrealistic.

\section{Stage 2a}

Stage $2 \mathrm{a}$ was derived as a means of providing similar or parallel ratings on linked job performance. The design of stage $2 \mathrm{a}$ is fully described in the case study for participant $\mathrm{B}$.

\section{Table A 2 participant A self perceived job performance}

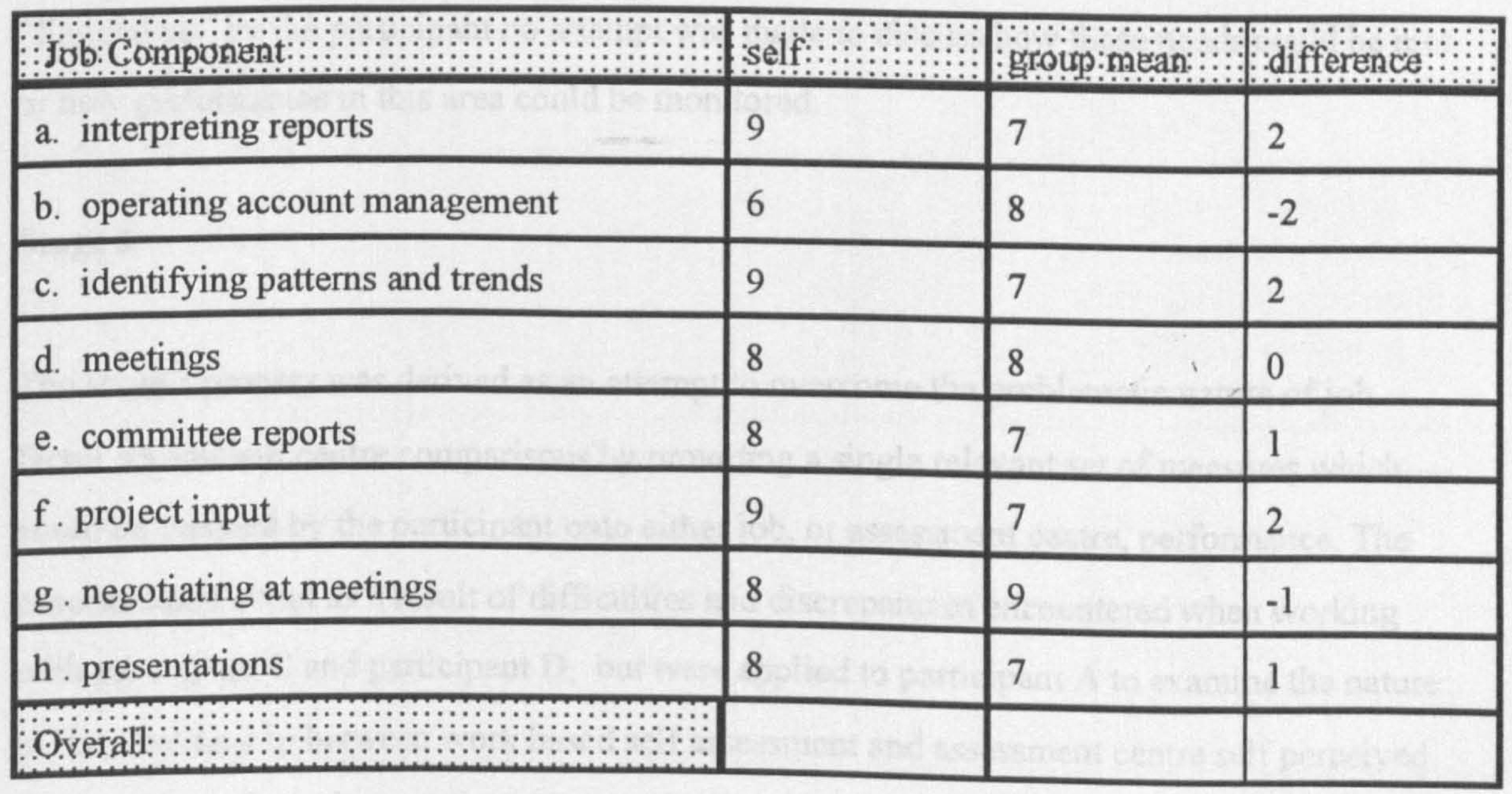

The use of the job factor perception enables a comparison to be made between different types 
of self assessment and for these to be compared to the initial development plans. The similarity between the perceived (relatively) poor performance in numerical tests and tasks requiring some financial acumen is interesting and suggested a common need in this area i.e. that the participant was separately aware of such a need prior to attending the centre and that his self perceived performance in the centre may itself have been influenced by views regarding his own skills prior to attending the centre. The contrast between the committee exercise rating and the negotiation rating was more difficult for the participant to explain but emerged as a product of the "unrealistic", i.e. cooperative, setting in which the exercise was placed. This exercise context and content contrasted to the genuine, non-co-operative or confrontational climate which existed within the organisation.

Stage 2a seemed to confirm numeracy in the context of comprehending the significance of numbers in the form of trends or relationships to be a key development area. Both job components and the assessment process self assessment indicated that the participant felt this area needed further attention. At this stage of the project, however, the focus of the research was on validation and only incidentally development. Although development needs were "flagged up" by the participant no attempt was made to discuss how these needs could be met or how performance in this area could be monitored.

\section{Stage 3}

The stage 3 process was derived as an attempt to overcome the problematic nature of job factor assessment centre comparisons by providing a single relevant set of measures which could be mapped by the participant onto either job, or assessment centre, performance. The process came about as a result of difficulties and discrepancies encountered when working with participant $C$ and participant $D$, but were applied to participant $A$ to examine the nature of the relationship between work based self assessment and assessment centre self perceived performance. Since the process had proved of benefit to those participants experiencing difficulties I was unsure of its value to a candidate with a clear development plan and two apparently confirmatory sets of self assessments. Nevertheless, I felt that the extension of the 
process could still be of value in examining certain issues relating to the development needs identified, not least, by suggesting job areas as opportunities for the development of numerical/financial skills.

The method for the derivation of the table or grid was a variation of the standard means of eliciting a repertory grid the full details of the process are described in case study C.

Table A 3 participant A performance constructs

\begin{tabular}{|c|c|c|c|c|c|c|}
\hline : & Qualities: & negative & self: & meap & diff: & positive \\
\hline 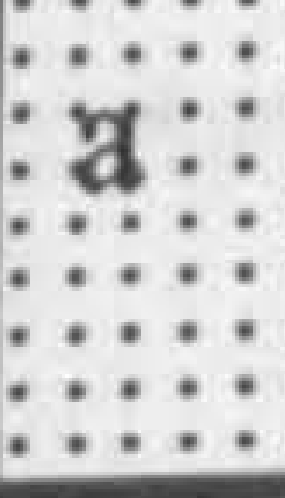 & analytic abulity & can read & 8 & 7 & 1 & $\begin{array}{l}\text { can undertake multiple } \\
\text { tasks }\end{array}$ \\
\hline $\begin{array}{l}\vdots \\
\vdots \\
\vdots\end{array}$ & onsitivity to & $\begin{array}{l}\text { bull in a china } \\
\text { shop }\end{array}$ & 7 & 6 & 1 & $\begin{array}{l}\text { capable of seeing a } \\
\text { number of different } \\
\text { situations and } \\
\text { reconciling them }\end{array}$ \\
\hline : & negotiation & single track & 7 & 7 & 0 & $\begin{array}{l}\text { flexible approach } \\
\text { responsive yet mindful } \\
\text { of objectives }\end{array}$ \\
\hline di: & sensifivity to & $\begin{array}{l}\text { aware of basic } \\
\text { needs }\end{array}$ & 6 & 5 & 1 & $\begin{array}{l}\text { aware of effect of self } \\
\text { on others }\end{array}$ \\
\hline 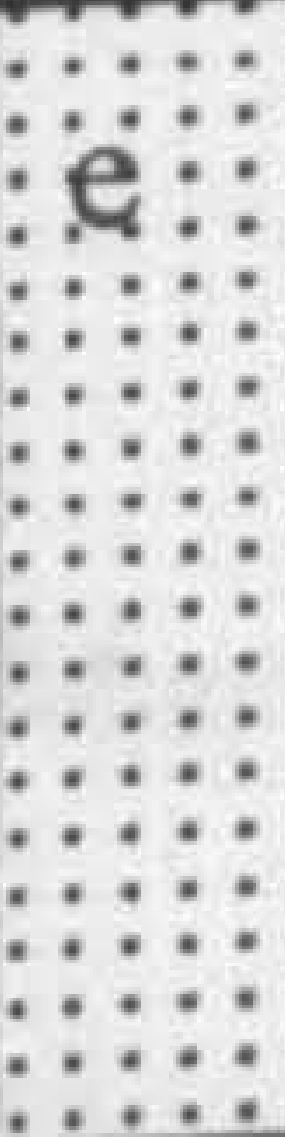 & 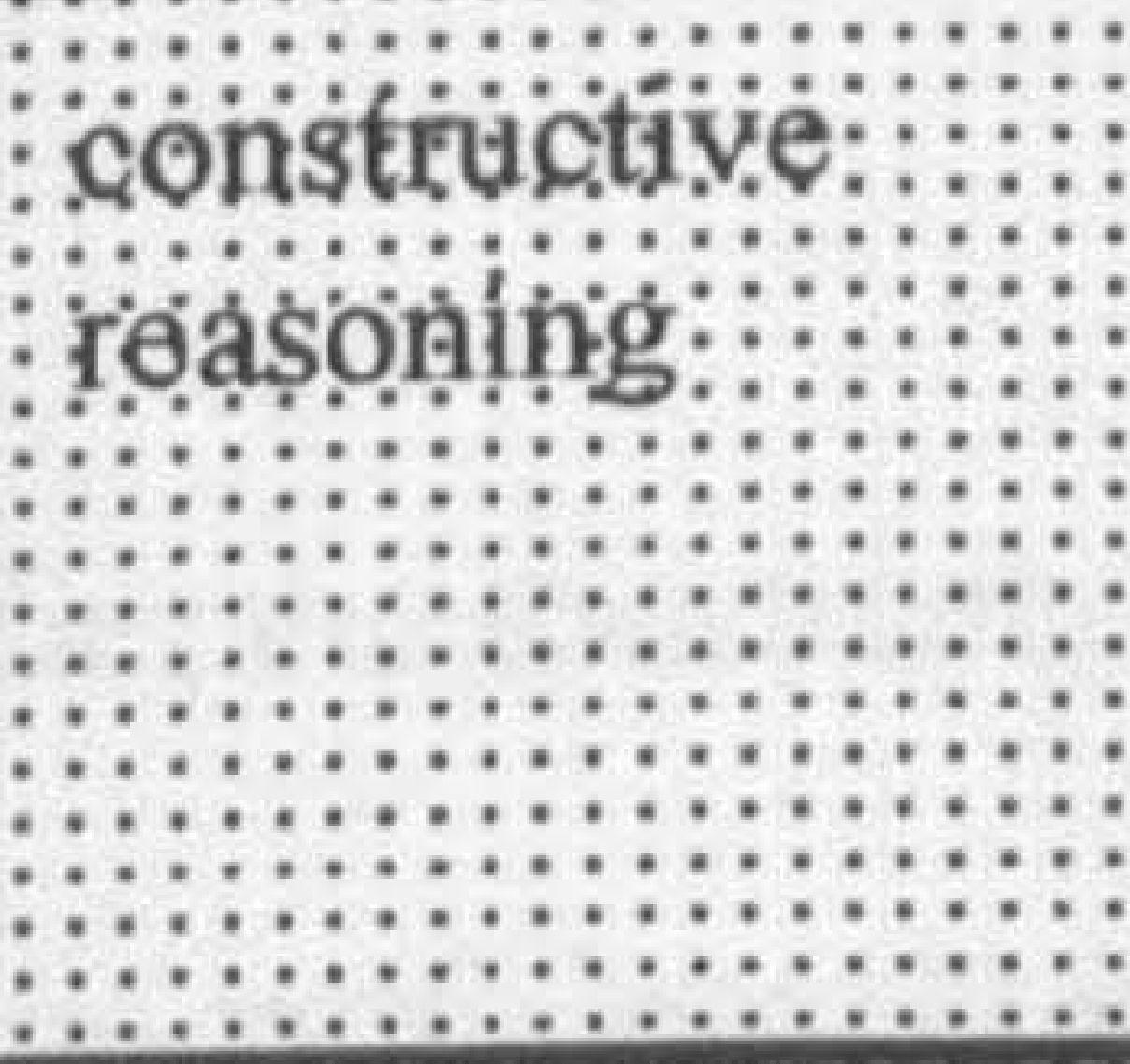 & stilted & 9 & 7 & 2 & $\begin{array}{l}\text { capable of arguing, } \\
\text { persuading and sharing } \\
\text { logical progression of } \\
\text { thought - exploring } \\
\text { possibilities }\end{array}$ \\
\hline : & gemoram & $\begin{array}{l}\text { can read speak } \\
\text { and write }\end{array}$ & 8 & 7 & 1 & $\begin{array}{l}\text { enables understanding } \\
\text { across wide range of } \\
\text { people and contexts }\end{array}$ \\
\hline : & making & single yes/no & 8 & 9 & -1 & $\begin{array}{l}\text { courage in difficult } \\
\text { decisions and complex } \\
\text { situations. }\end{array}$ \\
\hline
\end{tabular}




\section{Overview}

Although the negative or left hand column appears to contain some examples of stereotypic or extreme behaviour (certainly of senior managers) the participant was able to identify valid work performances to illustrate these labels. The positive column on the other hand remains a better indicator of the nature of the construct being used, and, in particular, of the complex nature of the construct system. The concept of collective decision making is also expressed in a more accessible form. Of special interest is the lack of any construct related to numerical skills. Although both job components and assessment exercises were used as elements to obtain the grid neither of these produced a relevant separate construct, being both subsumed within the term analytic ability. The development area identified also clarifies the nature of the earlier need in terms of negotiation which was not present in the committee exercise.

Stage 3a

Mapping the constructs back on to the assessment centre was developed as a means of assisting participant $\mathrm{D}$ since it provided a decode key for feedback information. It also enabled a further evaluation of the assessment centre in terms of perceived domain coverage. 
Table A 4 comparison of personal constructs to assessment centre components from participant A

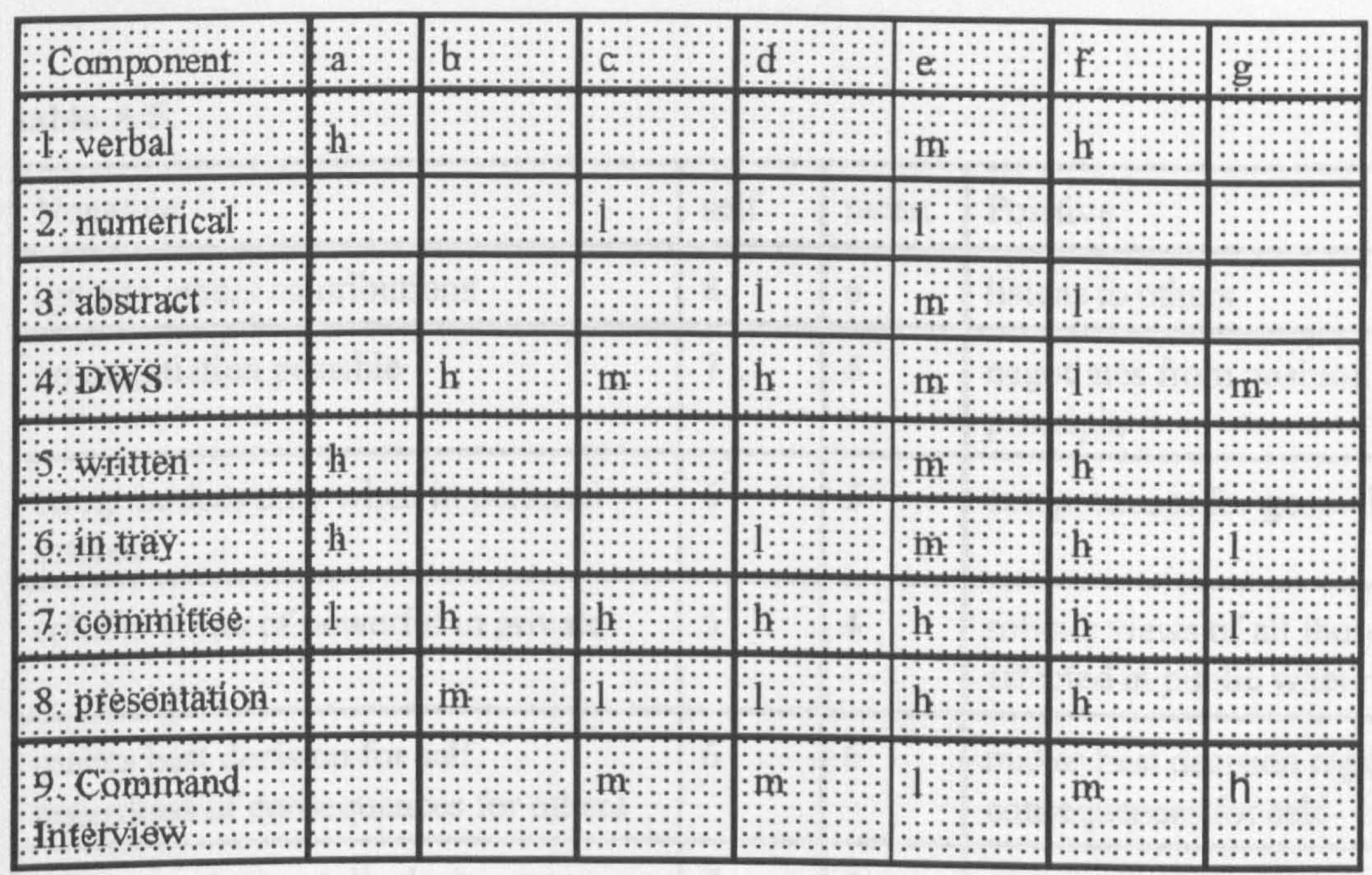

The stage 3a process was derived from a later participant and took place after some development issues had been explored (see stage 4). As such it provided a retrospective of the centre in terms of coverage but was not used directly for development planning. Overall the participant felt that the centre had reasonable coverage across most of his constructs and as such provided a useful means of decoding feedback information. By the time this had been derived, however, the process of development had already been initiated and further analysis of feedback using the decode key was not explored.

\section{Stage 4}

Like stage 3 stage 4 was derived from, and intended for, participants who needed to clarify their development strategies in the context of disparate and contradictory information. Participant A had few, if any, problems in this area, nevertheless the issue of decision making was explored with a view to supporting development in the workplace. Table A5 was derived 
from table $\mathrm{A} 3$ by extending the constructs available in a single context - that of decision making. The intention in this case was to derive a construct system for detailed self assessment which could be shared or exchanged with another colleague.

table A 5

\begin{tabular}{|l|l|l|l|}
\hline Negative & self & mean & Positive \\
\hline ignores others contributions & 8 & 6 & listens to others \\
\hline no negotiation possible & 7 & 6 & $\begin{array}{l}\text { negotiates from position of } \\
\text { principle }\end{array}$ \\
\hline $\begin{array}{l}\text { compromises only when in personal } \\
\text { interest }\end{array}$ & 6 & 5 & compromises for general good \\
\hline solicits views of powerful in private & 5 & 4 & $\begin{array}{l}\text { solicits views of all those } \\
\text { effected in public where possible }\end{array}$ \\
\hline $\begin{array}{l}\text { makes best decision for self, } \\
\text { regardless of consequences for others }\end{array}$ & 6 & 6 & $\begin{array}{l}\text { makes best decision regardless of } \\
\text { consequences for self }\end{array}$ \\
\hline $\begin{array}{l}\text { imposes solution, tells decision } \\
\text { impors }\end{array}$ & 7 & 6 & $\begin{array}{l}\text { seeks to build ownership of } \\
\text { solution, sells decision }\end{array}$ \\
\hline $\begin{array}{l}\text { aware of balance of power and key } \\
\text { players }\end{array}$ & 6 & 6 & $\begin{array}{l}\text { aware of principles involved and } \\
\text { key issues }\end{array}$ \\
\hline $\begin{array}{l}\text { short term solutions to immediate } \\
\text { problems - best decision now }\end{array}$ & 6 & 5 & $\begin{array}{l}\text { long term solutions - best } \\
\text { decision now and in future }\end{array}$ \\
\hline
\end{tabular}

Having expanded the construct to provide a range of components factors, the problem of applying it in a work context became evident. The above table indicates a strong value oriented component to the original construct and reflects personal values with which the organisation may not concur. My initial intention was to provide the participant with a mechanism to elicit better workplace performance feedback on the basis of the ability to exchange criteria. In this case, conflicting styles, or approaches, to decision making generated a reluctance to exchange the grid with his immediate line manager. As such it was not possible to agree a set of mutual criteria for the assessment of performance. Problems also existed in relation to sources of evidence. Deprived of the line manager, the grid could also 
prove difficult for peers to use. By extension, it might brand their own style as possibly being negative or alternatively encourage a style of decision making which they felt uncomfortable with.

The result was the use of the tool for reflection only i.e. as an extension of self assessment, using self perceptions as a data source but offering the possibility of discussion with someone outside the current work environment. It was agreed that the participant would maintain a log of the decisions made and the extent to which he felt his performance met the criteria established. He also agreed to discuss these with a third party outside the organisation to determine the extent to which the principles he had identified were being applied elsewhere by senior managers.

Table A 6 revised constructs from participant A

\begin{tabular}{|l|l|l|l|l|}
\hline Negative & self & man & mean & Positive \\
\hline $\begin{array}{l}\text { ignores or excludes others } \\
\text { contributions }\end{array}$ & 8 & 7 & 6 & $\begin{array}{l}\text { listens to others, encourages } \\
\text { others to participate }\end{array}$ \\
\hline $\begin{array}{l}\text { no negotiation possible at } \\
\text { meetings }\end{array}$ & 7 & 6 & 6 & $\begin{array}{l}\text { negotiates from position of } \\
\text { principle }\end{array}$ \\
\hline $\begin{array}{l}\text { compromises only when in } \\
\text { personal interest }\end{array}$ & 8 & 6 & 5 & compromises for general good \\
\hline $\begin{array}{l}\text { solicits views of powerful in } \\
\text { private }\end{array}$ & 6 & 5 & 4 & $\begin{array}{l}\text { solicits views of all those } \\
\text { effected in public where possible }\end{array}$ \\
\hline $\begin{array}{l}\text { makes best decision for self } \\
\text { regardless of consequences } \\
\text { for others }\end{array}$ & 7 & 6 & 6 & $\begin{array}{l}\text { makes best decision regardless of } \\
\text { consequences for self }\end{array}$ \\
\hline $\begin{array}{l}\text { imposes solution, tells } \\
\text { decision }\end{array}$ & 9 & 7 & 6 & $\begin{array}{l}\text { seeks to build ownership of } \\
\text { solution, sells decision }\end{array}$ \\
\hline $\begin{array}{l}\text { maintains balance of power } \\
\text { and satisfaction of key } \\
\text { players }\end{array}$ & 6 & 5 & 6 & $\begin{array}{l}\text { maintains own principles and } \\
\text { tailors solution to key issues }\end{array}$ \\
\hline $\begin{array}{l}\text { short term solutions to } \\
\text { immediate problems - best } \\
\text { decision now }\end{array}$ & 8 & 6 & 6 & $\begin{array}{l}\text { long term solutions - best } \\
\text { decision now and in future }\end{array}$ \\
\hline
\end{tabular}


The revised grid was produced after approximately six months use. Not only have the performance ratings changed but so have some of the criteria. Most interestingly the awareness of power/issues has become an issue about maintenance of power, or as it was initially in the first construct grid, maintaining or sticking to principles. The introduction of a line manager assessment was undertaken because it provided a more precise comparator than a group mean and enabled more detailed observation of a close colleague.

\section{Conclusions}

Participant A had relatively low development needs and a substantial development opportunity before being assessed. He experienced few problems in the assessment centre and this was reflected in his view of his job performance in which he was doing quite well. He also entered the assessment process with a prior success (that of gaining a course place). This positive stance was reflected in his actual assessment centre performance and subsequent feedback.

The low impact of the centre itself can be explained in terms of either performance or the extensive development opportunities already identified as available. Nevertheless, the centre raised a number of issues about performance and constructs relevant to development, including the question of mechanisms to deal with information or plan self development. The feedback provided to this successful candidate was seen to be of little value in the latter process as it reflected positive performance, rather than identified needs, much léss possible development areas.

The construct grid derived to explore the area of decision making could not be exchanged with the participant's line manager as it sought to establish values which the organisation finds problematic on a philosophic as well as practical level. Whilst the criteria could be applied to job performance, the possibility of obtaining evidence from others sources was difficult, particularly since the major available sources (line managers and peers) were unlikely to agree with some of the criteria. Similarly, subordinates, although possibly more in 
tune with the values identified by participant A, may not have been prepared to provide evidence. The solution adopted - to use the criteria as a reflective tool - afforded some limited developmental use and provided at least the opportunity to discus performance with someone uninvolved in the performance itself. Perhaps it is not the problem of the organisation but the nature of the construct itself, focusing as it does on personal integrity, which may have contributed to the limitations and even the eventual use as a reflective tool.

Sometimes personal constructs cannot be exchanged due to the nature of the construct itself, the nature of the environment in which it operates, or a mismatch between the two. Exchange should not therefore be sought as the ultimate test of validity, but rather the personal nature of the construct process respected and given appropriate treatment. It is not always necessary, safe, or even productive, to exchange constructs directly. In such circumstances consideration needs to be given to the use and interpretation of the constructs by their generator alone, until such time as a more fruitful conversation can be created. 


\subsection{Participant B}

Participant B was a substantive Divisional Officer who had been identified for temporary promotion to Divisional Commander (Senior Divisional Officer) prior to the running of the assessment centre. At the time of the first interview he was undertaking a Principal Officer role and had recently completed the centre but not received any feedback nor had decisions been made regarding his progress.

\section{Stage I}

a. pre centre development needs

- An overall enhancement of general management skills especially project management. - Greater operational breadth of experience via exposure to a broader range of incidents

b. pre centre development plans or strategies

The participant was intending to apply for attendance on the Home Office Brigade Command Course for potential Chief Fire Officers which is designed as a general management course for senior managers. He also intended to undertake an in-house short course in project management.

The issue of operational breadth was largely experiential and he envisaged greater discretion over attendance at incidents as a Senior Divisional Officer

c. post centre development needs

No new needs were identified as a result of attending the centre.

d. post centre development plans or strategies 
The Brigade Command Course was seen as a major step in achieving the development needs previously identified supplemented by in-house course provision as and when available. The issue of mentoring was discussed but not in relation to any specific needs or requirement.

\section{e. Bridges and barriers}

The participant saw the extended interview process (a form of assessment centre) as a barrier to his attendance on the Brigade Command Course and although he recognised the usefulness of attending the current assessment event he expressed some reservations over the objectivity of the former. The Extended Interview (or "EI") process for selection to the course remained problematic, as suspicions persisted that the process could in some way be "fixed" by either the Home Office or other Chief Fire Officers. To some extent, therefore, he regarded success at the $\mathrm{EI}$ as a combination of skills, his current assessment centre experiences and luck in terms of interviewers on the day. Once again the participant was positive about both his assessment centre performance and his job performance. He saw in his line manager a useful supporter both as advocate/champion and as mentor and was keen to examine how the latter role could be structured.

\section{e. Review}

As in the case of participant $A$ the lack of assessment centre impact seems to be associated with (self perceived) positive performance in both job and in the assessment centre. Both participants $A$ and $B$ share a positive view of themselves as candidates and managers and their responses to attending the centre seem to be curiosity rather than any sense of apprehension or more positive motivation. 
Table B 1. Participant B self perceived assessment centre performance

\begin{tabular}{|c|c|c|c|}
\hline Component : : & sedf: & group mean & difference \\
\hline Overall:DCDC: & 7 & 6 & 1 \\
\hline roubal & 6 & 6 & 0 \\
\hline 2 numerical & 5 & 4 & 1 \\
\hline 3: abstract & 7 & 5 & 2 \\
\hline MWWS:::::::::::::: & 7 & $\mathrm{n} / \mathrm{a}$ & $\mathrm{n} / \mathrm{a}$ \\
\hline sowntten & 7 & 5 & 2 \\
\hline بn tray & 6 & 6 & 0 \\
\hline 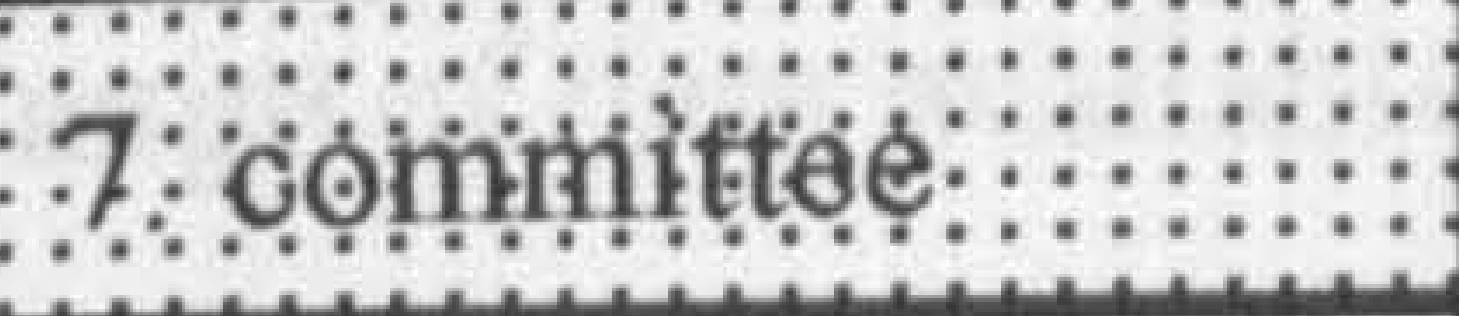 & 8 & 6 & 2 \\
\hline 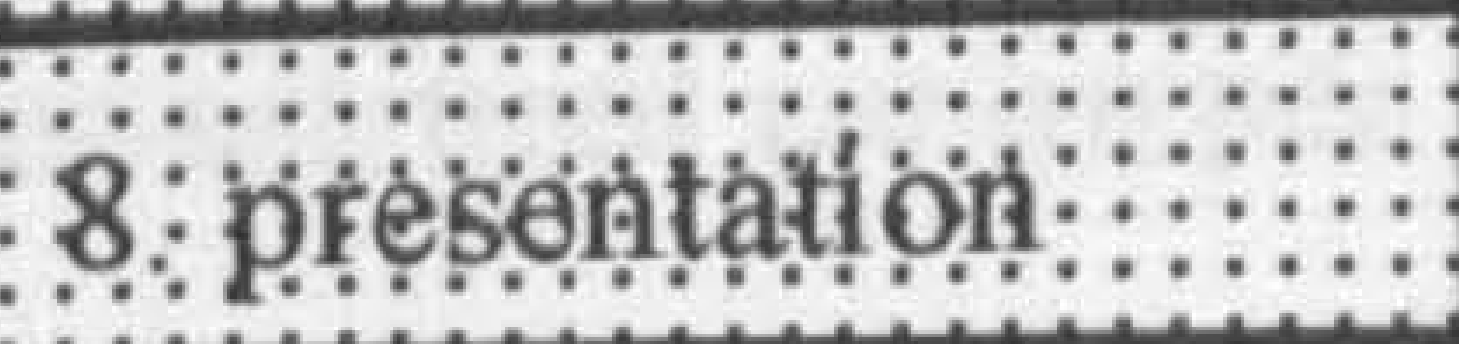 & 8 & 7 & 1 \\
\hline 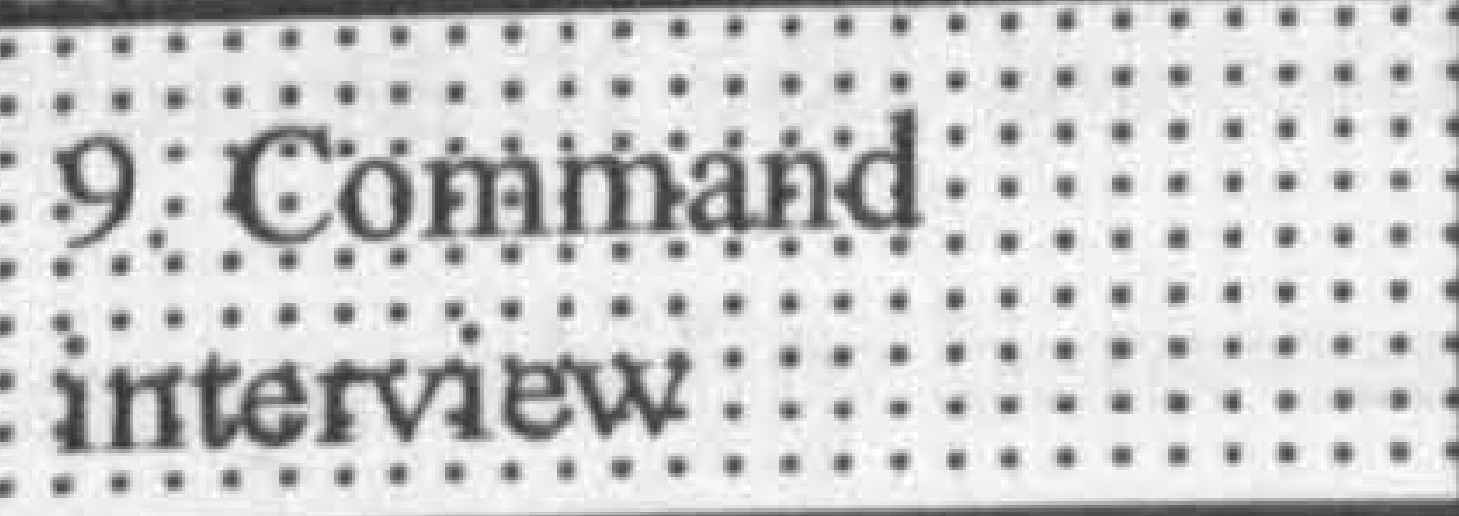 & 8 & 7 & 1 \\
\hline
\end{tabular}

The design of the above table was intended to open up the performance aspect of the assessment centre and examine in more detail its relationship (or lack of relationship) to developmental plans. Since the process was created before results were known or decisions made I included in the process a normative element in terms of other candidates. Thus each participant, beginning with participant B was asked to rate himself on a scale of 1 to 10 for effectiveness and then rate the mean performance for his peer group. All participants were drawn from the London Fire Brigade and therefore had substantial, if differential, levels of knowledge about their peers and their peers' performances. This idea of quasi-normative ratings was designed to provide some comparison with the assessment group who were in competition for promotion without recourse to a full analysis of each participant (subsequently for participant $\mathrm{C}$ this system proved a slightly less reliable indicator of performance). Participant B's view of his own performance was positive across all elements of the assessment centre. The only variability related to the perceived distance on a 1 to 10 
scale between him and his peer group. The absence of any clearly established needs as a result of attending the centre seemed to derive directly from this view of performance at the event.

\section{Stage 2a}

Since the participant was keen to examine the possibility of mentoring I suggested the completion of a second table in which specific job activities were linked to each exercise. Although there are clearly likely to be overlaps between discrete job activities and discrete exercises i.e. a single activity may encompass more than one exercise and vice versa the resultant table provided some indication of how the exercises and the performance in exercises could be related to job performance generally. As such it sought to broaden the range of data available to the discussion and extend the learning conversation from the assessment centre per se to other development opportunities in the job. Once again the process of self assessment was used against a comparator group and, for the sake of comparability between the two tables, the same group (other candidates at the centre) was chosen to provide an indication of relative performance in the job.

Table B 2. Participant B self perceived job performance

\begin{tabular}{|c|c|c|c|c|}
\hline 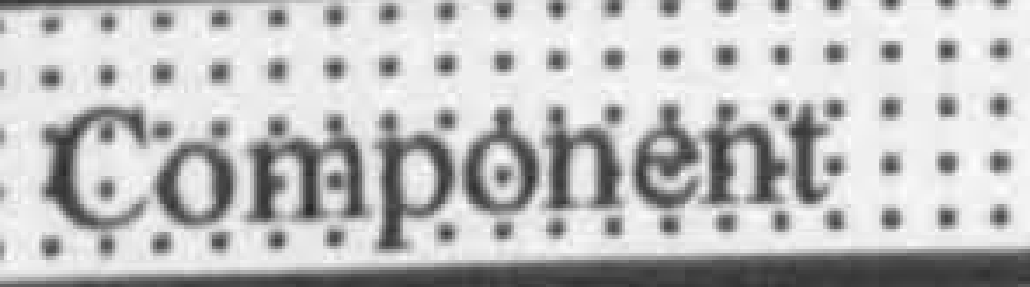 & job copopopent & self: $::$ & group meari & :diffentrice: \\
\hline 8 & presentations & 7 & 6 & 1 \\
\hline 2 & analysis of data & 8 & -6 & 2 \\
\hline 4 & management of people & 8 & 7 & 1 \\
\hline 5 & writing reports & 8 & 6 & 2 \\
\hline 7 & attending meetings & 6 & 6 & 0 \\
\hline 9 & operational command & 8 & 6 & 2 \\
\hline $9 / 8 / 7$ & other communications (verbal) & 7 & 6 & 1 \\
\hline 6 & dealing with competing priorities & 8 & 6 & 2 \\
\hline 1 & analysis of written reports & 9 & 7 & 2 \\
\hline
\end{tabular}


No direct comparator was available for the third component of the assessment centre (an abstract reasoning test). Components 7,8 and 9, the committee exercise, presentation and operational command could be related to specific tasks but they all also formed part of a larger job activity or process called other verbal communications.

Once again the participant's analysis of his own performance was generally positive with only one area or job activity showing an average (in terms of the peer group) performance. Interestingly the activity rating of 6 compares unfavourably to the related committee exercise rating of 8 suggesting that the participant felt that he did better in an exercise setting than in real life meetings. To some extent, this echoes the views expressed by participant A regarding the nature of the exercise and, in particular, the divergence between the context of the committee exercise and the more confrontational, or at least competitive, aspects of group decision making at work. Interestingly, the generally positive nature of the ratings in relation to the peer group may have served to disguise rather than uncover possible needs, as the comparators were composed of a range of personnel, some of whom (including this participant) had been identified in the past for temporary promotion whilst the majority had not. The mean rating, therefore, may not have been sensitive enough for this participant to be able to identify areas where further development could have been sought.

\section{Stage 3}

The stage 3 process was derived as an attempt to overcome the problematic nature of job factor/ assessment centre comparisons by providing a single relevant set of measures which could be mapped by the participant onto either job or assessment centre performance. They came about as a result of difficulties and discrepancies encountered when working with participant $C$ and participant $D$ particularly but were applied retrospectively to participant $B$, to examine the nature of the relationship between work based self assessment and assessment centre self perceived performance. 
Table B 3. Participant B performance constructs

\begin{tabular}{|c|c|c|c|c|c|}
\hline & negative & self: & :mẹan: & diffe & positive: \\
\hline$:$ & $\begin{array}{l}\text { no experience of service } \\
\text { issues, no background against } \\
\text { which to make judgements }\end{array}$ & 8 & 7 & 1 & $\begin{array}{l}\text { experience in the whole range } \\
\text { of service issues and how they } \\
\text { impact on the environment }\end{array}$ \\
\hline $\begin{array}{c}\mathfrak{B}: \\
\vdots \\
\vdots \\
\vdots \\
\vdots \\
\vdots\end{array}$ & $\begin{array}{l}\text { inconsistent in all decisions. } \\
\text { Actions and decisions based } \\
\text { on arbitrary assumptions }\end{array}$ & 9 & 7 & -2 & $\begin{array}{l}\text { consistent in approach to } \\
\text { decisions. Decisions based on } \\
\text { reliable reasons }\end{array}$ \\
\hline 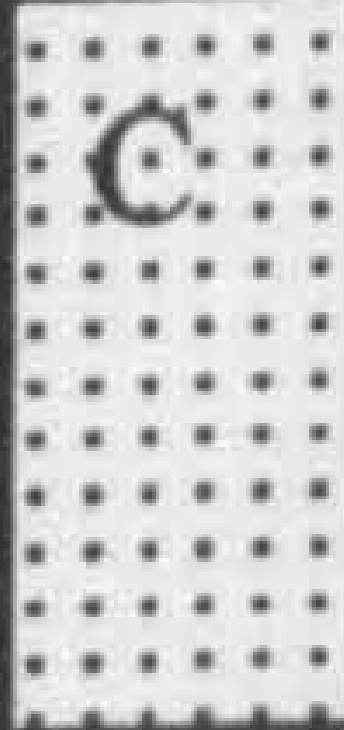 & $\begin{array}{l}\text { unable to use detail of issues in } \\
\text { making decisions. Decisions } \\
\text { based purely on an overview }\end{array}$ & 9 & 7 & 2 & $\begin{array}{l}\text { able to utilise the detail of } \\
\text { information to inform the } \\
\text { overview in making decisions }\end{array}$ \\
\hline 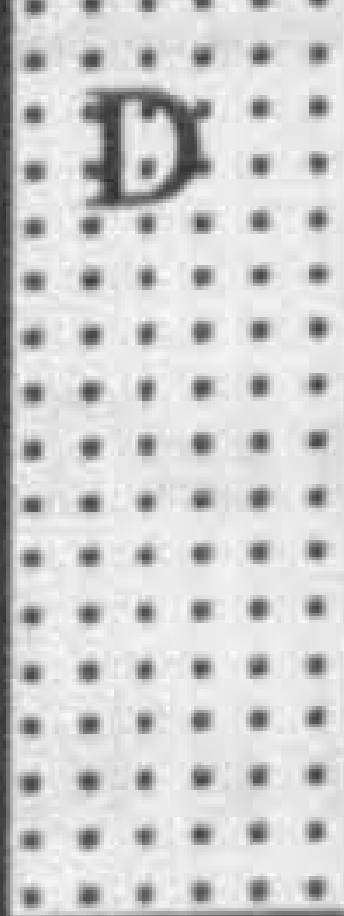 & $\begin{array}{l}\text { unable to work with even basic } \\
\text { numbers or to perform basic } \\
\text { calculations }\end{array}$ & 7 & 5 & 2 & $\begin{array}{l}\text { understands concepts of } \\
\text { mathematics and calculations. } \\
\text { Able to work effectively with } \\
\text { numerical data }\end{array}$ \\
\hline $\begin{array}{c}\dddot{\mathrm{E}}:: \\
\vdots \\
\vdots \\
\vdots \\
\vdots \\
\vdots \\
\vdots \\
\vdots \\
\vdots \\
\vdots \\
\vdots\end{array}$ & $\begin{array}{l}\text { unable to make decisions even } \\
\text { when in receipt of relevant } \\
\text { information. Avoids decision } \\
\text { making wherever possible }\end{array}$ & 9 & 8 & 1 & $\begin{array}{l}\text { able and willing to make } \\
\text { effective decisions even when } \\
\text { information is incomplete }\end{array}$ \\
\hline 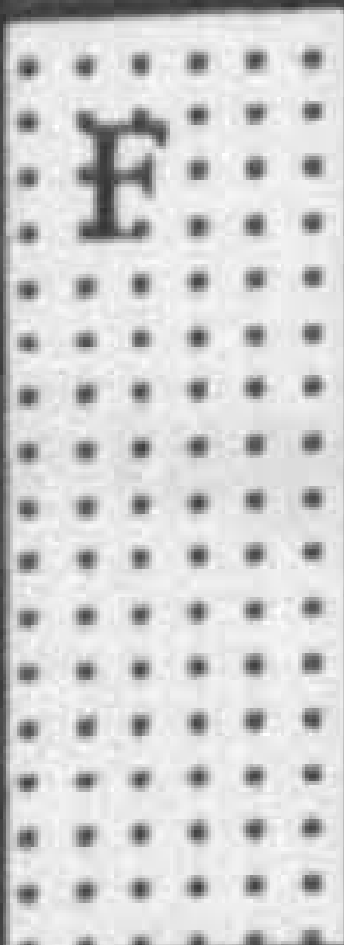 & $\begin{array}{l}\text { ineffective listening. Misses } \\
\text { important information in } \\
\text { verbal communication and } \\
\text { unable to concentrate }\end{array}$ & 8 & 8 & 0 & $\begin{array}{l}\text { listens attentively, uses good } \\
\text { body language to assist } \\
\text { listening. Collects all relevant } \\
\text { information }\end{array}$ \\
\hline $\begin{array}{c}0 \\
\vdots \\
\vdots \\
\vdots \\
\vdots \\
\vdots \\
\vdots \\
\vdots \\
\vdots\end{array}$ & $\begin{array}{l}\text { unable to question effectively } \\
\text { questioning is ambiguous and } \\
\text { alienates others }\end{array}$ & 9 & 6 & 3 & $\begin{array}{l}\text { good questioning technique by } \\
\text { use of language, obtains all } \\
\text { relevant information without } \\
\text { irritating or alienating others }\end{array}$ \\
\hline \begin{tabular}{c}
7 \\
\hdashline \\
$\vdots$ \\
$\vdots$ \\
$\vdots$ \\
$\vdots$ \\
$\vdots$
\end{tabular} & $\begin{array}{l}\text { insincere, unable to gain trust } \\
\text { of others }\end{array}$ & 8 & 5 & 3 & $\begin{array}{l}\text { completely sincere and } \\
\text { trustworthy, gains respect and } \\
\text { confidence of others easily }\end{array}$ \\
\hline 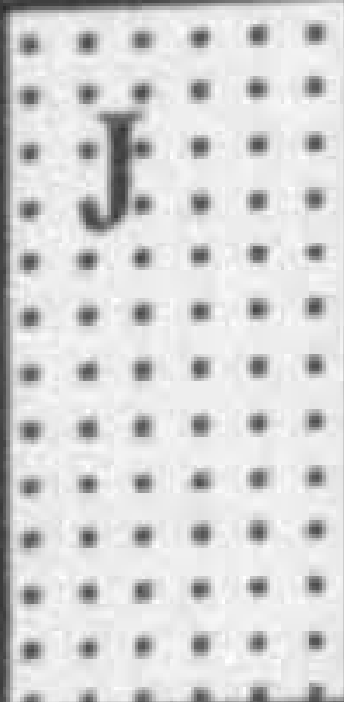 & $\begin{array}{l}\text { work mood swings liable to } \\
\text { react with extreme tendencies } \\
\text { to situations }\end{array}$ & 9 & 5 & 4 & $\begin{array}{l}\text { calm manner, remains calm } \\
\text { and reasonable in all } \\
\text { circumstances }\end{array}$ \\
\hline
\end{tabular}




\begin{tabular}{|c|c|c|c|c|c|}
\hline 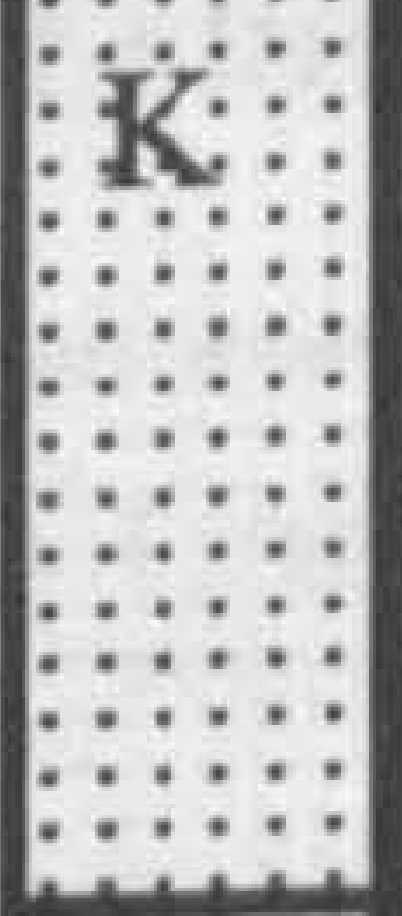 & $\begin{array}{l}\text { Poor vocabulary, uses } \\
\text { inappropriate words and } \\
\text { phrases often }\end{array}$ & 7 & 6 & 1 & $\begin{array}{l}\text { good vocabulary, uses plain } \\
\text { and appropriate words and } \\
\text { phrases to achieve effective } \\
\text { communication }\end{array}$ \\
\hline \begin{tabular}{c}
0 \\
\hdashline \\
$\vdots$ \\
$\vdots$ \\
$\vdots$ \\
$\vdots$ \\
$\vdots$ \\
$\vdots$ \\
$\vdots$ \\
$\vdots$ \\
$\vdots$ \\
$\vdots$
\end{tabular} & $\begin{array}{l}\text { Illogical reasoning used to deal } \\
\text { with workplace situations }\end{array}$ & 9 & 6 & 3 & $\begin{array}{l}\text { logical approach used in all } \\
\text { situations to deal with and } \\
\text { achieve effective solutions to } \\
\text { problems }\end{array}$ \\
\hline $\begin{array}{c}1 \\
1 \\
: \\
\vdots \\
\vdots \\
\vdots \\
\vdots \\
\vdots \\
\vdots \\
\vdots \\
\vdots \\
\vdots\end{array}$ & $\begin{array}{l}\text { unaware of political } \\
\text { implications of decisions and } \\
\text { actions. Actions taken with } \\
\text { only a one dimensional } \\
\text { perspective }\end{array}$ & 9 & 6 & 3 & $\begin{array}{l}\text { aware of, and takes account of, } \\
\text { the broader implications of all } \\
\text { decisions and actions }\end{array}$ \\
\hline
\end{tabular}

The construct grid is quite extensive and indicates a range of self assessments. It is suggestive of a broad view of performance across a range of different contexts. Although some redundancy may exist it was agreed to maintain the construct set in its entity at this point. The maintenance of a broad set of constructs enabled greater choices about development objectives but did not probe any underlying relationships between constructs.

\section{Stage 3a}

Mapping the constructs back on to the assessment centre was developed as a means of assisting participant $\mathrm{D}$ since it provided a decode key for feedback information. It also enabled a further evaluation of the assessment centre in terms of perceived domain coverage. It was derived retrospectively for participant B (i.e. after development discussions in stage 4 had taken place and after assessment centre feedback had been given), it was not therefore used as part of the development process described in stage 4. 
Table B 4. Comparison of personal constructs to assessment centre components

\begin{tabular}{|c|c|c|c|c|c|c|c|c|c|c|c|c|}
\hline Component: & :ä:::: & 6 & é: & : & è & f:::: & $\mathrm{g}:$ & h: : & : & 荄: & : & : \\
\hline (x & & & ii & & $\vdots$ & & & & & i: & & \\
\hline z numerical & 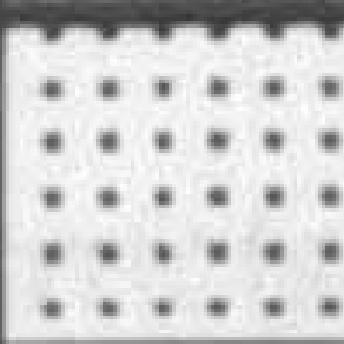 & & ini & ii: & & & & & & & : & \\
\hline a abstract & & & $\dddot{m}$ & & $\vdots:$ & & & & & & : & \\
\hline $4:$ PWS: & $\cdots$ & $\because:: \vdots$ & & & : & & & 緗: & :h:: & & :::: & : \\
\hline pistiten: & & & & & & & & & & & : & : \\
\hline 6 in tray: & : & m: & hi: & min: & $\therefore$ & & & & & : & : & :h: \\
\hline (2): & & & : & & : & mị: & :a: & : & & : & & 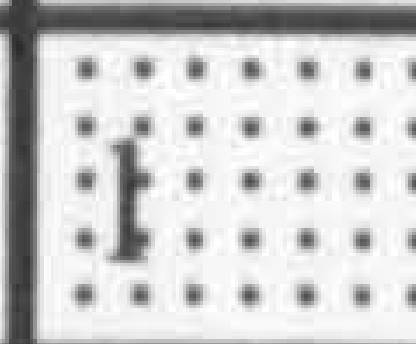 \\
\hline 8 presentation: & :::: & $\cdots$ & : & & & & & & & & : & : \\
\hline on & 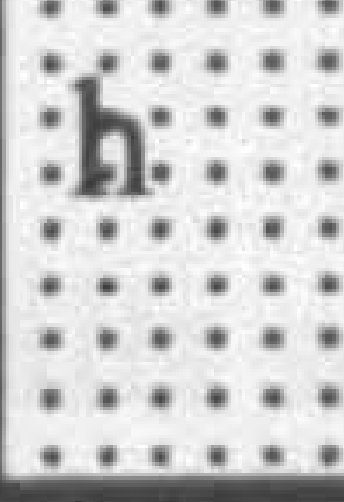 & 煎: & ma & & $\dddot{m}$ & & : & & : & & : & : \\
\hline
\end{tabular}

The stage 3a process was derived from a later participant and took place after some development issues had been explored (see stage 4), as such it provided a retrospective of the centre in terms of coverage but was not used directly for development planning. Overall the participant felt that the centre had reasonable coverage across most of his constructs and as such provided a useful means of decoding feedback information. By the time this has been derived however the process of development has already been initiated and further analysis of feedback using the decode key was not explored.

One area of interest to the participant was the extent to which his constructs loaded on to assessment centre exercises or the command interview. It was noted that the great majority of constructs were in some way command related and that in many cases the most appropriate area of performance was that of command. This contrasted with the development process described in stage 4 in which management contexts had been identified for the development of skills and in which evidence had been sought in the management domain. Although performance in the command function was seen as critical the opportunities for development of skills/competencies in this area were seen to be very limited and those for feedback more 
so. It emerged that, despite the constructs having greater validity for assessment in the command function, their value for self development was heavily reliant upon their use in the management domain. This contrast between an assessment context and a development context is significant for the use of development centres since it points to the different application of constructs for different purposes and suggests that constructs should be considered in the context of the purpose for which they are being used and not as if they were some "all purpose"variable such as traits of personality or learning preferences.

\title{
Stage 4
}

The construct grid can be seen as composed of three different areas -

- technical skills such as the use and manipulation of data

- interpersonal skills relating to the interaction with immediate colleagues, and

- decision making which is described by a number of constructs and which forms the major part of the constructs system.

\begin{abstract}
Although decision making was not seen as a particular need in terms of either job or assessment centre the level of detail provided by the constructs opened upan opportunity for self development. Unlike participant A, whose initial grid was broad but lacked detail, participant $B$ had focused in on decision making and extracted a number of significant personal constructs. I suggested that these might offer scope for further exploration in the context of mentoring i.e. to act as a focus for either day to day assessment or as a means of assessing specific performance in relation to project management (an area identified before and outside the assessment centre).
\end{abstract}

For the purposes of self development the comparator chosen was a known Principal Officer, in this case the participant's line manager. The development process was launched when the 
results of the assessment centre were known and his promotion confirmed. At this point the participant approached his line manager to agree the criteria for assessing his decision making performance. Table B5 was presented to the line manager without ratings for both comments and ratings of present performance. As a result of the comments received table B6 was agreed as a joint means of assessing performance, and as a starting point in terms of ratings. At this point both parties to the agreement gave some consideration to the issue of evidence and an evidence indicator was included as a reference in the agreed grid. 
Table B 5. Initial decision making grid by participant B

\begin{tabular}{|c|c|c|c|c|c|}
\hline & negative & self: & guod: & diff: & posstuive::: \\
\hline $\begin{array}{l}: \\
\vdots \\
\vdots \\
\vdots \\
\vdots \\
\vdots \\
\vdots\end{array}$ & $\begin{array}{l}\text { no experience of service issues, } \\
\text { no background against which to } \\
\text { make judgements }\end{array}$ & 8 & 9 & -1 & $\begin{array}{l}\text { experience in the whole range } \\
\text { of service issues and how they } \\
\text { impact on the environment }\end{array}$ \\
\hline$:$\begin{tabular}{ll}
$3:$ \\
\hdashline \\
\hdashline \\
\hdashline
\end{tabular} & $\begin{array}{l}\text { inconsistent in all decisions, } \\
\text { actions and decisions based on } \\
\text { arbitrary assumptions }\end{array}$ & 9 & 9 & 0 & $\begin{array}{l}\text { consistent in approach to } \\
\text { decisions. Decisions based on } \\
\text { reliable reasons }\end{array}$ \\
\hline$:$ & $\begin{array}{l}\text { unable to use detail of issues in } \\
\text { making decisions. Decisions } \\
\text { based purely on an overview }\end{array}$ & 9 & 10 & -1 & $\begin{array}{l}\text { able to utilise the detail of } \\
\text { information to inform the } \\
\text { overview in making decisions }\end{array}$ \\
\hline $\begin{array}{l}\vdots: \vdots \\
\vdots \\
\vdots \\
\vdots \\
\vdots\end{array}$ & $\begin{array}{l}\text { unable to make decisions even } \\
\text { when in receipt of relevant } \\
\text { information. Avoids decision } \\
\text { making wherever possible }\end{array}$ & 9 & 10 & -1 & $\begin{array}{l}\text { able and willing to make } \\
\text { effective decisions even when } \\
\text { information is incomplete }\end{array}$ \\
\hline $\begin{array}{c}10 \\
\vdots \\
\vdots \\
\vdots\end{array}$ & $\begin{array}{l}\text { work mood swings liable to } \\
\text { react with extreme tendencies to } \\
\text { situations }\end{array}$ & 9 & 7 & 2 & $\begin{array}{l}\text { calm manner, remains calm } \\
\text { and reasonable in all } \\
\text { circumstances }\end{array}$ \\
\hline 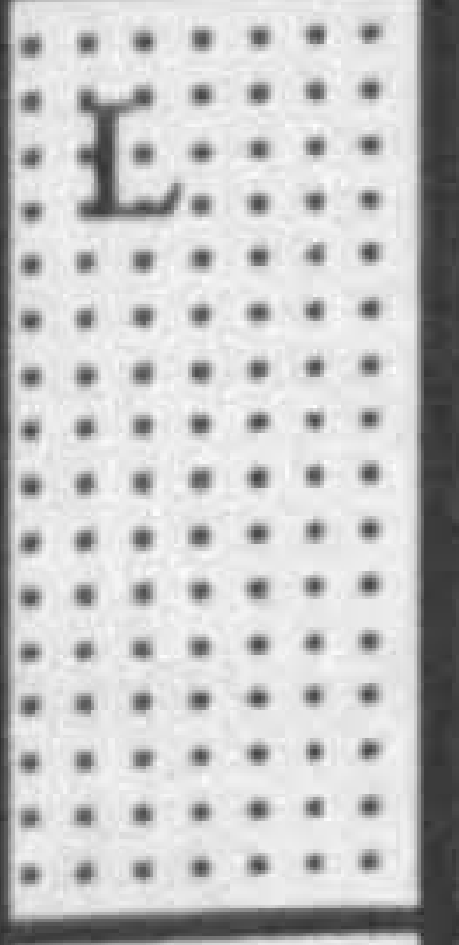 & $\begin{array}{l}\text { Illogical reasoning used to deal } \\
\text { with workplace situations }\end{array}$ & 9 & 9 & 0 & $\begin{array}{l}\text { logical approach used in all } \\
\text { situations to deal with and } \\
\text { achieve effective solutions to } \\
\text { problems }\end{array}$ \\
\hline : & $\begin{array}{l}\text { unaware of political implications } \\
\text { of decisions and actions. Actions } \\
\text { taken with only a one } \\
\text { dimensional perspective }\end{array}$ & 9 & 10 & -1 & $\begin{array}{l}\text { aware of, and takes account } \\
\text { of, the broader implications of } \\
\text { all decisions and actions }\end{array}$ \\
\hline
\end{tabular}


Table B 6.Agreed criteria for assessing decision making performance

\begin{tabular}{|c|c|c|c|}
\hline $\begin{array}{l}\text { Qualitie: } \\
::::::\end{array}$ & 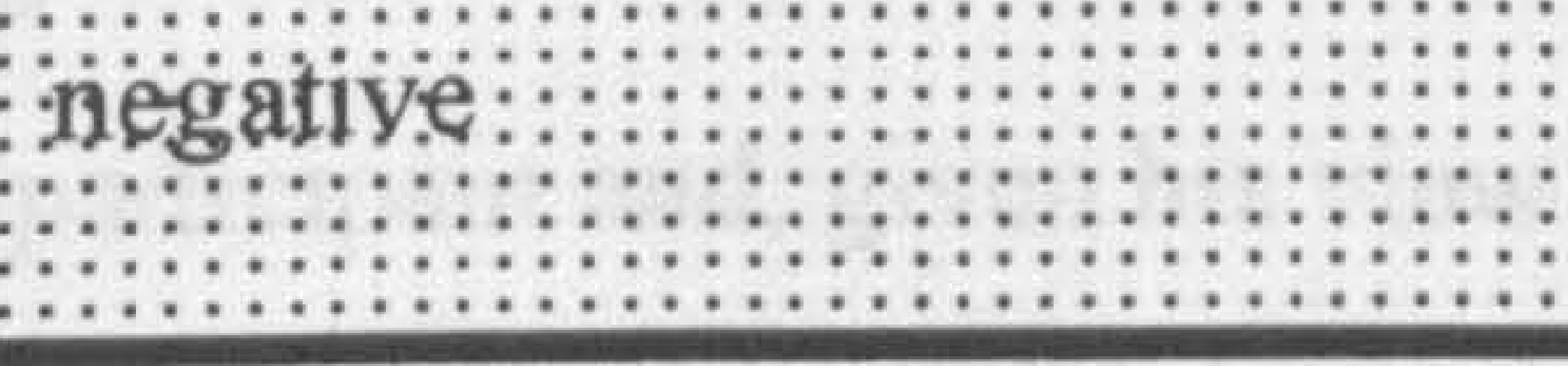 & currenit & \begin{tabular}{c} 
positive \\
\hdashline \\
\hdashline \\
\hdashline \\
\hdashline
\end{tabular} \\
\hline \begin{tabular}{c}
0 \\
\hdashline \\
\hdashline \\
\hdashline
\end{tabular} & $\begin{array}{l}\text { limited understanding of key } \\
\text { service issues, against which } \\
\text { to make judgements }\end{array}$ & 7 & $\begin{array}{l}\text { thorough understanding of } \\
\text { whole range of service issues } \\
\text { and how they impact on the } \\
\text { environment }\end{array}$ \\
\hline 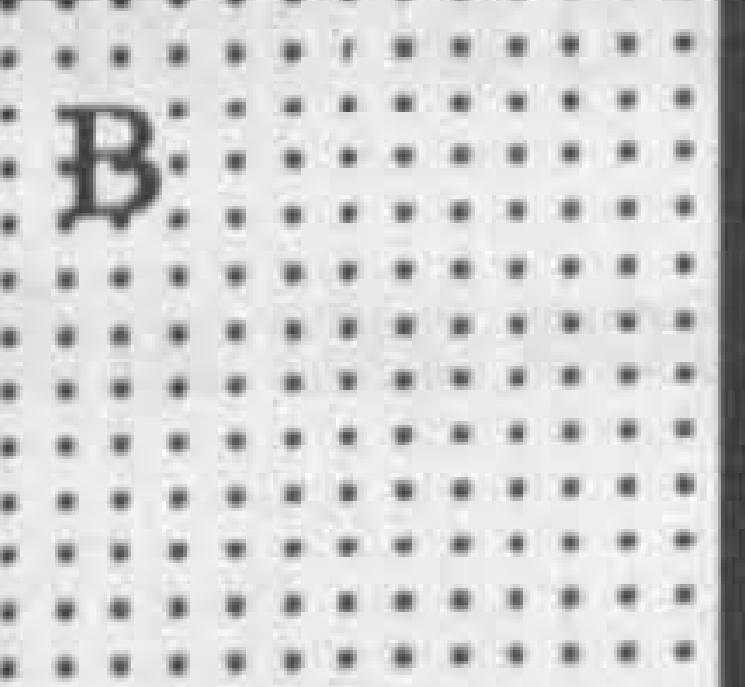 & $\begin{array}{l}\text { Decisions lack coherence } \\
\text { and are based on arbitrary } \\
\text { assumptions }\end{array}$ & 7 & $\begin{array}{l}\text { Coherent in approach to } \\
\text { decisions. Decisions based on } \\
\text { reliable and valid reasons }\end{array}$ \\
\hline \begin{tabular}{c}
0 \\
\hdashline \\
$\vdots$ \\
$\vdots$ \\
$\vdots$ \\
$\vdots$ \\
$\vdots$
\end{tabular} & $\begin{array}{l}\text { Unable to use detail of issues } \\
\text { in making decisions. } \\
\text { Decisions based purely on } \\
\text { generalisations }\end{array}$ & 6 & $\begin{array}{l}\text { Utilises the detail of } \\
\text { information to inform the } \\
\text { process of making decisions. } \\
\text { Comfortable with details. }\end{array}$ \\
\hline 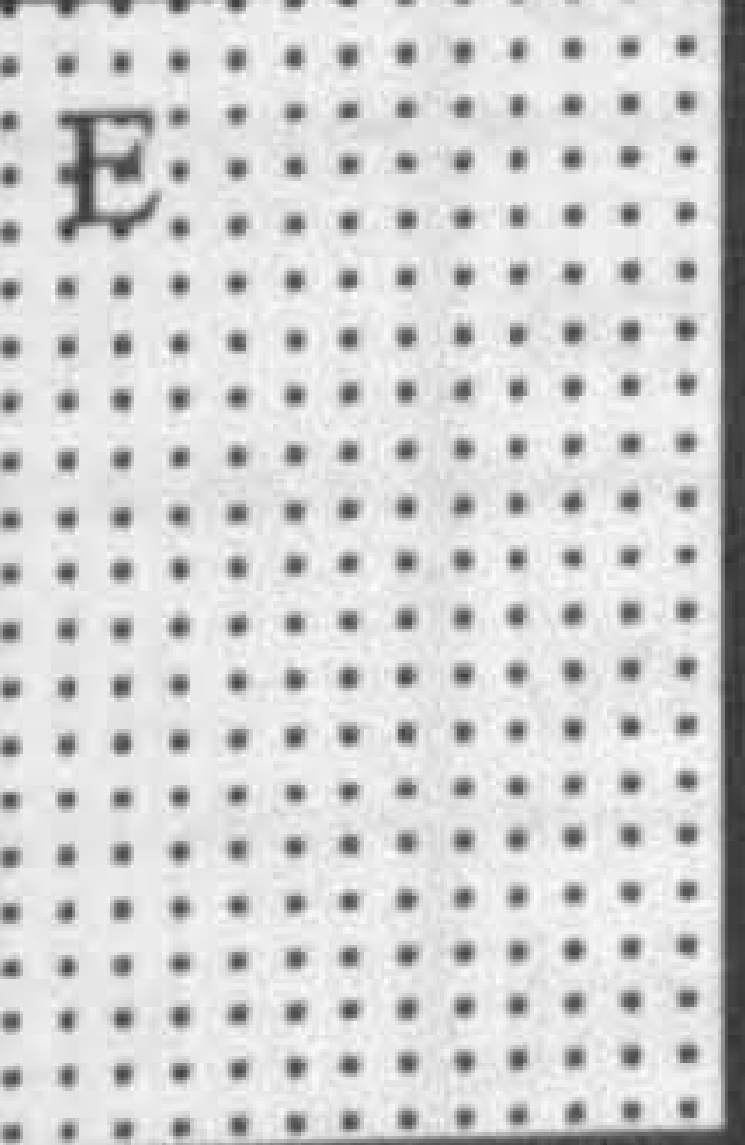 & $\begin{array}{l}\text { Avoids making decisions } \\
\text { even when it is clearly } \\
\text { necessary to do so. }\end{array}$ & 7 & $\begin{array}{l}\text { Willing to make effective } \\
\text { decisions even when } \\
\text { necessary even if detailed } \\
\text { information is incomplete or } \\
\text { unavailable. }\end{array}$ \\
\hline 通 & $\begin{array}{l}\text { Illogical reasoning used to } \\
\text { deal with workplace } \\
\text { situations }\end{array}$ & 6 & $\begin{array}{l}\text { Logical approach used in all } \\
\text { situations to deal with and } \\
\text { achieve effective solutions to } \\
\text { problems }\end{array}$ \\
\hline 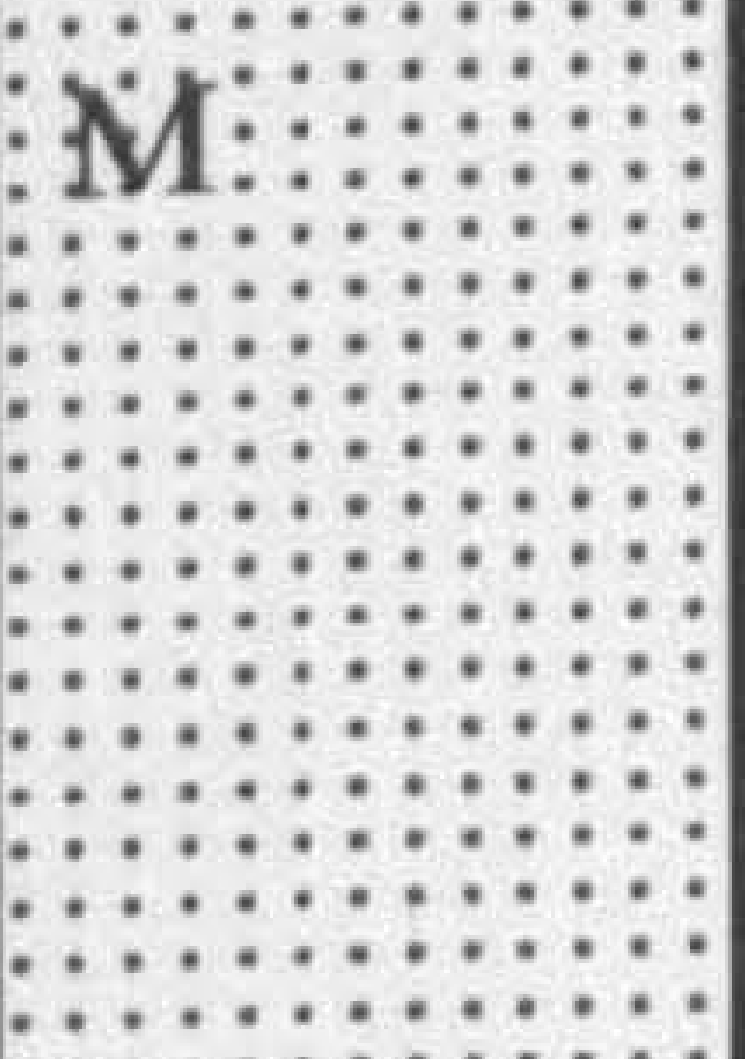 & $\begin{array}{l}\text { Unaware of political } \\
\text { implications of decisions and } \\
\text { actions. Actions taken with } \\
\text { only a one dimensional } \\
\text { perspective }\end{array}$ & 6 & $\begin{array}{l}\text { Aware of, and takes account } \\
\text { of, the broader implications } \\
\text { of all decisions and actions }\end{array}$ \\
\hline
\end{tabular}

The differences in the two sets of criteria are of some interest since the one area perceived a potential shortcoming in the line manager was the one he chose to remove. This aside, the modifications tend to make the criteria more precise and shift the focus away from experience to a broader understanding of decision making in a managerial context. Generally the line manager's ratings are much more severe than those of the participant, suggesting that the latter's self perception may be rather optimistic. As a starting point for development, 
however, they offer considerable scope for improvement and are not uniformly negative. Having a higher standard than that provided by the assessment centre seemed to make more sense to the participant and, given his view of the centre, a higher target seemed to be more appropriate. In addition to the performance criteria, the participant and his manager also identified an agreed schedule of evidence. Initially it was envisaged that evidence for different criteria would emerge from different activities, however, when activities were mapped on to the criteria, it was discovered that there was not a discrete activity for each and that the constructs were all relevant to the domain of decision making.

\section{table B 7. Schedule of relevant evidence}

\begin{tabular}{|l|l|}
\hline & evidence \\
\hline i & explanation of participant's decisions to line manager \\
\hline ii & briefing of colleagues by participant \\
\hline iii & briefing of subordinates by participant \\
\hline iv & joint examination of key projects by participant and line manager to identify options \\
\hline v & stakeholder analysis to be conducted by participant and reviewed by line manager \\
\hline
\end{tabular}




\section{Conclusions}

The lack of impact of attending the assessment centre seems to be related to a positive self perception regarding current and assessment centre performance. The derived or elicited constructs similarly represent a positive view of self. The relatively low coverage of the assessment centre in terms of domain constructs may also explain why the assessment centre provided very little new information of relevance to self development. The use and exchange of the decision making criteria was a fortuitous spin off, in as much as the strategy of mentoring had been identified prior to attending the assessment centre, and the constructs simply allowed a more coherent assessment of performance to take place.

The resultant use of assessment by the line manager and participant $B$ represents a personalised, job-relevant and job-centred appraisal system, using agreed criteria and a predetermined set of evidence. It enables evidence collection on a day to day basis, mostly using naturally occurring products. The process also involves the line manager sharing his responsibilities by discussing broader decisions with the participant and jointly developing and evaluating options. Finally, the system uses a more specific piece of research - the analysis of stakeholders - as a means of developing and demonstrating an understanding of strategic issues. 


\subsection{Participant C}

Participant $\mathrm{C}$ was a substantive Divisional Officer who had not been identified for temporary promotion to Divisional Commander (Senior Divisional Officer) prior to the running of the assessment centre and who was operating at his substantive rank albeit in a specialist team. At the time of the first interview he was undertaking a senior officer or middle manager role and had recently completed the centre but not received any feedback nor had decisions been made regarding his progress.

\section{Stage I}

a. pre centre development needs

- General management skills, especially communication skills.

- Greater operational experience via more extensive exposure in an area role

b. pre centre development plans or strategies

- The participant was keen to apply for attendance on the Home Office Brigade Command Course for potential Chief Fire Officers which wouldassist in the development of key skills.

- The issue of operational exposure was seen to be experiential and he sought greater operational responsibilities following transfer to an area command.

c. post centre development needs

- General management skills but especially communication skills. 
d. post centre development plans or strategies

The Brigade command course was seen as a longer term requirement following a range of in-house, almost remedial, events in relation to communication skills.

a transfer to an operational role at an area

e. Bridges and barriers

The main barriers to effective development related to the current assessment centre (which would also affect decisions regarding any attempt at the extended interview process) and his current location in a specialised headquarters team. The lack of operational experience was becoming an urgent concern.

\section{f. Review}

Unlike participants A and B this participant was clearly affected by attending the centre and had significant concerns about his overall performance at the event. This conversation, which took place prior to any knowledge of results, was characterised by significant anxiety on the part of the participant over the potential damage which could be done to his long term career prospects. Strategies which had previously been of relatively low concern, had now been prioritised by his attendance at the assessment centre, and the area of communications was highlighted as a developmental need. The developmental barrier in terms of operational experience was perceived by the participant to be acute, and his immediate post centre intentions included seeking a transfer to other duties as a matter of urgency. Whilst not traumatic, attending the assessment centre had given the participant sufficient cause for concern, it had also led him to considerably modify his short term development strategies and, temporarily at least, to suspend his longer term proposals regarding the Brigade Command Course. 


\section{Stage 2}

The stage 2 process was designed to look at self perceived assessment performance in more detail and compare the results of assessment centre attendance with self perceived job performance. Initially derived from discussions with participant B it was used in this case to clarify the concerns of the participant regarding his performance in the assessment centre.

Table C 1 participant a self perceived assessment centre performance

\begin{tabular}{|c|c|c|c|}
\hline Conponent & sèf: & giroup meài & differènce \\
\hline OrerallDCDC & 4 & 7 & -3 \\
\hline i:verbal :::::::::::: & 5 & 6 & -1 \\
\hline 2:numerical: & 5 & 6 & -1 \\
\hline 3:abstract: & 4 & 6 & -2 \\
\hline 4 PWW & 5 & 5 & 0 \\
\hline swownten & 7 & 7 & 0 \\
\hline buntray & 7 & 8 & -1 \\
\hline : & 8 & 9 & -1 \\
\hline 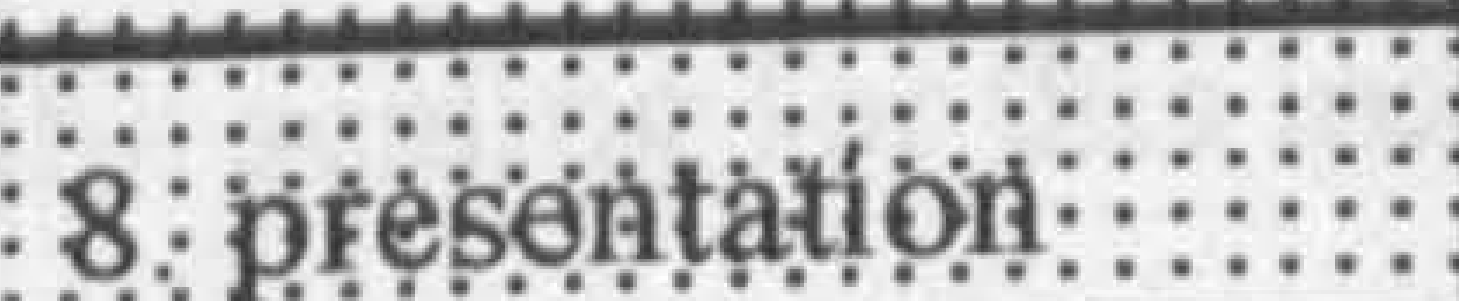 & 10 & 8 & 2 \\
\hline
\end{tabular}

Two themes emerge from the above table. Firstly, a concern over the results of tests in which the participant described himself as "doing poorly". Secondly, a discrepancy between concern over communication and apparent satisfaction with the presentation exercise. During subsequent discussion of the latter it emerged that the participant had recently attended a presentation skills course and been commended for his performance. One explanation of these two factors may lie in prior experience of being assessed or being trained. Certainly, the participant was keen to obtain some type of formal training in those areas in which he regarded his performance as below average. My main concern in discussing development with the participant was his focus on test taking as a means of beating the system. Whilst 
some form of preparation could be useful, this approach was unlikely to yield significant improvement in job performance, indeed preparation for test taking could impede other job related or job based development activities.

Table C 2. Participant C self perceived job performance

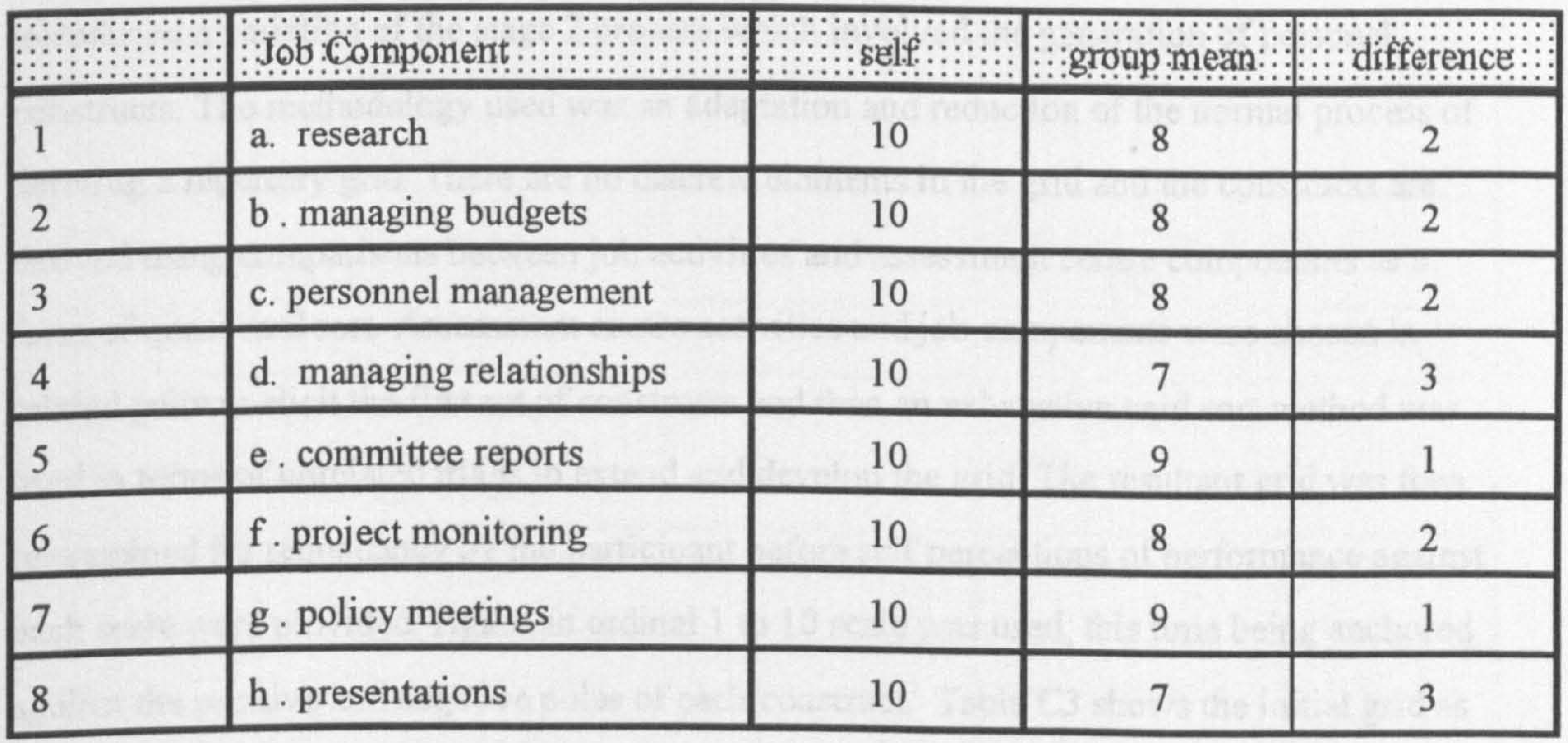

The table of job activities against assessment centre components is reproduced above and provides some guide to the linkage between the two. Unfortunately the participant interpreted the scaling for this instrument in a rather peculiar, though rational way. The terms used to describe the scale were effective (10) and ineffective (1). In this case, the participant sees himself as completely effective in all job activities even when compared to his colleagues.

Whilst the absolute (or objective) rating system breaks down, we may still use the differences between this participant and the perceived mean performance to derive some normative information. In this context, the smallest differences are significant i.e. those where the participant saw the best performance by his peers. The results were still less than satisfactory in explaining the impact of the assessment centre on the participant. Although they suggested that he held a positive view of himself prior to attending the event, they failed to explain, or account for, the discrepancy between the previously favourable self impression and the 
subsequent level of concern.

\section{Stage 3}

At this stage, and largely to help the participant focus on genuine (long term) needs, I introduced a variation of the stage 2 process which involved the generation of personal constructs. The methodology used was an adaptation and reduction of the normal process of deriving a repertory grid. There are no discrete elements in the grid and the constructs are derived using comparisons between job activities and assessment centre components as a form of quasi card sort. Assessment centre activities and job components were chosen in related pairs to elicit the first set of constructs and then an exhaustive card sort method was used in terms of unrelated triads to extend and develop the grid. The resultant grid was then reexamined for redundancy by the participant before self perceptions of performance against each scale were provided. Again an ordinal 1 to 10 scale was used, this time being anchored against the positive and negative poles of each construct. Table C3 shows the initial grid as elicited and table $\mathrm{C} 3 \mathrm{a}$ the resultant refined grid as designed to be used for developmental purposes. Note: at the earlier stage the use of construct labels provided better differentiation of constructs than some of the behavioural descriptions given as poles. The improvement in behavioural descriptions took place as the candidate was asked to focus on a smaller group of known comparators who could reasonably be described as peers rather than the full group of assessment centre candidates (i.e. the switch of focus from the general peer group to specific comparators forced the participant to describe behaviours he had witnessed directly rather than some of the more stereotypic behaviours he had initially identified) 


\section{Table C 3. Participant $\mathrm{C}$ performance constructs initial grid}

\begin{tabular}{|c|c|c|c|c|c|}
\hline Qualities: & 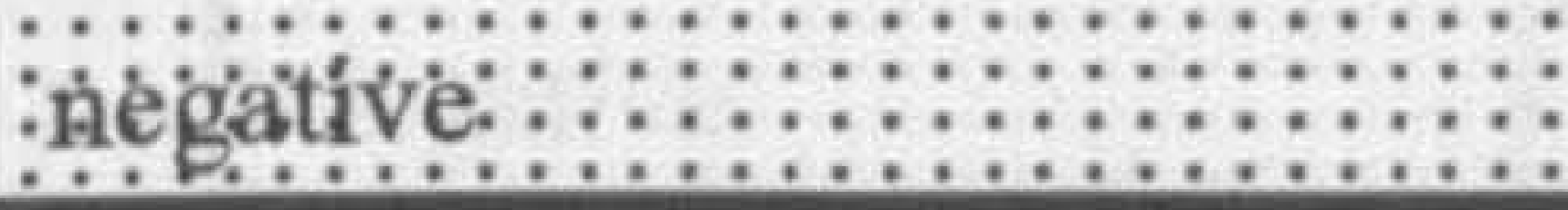 & self: & mean: & diff: & possitive : \\
\hline articulate: & $\begin{array}{l}\text { unacceptable language - } \\
\text { swears a lot }\end{array}$ & 8 & 8 & 0 & $\begin{array}{l}\text { displays good use of vocabulary, } \\
\text { but keeps it in plain English }\end{array}$ \\
\hline arpifdent: & $\begin{array}{l}\text { sweats a lot, shy, stammers, } \\
\text { wriggling hands }\end{array}$ & 7 & 6 & 1 & $\begin{array}{l}\text { relaxed body, takes active } \\
\text { involvement in events }\end{array}$ \\
\hline 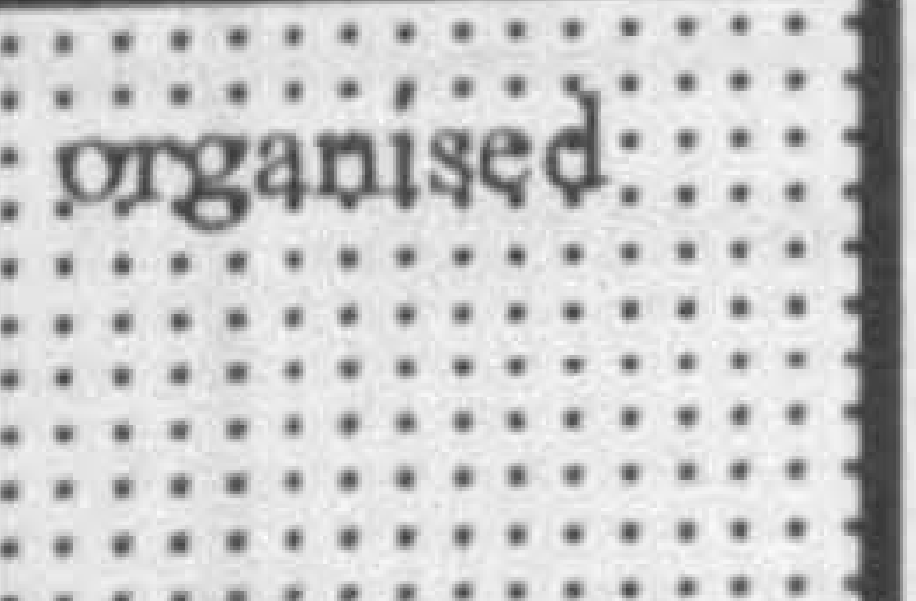 & $\begin{array}{l}\text { untidy desk, cannot find } \\
\text { things, does not have tools/ } \\
\text { resources required }\end{array}$ & 7 & 8 & -1 & $\begin{array}{l}\text { neat desk, punctual, has everything } \\
\text { to hand }\end{array}$ \\
\hline 1ogicat: & $\begin{array}{l}\text { loses every argument. No } \\
\text { sound basis for decisions }\end{array}$ & 7 & 7 & 0 & $\begin{array}{l}\text { does everything in order, wins } \\
\text { every argument }\end{array}$ \\
\hline jiturate: :: & looks at Daily Star & 8 & 8 & 0 & reads Telegraph, Times, Guardian \\
\hline 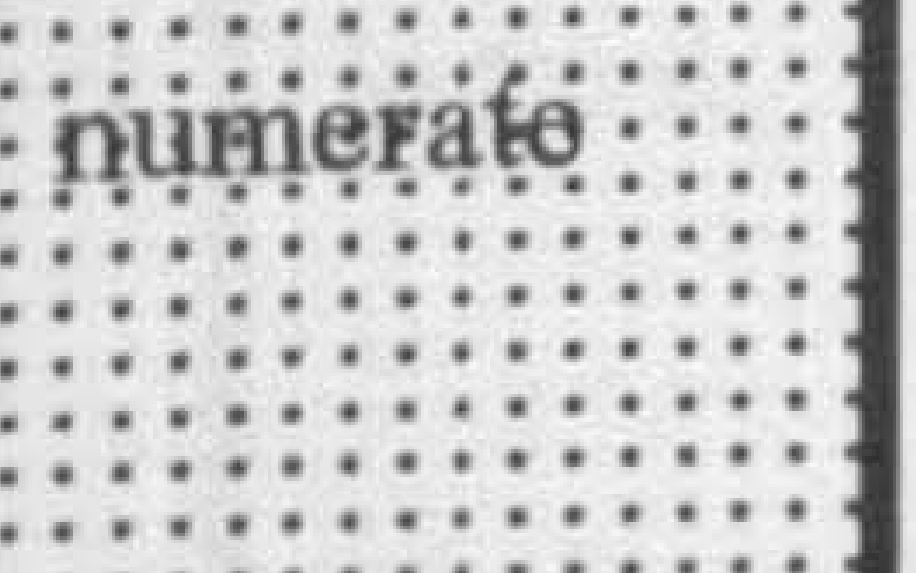 & $\begin{array}{l}\text { finds difficulty with basic } \\
\text { calculations - needs to use } \\
\text { calculator all the time }\end{array}$ & 6 & 9 & -3 & $\begin{array}{l}\text { keeps accounts, scores when } \\
\text { playing darts }\end{array}$ \\
\hline perisistent: & $\begin{array}{l}\text { capitulates every time, only } \\
\text { asks for something once }\end{array}$ & 9 & 8 & 1 & $\begin{array}{l}\text { pain in the neck, always going on } \\
\text { and on }\end{array}$ \\
\hline 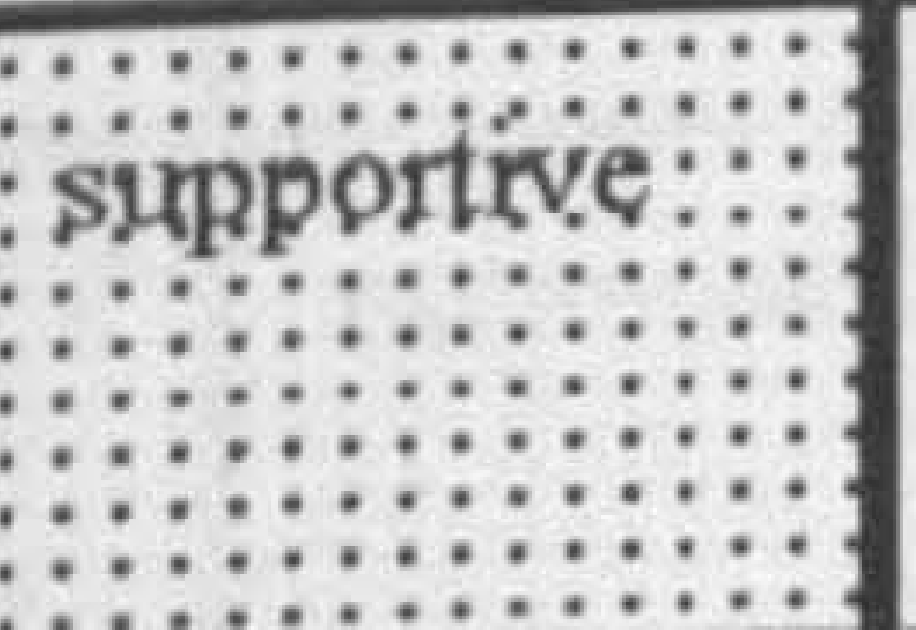 & $\begin{array}{l}\text { on your own. Leaves work } \\
\text { on time every day, has } \\
\text { lunch }\end{array}$ & 8 & 6 & 2 & $\begin{array}{l}\text { asks colleagues to provide help } \\
\text { and gets help from others }\end{array}$ \\
\hline 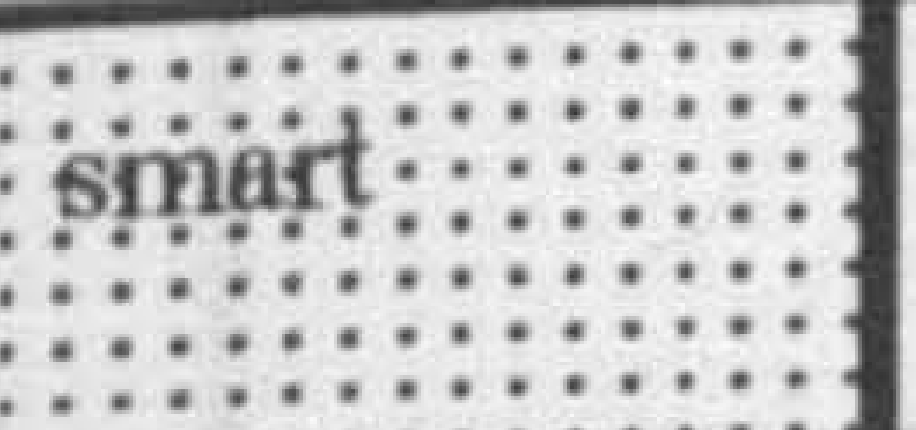 & $\begin{array}{l}\text { creases everywhere, shirt } \\
\text { tail out, scuffed shoes }\end{array}$ & 9 & 7 & 2 & $\begin{array}{l}\text { polished shoes, white shirt, } \\
\text { straight creases }\end{array}$ \\
\hline $\begin{array}{l}\text { discippined } \\
\vdots \\
\vdots \\
\vdots \\
\vdots\end{array}$ & $\begin{array}{l}\text { no respect for } \\
\text { organisational policy or } \\
\text { procedures }\end{array}$ & 10 & 10 & 0 & $\begin{array}{l}\text { never late, respects rank when } \\
\text { required }\end{array}$ \\
\hline 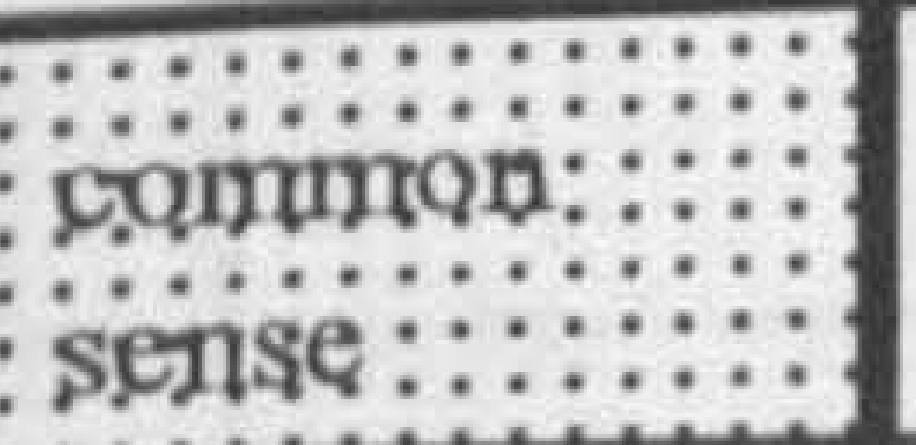 & $\begin{array}{l}\text { loses lots of money, always } \\
\text { in accidents }\end{array}$ & 8 & 7 & 1 & reacts well in new situations \\
\hline
\end{tabular}




\section{table C3a. Participant $\mathrm{C}$ performance constructs revised construct grid}

\begin{tabular}{|c|c|c|c|c|c|c|}
\hline$\vdots: \vdots$ & Qụatitues:::: & 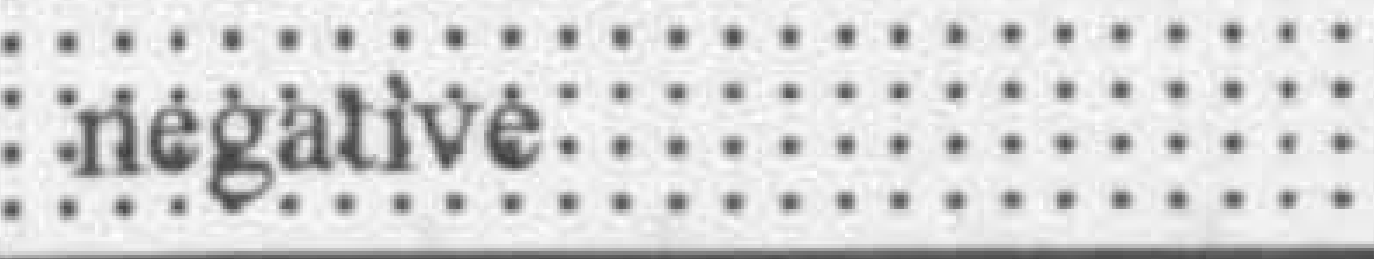 & sedf: & meañ:: & daffe: & positive: \\
\hline 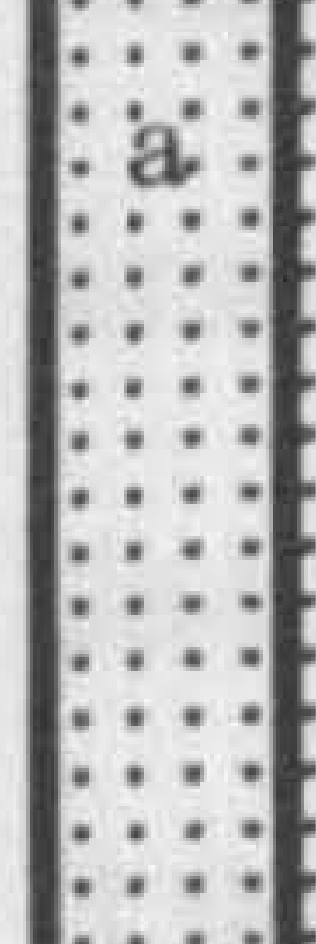 & 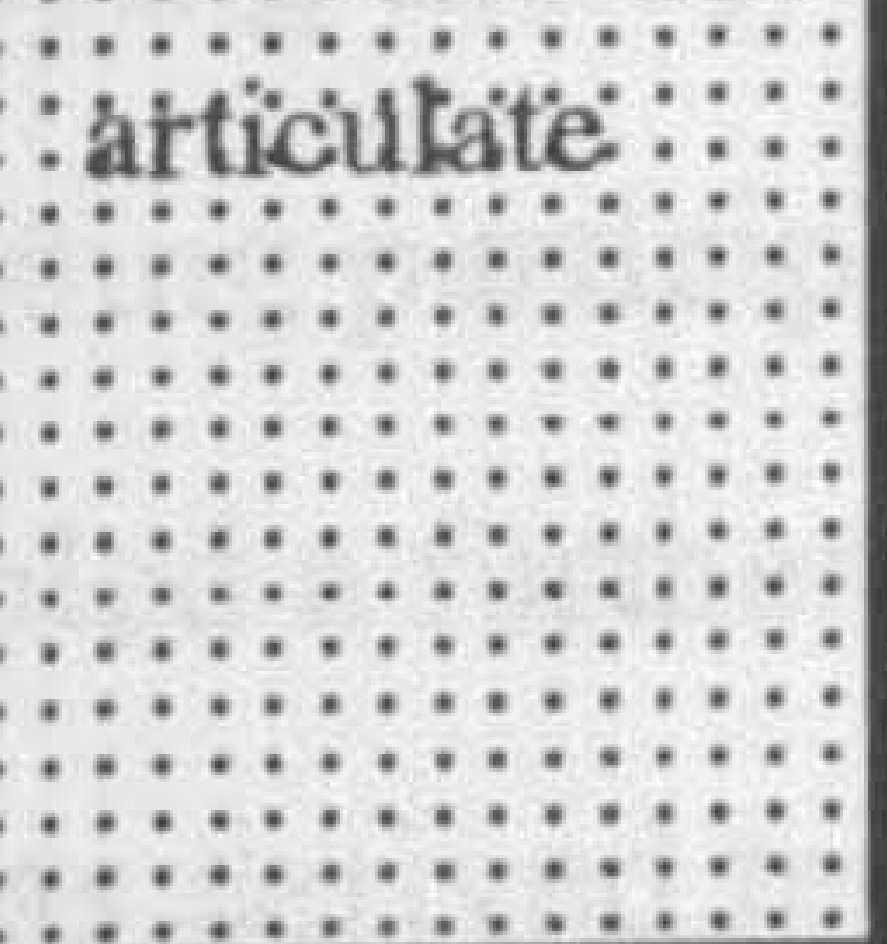 & $\begin{array}{l}\text { Unacceptable } \\
\text { language - fails to get } \\
\text { point across and } \\
\text { resorts to shouting } \\
\text { and swearing }\end{array}$ & 8 & 8 & 0 & $\begin{array}{l}\text { displays good use of vocabulary, } \\
\text { but keeps it in plain English }\end{array}$ \\
\hline : & 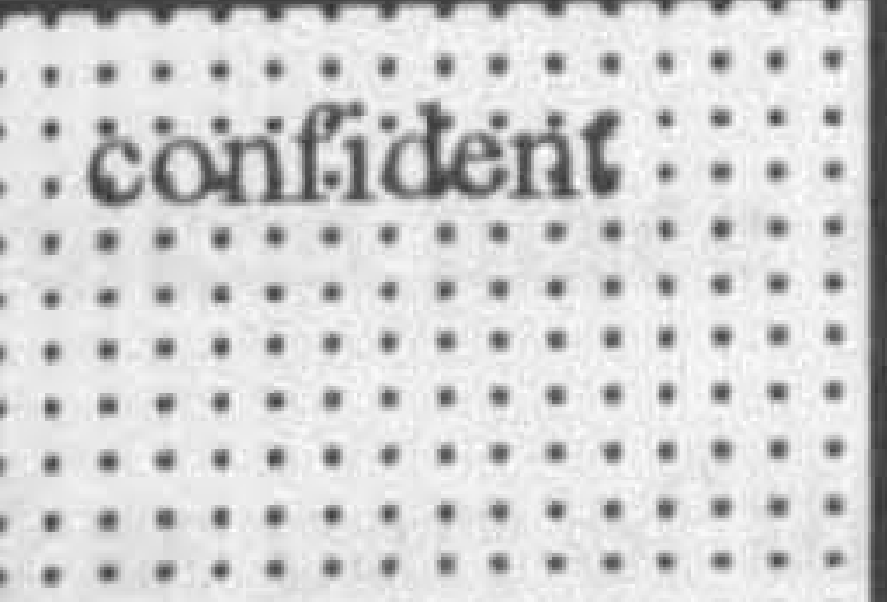 & $\begin{array}{l}\text { avoids limelight, } \\
\text { prefers to let others } \\
\text { do talking }\end{array}$ & 7 & 6 & 1 & $\begin{array}{l}\text { relaxed, takes active } \\
\text { involvement in events }\end{array}$ \\
\hline 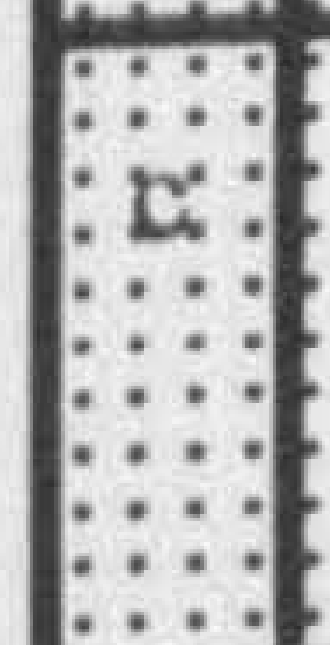 & 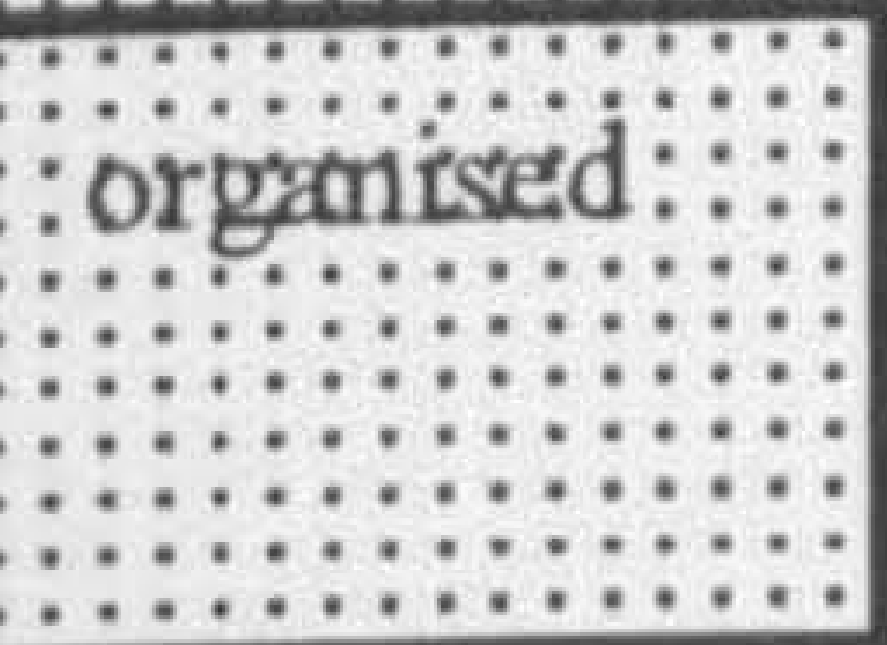 & $\begin{array}{l}\text { Does not have tools/ } \\
\text { resources required to } \\
\text { complete tasks }\end{array}$ & 7 & 8 & -1 & $\begin{array}{l}\text { Plans tasks has everything to } \\
\text { hand and knows what to do }\end{array}$ \\
\hline \begin{tabular}{c}
0 \\
\hdashline \\
$\vdots$ \\
$\vdots$ \\
$\vdots$ \\
$\vdots$
\end{tabular} & 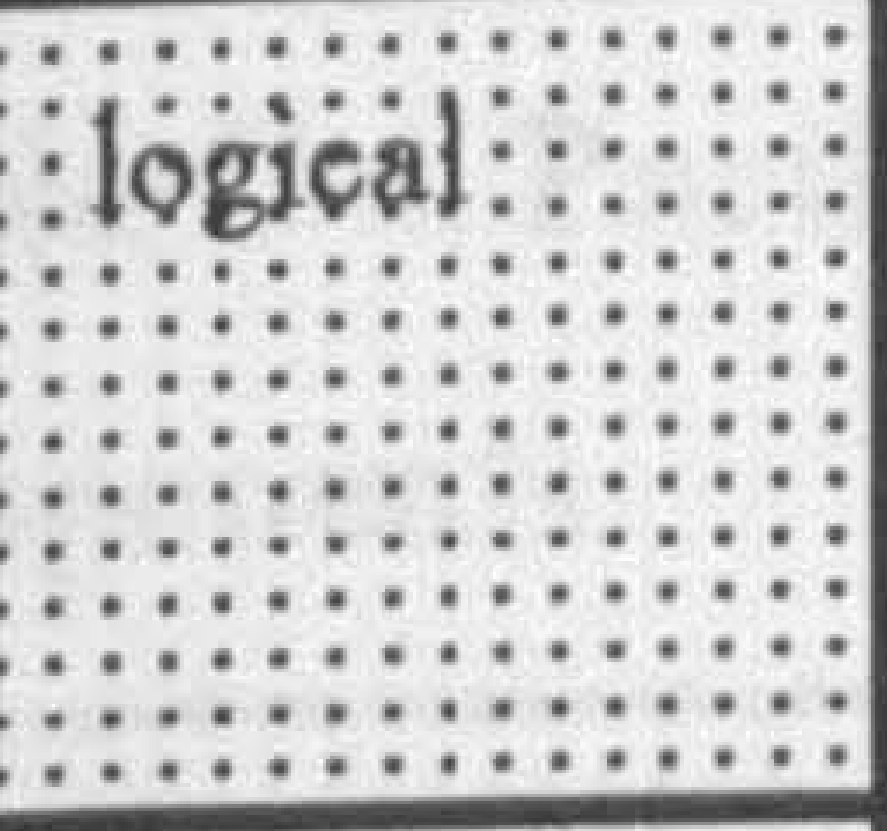 & $\begin{array}{l}\text { No sound basis for } \\
\text { decisions, cannot } \\
\text { sustain argument }\end{array}$ & 7 & 7 & 0 & $\begin{array}{l}\text { sound decision making, does } \\
\text { things logically in order, wins } \\
\text { argument through persuasion } \\
\text { and logic }\end{array}$ \\
\hline : n & linterate: & $\begin{array}{l}\text { takes superficial } \\
\text { view of events }\end{array}$ & 8 & 8 & 0 & $\begin{array}{l}\text { looks for underlying causes, } \\
\text { seeks additional information }\end{array}$ \\
\hline $\begin{array}{l}0 \\
\vdots \\
\vdots \\
\vdots \\
\vdots \\
\vdots \\
\vdots \\
\vdots\end{array}$ & mitmerate & $\begin{array}{l}\text { Finds difficulty with } \\
\text { basic calculations - } \\
\text { needs to use } \\
\text { calculator all the } \\
\text { time, cannot } \\
\text { understand what is } \\
\text { going on }\end{array}$ & 6 & 9 & -3 & $\begin{array}{l}\text { Can read financial accounts. } \\
\text { Can interpret complex tables or } \\
\text { statistics }\end{array}$ \\
\hline \begin{tabular}{l}
$::$ \\
\hdashline \\
$\vdots$ \\
$\vdots$ \\
$\vdots$
\end{tabular} & :persistentat & $\begin{array}{l}\text { Not assertive, only } \\
\text { asks for something } \\
\text { once }\end{array}$ & 9 & 8 & 1 & Doesn't give up easily. \\
\hline 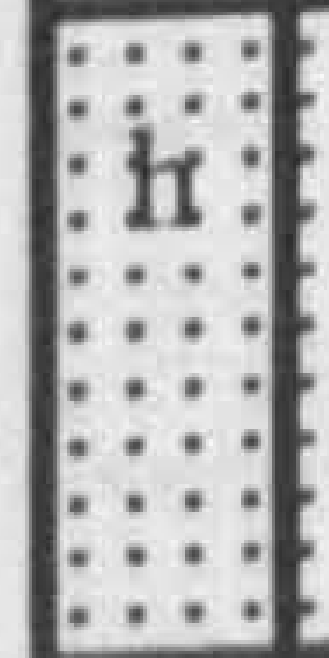 & supportives & $\begin{array}{l}\text { As manager someone } \\
\text { who leaves you on } \\
\text { your own. }\end{array}$ & 8 & 6 & 2 & $\begin{array}{l}\text { Someone who asks others to } \\
\text { provide help and gets help from } \\
\text { others }\end{array}$ \\
\hline 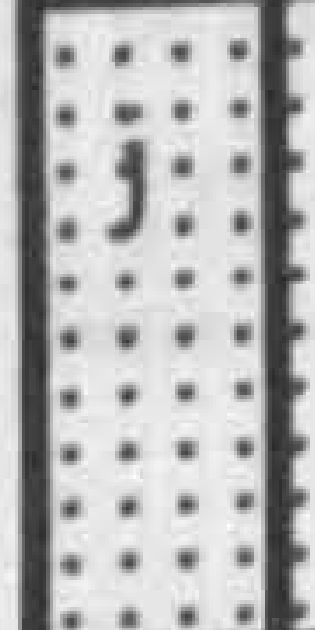 & apresentable & $\begin{array}{l}\text { fails to present } \\
\text { credible image as } \\
\text { senior officer }\end{array}$ & 9 & 7 & 2 & $\begin{array}{l}\text { presents credible physical and } \\
\text { managerial impression }\end{array}$ \\
\hline 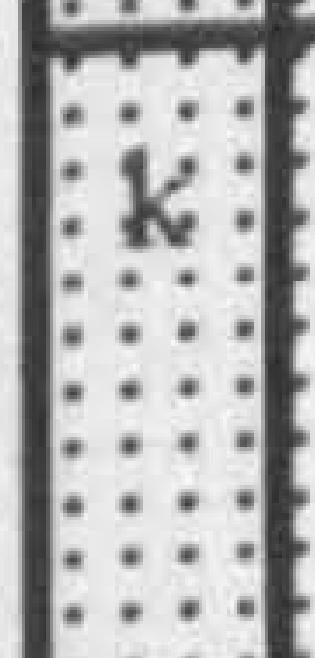 & asseciplined & $\begin{array}{l}\text { no respect for } \\
\text { organisational policy } \\
\text { or procedures }\end{array}$ & 10 & 10 & 0 & $\begin{array}{l}\text { Respects rank when required, } \\
\text { understands organisation and its } \\
\text { needs }\end{array}$ \\
\hline : & 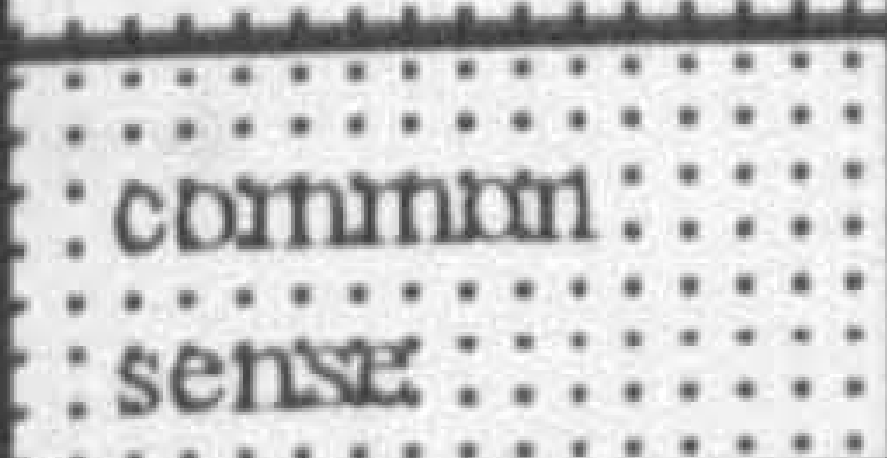 & $\begin{array}{l}\text { reacts too late to } \\
\text { change }\end{array}$ & 8 & 7 & 1 & reacts well in new situations \\
\hline
\end{tabular}




\section{Stage 3a}

Mapping the constructs back on to the assessment centre was developed as a means of assisting participant $\mathrm{D}$ since it provided a decode key for feedback information. It also enabled a further evaluation of the assessment centre in terms of perceived domain coverage. It was derived retrospectively for participant C (i.e. after development discussions in stage 4 had taken place and after assessment centre feedback had been given) it was not, therefore, used as part of the development process described in stage 4.

\section{Table C 4. Participant $\mathrm{C}$ comparison of personal constructs to assessment centre} components

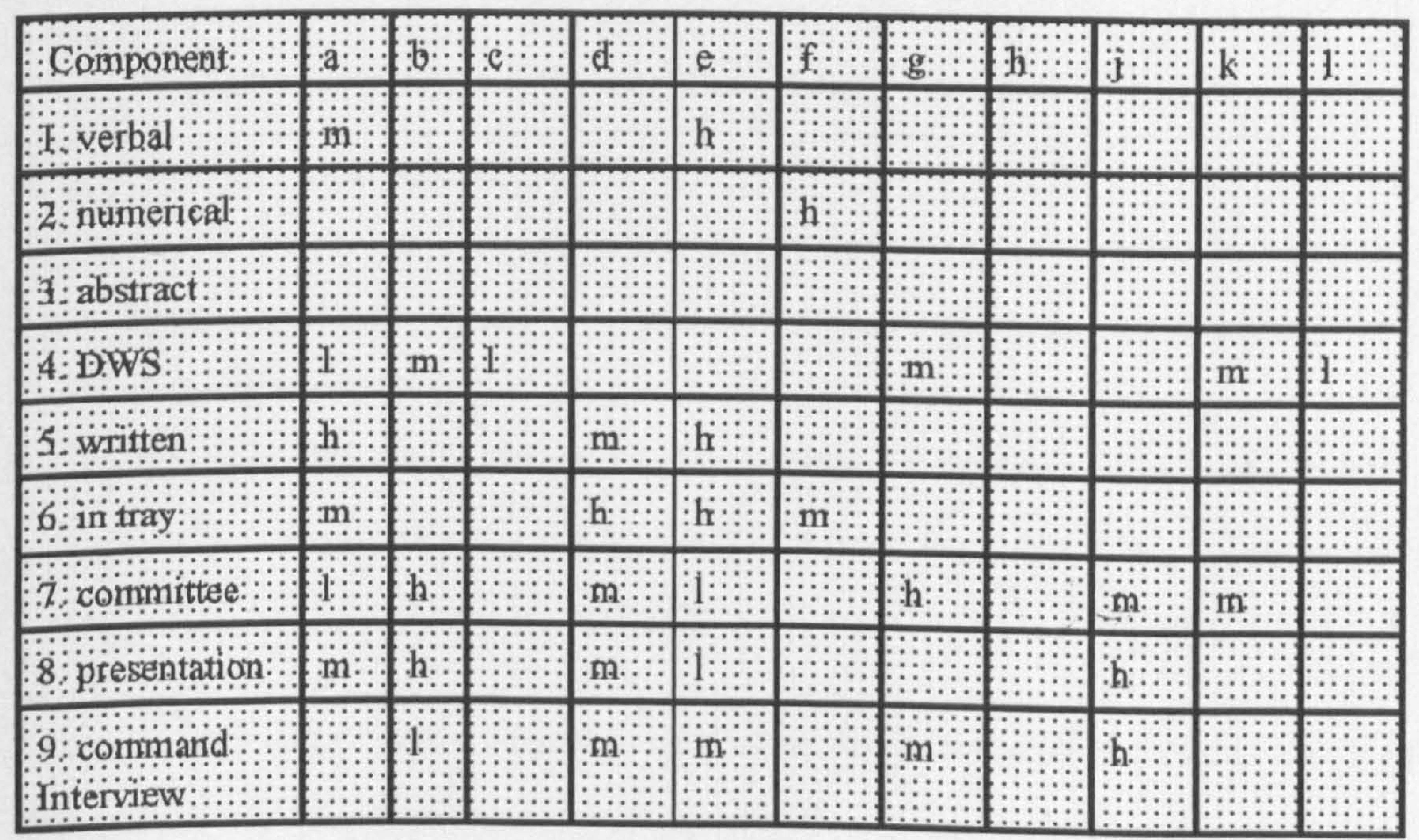

stage 4

Participant $\mathrm{C}$ agreed to exchange constructs with participant $\mathrm{F}$ as a means of developing a 
better understanding of the management domain. As a consequence, the use of constructs in self development by participant $\mathrm{C}$ is described in case study $\mathrm{F}$. 


\section{Participant D}

Participant $D$ was a substantive Divisional Officer who had been identified for temporary promotion to Divisional Commander (Senior Divisional Officer) prior to the running of the assessment centre. At the time of the first interview he was undertaking a Principal Officer role and had recently completed the centre. He had not received detailed feedback but some decisions been made regarding his progress and he had not been invited to the second stage interviews on the basis of his performance at the command interview. In terms of promotion, therefore, this participant had effectively been failed.

stage 1

a. pre centre development needs

- A general broadening of management skills, especially in the areas of assertiveness and self presentation.

- The issue of operational development was not seen as relevant prior to the centre

b. pre centre development plans or strategies

The participant had expressed interest in short course attendance both within and outside the Brigade.

c. post centre development needs

A specific need in the area of operational command.

d. post centre development plans or strategies 
The participant was looking for intensive command training based on course attendance, the use of a simulator and greater command exposure as a Divisional Officer

e. Bridges and barriers

- The most significant barriers identified were related to the absence of any coherent senior command training and, following the loss of temporary rank, the unavailability of appropriate senior command experience i.e. as a result of failing this component the participant would lose his temporary rank and with it the opportunity to act as a Senior Divisional Officer at incidents. This loss of temporary rank would preclude his taking charge of larger scale or more complex incidents.

\section{f. Review}

The decision to fail candidates was taken as a means of reducing numbers before a final stage interview. It had not been envisaged when the process was established, nor had it been considered at the time of setting up the review process. To some extent the review process itself had emerged from concerns expressed about the command interview component. It therefore presented some problems in discussing a possible contentious issue with a participant who had clearly been adversely affected by the use of a given exercise.

Nevertheless, the participant was keen to examine his performance and to contribute to the review.

Clearly, the assessment centre had considerable impact on the participant, however, it is not possible to subtract the effect (if any) of attendance from the overwhelming effect of a decision. Initially, at least, the entire focus of the conversation was on the decision itself and the exercise which had been used. In terms of development planning, the participant was anxious to develop himself, but also acutely aware of the lack of facilities or support being offered by the organisation. 
Stage 2

table D 1. Participant D self perceived assessment centre performance

\begin{tabular}{|c|c|c|c|}
\hline Component: & seif: & : & difference \\
\hline Overall DC DC: & 6 & 6 & 0 \\
\hline : $:$ : rerbabal::::::::::::::: & 8 & 6 & 2 \\
\hline nnumerical : & 6 & 5 & 1 \\
\hline 3 abstract & 6 & 5 & 1 \\
\hline 4 19: & $\mathrm{n} / \mathrm{a}$ & $\mathrm{n} / \mathrm{a}$ & 0 \\
\hline |S & 8 & 6 & 2 \\
\hline 60 & 5 & 6 & -1 \\
\hline 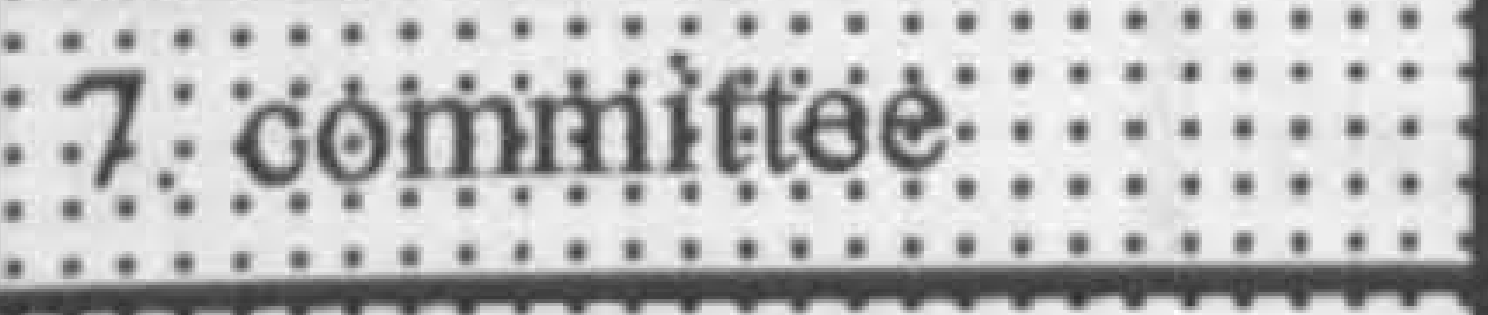 & 7 & 7 & 0 \\
\hline 8 presentation & 7 & 6 & 1 \\
\hline $\begin{array}{l}\text { compand: } \\
\text { unteriow }\end{array}$ & 3 & 6 & -3 \\
\hline
\end{tabular}

The impact of the decision relating to the command interview is self evident. Having identified this, it should be noted that not all of the other areas of performance are positive although the scale of the difference (the next lowest score is 5) is significant. Overall the participant viewed his performance as near the average, with positive performance in some areas, but notable negative performance in the in tray exercise and the presentation.

stage 2a 
Table D 2. Participant D self perceived job performance

\begin{tabular}{|c|c|c|c|c|}
\hline A: & Job Conponent & : & 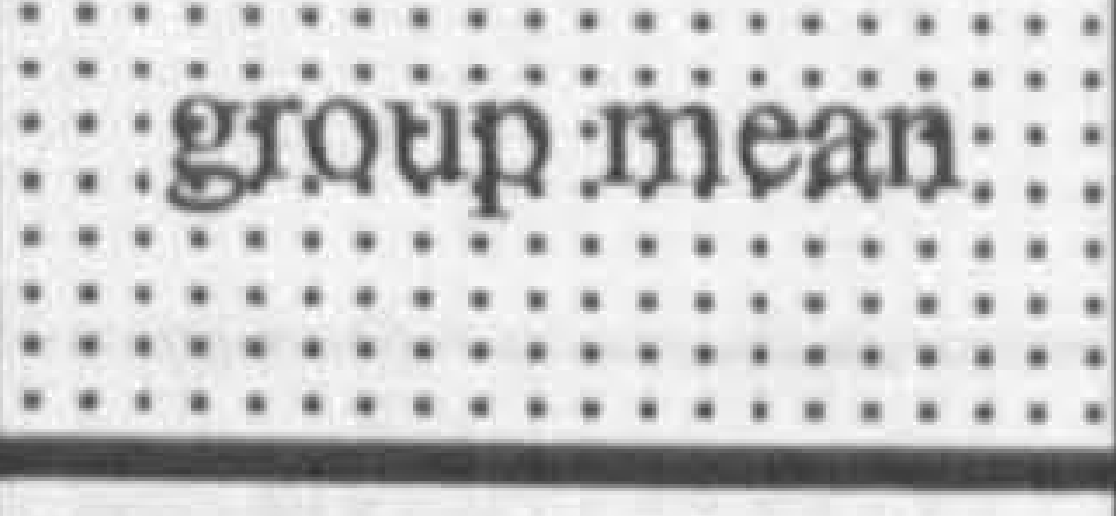 & : difference \\
\hline 1 & Meetings & 8 & 5 & 3 \\
\hline 2 & budgets & 6 & 6 & 0 \\
\hline 3 & no linked activity & 0 & 0 & 0 \\
\hline 4 & counselling & 8 & 5 & 3 \\
\hline 5 & briefing papers & 8 & 6 & 2 \\
\hline 6 & policy making & 7 & 7 & 0 \\
\hline 7 & meetings & 8 & 5 & 3 \\
\hline 8 & seminars & 7 & 7 & 0 \\
\hline 9 & command at incidents & 6 & 6 & 0 \\
\hline
\end{tabular}

Although he did not rate his own job performance highly in the area of incident command (one of two sixes), this still compared favourably with his perception of the mean of the group (also 6). Overall the participant seemed to view himself as better in some areas than his peers but on a par in others. He did not perceive any area in which his performance was below the mean of the candidate group. The areas of policy making and presenting seminar are of interest, since they are linked to areas of relatively poor (self perceived) performance in the assessment centre and emerge here as equal to the average. The two tables, therefore, contain a mixture of confirmatory and contradictory information about performance. 
Table D 3. Participant D performance constructs

\begin{tabular}{|c|c|c|c|c|c|}
\hline Qualities & negative & self: & mean: & diff & positive \\
\hline an thinkng & $\begin{array}{l}\text { fails to take on } \\
\text { board all relevant } \\
\text { information }\end{array}$ & 6 & 6 & 0 & $\begin{array}{l}\text { ability to rapidly absorb } \\
\text { and analyse information to } \\
\text { make decisions }\end{array}$ \\
\hline b listening & $\begin{array}{l}\text { interrupts or cuts } \\
\text { across colleagues }\end{array}$ & 8 & 6 & 2 & $\begin{array}{l}\text { allows contributions to } \\
\text { debate and considers them }\end{array}$ \\
\hline mading & $\begin{array}{l}\text { inability to decide, } \\
\text { regardless of length } \\
\text { of time provided }\end{array}$ & 7 & 6 & 1 & $\begin{array}{l}\text { ability to make informed } \\
\text { decision based on } \\
\text { information available }\end{array}$ \\
\hline 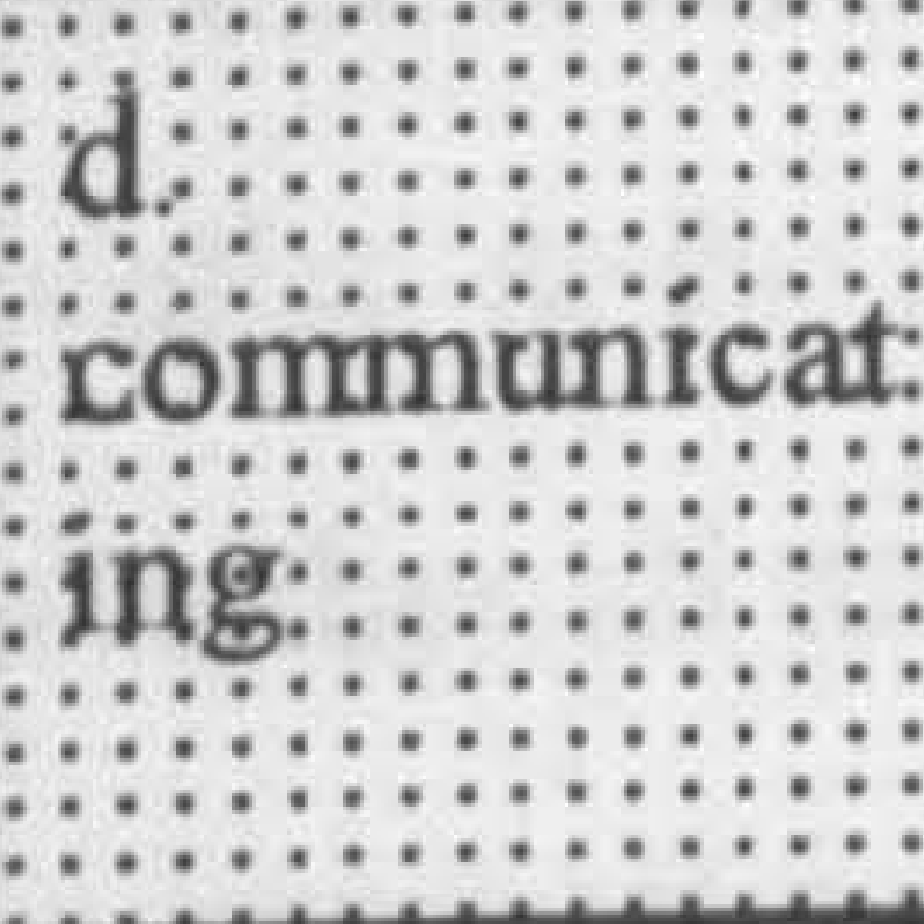 & $\begin{array}{l}\text { inability to generate } \\
\text { understanding in } \\
\text { others. Unclear or } \\
\text { confused }\end{array}$ & 8 & 7 & 1 & $\begin{array}{l}\text { ability to communicate } \\
\text { clearly and concisely to } \\
\text { generate mutual } \\
\text { understanding }\end{array}$ \\
\hline o arajaysing & $\begin{array}{l}\text { inability to reach } \\
\text { conclusions on } \\
\text { information } \\
\text { available }\end{array}$ & 7 & 6 & 1 & $\begin{array}{l}\text { ability to reach sound } \\
\text { conclusions }\end{array}$ \\
\hline f creativity & $\begin{array}{l}\text { able to generate } \\
\text { ideas only on basis } \\
\text { of previous } \\
\text { solutions }\end{array}$ & 8 & 6 & 2 & $\begin{array}{l}\text { able to generate new } \\
\text { radical approaches to } \\
\text { problem solving }\end{array}$ \\
\hline sensitivity & $\begin{array}{l}\text { tactless, unable to } \\
\text { sense delicate areas } \\
\text { or issues }\end{array}$ & 8 & 5 & 3 & $\begin{array}{l}\text { able to sense delicate } \\
\text { issues and discuss without } \\
\text { traumatising }\end{array}$ \\
\hline
\end{tabular}

Self perceived performance against the constructs was generally positive and revealed few of the concerns expressed when discussing the assessment centre. Indeed, in his own construct system, participant $D$ was satisfied with his own performance Whilst he recognised significant areas for development, they did not necessarily correspond to his own view about the role of a senior fire officer. The key issue for participant D was not about how to develop managerial skills, but how to make sense of an assessment process which he felt did not cover the key areas of performance particularly well. Given the promise of detailed feedback, he 
was keen to apply his own constructs to the information he was about to receive.

\section{Stage 3a}

Having derived and revised the constructs, the next task was to reapply these to the assessment centre. This fulfilled two distinct functions. Firstly, it encouraged the candidate to reinterpret actual performance in the light of his own personal view of performance. Secondly, it allowed a more detailed evaluation of the assessment centre event in terms of coverage of the management domain using the participant's view of success criteria. The two processes of evaluation and development were thus rejoined by creating a mechanism which, on one level allowed the candidate to reinterpret the outcomes of the centre in his own terms, whilst, at the same time allowed the designer to re-examine the process (and to determine whether all the relevant performance constructs were being met). This review of the assessment centre provided the participant with both a decode key in terms of how the assessment centre related to his performance criteria and, to the extent that significant areas were not fully covered, helped generate a critique of the process from an extemal and independent viewpoint. This latter facility was particularly important to participant $D$, in enabling him to create a distance between the immediate impact of the process and a secondary consideration of its value (and implicitly its limitations).

\section{Table D 4. Participant D assessment centre components as indicators of personal constructs}

This table was initially scored on a 0 to 10 scale to indicate the extent to which an exercise assessed, or was capable of assessing, the construct elicited. Subsequently, the scaling was simplified into strong, medium and weak coverage. The 1 to 10 ratings have been translated into a 3 point scale with blank cells as not assessed or , $w$ as weak, $m$ as medium, and $s$ as strong. 


\begin{tabular}{|c|c|c|c|c|c|c|c|}
\hline qualities & a & $\mathrm{b}$ & c & d & e & $\mathrm{f}$ & g \\
\hline \multicolumn{8}{|l|}{ components } \\
\hline 1rverbal::::::::::: & $\mathrm{m}$ & & $\mathrm{m}$ & & w & & \\
\hline | & $\mathrm{m}$ & & $\mathrm{m}$ & & $\mathrm{m}$ & & \\
\hline |3 & & & $\mathrm{m}$ & & $\mathrm{m}$ & & \\
\hline \multicolumn{8}{|l|}{ } \\
\hline S Wirtuen : : : : : : & & & was & $\mathrm{m}$ & & & \\
\hline 6 in tray $:::::::::$ & & & $\mathrm{m}$ & $\mathrm{m}$ & $\mathrm{m}$ & & \\
\hline 7 committee & $\mathrm{m}$ & w & $\mathrm{m}$ & $\mathrm{m}$ & $\mathrm{m}$ & w & w \\
\hline opresentation : & w & w & & $\mathrm{m}$ & & w & \\
\hline $\begin{array}{l}9 \text { compina } \\
\text { nuteriow }\end{array}$ & $\mathrm{m}$ & W & $\mathrm{m}$ & $\mathrm{m}$ & $\mathrm{m}$ & & \\
\hline
\end{tabular}

The problem of coverage, or lack of coverage, is significant, since it suggests that the participant's views concerning success in the management domain are derived from completely different sources than the assessment centre design. Not only is coverage of some constructs very low, but no single exercise provides strong coverage of any construct. The implications for the design and delivery of feedback are immense, since on the face of the coverage, little of any value can emerge for the participant in terms of his own view of management.

\section{Stage 4}

The lack of coverage of personal constructs by the assessment process was of concern to participant D, as it suggested to him that he was operating in some different way from his peer group and colleagues generally. Since he thought of himself as relatively conventional in most of his work views, this came as a surprise. He was keen to find out how others viewed him and, in particular, what criteria they used to assess his performance at work. 
Participant D's initial proposal, therefore, was not to use his constructs for self development, but to seek to extend his construct system by eliciting (informal) constructs from colleagues and managers.

Table D 5. Potential new constructs

\begin{tabular}{|c|c|c|c|}
\hline & positive & negative & context used \\
\hline i. & $\begin{array}{l}\text { reliable, gets job } \\
\text { done with minimum } \\
\text { of fuss }\end{array}$ & $\begin{array}{l}\text { unreliable, over-complicates } \\
\text { simple tasks }\end{array}$ & day to day management \\
\hline ii & $\begin{array}{l}\text { innovative and } \\
\text { creative }\end{array}$ & traditional, conservative & managing change \\
\hline iii & $\begin{array}{l}\text { gets the information } \\
\text { needed before } \\
\text { making decisions }\end{array}$ & $\begin{array}{l}\text { makes rash decisions on } \\
\text { inadequate information }\end{array}$ & decision making \\
\hline iv & $\begin{array}{l}\text { can make decisions } \\
\text { without full } \\
\text { information }\end{array}$ & $\begin{array}{l}\text { needs to consult before } \\
\text { making decision refers too } \\
\text { many things upwards }\end{array}$ & decision making \\
\hline $\mathbf{v}$ & $\begin{array}{l}\text { in control, gets } \\
\text { things done through } \\
\text { people }\end{array}$ & $\begin{array}{l}\text { in charge, lets people know } \\
\text { who is the boss }\end{array}$ & managing people \\
\hline vi & $\begin{array}{l}\text { methodical, works } \\
\text { through problems }\end{array}$ & $\begin{array}{l}\text { impressionistic, looks for } \\
\text { easy solutions to difficult } \\
\text { problems }\end{array}$ & decision making \\
\hline vii & $\begin{array}{l}\text { good team player, } \\
\text { easy to get on with } \\
\text { comfortable to work } \\
\text { with }\end{array}$ & $\begin{array}{l}\text { loner, hard to get to know } \\
\text { doesn't contribute to team }\end{array}$ & groúp activities \\
\hline viii & $\begin{array}{l}\text { sensitive to needs } \\
\text { and feelings of } \\
\text { others, people } \\
\text { oriented }\end{array}$ & $\begin{array}{l}\text { task focussed, can be abrupt } \\
\text { or abrasive }\end{array}$ & group activities \\
\hline
\end{tabular}




\section{Conclusion}

The new constructs broadened participant D's view of the management domain. It differed significantly from the assessment centre dimensions as he perceived them (in stage 3a) and suggested to him that there existed, within the organisation, considerable variance in the perception of effective performance. Whilst he respected the assessment centre results as one piece of information about his performance, he was clear as to the partiality of the assessment made. The constructs which emerged from discussions with colleagues provided a broader base for self assessment and self development. They suggested areas which had not been formally assessed but which were widely regarded as significant for effectiveness. 


\subsection{Participant E}

Participant E was a substantive Divisional Officer who had been identified to manage a special project. He had not been offered temporary promotion to Divisional Commander (Senior Divisional Officer) prior to the running of the assessment centre. At the time of the first interview he was undertaking a unique senior officer role. He had recently completed the centre but not received any feedback. However, decisions had been made regarding his progress and he had been advised that his performance in the Command Interview would mean that he would not be recommended for further stages of the process.

\section{Stage I}

a. pre centre development needs

- prior to his most recent appointment the participant had been part of a strategic review group. This had enabled him to take a broader view of the organisation. He felt comfortable in the area of strategic management but expressed a desire to return to a hands on management role.

b. pre centre development plans or strategies

The participant had applied to undertake a Masters degree course in management (MBA) but had been refused support. He was guided towards the Home Office Brigade Command Course for potential Chief Fire Officers. Although this might assist in the development of his career in the Fire Service, he was not convinced it offered sufficient breadth for his development. He retained an interest in more academic courses related to managing organisations.

\footnotetext{
c. post centre development needs
} 
This participant was interested in using his assessment centre performance as a means of self development, but had not at this stage identified any specific needs. He was, however, critical of the process in respect of the Command Interview, as he judged this to be subjective and highly influenced by personal relationships.

d. post centre development plans or strategies

A retum to a more hands on role was now considered imperative as the specialist role had effectively excluded him from operations. His performance in the Command Interview was cited as a lever with which to obtain release from his special project.

e. Bridges and barriers

The main barrier to development at this point in time was the continued project requirements which prevented a return to duties of a more general nature. He believed that the Command Interview, although not in itself a valid assessment of his performance would lend weight to his request.

\section{f. Review}

Participant $E$ appeared cynical about the way in which the assessment centre had been managed. In particular, he was looking for "the fix", as he termed it, to go in. This meant that he was evaluating the different components against the extent to which they would enable or prevent subjective judgement. In his view, the Command Interview was clearly fixed, in as much as it produced an appropriate means of deselecting some candidates. The impression given was of a candidate looking for something to go wrong during the centre and whose suspicions were confirmed by the results. This focus on the negative, was, however, restricted to one element and, this being identified, he viewed the remainder of the process as both valid and potentially useful. 


\section{Stage 2}

The stage 2 process was adopted as a means of focusing attention on the components of the assessment centre and the participant's view of his own performance. This was suggested as a first stage of reviewing the process and was undertaken prior to any detailed feedback.

Overall the candidate viewed his performances as satisfactory and even in the one element in which his performance had been judged unacceptable felt that he was at least as good as colleagues who had been let through. He considered the command interview to have been his poorest performance but regarded this as a product of a prior intention on the part of the assessors rather than his genuine performance. He referred to the existence of a preferred list which had come into operation during the assessment process by virtue of the way in which the command interview had operated.

Table E 1.

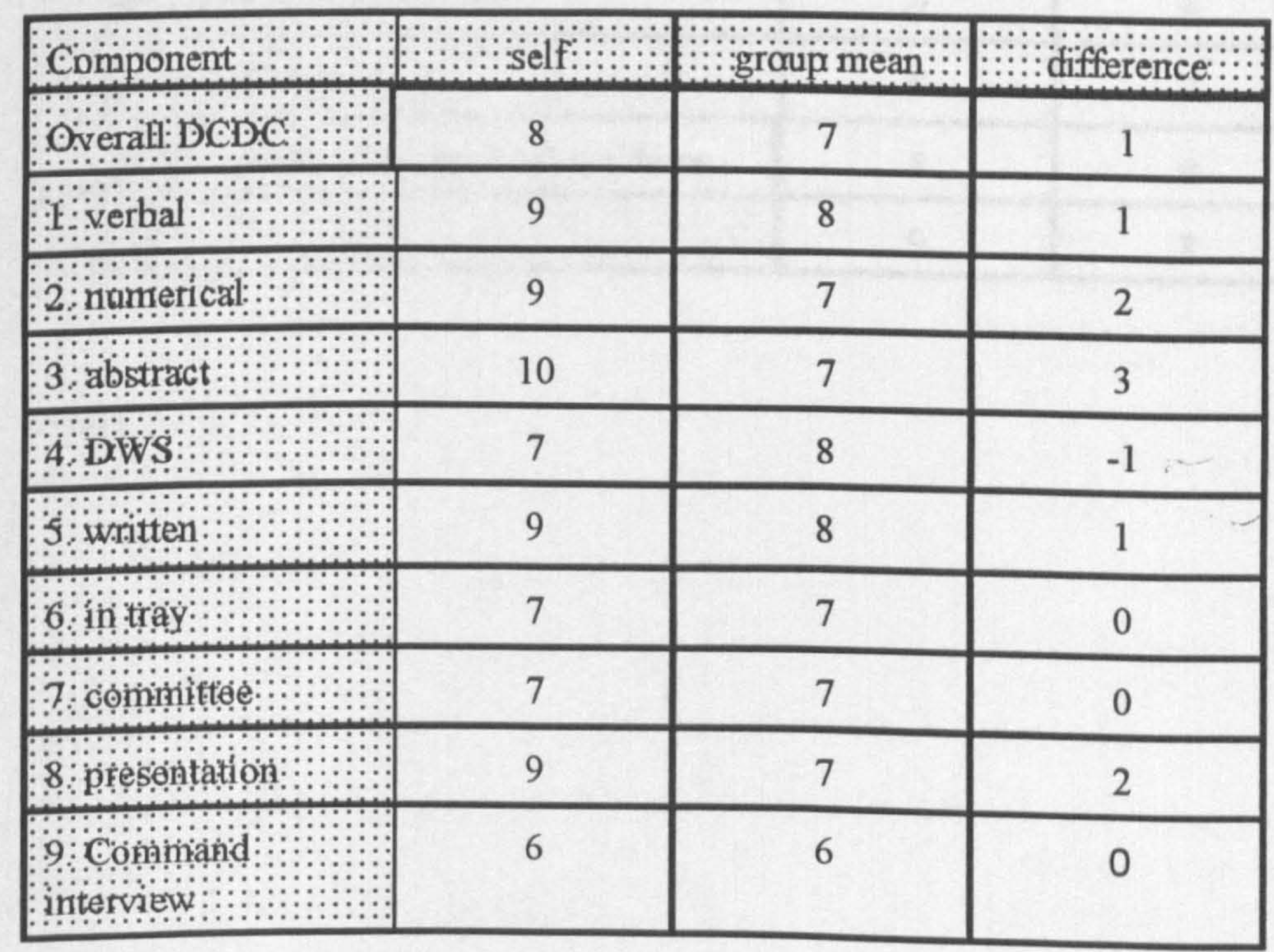


stage 2 a

The initial intention of stage 2 a was to compare assessment performance with normal day to day job performance by way of linking assessment components with job activities.

Table E 2.

\begin{tabular}{|l|c|c|c|}
\hline a. Communicating with staff & 9 & 7 & 2 \\
\hline b. Working with statistics & 9 & 5 & 4 \\
\hline c. Generating ideas & 8 & 5 & 3 \\
\hline d. Dealing with external agencies & 8 & 8 & 0 \\
\hline e. Writing reports & 9 & 7 & 2 \\
\hline f. Time management & 7 & 7 & 0 \\
\hline g. Meetings and discussions & 9 & 9 & 0 \\
\hline h. Giving presentations & 8 & 7 & 1 \\
\hline j. Taking change of operational incidents & 8 & 8 & 0 \\
\hline Qjerati: & 9 & 8 & 1 \\
\hline
\end{tabular}

\section{Stage 3}


Table E 3. Participant E personal constructs

\begin{tabular}{|c|c|c|c|c|c|}
\hline & negatrve & self: & mean & diff: & positive \\
\hline$a$ & $\begin{array}{l}\text { unable to communicate } \\
\text { clearly and precisely, as a } \\
\text { result is often } \\
\text { misunderstood }\end{array}$ & 9 & 8 & 1 & $\begin{array}{l}\text { communicates clearly and } \\
\text { precisely getting the message } \\
\text { across effectively }\end{array}$ \\
\hline b & $\begin{array}{l}\text { does not listen to } \\
\text { information being } \\
\text { received }\end{array}$ & 8 & 8 & 0 & $\begin{array}{l}\text { listens effectively to all } \\
\text { communication being received }\end{array}$ \\
\hline 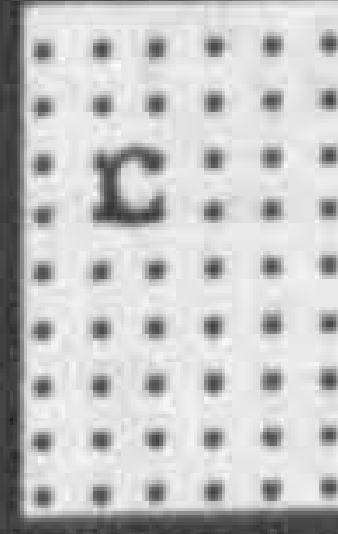 & $\begin{array}{l}\text { acts inappropriately on } \\
\text { information being given }\end{array}$ & 8 & 8 & 0 & $\begin{array}{l}\text { acts appropriately on } \\
\text { information being given }\end{array}$ \\
\hline did & $\begin{array}{l}\text { incapable of generating } \\
\text { ideas or facilitating others } \\
\text { to do so }\end{array}$ & 8 & 7 & 1 & $\begin{array}{l}\text { a level of creativity enabling } \\
\text { the generation of ideas in self } \\
\text { and others }\end{array}$ \\
\hline 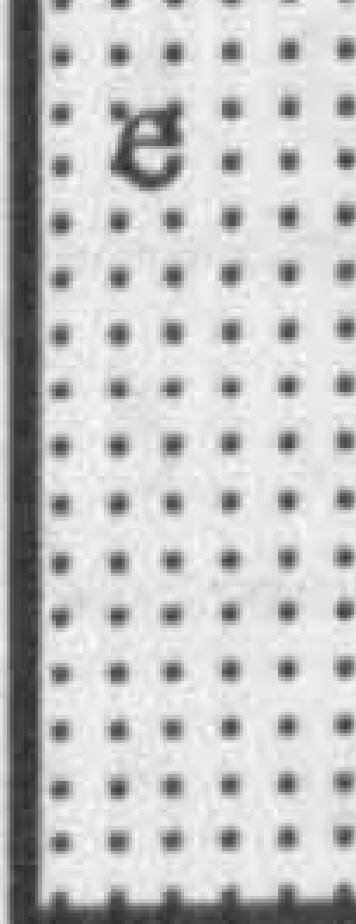 & $\begin{array}{l}\text { ineffective at interacting } \\
\text { with others and avoids } \\
\text { group contact if possible }\end{array}$ & 9 & 7 & 2 & $\begin{array}{l}\text { able to interact with others on } \\
\text { an individual and group basis, } \\
\text { inside and outside direct } \\
\text { environment }\end{array}$ \\
\hline f: & $\begin{array}{l}\text { fails to complete tasks on } \\
\text { schedule and late for } \\
\text { appointments }\end{array}$ & 9 & 9 & 0 & $\begin{array}{l}\text { completes tasks on schedule } \\
\text { by organising time effectively }\end{array}$ \\
\hline : & $\begin{array}{l}\text { fails to be heard or get } \\
\text { point across at meetings }\end{array}$ & 8 & 8 & 0 & $\begin{array}{l}\text { leads and participates in } \\
\text { discussion effectively }\end{array}$ \\
\hline 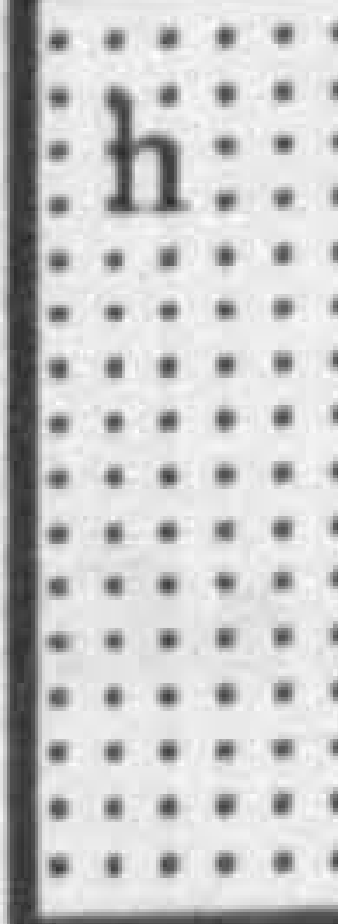 & $\begin{array}{l}\text { slow in thought resulting } \\
\text { in delays in making } \\
\text { decisions or complete } \\
\text { deferral of decision }\end{array}$ & 8 & 7 & 1 & $\begin{array}{l}\text { weighs up options quickly and } \\
\text { doesn't avoid making } \\
\text { decisions }\end{array}$ \\
\hline 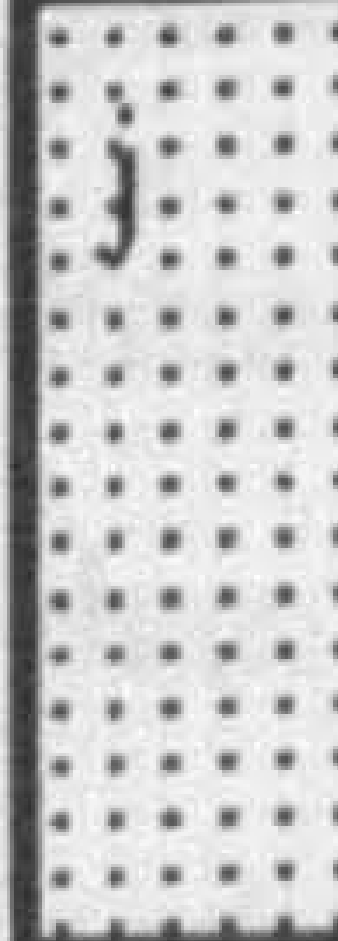 & $\begin{array}{l}\text { not prepared to make } \\
\text { unapproved decisions or } \\
\text { to work without higher } \\
\text { approval }\end{array}$ & 9 & 8 & 1 & $\begin{array}{l}\text { prepared to take calculated } \\
\text { risks when the situation } \\
\text { demands it }\end{array}$ \\
\hline k & $\begin{array}{l}\text { fails to exploit } \\
\text { opportunities for personal } \\
\text { and organisational } \\
\text { development }\end{array}$ & 9 & 8 & 1 & $\begin{array}{l}\text { identifies and exploits } \\
\text { opportunities for personal and } \\
\text { organisational development }\end{array}$ \\
\hline
\end{tabular}




\section{Stage 3a}

Participant $\mathrm{E}$ rated the assessment centre in relation to coverage using a four point scale being no coverage, 1 representing low coverage, $\mathrm{m}$ being medium, and $\mathrm{h}$ indicating a strong relationship.

Table E 4.

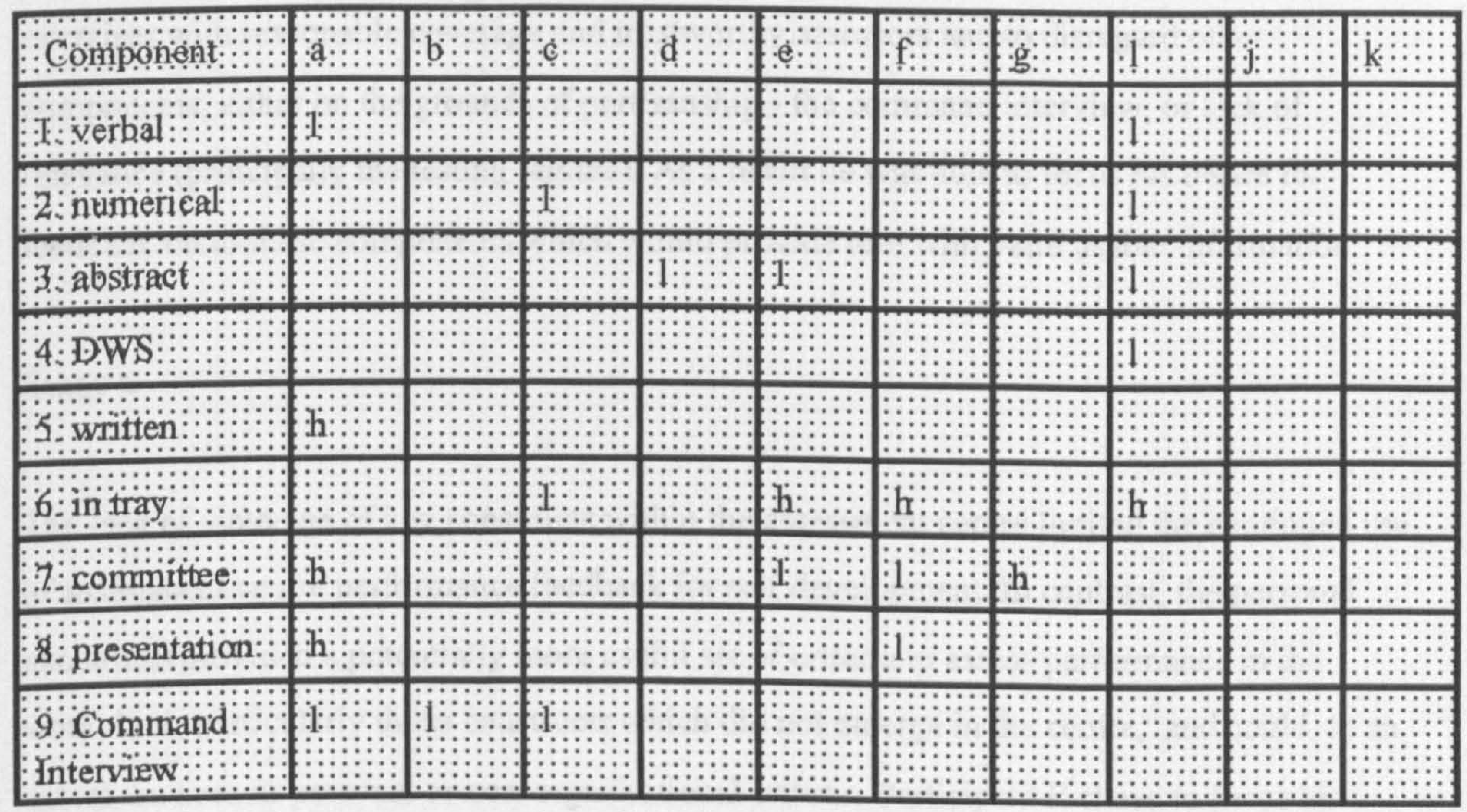

The lack of coverage of the assessment process is evident across most of the constructs generated by participant $\mathrm{E}$. Although most exercises have some relevance they seem to lack breadth, with only three, the in tray, committee and presentation, strongly loading on to more than one construct. Overall there is a very weak relationship between the assessment process and the construct system with the tests and the command interview showing very low coverage. The corollary also holds true, with a low correlation between the constructs system and centre. Although 4 constructs are seen to be tested by the system, two constructs are completely untested and two more only tested weakly. For this candidate, the centre has very low validity. 
Whether we choose to term this face validity or construct validity is a matter of debate. In the candidates's view, as a participant, the centre failed to examine significant aspects of performance in the relevant domain. As such in terms of his constructs the centre has relatively low validity. Earlier concerns expressed by the participant $E$ relating to a lack of genuine objectivity within the assessment process were now compounded by a more reasoned and coherent analysis of the centre in terms of coverage. This enabled the participant to identify areas where he felt the assessment process could provide useful information - those exercises with reasonable coverage and trustworthy assessors and to disregard other components, either on the grounds of partisanship - the command interview, or lack of relevance (principally the testing regime). As a result he was able to focus his desire for feedback on to these components which would provide him with valid usable information.

\section{Stage 4}

The lack of coverage of key constructs within the assessment centre limited the continued use of assessment centre performance feedback for self development. In contrast, the personal constructs provided a potentially more useful set of criteria to assess performance in the workplace, particularly those constructs which did not emerge in the centre, and could, to an extent, be seen as personal or non-organisational criteria. Participant E chose to focus his development around three of his own constructs - risk taking, generating ideas and self development and in discussion a more detailed set of performance constructs was generated for this purpose. In place of the mean performance of the candidate group, he selected a small number of known peer comparators, whose views he respected and whose opinions he valued. 
Table E 5.

\begin{tabular}{|c|c|c|c|c|c|c|c|}
\hline positive & a & b & c & $d$ & e & self & negative \\
\hline $\begin{array}{l}\text { looks for } \\
\text { innovative } \\
\text { solutions }\end{array}$ & 9 & 7 & 6 & 7 & 8 & 8 & $\begin{array}{l}\text { plays things by } \\
\text { the book }\end{array}$ \\
\hline $\begin{array}{l}\text { assesses risk and } \\
\text { acts accordingly }\end{array}$ & 7 & 7 & 8 & 6 & 8 & 7 & $\begin{array}{l}\text { assesses and } \\
\text { avoids risks }\end{array}$ \\
\hline $\begin{array}{l}\text { encourages others } \\
\text { to think } \\
\text { creatively by } \\
\text { setting a positive } \\
\text { example }\end{array}$ & 8 & 8 & 7 & 6 & 8 & 7 & $\begin{array}{l}\text { encourages } \\
\text { people to follow } \\
\text { existing } \\
\text { procedures by } \\
\text { threats and } \\
\text { punishment }\end{array}$ \\
\hline $\begin{array}{l}\text { looks at failure as } \\
\text { something to be } \\
\text { leamed from }\end{array}$ & 7 & 8 & 6 & 7 & 7 & 8 & $\begin{array}{l}\text { looks at failure } \\
\text { as something to } \\
\text { avoid at all costs }\end{array}$ \\
\hline $\begin{array}{l}\text { can work with } \\
\text { partial or } \\
\text { inconsistent } \\
\text { information }\end{array}$ & 9 & 8 & 7 & 7 & 8 & 7 & $\begin{array}{l}\text { needs everything } \\
\text { in black and } \\
\text { white, makes the } \\
\text { information fit } \\
\text { even when } \\
\text { contradictory }\end{array}$ \\
\hline $\begin{array}{l}\text { encourages others } \\
\text { to take risks }\end{array}$ & 8 & 7 & 8 & 6 & 7 & 9 & $\begin{array}{l}\text { discourages risk } \\
\text { taking and exerts } \\
\text { strict control } \\
\text { over } \\
\text { subordinates }\end{array}$ \\
\hline
\end{tabular}


Stage 4 a

Table E 6

\begin{tabular}{|c|c|c|c|c|c|c|}
\hline positive & a & b & c & e & self & negative \\
\hline $\begin{array}{l}\text { looks for more } \\
\text { than one solution }\end{array}$ & 8 & 8 & 7 & 8 & 8 & $\begin{array}{l}\text { plays things by } \\
\text { the book looks } \\
\text { for one solution }\end{array}$ \\
\hline $\begin{array}{l}\text { assesses risk and } \\
\text { acts accordingly }\end{array}$ & 7 & 7 & 7 & 8 & 7 & $\begin{array}{l}\text { assesses and } \\
\text { avoids risks }\end{array}$ \\
\hline $\begin{array}{l}\text { encourages others } \\
\text { to think } \\
\text { creatively by } \\
\text { setting a positive } \\
\text { example }\end{array}$ & 8 & 8 & 7 & 8 & 8 & $\begin{array}{l}\text { encourages } \\
\text { people to follow } \\
\text { existing } \\
\text { procedures by } \\
\text { threats and } \\
\text { punishment }\end{array}$ \\
\hline $\begin{array}{l}\text { looks at failure as } \\
\text { something to be } \\
\text { learned from }\end{array}$ & 7 & 7 & 8 & 7 & 7 & $\begin{array}{l}\text { looks at failure } \\
\text { as something to } \\
\text { avoid at all costs }\end{array}$ \\
\hline $\begin{array}{l}\text { looks at all } \\
\text { available data and } \\
\text { can work with } \\
\text { partial or } \\
\text { inconsistent } \\
\text { information }\end{array}$ & 8 & 8 & 7 & 7 & 8 & $\begin{array}{l}\text { looks for known } \\
\text { data, needs } \\
\text { everything in } \\
\text { black and white, } \\
\text { and makes the } \\
\text { information fit } \\
\text { even when } \\
\text { contradictory } \\
\text { data is presented }\end{array}$ \\
\hline $\begin{array}{l}\text { encourages others } \\
\text { to take risks, } \\
\text { delegates } \\
\text { complete projects } \\
\text { to subordinates }\end{array}$ & 8 & 8 & 9 & 8 & 8 & $\begin{array}{l}\text { discourages risk } \\
\text { taking and exerts } \\
\text { strict control } \\
\text { over } \\
\text { subordinates, } \\
\text { parcels out } \\
\text { information and } \\
\text { tasks }\end{array}$ \\
\hline
\end{tabular}

Participant $\mathrm{E}$ did not create a specific development plan. Instead he turned his attention to his normal duties and attempted to redefine effective workplace performance. Using his peers as 
elements in a revised grid, he sought to identify specific examples of positive and negative behaviour. Underlying the revised grid, therefore, are specific behavioural indicators for each construct. This detailed behavioural mapping of performance served to specify effectiveness and indicate how it could be assessed within self and others.

Over time the elicitation of feedback became more behaviourally oriented. Rather than seeking impressions of performance from others, participant $\mathrm{E}$ was able to seek information on directly observable behaviour. In doing so he sought to develop a system which fulfilled three requirements. It was personal to him in as much as its constructs were his own. It remained confidential to him, in that the constructs were not shared or exchanged. It also provided an objective assessment, in as much as it relied on third party observation.

Participant E's system thus met many of the design criteria for a full blown assessment centre, but had the additional benefit of being applicable across a range of work activities. The decision to omit one person (d) as a referent came about as this observation of this person failed to identify positive behaviours.

\section{Conclusion}

Participant $\mathrm{E}$ had a sophisticated, if somewhat cynical view of the assessment process. He regarded its contents, and, therefore, some of the data, as valid and legitimate, but saw it as a formal process, underlying which was an informal, and implicitly corrupt, intention. Having identified the method by which the latter was pursued, he felt open to the data emerging from other elements, and was capable of using this for his own development. He was suspicious of many of the officers involved in the assessment process and chose to pursue his development known only to a carefully selected group of peers. He was not prepared to discuss his needs or plans with senior managers and created what was, in effect, a clandestine development programme, using his peers as sources of feedback, but also relying heavily on his own self assessments. He was not particularly focused on the assessment process, as he predicted that he would not be allowed to achieve success through it. 
Perversely, this rather negative view of the assessment centre enabled him to define his own objectives more clearly and to concentrate on development outside the assessment arena. The use of personal constructs enabled a more relevant data collection process, involving trusted colleagues and information about key decision making and developmental activities.

Although the constructs themselves were not shared, i.e. they remained known to the participant but not those whose feedback was sought, the system was nevertheless adapted in response to the information being received. To this extent the construct system derived by participant $E$ can be seen to be independent of, but capable of using information from, his colleagues. 


\subsection{Participant F}

Participant F was a substantive Divisional Officer who had not been identified for temporary promotion to Divisional Commander (Senior Divisional Officer) prior to the running of the assessment centre and was operating at his substantive rank, albeit in a specialist team. At the time of the first interview he was undertaking a senior officer or middle manager role. He had recently completed the centre and been advised that he had not been selected for the next stage. However he had not received any formal feedback. Effectively at the time of the interview he had failed the assessment centre.

\section{Stage I}

a. pre centre development needs

- A general broadening of management skills was identified together with specific needs in relation to written and verbal communication.

b. pre centre development plans or strategies

The participant was not scheduled for attendance on any future courses. He had recently attended a presentation course which he felt had been very useful, particularly in the context of the assessment centre presentation exercise.

c. post centre development needs

Participant $F$ was generally quite pleased with his performance in the assessment centre, specifically in the presentation exercise. He was less concerned with his performance in verbal communication, and had received informal peer feedback which suggested that a number of fellow participants had viewed his group exercise performance positively. 
d. post centre development plans or strategies

In the longer term participant $F$ looked to the Brigade Command Course. At this point, however, he was interested in written communication skills, particularly in the context of impression management.

e. review

Participant F's analysis of needs derived from specific concerns about the way in which he appeared to peers and superiors. His assessment of his own performance was at this stage favourable. The availability of assessment centre data was seen as potentially useful, and he had found informal feedback quite supportive. The apparent positive impact of the centre was unusual. Although he remained concerned about his communication skills, he was able to focus this more clearly in relation to managing his image. Participant $F$ had previously been concerned that he was seen as intellectually limited because of his past performance in roles which required a certain degree of bluntness. He felt that his interpersonal skills had been overlooked, and he had been labelled because of the tasks he had been asked to undertake. The assessment centre had suggested that the problem was one of interpretation, rather than actual skills. He had been satisfied with his own performance, and had been pleasantly surprised by the informal feedback he had received.

He expressed some disappointment at not being selected for the next stage, but recognised that, at present, other officers were seen as closer to promotion. 


\section{Stage 2}

Table F 1. Participant F self perceived assessment centre performance

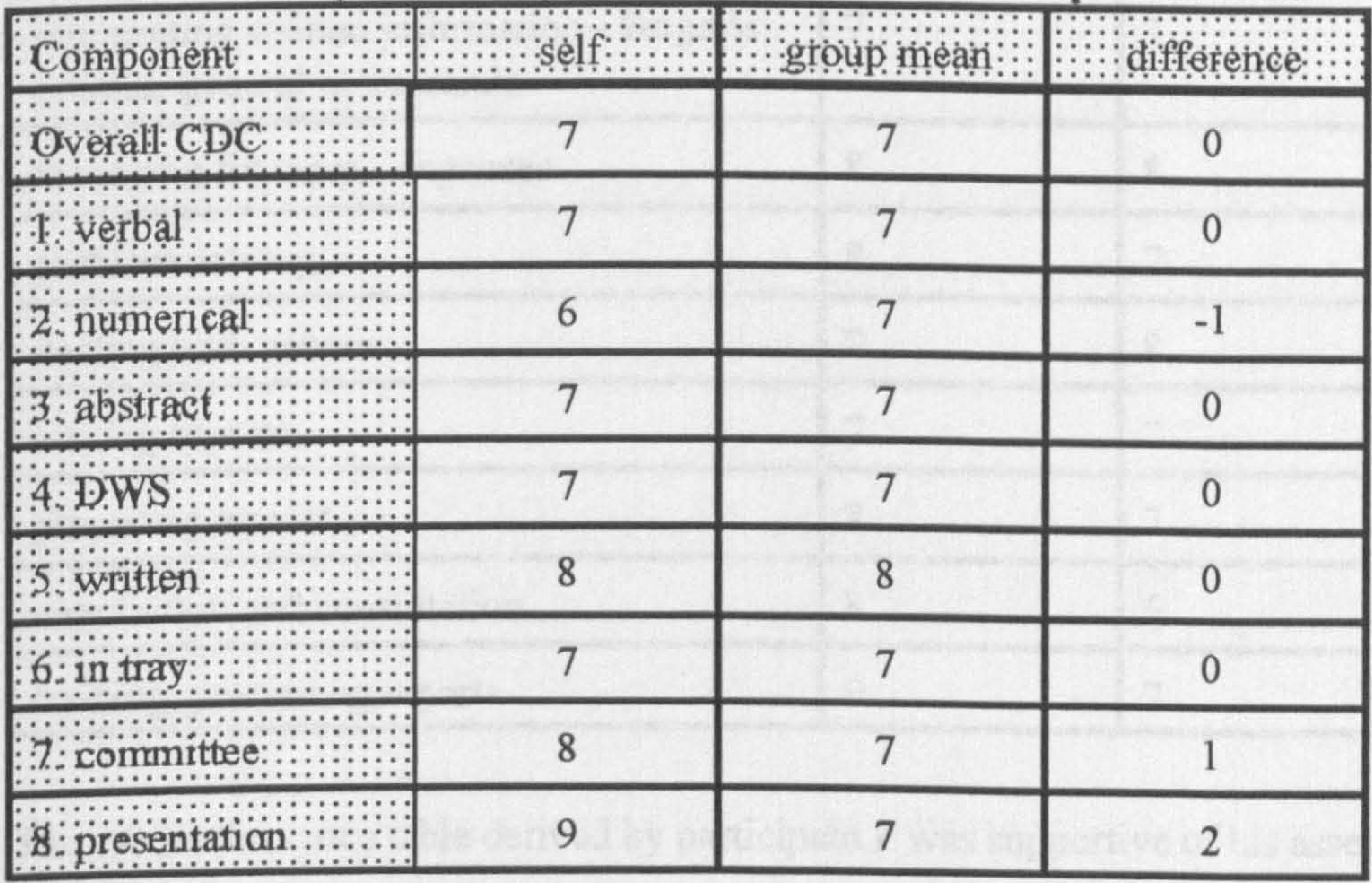

Participant F's more detailed view of his performance indicates a further need in relation to numerical reasoning. His self perceived performance is positive in relation to his peers, particularly in relation to the presentation exercise and, to a lesser extent, the committee or group exercise. The former may be explained as a result of attending a very specific course i.e. he had available a clear set of criteria against which to develop and judge his own performance. In the latter his views are influenced by the comments of his colleagues, which reinforced his own positive views. The availability of informal peer feedback is seldom considered in the context of assessment or development centres. This case study suggests that feedback, in this form, may be more significant in terms of impact than simple attendance.

The availability of other, pre existing performance criteria, indicates that the candidate is not a passive figure in the assessment process, but one who evaluates his or her own performance using available public perceptions of the domain. 
Table F 2. Participant F self perceived job performance

\begin{tabular}{|l|l|l|l|}
\hline & self component: & & \\
\hline $\begin{array}{l}\text { interpreting written information - Brigade } \\
\text { orderss, general memoranda }\end{array}$ & 7 & 7 & 0 \\
\hline managing finances - expenses & 8 & 8 & 0 \\
\hline problem solving & 8 & 7 & 1 \\
\hline dealing with people & 9 & 8 & 1 \\
\hline writing reports & 7 & 7 & 0 \\
\hline preparing reports & 8 & 7 & 1 \\
\hline negotiation and consultation & 8 & 6 & 2 \\
\hline training, presenting reports & 9 & 7 & 2 \\
\hline
\end{tabular}

The job performance table derived by participant $\mathrm{F}$ was supportive of his assessment centre performance in most respects. The self assessment of his performance in presenting reports reflected his recent course attendance, whilst his experience in formal negotiations was illustrated in his self assessment for this activity. Interestingly, this area also saw a significant difference between his own assessment and that of the peer group comparator. Further discussion indicated that his role in trade union consultation had emphasised the negative or antagonistic aspect of the process (from which his reputation amongst managers derived) but that this was offset by the respect he enjoyed amongst trade union negotiators as someone who was straight or honest. The area of numerical skills was of interest, since the activity identified was significantly below that of the tests used in terms of complexity. Having examined his job activities in some detail, the participant felt that his only realistic experience in the area of manipulating figures lay in submitting expenses, as most of the other financial responsibilities were of a fixed or routine nature. 


\section{Stage 3}

The stage 3 process was derived as an attempt to overcome the problematic nature of job factor assessment centre comparisons by providing a single relevant set of measures which could be mapped by the participant onto either job or assessment centre performance. The method for the derivation of the table or grid was a variation of the standard means of eliciting a repertory grid the full details of which are described in case study C.

Table F 3. Participant F performance constructs

\begin{tabular}{|c|c|c|c|c|c|c|}
\hline & Qualities: : & negative: : & Self: & mean & diffe:: & :a: \\
\hline à & persistence & $\begin{array}{l}\text { leaves things to others } \\
\text { to do, not interested in } \\
\text { outcomes }\end{array}$ & 8 & 7 & 1 & $\begin{array}{l}\text { has clear view of end } \\
\text { result and makes } \\
\text { efforts to achieve it }\end{array}$ \\
\hline b & : & $\begin{array}{l}\text { confused over } \\
\text { objectives }\end{array}$ & 7 & 7 & 0 & $\begin{array}{l}\text { clear views of what is } \\
\text { needed }\end{array}$ \\
\hline & intogrity: & $\begin{array}{l}\text { has too many hidden } \\
\text { agendas }\end{array}$ & 8 & 7 & 1 & $\begin{array}{l}\text { knows what is needed } \\
\text { and lets people know } \\
\text { how they fit in }\end{array}$ \\
\hline id & :::äing::::: & $\begin{array}{l}\text { relies on rank or } \\
\text { position }\end{array}$ & 7 & 7 & 0 & $\begin{array}{l}\text { diplomatic and } \\
\text { influential }\end{array}$ \\
\hline$e$ & ivintten style & $\begin{array}{l}\text { brusque and to the } \\
\text { point but not tailored } \\
\text { for the reader }\end{array}$ & 6 & 8 & -2 & $\begin{array}{l}\text { easy to read, makes } \\
\text { point well, makes } \\
\text { things easy for the } \\
\text { reader }\end{array}$ \\
\hline f & 促: & $\begin{array}{l}\text { concerned about image } \\
\text { and people's views }\end{array}$ & 8 & 7 & 1 & $\begin{array}{l}\text { makes sure that things } \\
\text { get done, chases people } \\
\text { up }\end{array}$ \\
\hline & visible: $::::::$ & $\begin{array}{l}\text { avoids awkward } \\
\text { decisions or situations, } \\
\text { blames others when } \\
\text { things go wrong. }\end{array}$ & 8 & 7 & 1 & $\begin{array}{l}\text { lets everyone know } \\
\text { that they are } \\
\text { responsible and is } \\
\text { prepared to admit if } \\
\text { things go wrong }\end{array}$ \\
\hline
\end{tabular}




\section{Overview}

Participant F's construct grid tended to reflect his view that his performance had often been judged at a very superficial level. He felt that his concern for outcomes rather than image had resulted in the development of a stereotype of someone who looked for conflict. His own view was that he recognised conflict and, where necessary, dealt with it. Often the conflict was of someone else's making, but that when things got tough, he was called upon to deal with the mess. He felt that he had been labelled as someone involved in problems, where often he was involved in solutions to a problem. At the same time, he recognised that his written communication could let him down, as he had a tendency to represent things in rather terse terms, often with stark criticisms of previous attempts at problem solving. He also felt that, at times, he was too reliant upon his rank, and, in certain situations, he had failed to use his skills in dealing with people because the use of rank was simpler and sometimes more effective. Indeed he felt that he had been encouraged to use his rank by more senior officers, only to find himself castigated when things went wrong. His personal preference was to avoid using rank, and he identified this as an area for further development.

\section{Stage 3a}

Table F 4.

\begin{tabular}{|c|c|c|c|c|c|c|c|}
\hline :Cöniponenat:::::: & :à:::::::!::!: & : & 脑:::::::::::::: & $\vdots \vdots$ & :i: & & \\
\hline 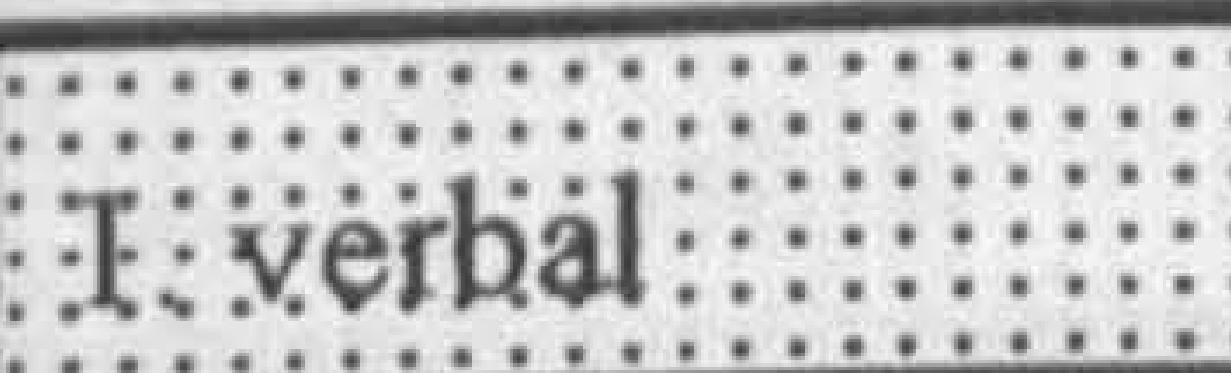 & & & & 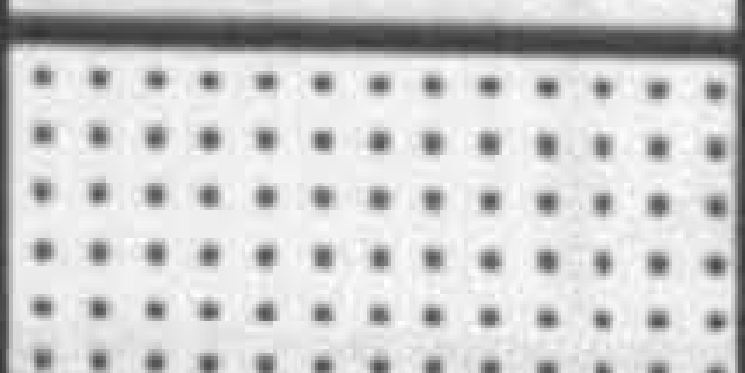 & : & & \\
\hline 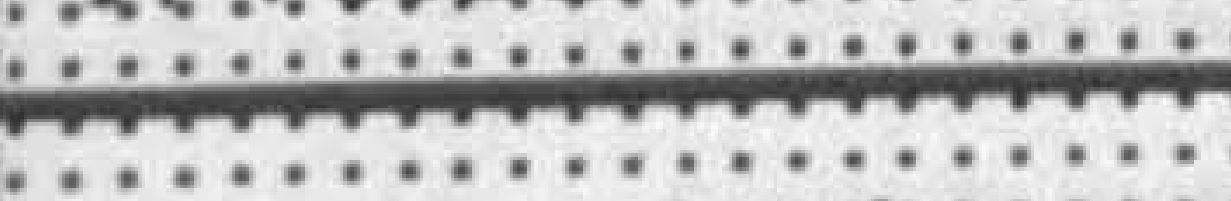 & & 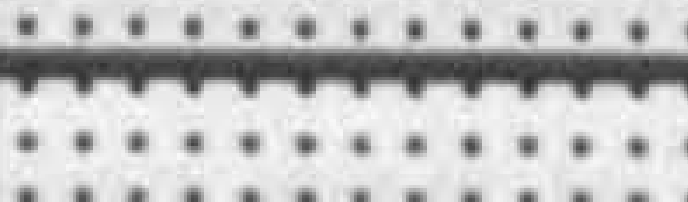 & …… & iㅜ & ;:: & & \\
\hline z numerieal: & & & & & & & \\
\hline abstract & 累::::: & & & & & & \\
\hline 4 DWS: & 角::::::::: & $m$ & :m: & h: & $\begin{array}{l}:::::::: \\
:::::::\end{array}$ & i⿱ & : \\
\hline S: written::::: & & & & 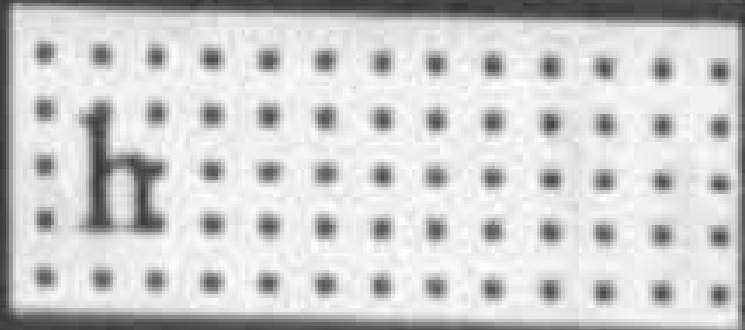 & h: & & \\
\hline o:in tray:: & & & & : & & & \\
\hline inconnuttee & 思: & in & 苒: & : & & :m: & :a: \\
\hline 8 presentation & & & & & & & \\
\hline
\end{tabular}


The table of personal constructs against assessment centre components indicates a very low level of coverage. In relation to the centre only DWS (a personality inventory) shows any broad correlation with the constructs. The three reasoning tests have no or very little relevance to the constructs as does the presentation exercise. In terms of constructs, four of seven constructs have only medium levels of coverage, with the remaining three loading heavily on to written elements and image management in the committee exercise.

\section{Stage 4}

As a preliminary to development participants $\mathrm{C}$ and $\mathrm{F}$ agreed to share their constructs and the following table is a simple amalgamation of the two individual grids.

\section{Table F 5. Shared constructs participants $C$ and $F$}

\begin{tabular}{|c|c|c|c|}
\hline & Qưlities: : & 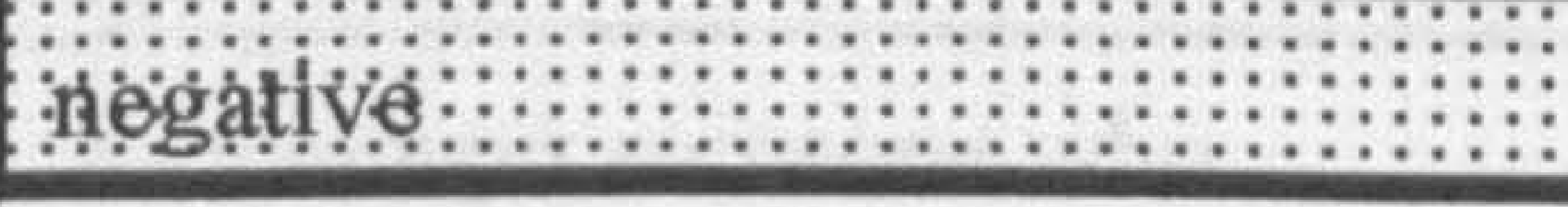 & 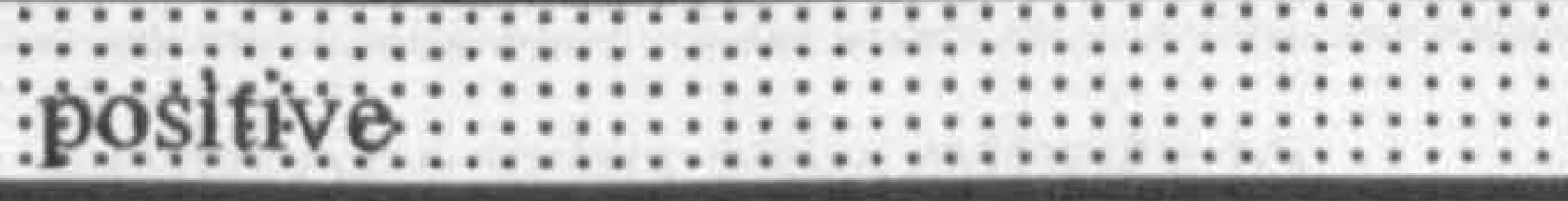 \\
\hline a & 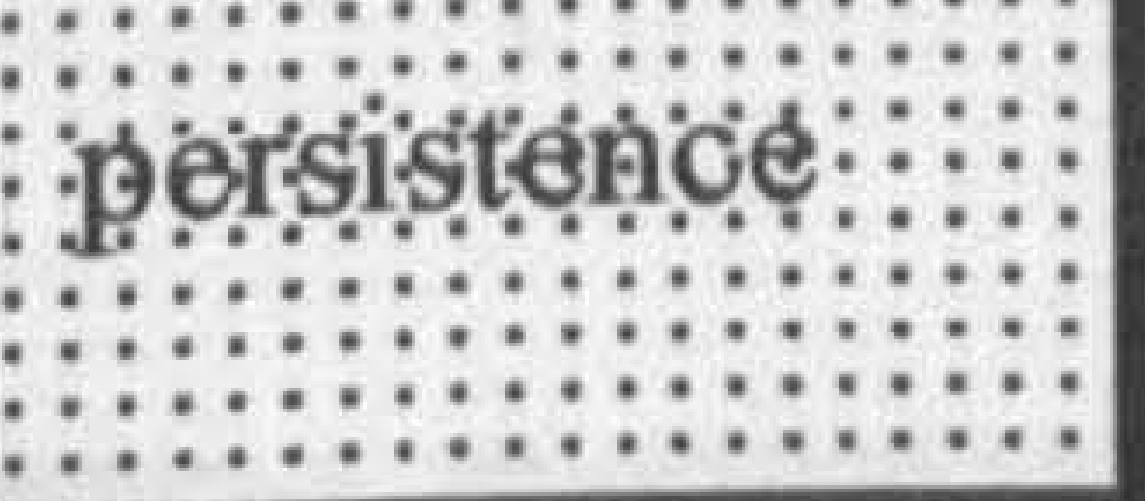 & $\begin{array}{l}\text { leaves things to others to do, not } \\
\text { interested in outcomes }\end{array}$ & $\begin{array}{l}\text { has clear view of end result and } \\
\text { makes efforts to achieve it }\end{array}$ \\
\hline ba & clarity: : & confused over objectives & clear views of what is needed \\
\hline 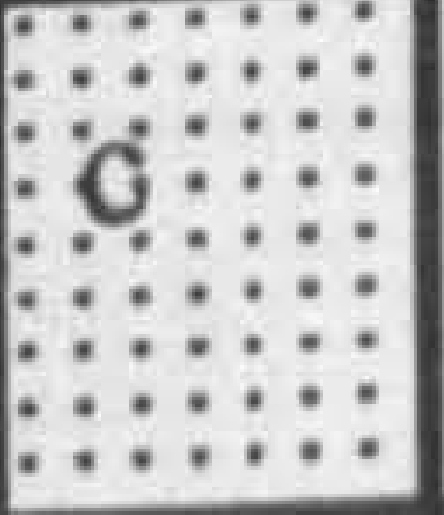 & 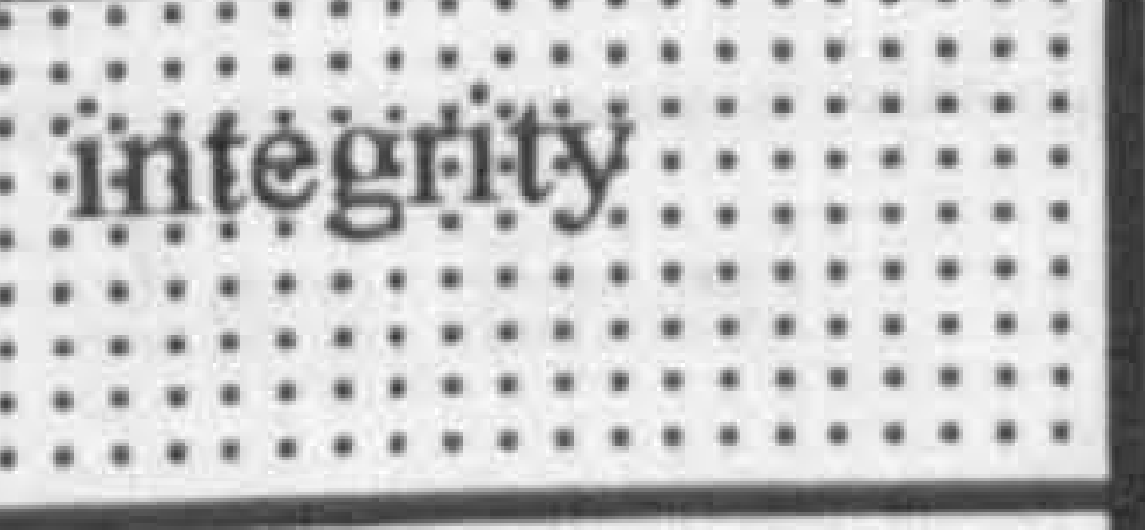 & has too many hidden agendas & $\begin{array}{l}\text { knows what is needed and lets } \\
\text { people know how they fit in }\end{array}$ \\
\hline : & pollish:::::: & relies on rank or position & diplomatic and influential \\
\hline $\begin{array}{c}\vdots \\
\vdots \\
\vdots \\
\vdots\end{array}$ & wrotten styde & $\begin{array}{l}\text { brusque and to the point but not } \\
\text { tailored for the reader }\end{array}$ & $\begin{array}{l}\text { easy to read, makes point well, } \\
\text { makes things easy for the reader }\end{array}$ \\
\hline : & (a) & $\begin{array}{l}\text { concerned about image and } \\
\text { people's views }\end{array}$ & $\begin{array}{l}\text { makes sure that things get done, } \\
\text { chases people up }\end{array}$ \\
\hline :: & 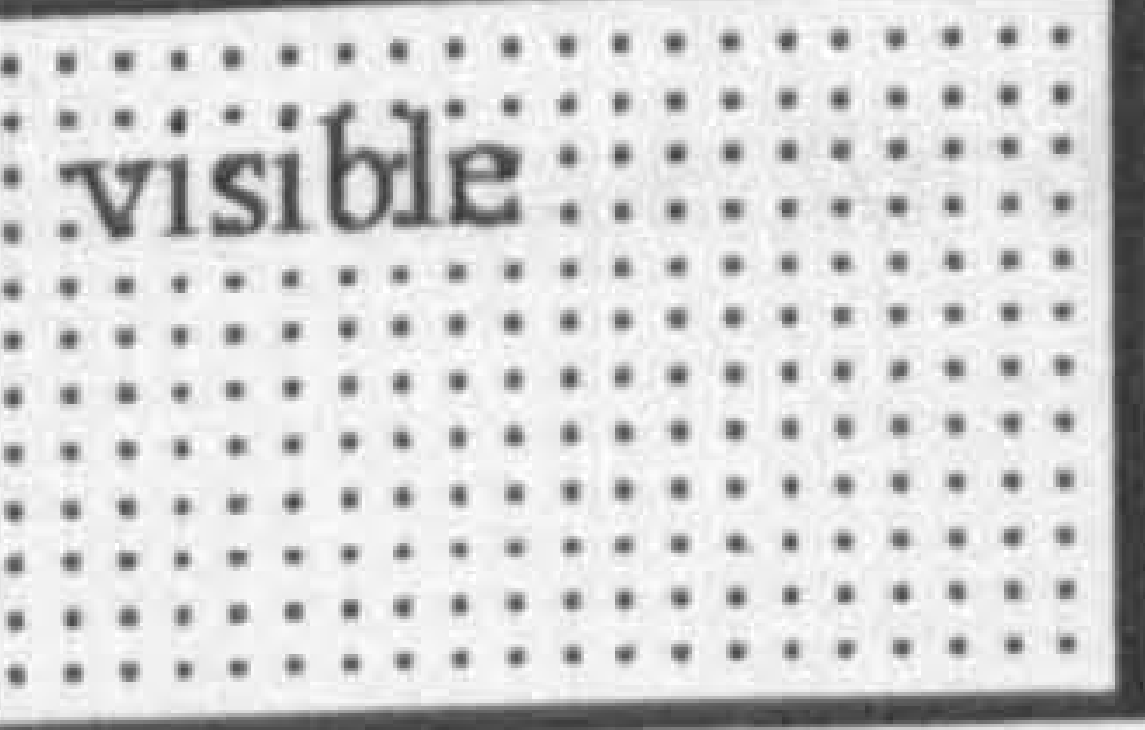 & $\begin{array}{l}\text { avoids awkward decisions or } \\
\text { situations, blames others when } \\
\text { things go wrong. }\end{array}$ & $\begin{array}{l}\text { lets everyone know that they are } \\
\text { responsible and is prepared to } \\
\text { admit if things go wrong }\end{array}$ \\
\hline
\end{tabular}




\begin{tabular}{|c|c|c|c|}
\hline : & articulate & $\begin{array}{l}\text { Unacceptable language - fails to } \\
\text { get point across and resorts to } \\
\text { shouting and swearing }\end{array}$ & $\begin{array}{l}\text { displays good use of } \\
\text { vocabulary, but keeps it in plain } \\
\text { English }\end{array}$ \\
\hline $\mathrm{bl}$ & confifient & $\begin{array}{l}\text { avoids limelight, prefers to let } \\
\text { others do talking }\end{array}$ & $\begin{array}{l}\text { relaxed, takes active } \\
\text { involvement in events }\end{array}$ \\
\hline 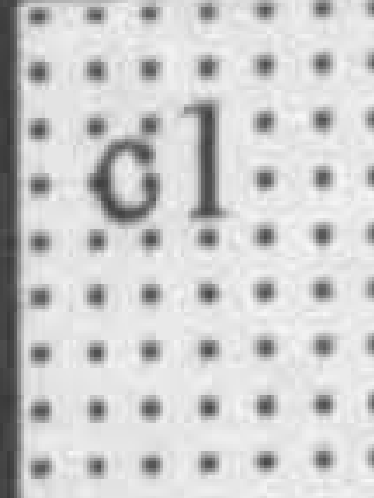 & orgạised & $\begin{array}{l}\text { Does not have tools/resources } \\
\text { required to complete tasks }\end{array}$ & $\begin{array}{l}\text { Plans tasks, has everything to } \\
\text { hand and knows what to do }\end{array}$ \\
\hline dì & lógual & $\begin{array}{l}\text { No sound basis for decisions, } \\
\text { cannot sustain argument }\end{array}$ & $\begin{array}{l}\text { sound decision making, does } \\
\text { things logically in order, wins } \\
\text { argument through persuasion } \\
\text { and logic }\end{array}$ \\
\hline ii: & Thterate & takes superficial view of events & $\begin{array}{l}\text { looks for underlying causes, } \\
\text { seeks additional information }\end{array}$ \\
\hline $\mathrm{fi:}$ & mupurate: & $\begin{array}{l}\text { Finds difficulty with basic } \\
\text { calculations - needs to use } \\
\text { calculator all the time, cannot } \\
\text { understand what is going on }\end{array}$ & $\begin{array}{l}\text { Can read financial accounts. } \\
\text { Can interpret complex tables or } \\
\text { statistics }\end{array}$ \\
\hline iji: & persistem & $\begin{array}{l}\text { Not assertive, only asks for } \\
\text { something once }\end{array}$ & Doesn't give up easily. \\
\hline iij: & opportive & $\begin{array}{l}\text { As manager someone who } \\
\text { leaves you on your own. }\end{array}$ & $\begin{array}{l}\text { Someone who asks others to } \\
\text { provide help and gets help from } \\
\text { others }\end{array}$ \\
\hline i & presentable & $\begin{array}{l}\text { fails to present credible image } \\
\text { as senior officer }\end{array}$ & $\begin{array}{l}\text { presents credible physical and } \\
\text { managerial impression }\end{array}$ \\
\hline $\mathrm{ki}$ & disciptined & $\begin{array}{l}\text { no respect for organisational } \\
\text { policy or procedures }\end{array}$ & $\begin{array}{l}\text { Respects rank when required, } \\
\text { understands organisation and its } \\
\text { needs }\end{array}$ \\
\hline 1$]$ & senomen & reacts too late to change & reacts well in new situations \\
\hline
\end{tabular}

Agreed constructs for development

Having examined the two sets of constructs and their application to a specimen group of peers the resulting table was agreed as a basis for assessment during self development. 
Table F 6.

\begin{tabular}{|c|c|c|c|}
\hline & Qualities: & ioggative: & pösitive :::::::::::::::: \\
\hline $\mathrm{A}$ & 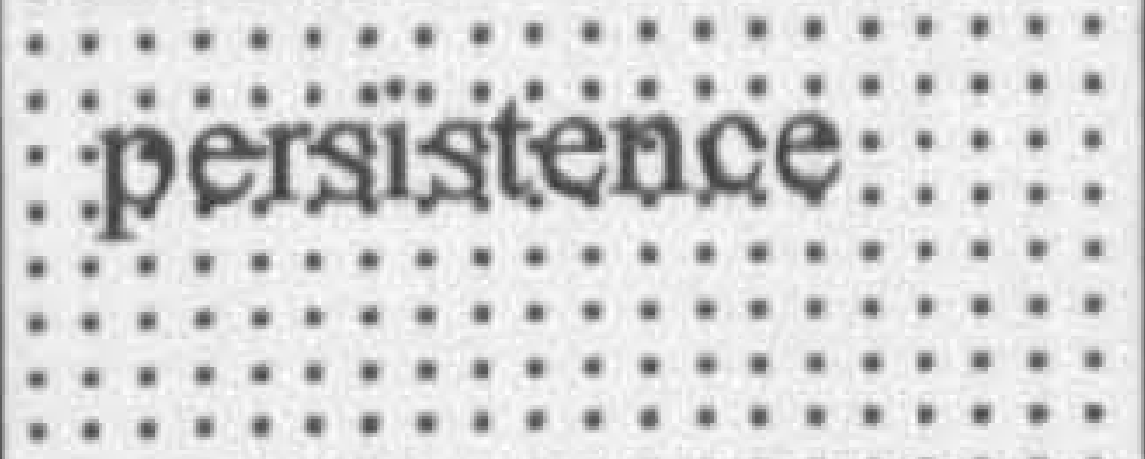 & $\begin{array}{l}\text { leaves things to others to do, not } \\
\text { interested in outcomes }\end{array}$ & $\begin{array}{l}\text { has clear view of end result and } \\
\text { makes efforts to achieve it }\end{array}$ \\
\hline $\mathrm{B}$ & 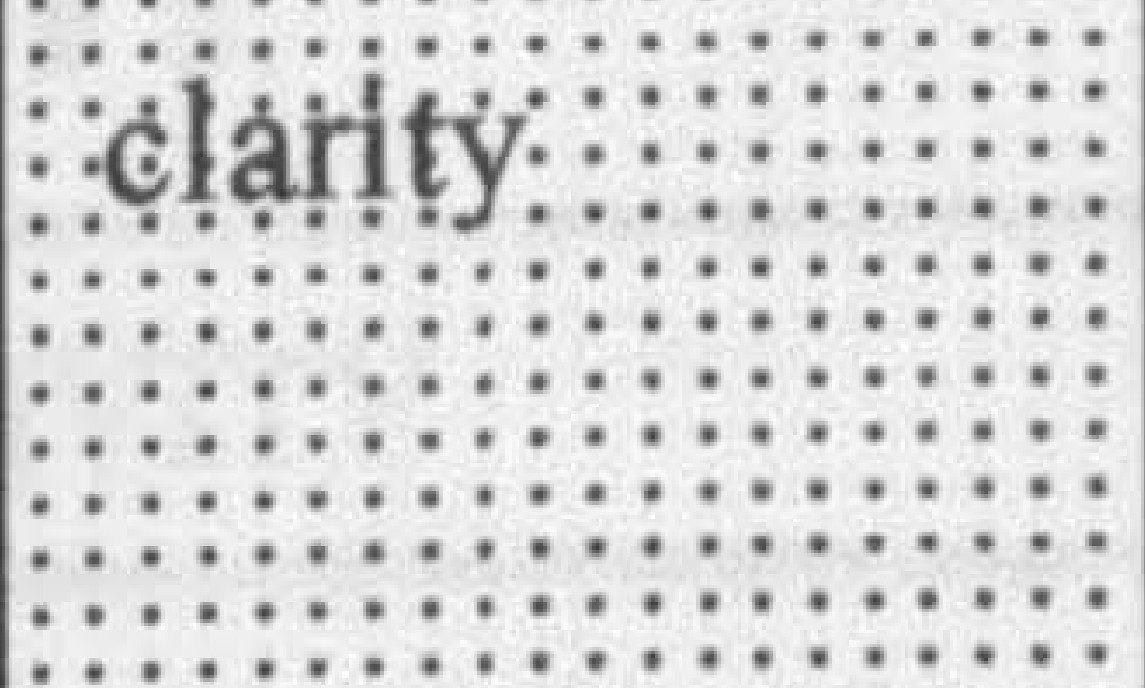 & $\begin{array}{l}\text { confused over objectives, fails } \\
\text { to get point across }\end{array}$ & $\begin{array}{l}\text { clear views of what is needed, } \\
\text { displays good use of } \\
\text { vocabulary, but keeps it in plain }\end{array}$ \\
\hline & & & English \\
\hline $\begin{array}{l}\vdots: \vdots \\
\vdots \\
\vdots \\
\vdots \\
\vdots \\
\vdots\end{array}$ & 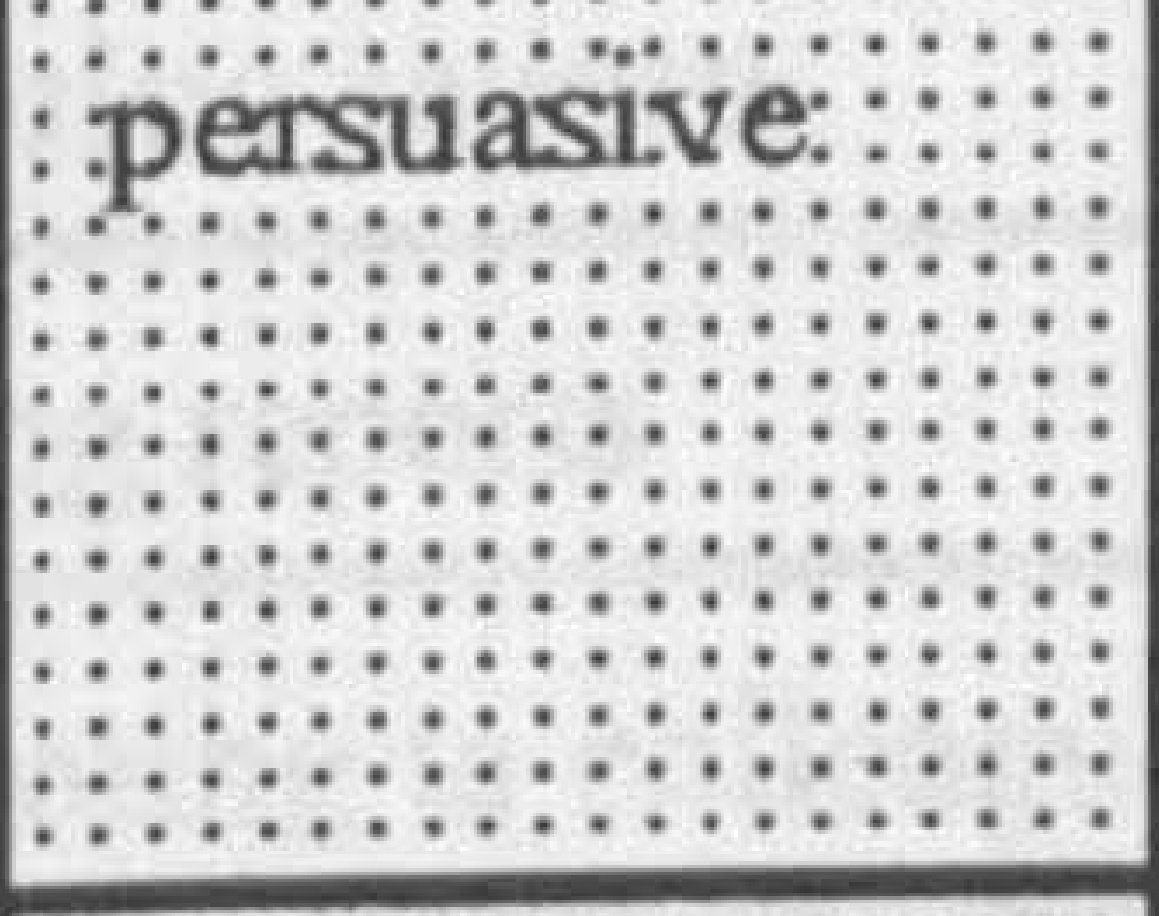 & $\begin{array}{l}\text { relies on rank or position, no } \\
\text { sound basis for decisions, } \\
\text { cannot sustain argument }\end{array}$ & $\begin{array}{l}\text { diplomatic and influential, } \\
\text { sound decision making, does } \\
\text { things logically in order, wins } \\
\text { argument through persuasion }\end{array}$ \\
\hline$:$ & worttenstyde & $\begin{array}{l}\text { brusque and to the point but not } \\
\text { tailored for the reader }\end{array}$ & $\begin{array}{l}\text { easy to read, makes point well, } \\
\text { makes things easy for the reader }\end{array}$ \\
\hline $\begin{array}{lll}\mathrm{E} \\
\vdots: \vdots \\
\vdots: \vdots \\
\vdots:\end{array}$ & concernfor & $\begin{array}{l}\text { concerned about image and } \\
\text { people's views }\end{array}$ & $\begin{array}{l}\text { makes sure that things get done, } \\
\text { chases people up }\end{array}$ \\
\hline 屰::: & ::oisible::::::: & $\begin{array}{l}\text { avoids awkward decisions or } \\
\text { situations, blames others when } \\
\text { things go wrong. Avoids } \\
\text { limelight, prefers to let others do } \\
\text { talking }\end{array}$ & $\begin{array}{l}\text { takes active involvement in } \\
\text { events, lets everyone know that } \\
\text { they are responsible and is } \\
\text { prepared to admit if things go } \\
\text { wrong }\end{array}$ \\
\hline : & organised: & $\begin{array}{l}\text { Does not have tools/ resources } \\
\text { required to complete tasks }\end{array}$ & $\begin{array}{l}\text { Plans tasks, has everything to } \\
\text { hand and knows what to do }\end{array}$ \\
\hline :王: & numiate & $\begin{array}{l}\text { Finds difficulty with basic } \\
\text { calculations - needs to use } \\
\text { calculator all the time, cannot } \\
\text { understand what is going on }\end{array}$ & $\begin{array}{l}\text { Can read financial accounts. } \\
\text { Can interpret complex tables or } \\
\text { statistics }\end{array}$ \\
\hline $\begin{array}{l}1: 1 \\
\vdots \\
\vdots \\
\vdots \\
\vdots \\
\vdots \\
\vdots\end{array}$ & 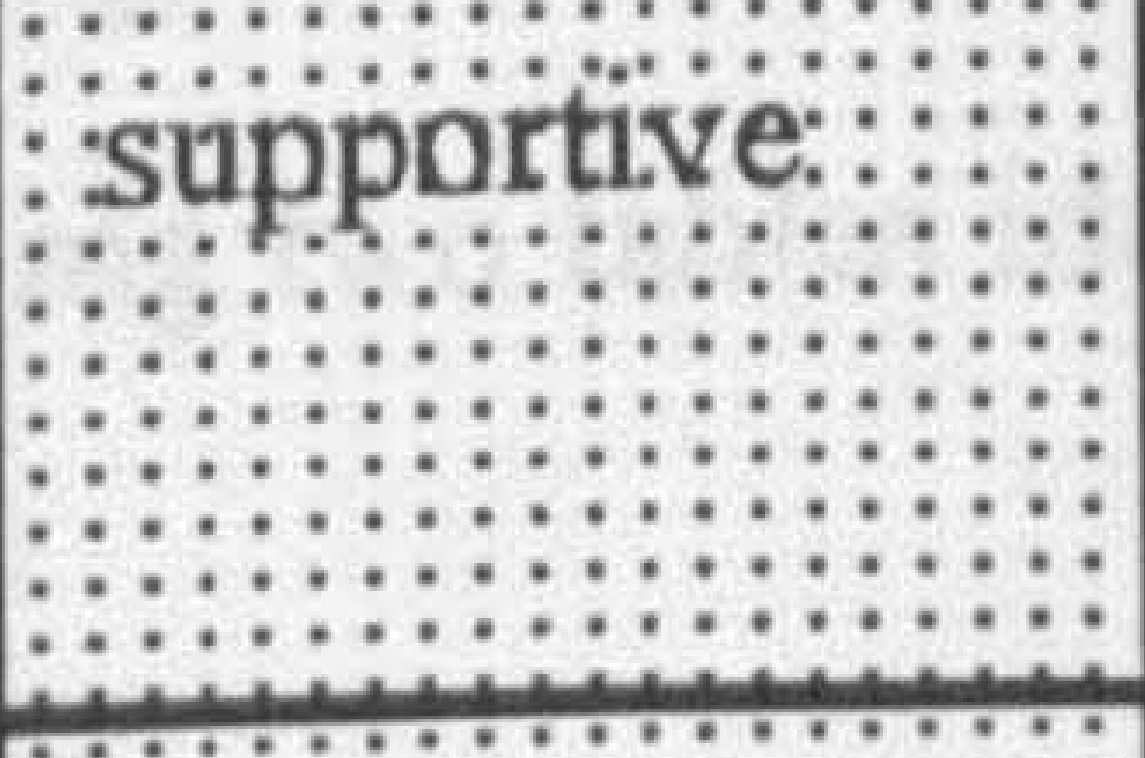 & $\begin{array}{l}\text { As manager someone who } \\
\text { leaves you on your own. }\end{array}$ & $\begin{array}{l}\text { Someone who asks others to } \\
\text { provide help and gets help from } \\
\text { others }\end{array}$ \\
\hline$:$ & presentabele & $\begin{array}{l}\text { fails to present credible image } \\
\text { as senior officer }\end{array}$ & $\begin{array}{l}\text { presents credible physical and } \\
\text { managerial impression }\end{array}$ \\
\hline K & : & reacts too late to change & reacts well in new situations \\
\hline
\end{tabular}

Some constructs have been amended, but most are either simple additions of descriptors, or, 
in effect, the product of one individual. To provide a framework for development the participants decided to map the constructs back on to their team activities and to identify those which were most relevant to their current work.

\section{Table F 8.}

\begin{tabular}{|c|c|c|c|c|c|c|c|c|c|c|c|}
\hline ACTIVITY & : & 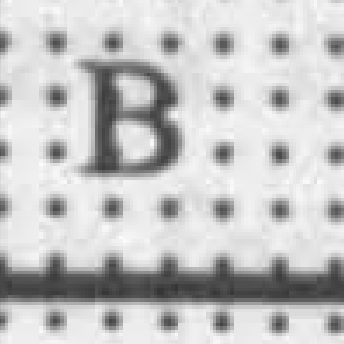 & 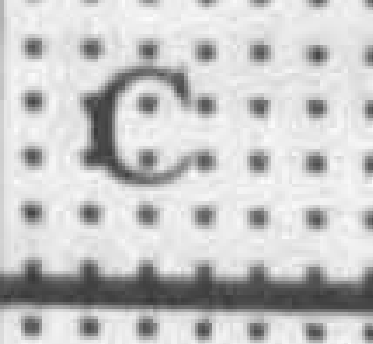 & D: : & E: & : & G & $\mathrm{H}$ & I & $\mathbf{J}$ & $\mathrm{K}$ \\
\hline Research & : & 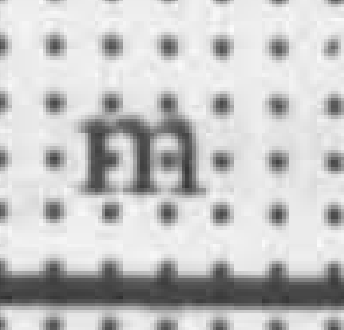 & ma & 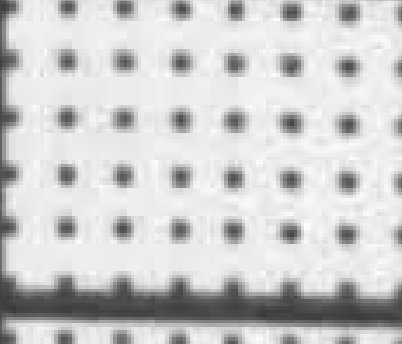 & :min: & & 1 & 1 & & 1 & $\mathrm{~h}$ \\
\hline preparing reports & & ني: & 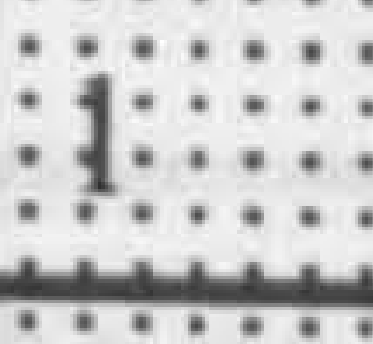 & 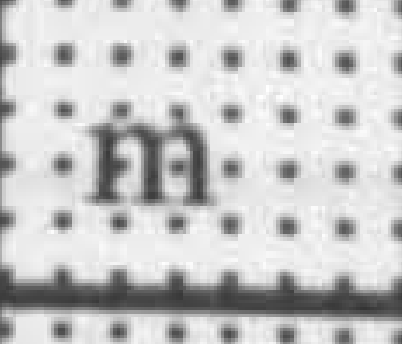 & 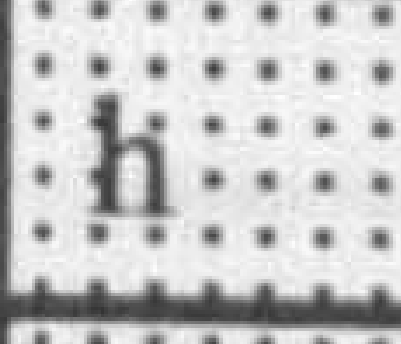 & : & 1 & & & & 1 \\
\hline writing reports & بيَبْبِ & ب: & نبيجب: & يبن: & ب: & & 1 & & & & 1 \\
\hline presenting to colleagues & আm: & : & m: & a & 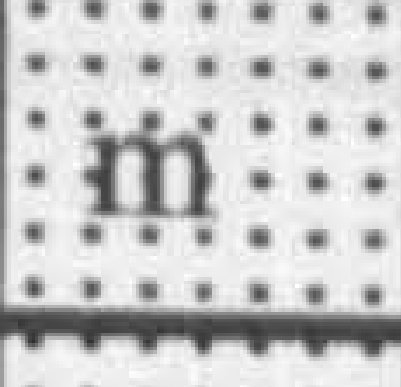 & $\frac{1}{9:}:$ & 1 & & & & 1 \\
\hline presenting to managers & 莯: & 染: & : & an & 萿: & & $\mathrm{m}$ & 1 & & $\mathrm{~h}$ & $\mathrm{~m}$ \\
\hline developing the team & 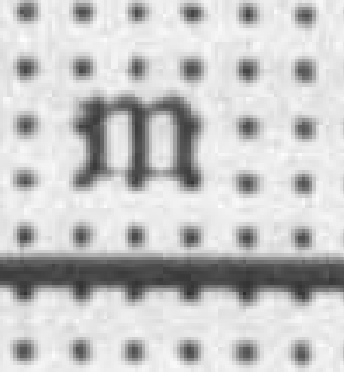 & : & h: & & $\begin{array}{c}\vdots \\
\vdots \\
\vdots \\
\vdots\end{array}$ & & & & $\mathrm{h}$ & & $\mathrm{m}$ \\
\hline managing subordinates & 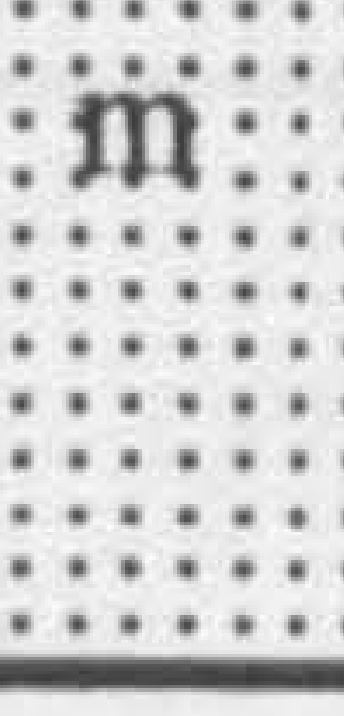 & : & ì: & & : & :I:A & & & $\mathrm{h}$ & & $\mathrm{m}$ \\
\hline
\end{tabular}

This table enabled the process of self assessment to be broken down into two clear areas:

writing and presenting reports and,

developing the team and its members.

It was agreed that each area would be addressed in terms of no more than 5 constructs and the following two tables identify how constructs were to be used. 
Table F 9. Writing and presenting reports

\begin{tabular}{|c|c|c|c|}
\hline & Qualities: & inegative: & positive: \\
\hline B: & clarity: & $\begin{array}{l}\text { confused over objectives, fails } \\
\text { to get point across }\end{array}$ & $\begin{array}{l}\text { clear views of what is needed, } \\
\text { displays good use of } \\
\text { vocabulary, but keeps it in plain } \\
\text { English }\end{array}$ \\
\hline ب⿳⺈ & persuasive & $\begin{array}{l}\text { relies on rank or position, no } \\
\text { sound basis for decisions cannot } \\
\text { sustain argument }\end{array}$ & $\begin{array}{l}\text { diplomatic and influential, } \\
\text { sound decision making, does } \\
\text { things logically in order, wins } \\
\text { argument through persuasion }\end{array}$ \\
\hline D: & Writteen style & $\begin{array}{l}\text { brusque and to the point but not } \\
\text { tailored for the reader }\end{array}$ & $\begin{array}{l}\text { easy to read, makes point well, } \\
\text { makes things easy for the reader }\end{array}$ \\
\hline E & 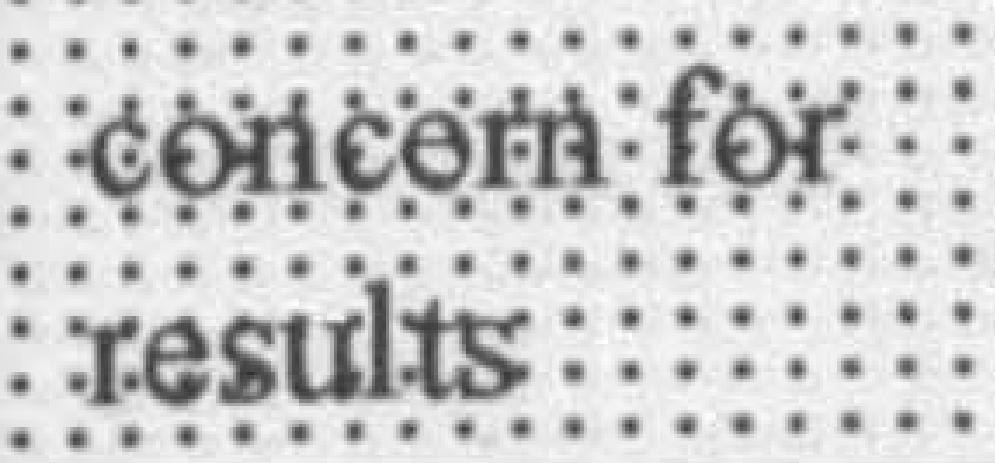 & $\begin{array}{l}\text { concerned about image and } \\
\text { people's views }\end{array}$ & $\begin{array}{l}\text { makes sure that things get done, } \\
\text { chases people up }\end{array}$ \\
\hline G: & organod & $\begin{array}{l}\text { Does not have tools resources } \\
\text { required to complete tasks }\end{array}$ & $\begin{array}{l}\text { Plans tasks has everything to } \\
\text { hand and knows what to do }\end{array}$ \\
\hline
\end{tabular}


Table F 10. Developing the team and its members

\begin{tabular}{|c|c|c|c|}
\hline & Qualities: & negative: & positive: \\
\hline A: & persistence: & $\begin{array}{l}\text { leaves things to others to do, not } \\
\text { interested in outcomes }\end{array}$ & $\begin{array}{l}\text { has clear view of end result and } \\
\text { makes efforts to achieve it }\end{array}$ \\
\hline$B$ & clarity:: & $\begin{array}{l}\text { confused over objectives, fails } \\
\text { to get point across }\end{array}$ & $\begin{array}{l}\text { clear views of what is needed, } \\
\text { displays good use of } \\
\text { vocabulary, but keeps it in plain } \\
\text { English }\end{array}$ \\
\hline $\mathrm{c}$ & persuasive & $\begin{array}{l}\text { relies on rank or position, no } \\
\text { sound basis for decisions cannot } \\
\text { sustain argument }\end{array}$ & $\begin{array}{l}\text { diplomatic and influential, } \\
\text { sound decision making does } \\
\text { things logically in order wins } \\
\text { argument through persuasion }\end{array}$ \\
\hline : & io & $\begin{array}{l}\text { concerned about image and } \\
\text { people's views }\end{array}$ & $\begin{array}{l}\text { makes sure that things get done, } \\
\text { chases people up }\end{array}$ \\
\hline t: & visibie: & $\begin{array}{l}\text { avoids awkward decisions or } \\
\text { situations, blames others when } \\
\text { things go wrong. Avoids } \\
\text { limelight prefers to let others do } \\
\text { talking }\end{array}$ & $\begin{array}{l}\text { takes active involvement in } \\
\text { events, lets everyone know that } \\
\text { they are responsible and is } \\
\text { prepared to admit if things go } \\
\text { wrong }\end{array}$ \\
\hline I & suppottive & $\begin{array}{l}\text { As manager someone who } \\
\text { leaves you on your own. }\end{array}$ & $\begin{array}{l}\text { Someone who asks to provide } \\
\text { help and gets help from others }\end{array}$ \\
\hline i: & presentable & $\begin{array}{l}\text { fails to present credible image } \\
\text { as senior officer }\end{array}$ & $\begin{array}{l}\text { presents credible physical and } \\
\text { managerial impression }\end{array}$ \\
\hline $\mathrm{K}$ & change: & reacts to late to change & reacts well in new situations \\
\hline
\end{tabular}

\section{Conclusions}

The two tables provided a structure for peer review of performance over the next three months. As such they enabled developmental consideration to be given to a range of day to day activities in which both participants were involved. Although some minor modifications were made to the tables they remain very much as initially designed. The process of exchange can be seen as a means of extending the domain for consideration. In this way it extended and developed participant C's constructs into integrity, which may have been implicit in the original individual table, but are here represented more explicitly. The extension for 
participant $\mathrm{F}$ was more radical and took the form of adding completely new dimensions to self assessment of performance in terms of managing people and team membership. The self assessment system operates at the level of individual pieces of work (which either participant may agree to submit for joint "examination"), and at an overall level through peer performance reviews. The system operates as a personal appraisal and evidence may be provided either directly by observation or examination or indirectly through the views expressed by a third party. In this way a number of external assessors may unknowingly contribute by commenting to one participant about the performance of the other. Formal courses, whilst still a part of development, have been used to supplement the system rather than provide the main means of development. Their effectiveness has been subsequently measured using the agreed performance tables.

The formal exchange of constructs between two participants marks the furthest extension to date of the self organised approach to learning and indicates a considerable departure from the starting point of the assessment centre. An assessment process is still in use, but it is one that the participants themselves manage. It is about their view of their own performance in their own jobs, using their own agreed criteria. 


\subsection{Participant G}

Participant $G$ was a substantive Divisional Officer who had been seconded to the Home Office and temporarily promoted to the rank of Assistant Inspector (Senior Divisional Officer) some time prior to the running of the assessment centre. He had previously been seconded to the Fire Service College also in the rank of Senior Divisional Officer and had thus spent some significant time away from his base Brigade at a more senior rank. At the time of the first interview he was undertaking a Principal Officer role for the Home Office. He had recently completed the centre and had been advised that he would not be recommended for the second stage interview process. However he had not received any detailed feedback.

\section{Stage I}

a. pre centre development needs

- A general broadening of senior management skills.

b. pre centre development plans or strategies

The participant had been guided towards attendance on the Home Office Brigade Command Course for potential Chief Fire Officers and indications from his present (Home Office) line manager suggested to him that his application would be successful. He had managed a similar management development programme at the next level down (Divisional Officer/ Commander) and had a detailed knowledge of the course aims and syllabus. He felt that this was the most appropriate course for his own development, and that the course would assist in the broadening of his views which had already been affected by long term secondment.

The issue of additional operational exposure not was seen to be particularly significant to this officer at this stage in his career. 
c. post centre development needs

No new additional needs were identified. Despite his performance in the command element of the assessment centre he did not think that this represented a significant development need.

d. post centre development plans or strategies

The Brigade command course remained the most appropriate means of meeting his needs.

e. Bridges and barriers

No significant barriers were identified whilst his secondment experience was seen as a significant bridge.

f. review

Despite being seen by some as a failure at the command interview, participant $G$ showed no signs of any changes in his outlook towards development. His views of the centre suggested that the information provided was of little more than passing interest, in particular when he compared it to the feedback received from his superiors at the Home Office. His relationships with both the Home Office and the Fire Service College (providers of the Brigade Command Course) were stronger and more beneficial to him than those with his home Brigade. His current role brought him into contact with many of the UK's most senior Fire Officers, and he believed that his performance in this context had been judged as effective. To this extent, the centre provided little additional information (i.e. in relation to skills not assessed during his normal work) and he remained unconvinced as to any enhanced validity, either as a result of the "objectivity" of the process, or the design and construction of the exercises. Participant G was indifferent to the assessment centre. Although it formed a barrier to his current career intentions, he was aware of other routes to promotion (offered by the Home Office and by other Brigades). 


\section{Stage 2}

Although participant $\mathrm{G}$ was unimpressed by the assessment centre (which he compared unfavourably with that used for entry to the Brigade Command Course), he nevertheless recognised that his own performance, in some areas, was below that of other candidates. The assessment centre could thus provide a source of possible development information for future use. Once again, however, the participant chose to compare the process to that used for the Brigade Command Course, clearly expressing his preference for the latter. Those elements in which he identified himself performing poorly were not seen as relevant to his role as a senior fire officer. This criticism was directed not at the underpinning skills, however, but at the actual contents of the exercises, which he felt were unrealistic and poorly designed. He became critical of the centre as a vehicle for assessing skills and abilities even where he recognised that the skills themselves were relevant. He provided a more technical evaluation of the assessment process based on his own understanding of similar (Home Office) approaches.

Table G 1. Participant G self perceived assessment centre performance

\begin{tabular}{|c|c|c|c|}
\hline Camponent & 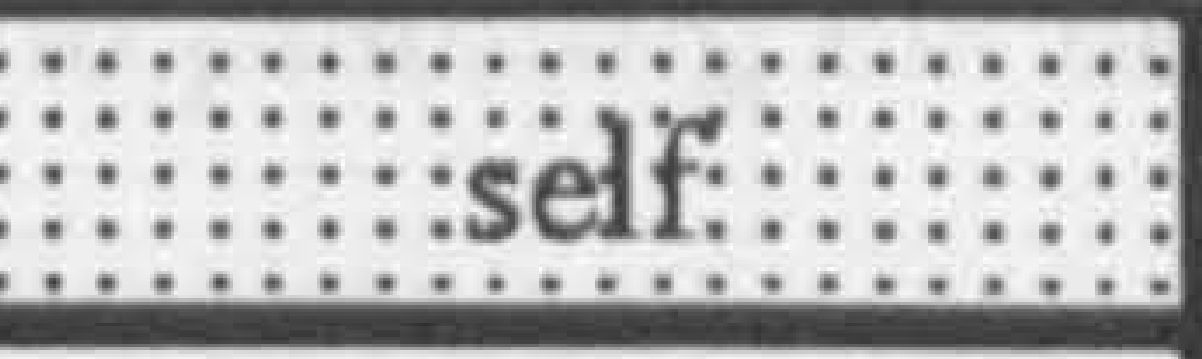 & 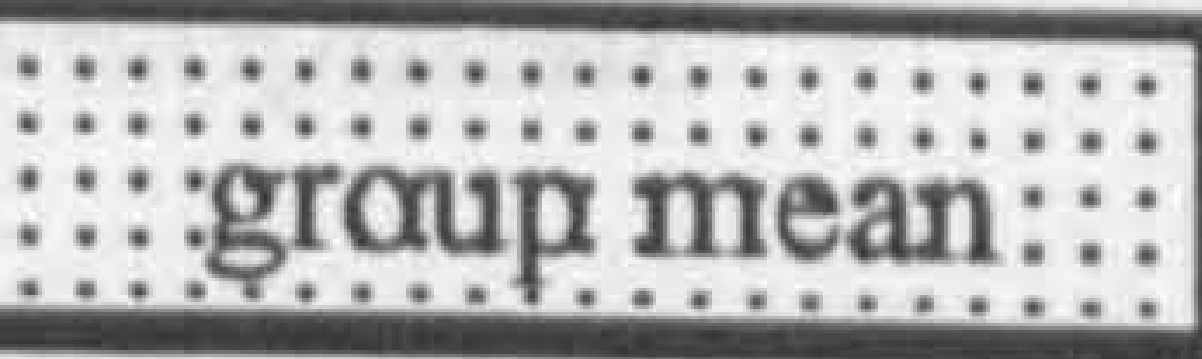 & 保ference \\
\hline Overal DCPQC & 4 & 6 & -2 \\
\hline : & 7 & 5 & 2 \\
\hline 2 numerical & 4 & 6 & -2 \\
\hline A & 7 & 5 & 2 \\
\hline 4 WWS: : & 6 & 7 & -1 \\
\hline S & 6 & 4 & 2 \\
\hline 6 & 4 & 7 & -3 \\
\hline 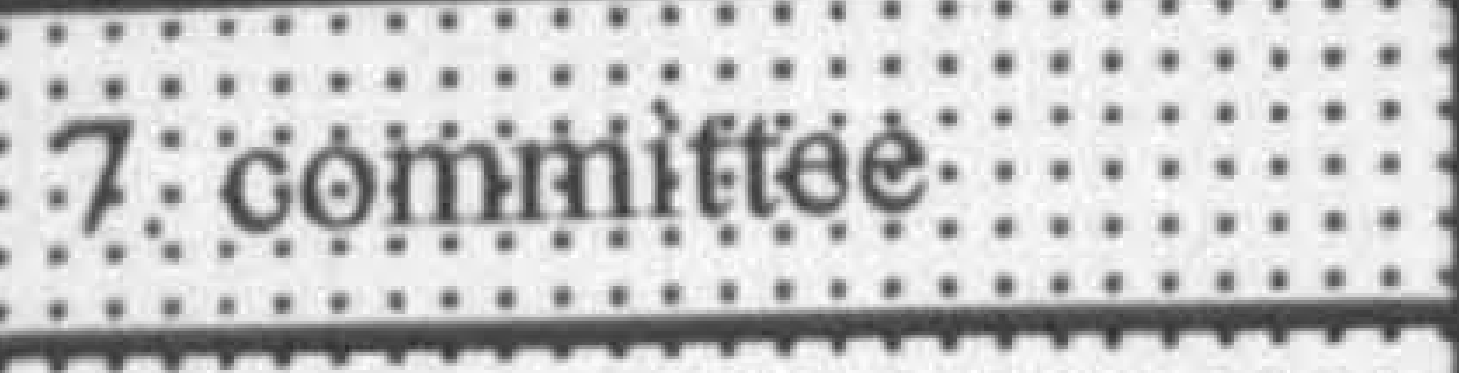 & 6 & 5 & 1 \\
\hline 8 presentation : & 3 & 6 & -3 \\
\hline $\begin{array}{l}\text { gomponand } \\
\text { interviow }\end{array}$ & 3 & 5 & -2 \\
\hline
\end{tabular}


This contrast, between the relevance of the skills, and the lack of perceived validity of the assessment process, was best demonstrated in stage $2 \mathrm{a}$.

\section{Stage 2a}

This process was designed to allow participants to consider their day to day work performance and to examine confirmatory and contrasting evidence. In the case of participant G, the contrasts were used to demonstrate the extent to which the assessment centre had failed to provide appropriate measures. Also of significance to the participant was the context in which some of the skills were being utilised in day-to-day performance. Abstract reasoning was related by the participant to assessing the cultures of brigades which he visited with an Inspectorate Team. The Command Interview, ostensibly an assessment of operational performance as an officer in charge of a large scale fire, was linked to providing face to face feedback to an Inspector. Participant $G$ used these job elements as a means of assessing his day-to-day performance based on direct and frequent feedback from his line manager. As such, he considered this more accurate and more relevant than the exercises used, and, therefore, more useful to planning his development. 
Table G 2.

\begin{tabular}{|l|c|c|c|}
\hline a. interpersonal skills & 8 & 5 & 3 \\
\hline b. statistics for reports & 9 & 6 & 3 \\
\hline c. Assess brigade culture & 8 & 3 & 5 \\
\hline d. Deal with members & 7 & 6 & 1 \\
\hline e. write reports & 9 & 6 & 3 \\
\hline $\begin{array}{l}\text { f. research information for } \\
\text { reports }\end{array}$ & 9 & 7 & 2 \\
\hline g. member of It committee & 8 & 4 & 4 \\
\hline h. teach at FSC & 9 & 5 & 4 \\
\hline I. feedback to HMI & 6 & 3 & 3 \\
\hline
\end{tabular}

\section{Stage 3}

The outcome of stages 2 and 2 a strongly suggests that the participant was "immune" from the assessment centre, having already developed a clear development plan. The use of stage 3 , therefore, as a means of extending existing understanding, was focused on examining this existing understanding rather than on utilising the results of the assessment centre. The participant's rejection of the assessment centre, as a valid means of measurement, resulted in the use of his own job as a sources of constructs. Rather than contrast different job components, however, he chose to substitute the elicitation process with a set of descriptors of necessary skills. Since the participant seemed more comfortable with these, than with the construct elicitation process, the unipolar constructs were included in stage 3 and attempts made to identify possible positive and negative features. 
Table G 3.

\begin{tabular}{|c|c|c|c|c|c|}
\hline Qualities: & : & self: & mean: & diff: & positive::::::: \\
\hline & & 7 & 5 & 2 & $\begin{array}{l}\text { personable, } \\
\text { pleasant, non } \\
\text { threatening }\end{array}$ \\
\hline 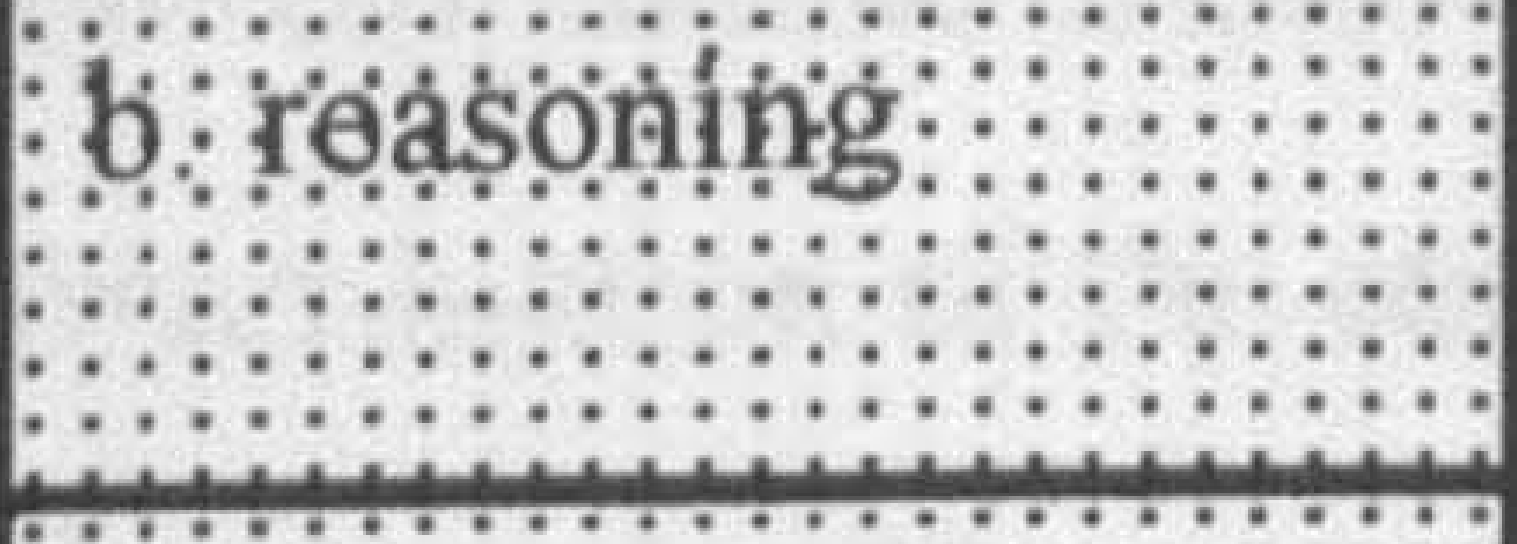 & & 9 & 6 & 3 & $\begin{array}{l}\text { recognises need for } \\
\text { information }\end{array}$ \\
\hline 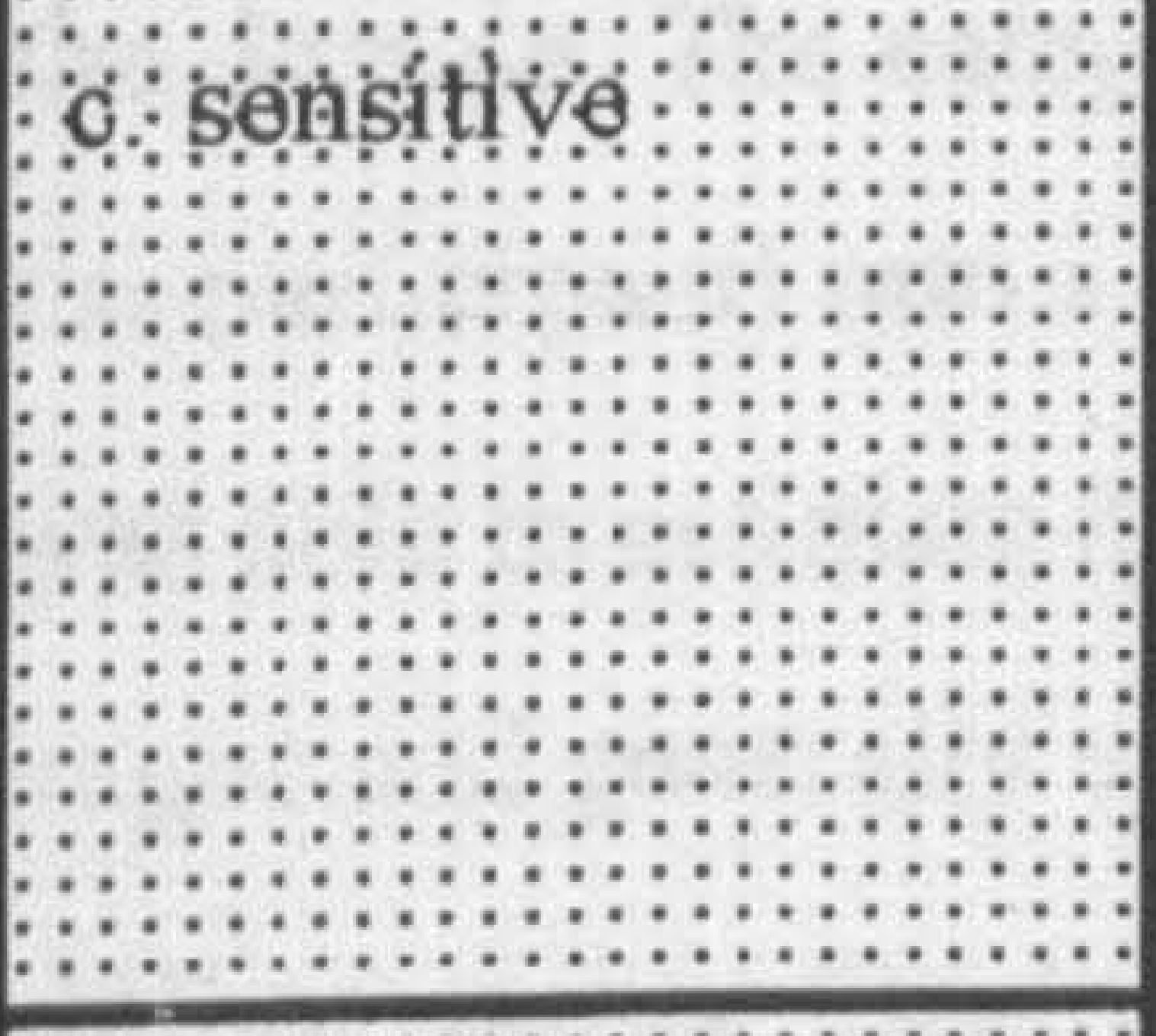 & & 6 & 5 & 1 & $\begin{array}{l}\text { sensitive to others } \\
\text { and aware of } \\
\text { concerns, balances } \\
\text { need to gather } \\
\text { information with } \\
\text { possible costs }\end{array}$ \\
\hline 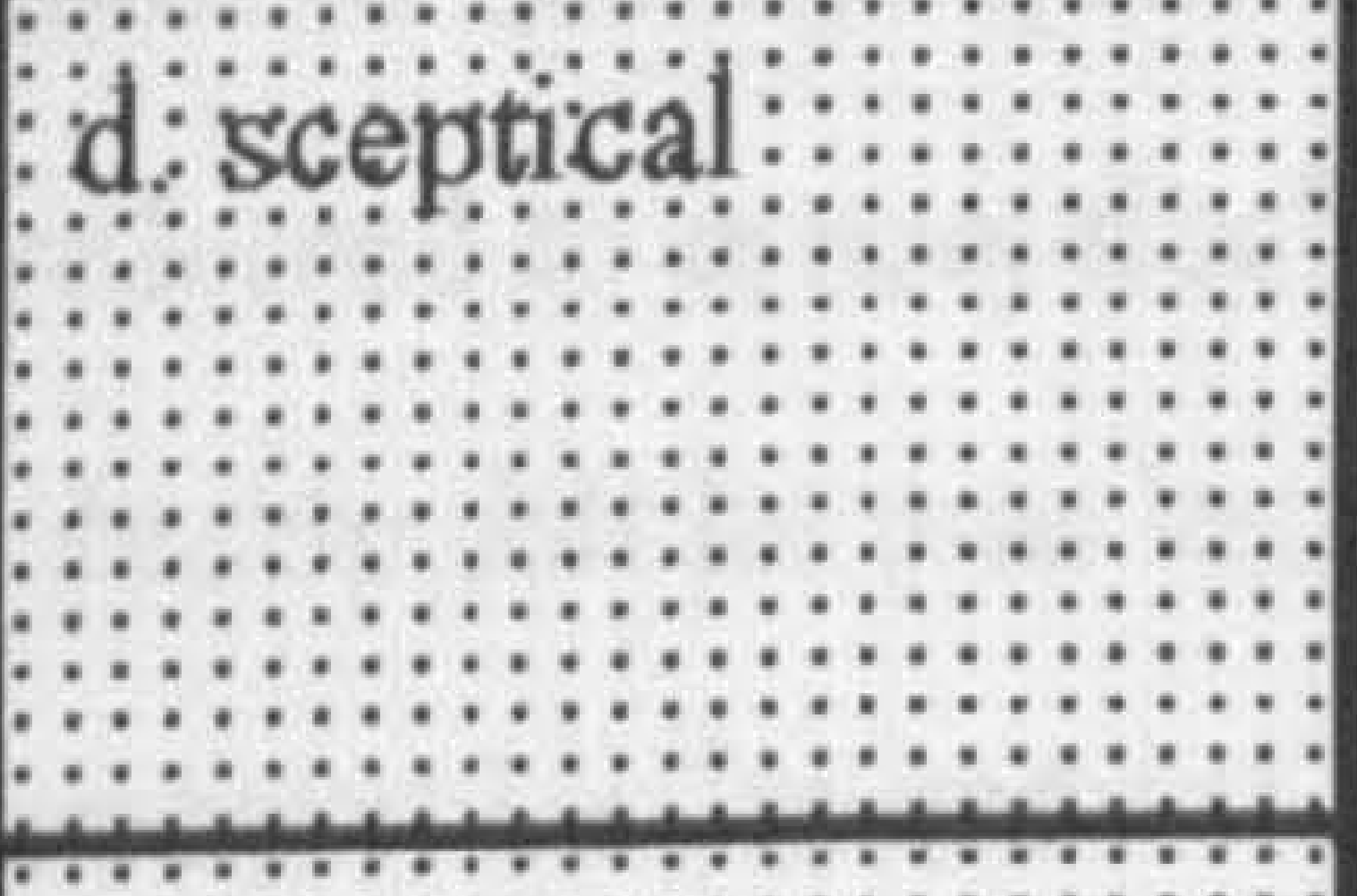 & $\begin{array}{l}\text { doesn't believe what } \\
\text { is offered, doesn't } \\
\text { accept supplier } \\
\text { understands }\end{array}$ & 3 & 2 & 1 & \\
\hline 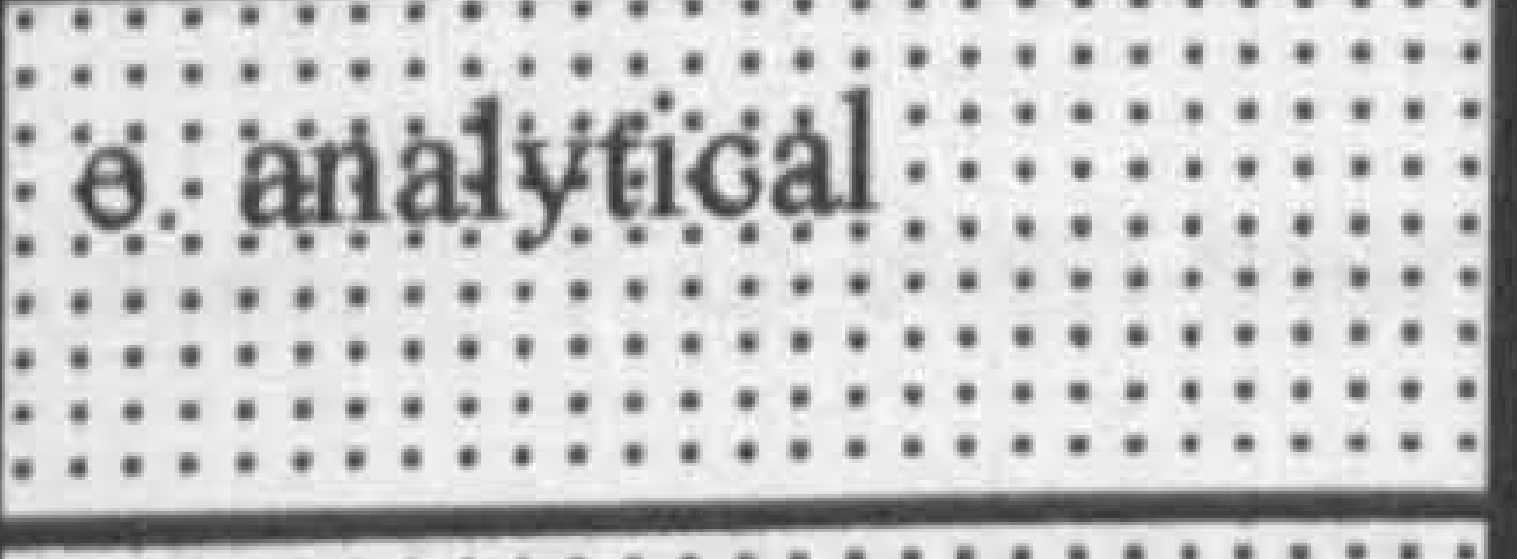 & & 9 & 7 & 2 & $\begin{array}{l}\text { analytical, stands } \\
\text { back. Depth }\end{array}$ \\
\hline 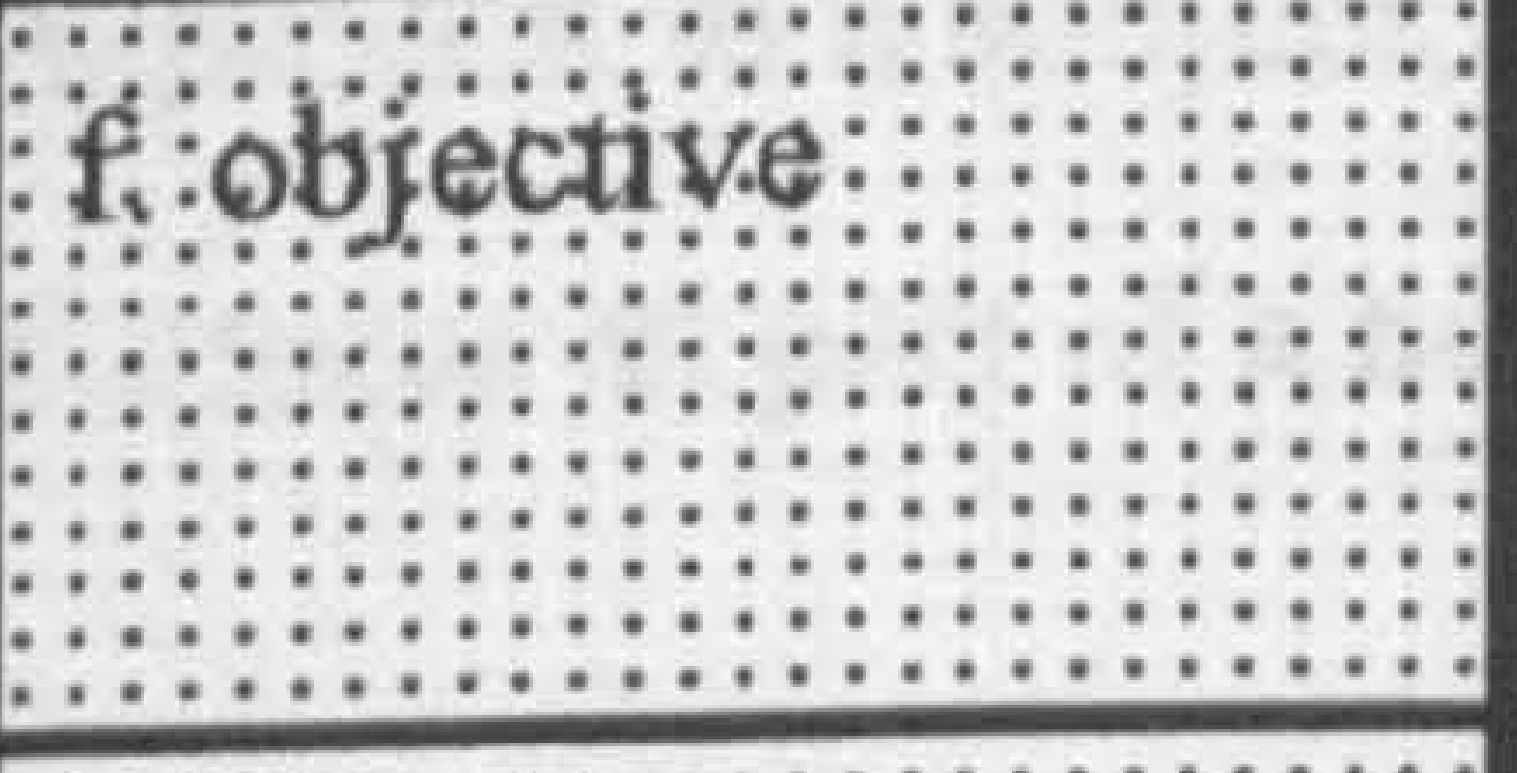 & $\begin{array}{l}\text { open views, can be } \\
\text { distracted from goal } \\
\text { objectives }\end{array}$ & 5 & 5 & 0 & \\
\hline 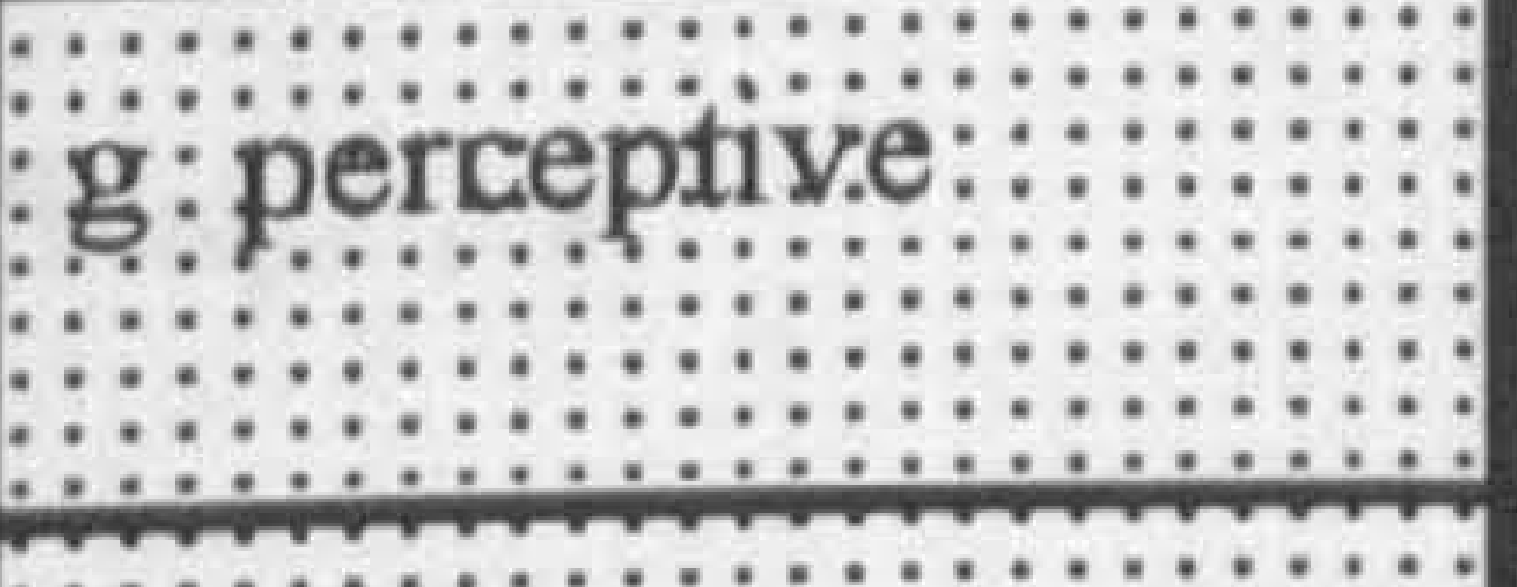 & & 9 & 7 & 2 & $\begin{array}{l}\text { aware of place in } \\
\text { relation to goal }\end{array}$ \\
\hline 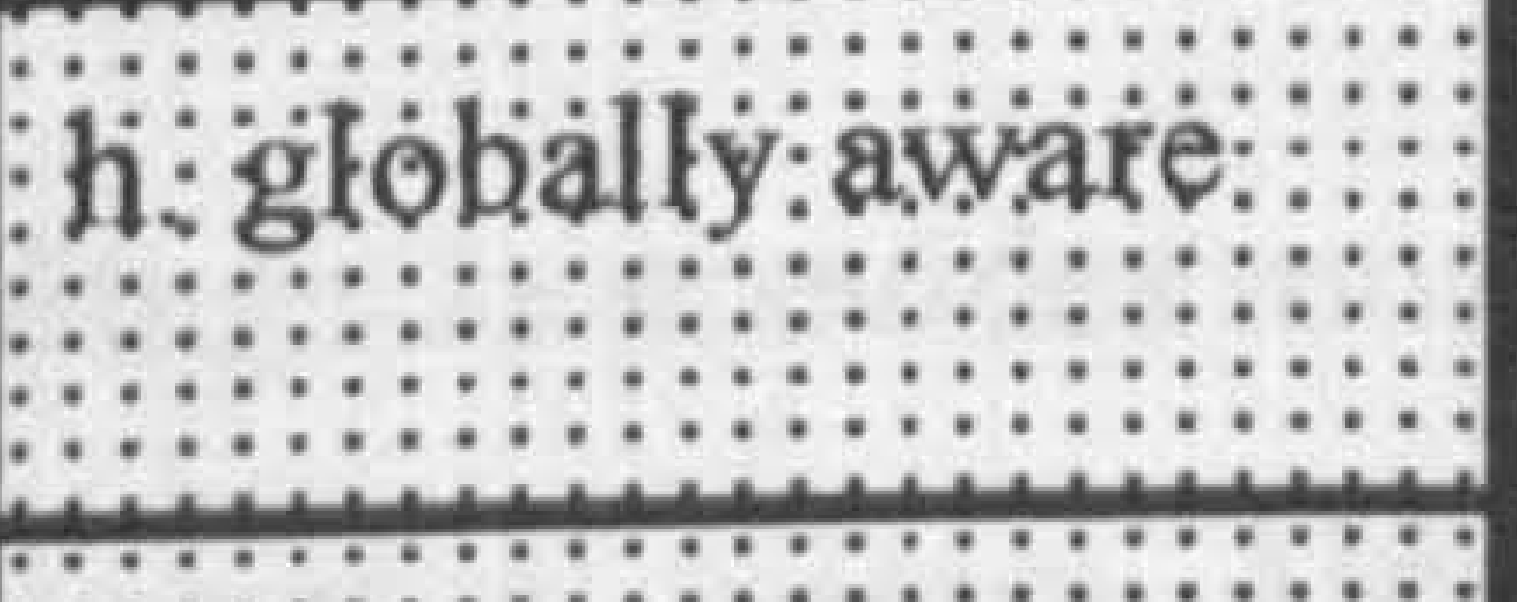 & & 9 & 4 & 5 & $\begin{array}{l}\text { ability to look } \\
\text { beyond the obvious }\end{array}$ \\
\hline 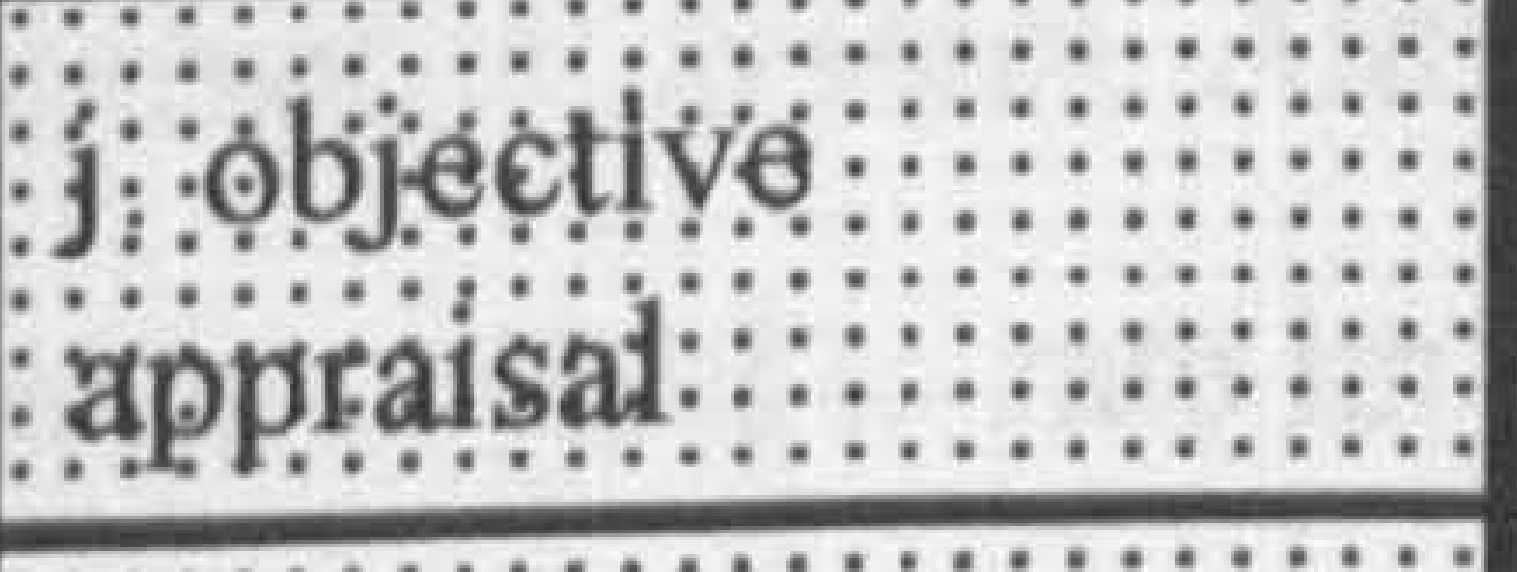 & & 7 & 5 & 2 & $\begin{array}{l}\text { not preconceived or } \\
\text { prejudiced }\end{array}$ \\
\hline 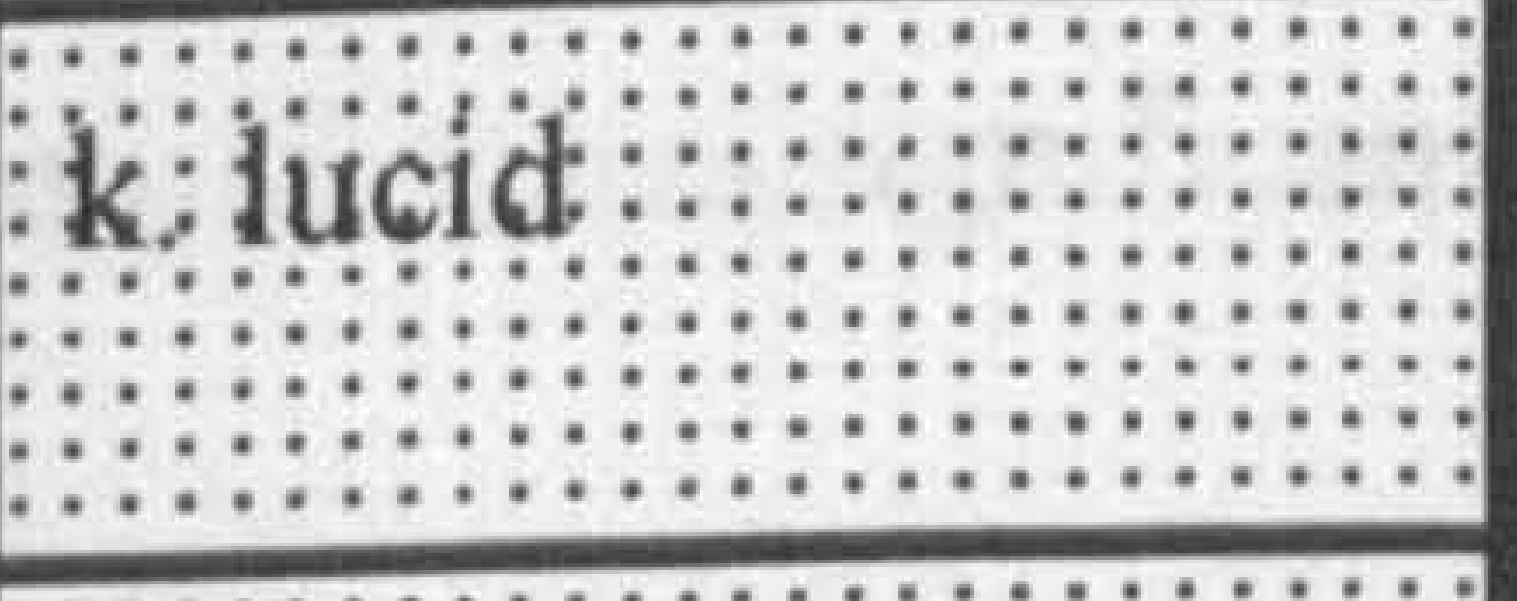 & & 9 & 6 & 3 & $\begin{array}{l}\text { clear speech, } \\
\text { writing and vision }\end{array}$ \\
\hline $\begin{array}{l}1 \\
0 \\
0\end{array}$ & & 8 & 6 & 2 & $\begin{array}{l}\text { structured, knows } \\
\text { goals and strategy }\end{array}$ \\
\hline 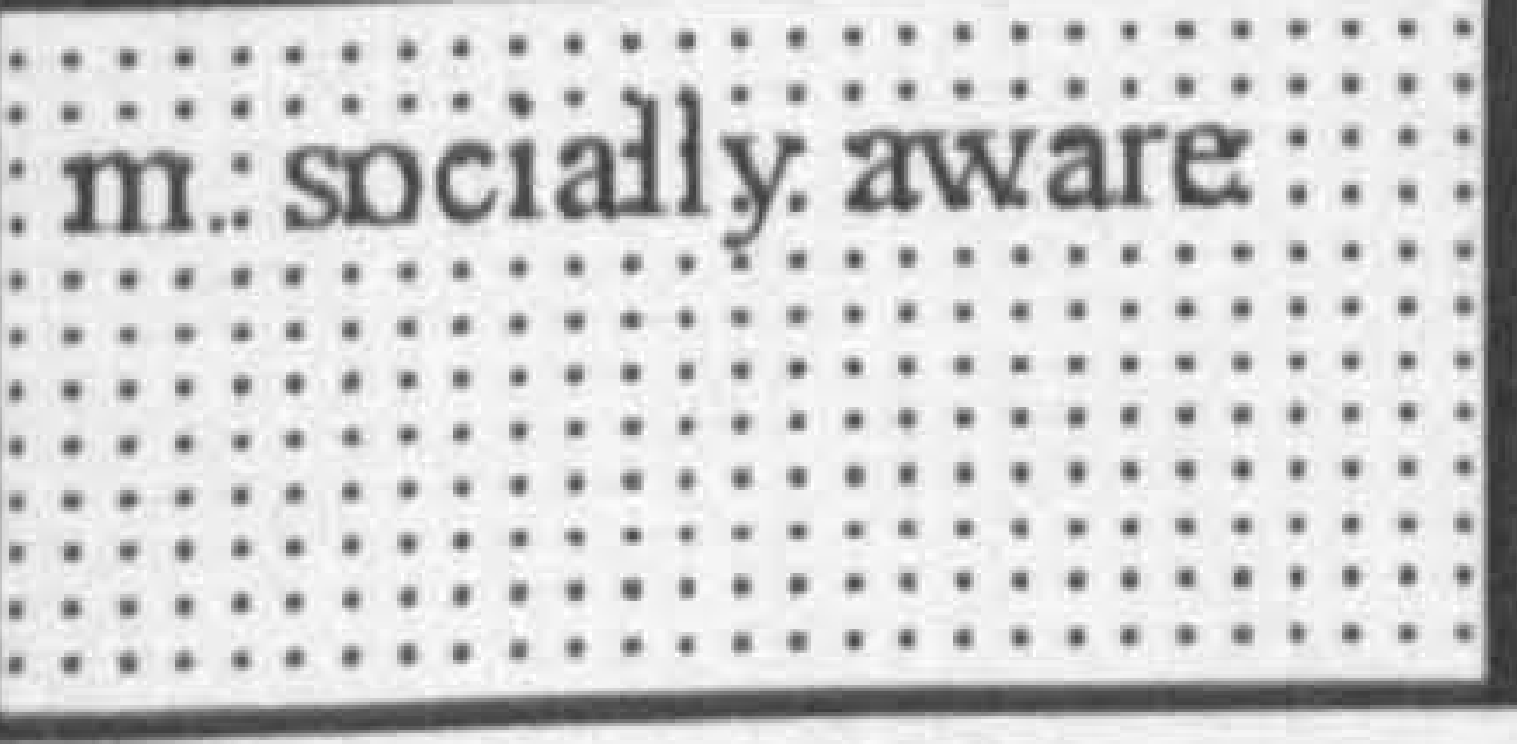 & & 10 & 6 & 4 & $\begin{array}{l}\text { recognise causation } \\
\text { and process, links } \\
\text { effects to outcomes }\end{array}$ \\
\hline
\end{tabular}


The inability, or reluctance, of the participant to clearly identify positive and negative behaviours in the context of job related skills came as a surprise, particularly since it contrasted with his confidence in the system of descriptors which he used. As a developmental framework stage 3 was a failure. Not only did it not provide a detailed examination of the construct system, it also seemed to suggest a rather superficial approach to the domain. The categories used by the participant were not capable of being translated (by the participant) into a meaningful judgemental or scaling system. Although the participant was able to estimate his own performance in comparison with others, this took place against a vague and generally unanchored set of either positive or negative descriptions of a required skill or quality. Quality D gives an indication of the problem encountered. The quality referred to is sceptical, the descriptor negative and the relative score positive. The participant clearly felt he was less sceptical than his colleagues, yet he cannot identify this in a positive context i.e. he cannot identify the characteristics of more positive behaviour for this quality. Quality F is even more problematic, since the term used, "objective", suggests a positive approach to a subject, whilst the description of open (again normally a positive attribute) features as part of a negative pole.

\section{Stage 3a}

Stage 3a provides more evidence of the confused and possibly contradictory nature of the construct system. Although the participant was unconvinced as to the validity of the process, when asked to rate its relationship to his own perceived qualities, the outcomes suggested much more significant links. 
Table G 4.

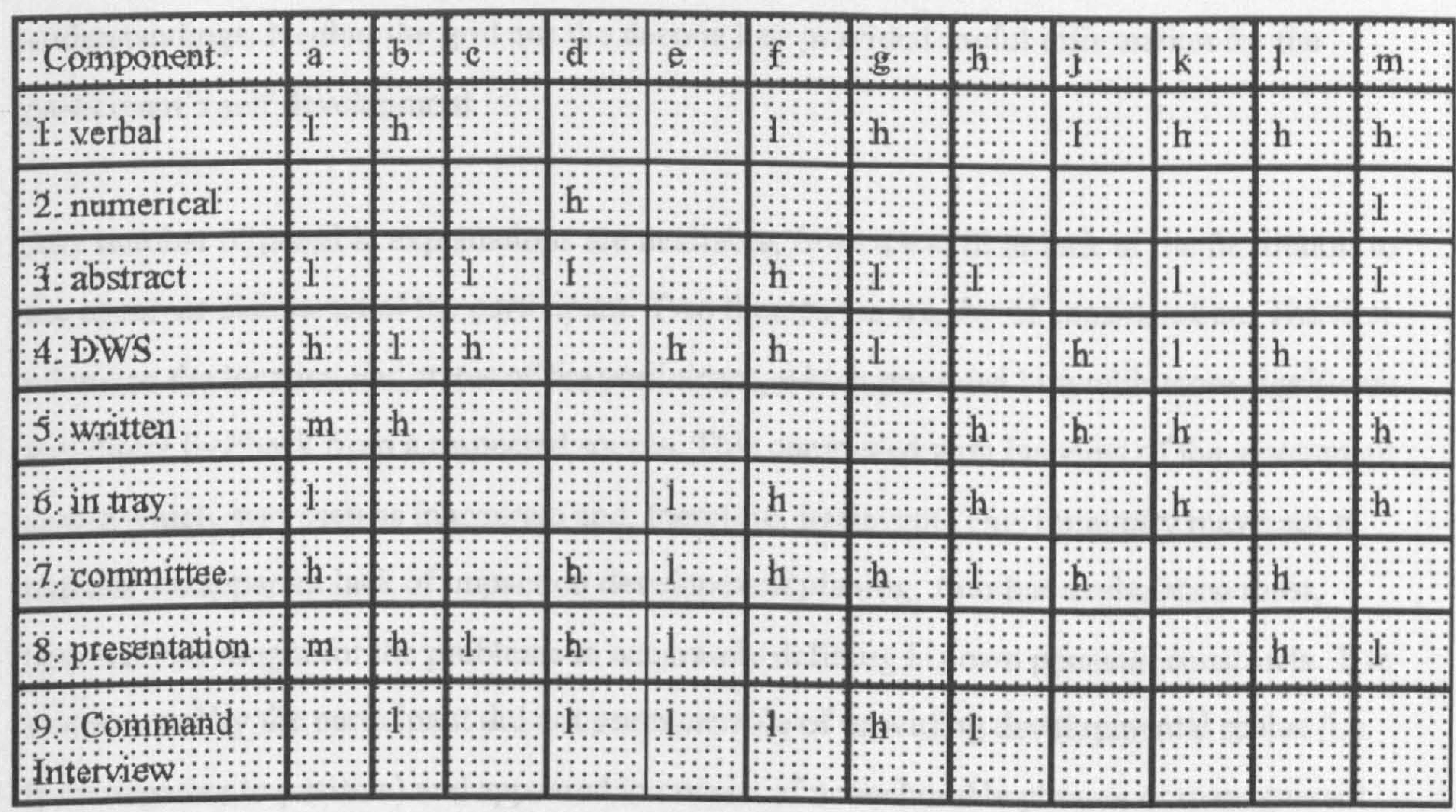

Rather than providing a decode key for the assessment process, the mapping process used for stage 3a suggests more problems with the construct or quality system described by the participant. Whilst all the qualities were assessed to some extent, the degree to which individual exercises were seen to assess more than one quality were numerous. The Verbal Reasoning Test, for example, seem to assess eight different qualities, one of which is socially aware. Similarly, different exercises all seen to be assessing the same qualities. Quality F "Objective", for example, is assessed, according to the participant, across six different components, whilst being personable forms part of seven, including two written components. Numerical reasoning seems to load on to the qualities of being sceptical and being socially aware.

\section{Conclusion}

The failure to pursue any form of developmental activity with participant $\mathrm{G}$ can be traced to the difficulties experienced in stage 3 and the problems evident from stage $3 a$. To some extent, these must be seen as research failures, since the intention by this point of the 
research process was to encourage and enable the participants to develop their own understandings. Neither the grid nor the decode key provided useful information for the participant's self development.

Any number of possible explanations are available, from the skill or lack of the facilitator, to the apparent disinterest of the participant. Two themes are worthy of consideration. The first relates to the location and status of the participant, which provided him with more significant and direct feedback from a respected source. This contrasted with his view of the assessment centre which, was seen as inaccurate and, therefore, irrelevant. This immunity may help to explain the apparent lack of impact on development planing. Another explanation must, however, be sought for the problems in accurately defining his own personal constructs. The system used by the participant did not seem capable of providing developmental scales (i.e. from negative to positive) and appeared to consist of unanchorable phrases or management buzz words, which may have made sense to the participant, but proved difficult to locate within the assessment centre. Once again, disinterest may have played a part, but a more critical explanation may be that, the feedback being provided by his managers had, together with some previous and valued experience (as a lecturer in management) created a system of values which were not entirely those of the participant possibly but those of his managers or work colleagues.

The existence of a separate and well established public system of constructs is not fully discussed either in the literature regarding assessment centres or that of personal construct psychology. The idea that personal constructs are capable of being overwritten by such a system, is at odds with the concept of a fully functioning and, therefore, reasoning human being. For this reason alone, many personal construct psychologists have tended to reject the existence of such systems as anything more than a temporary barrier, behind which lays the persons true personal constructs. In this particular situation, one must also examine the motivation to conduct such an exploration. If, as in this case, the participant felt no need to consider or assimilate the information provided by an assessment process, it follows that this also failed to provide any motivation to explore his own construct system. The assessment 
centre results were simply not valid, therefore, there was no need to examine the nature of the information with which they were at odds. Different information from different sources need not be combined, provided that the person can successfully demonstrate the validity of one over the other. 


\subsection{Summary of Case Studies}

With the exception of participant $G$ the research process is common to all participants although timing and presentation of different stages varies considerably. Viewed retrospectively, the intention of the research was to examine ways of making the assessment process accessible for development and subsequently to encourage participants to manage their own learning. The problems exhibited in the last case study are included as an indication that the process is far from perfect and still requires considerable tailoring to the needs of the individual. In this context, the participants played a major role in creating the research process and the data derived from them is as much part of their own actions as my own designs. Different stages were derived for different purposes and with slightly different results. Taken as a whole, they indicate how learning can be achieved, and how assessment centre data (both hard data in the forms of scores and results and soft data in the form of impressions and feelings) can be used in a developmental context.

The extent to which the constructs were used for development remains disappointing, given their obvious potential. Two organisational factors may help to put this result into context. Firstly, the use of constructs for self development would tend to exist within a framework which recognised and supported self development. Many of the initial development proposals by the participants in this study were, and to an extent still are, heavily involved in the consumption of formal training courses. Self development, in any form, therefore, can be seen as innovative for this group.

A second, and related, limitation derives from the absence of any coherent system of performance assessment or appraisal. Whilst the absence of a formal system may encourage individuals to use their own constructs as performance criteria, the absence of any history or tradition of seeking or providing accurate relevant feedback also mitigated against the development of a developmental framework. 


\section{Chapter 6 Assessment Centre Conclusions}

The initial focus of my research was on the "impact" of assessment on learning. My first attempts at exploring the issues looked to isolate possible impact or effects of independent variables. These early possible variables included:-

attendance impact, or the effects of actually attending an assessment centre,

- decision impact, which related to the effect of a selection decision (research by Fletcher having suggested that negative decisions tended to be related to an absence of learning and development, and finally,

- feedback impact, which although potentially contaminated by an earlier decision, could be seen as a separate variable influenced by the quality, quantity and timing of the feedback provided.

These variables appeared to be implicit within the assessment centre literature, although, as pointed out in Chapter 3 much of the consideration of learning within the literature is based on presumption rather than actual data.

\subsection{The research process}

\subsubsection{Stage 1}

In order to assess the impact of attending assessment centres it was important to make contact with candidates as soon as possible after the actual assessment centre and before any decision had been communicated. Unfortunately the LFCDA varied the agreed assessment process. In place of a two stage process with all candidates undertaking all parts of the assessment, the selection process was modified and the first (assessment centre) stage used a cut off 
mechanism. As a result, an interim decision was created about who passed or failed the assessment centre stage. This decision was communicated to candidates mid way through my research. It was therefore no longer possible to directly distinguish attendance as a possible source of learning from the positive and (mainly) negative effects of the interim selection decision. The evidence that did emerge indicated that candidates were far from passive objects and that their responses to the assessment centre could not be understood in isolation from their previous experiences. The effects of attendance varied considerably between participants. Rather than provoking a consideration of possible development needs, however, candidates seemed either indifferent to the process or to focus on exercises rather than underpinning skills. The claims made in the literature for widespread positive effects were therefore not supported by the evidence which emerged.

Fortunately, by this point, the focus of my research was already shifting. Under the weight of evidence produced by participants, I began to recognise that the whole assessment process needed to be seen in a broader more humanistic (and less experimental) light. Having decided to look at the effect of attending an assessment centre, the first stage interviews were designed to identify changes in developmental plans. If, having attended an assessment process, there was a significant change in how the person saw their own development needs, or in the way in which they planned to met these needs, then one could reasonably argue that the centre had an effect on their development - to the extent that it had contributed to a change in their self perceived development proposals. This effect proved a particularly elusive commodity. Participants A and B were notable for the almost complete lack of any effect in as much as their plans showed no significant changes. Participants $\mathrm{C}$ and $\mathrm{E}$ although showing changes were not fundamentally altered. Although participant $D$ had identified a specific need, this came only after initial feedback on the decision not to select him for the second stage. Participant F came to see the process as inherently "fixed" to the advantage of those personnel who had been identified in advance (the so called "A list") whilst participant G seemed to exist in a completely separate organisation and appeared to be largely immune from anything that the LFCDA could do to him. 
In contrast to the measurable impact, which the research process was designed to highlight, the emotional impact was, for some, all too clear. Participants $\mathrm{C}$ and $\mathrm{D}$ had been affected. The former, interviewed before a decision had been made, was aware of shortcomings in his own performance and sought to remedy these. The latter expressed similar views, although, by the time of his interview, the decision had already been communicated to him and the specific failure - in relation to the command interview - identified. The idea that assessment centre performance (or at least the candidate's own impression of his/her performance) might be more significant than simple attendance began to emerge. With it came the recognition that assessment centre candidates do not enter the process as passive subjects but active, self aware individuals. This point was particularly significant for those participants who had least cause to vary any development plan. Discussions with participant A revealed that prior attendance on a similar event (in which he had been successful). For this participant at least, prior experience was a more significant factor in structuring development than the centre itself. By this stage, however, the lack of significant data concerning the impact of the centre on some participants was less important than the actual impact on others. Rather than continue to look for evidence where non existed, I began to examine the evidence which did exist and how it had been generated.

\subsubsection{Stage 2}

Once again the research process began from the quasi experimental perspective, trying to isolate and where possible measure variables. In this case the variables seemed to relate to the participant's view of their own performance (sometimes confirmed by decisions or feedback from others but, interestingly, often separate and isolated from other's views). Stage 2 came about as an attempt to measure candidates views of their own performance and to relate this to normal work activities. This was an attempt to identify possible differences in self perception which the assessment centre had created or promoted. The use of a group mean was intended to provide some quasi normative data. Normative assessment was included to reflect the extent to which self perception can be seen as a normative process, i.e. comparison against others, rather than fixed against some known (objective) criterion or standard. The 
overall purpose of stage 2 was to provide some mean of eliciting and comparing work place self assessments and assessment centre self assessments as a way of exploring possible influences on candidates i.e. as something which would confirm or oppose their day to day view of themselves. My hypotheses suggested that congruence between day to day and assessment centre ratings would be of less significance in promoting development than cases in which the ratings were different.

The resultant sets of tables should have identified ways in which the assessment centre operated as contrasted to day to day performance in the workplace. Because participants were asked to make links between the assessment components and their everyday activities significant differences in relative performance should have been significant to the way in which possible needs were identified. Differences between self perceived performance in the assessment centre when compared to a (nominal peer group) and performance at work in similar tasks (the similarity being determined by the participant) should have suggested areas in which assessment centre performance was significantly different from that perceived during normal work. As such differences could be seen as new information about skills and abilities and hence a potential source for new development plans.

To some extent, the absence of such differences within participant $A$ can be seen as supporting evidence, but this is absence of evidence rather than evidence of absence. The lack of significant differences between self perceived work performance and self perceived assessment centre performance relates to a stable development plan. However the participant, by virtue of successful performance elsewhere (in another assessment centre had already achieved entry to the preferred development option. He had, as one person referred to it, "booked his ticket" on an organisationally approved course. In contrast, those persons most obviously affected by the assessment process (in terms of visible anxiety), showed relatively little differences between assessment centre and job performance. Through discussions with participants $C$ and $D$ in particular, there began to emerge a more significant developmental issue. One which impacted not only on their development but which could be traced directly back to the assessment centre. Although both recognised poor performance and both 
perceived themselves performing better in the workplace, there was no clear link between the assessment process and the day to day. Most importantly skills required by one, may, or may not, have been required or assessed in the other.

Stage 2 had examined one problem - that of the relationship between prior self ratings and those of performance the assessment centre, but had raised a further problem - that of relevance. In terms of assessment centre effects, these could be said to be most apparent when the candidate saw themselves as performing significantly differently in the assessment centre from in normal work. In this context attending assessment centres provided an opportunity to reflect on performance in a different and competitive arena and those who saw themselves as performing differently were conscious of that difference. When it comes to development planning however, this difference was not necessarily positive - a difference between perceived performance in the job (positive) and the assessment centre (negative) was encouraging participants to focus on the assessment centre rather than any underlying skills. Without a clear link between the assessment centre and the day to day, participants were focusing on the former as a barrier and not recognising the latter as a context for development. In crude terms the only major effect of attending the assessment centre was to focus some candidates on performing better in assessment centres.

This lack of linkage posed two problems. One, for the organisation was about making the process appear valid. The second, more significant for the participants, was being able to deal with, and subsequently use, the information available to plan and structure their development. By this point, my research was beginning to gain a new emphasis. Although the needs of the organisation remained important, not least because these provided the opportunity to conduct research, the needs of the participants were more pressing. From being concerned with impact and effects and seeking to create some objective measure, the collaboration with the participants lead me to explore the actual needs and consider mechanisms which might enable their learning. If attending an assessment centre does actually have an impact on candidates, my research failed to find anything remotely developmental about such an effect. On the contrary, those most affected were left without a means to plan their own development and 
with information for which they had no use. Some form of meaningful development remained a possibility, provided a mechanism could be used to make the information more easily applicable to the individuals themselves

\subsubsection{Stage 3}

The use of the repertory grid process was specifically designed to make available to each participant a set of personal constructs related to effective performance in the management domain. Because the assessment centre components were available and the related work activities had been identified by each individual, these were used as elements in order to generate constructs which would be relevant to both work and the assessment centre. The use and extension of the grid system provides the real exploration of learning within the case studies. Without the use of the grids learning would have remained an elusive and somewhat irrelevant commodity. The grid technique allowed data to be used to inform, if not actually determine, needs. It was the grid system, rather than the assessment centre which structured the subsequent development.

It would be naive to suggest that the use of the personal constructs and the sudden transformation of the participants into purposeful learners were in some way unconnected, or that the emergence of learning proposals was simply the discovery of "hidden" needs. In reality the technique of elicitation and representation assisted or supported the process. By focusing on leaming plans, the early research had effectively limited itself to finding no real learning. The introduction of a technique based around personal meaning was always likely to result in some learning proposals. What took me by surprise was the way in which participants responded to this opportunity. Even where the actual assessment impact was small, the participants were prepared to examine the information available in a new light.

An argument against the use of the grid technique in this research could be that, far from allowing participants to consider existing needs, it created or at least uncovered new needs which had little or nothing to do with the assessment centre. To some extent such a view is 
valid, there is certainly no lack of evidence for contamination between research methodology and outcome, nor even between my purpose in supporting the participants and the outcome in relation to more coherent learning activities.As the emphasis changed so the research became more participant oriented. Simultaneously, as evidence failed to appear for learning as a result of the assessment centre (in isolation) so the support provided to learners generated learning activities and thus data about their actual and proposed activities. The extent to which the latter would have operated, without any assessment process, is impossible to predict. My response to such criticism, is to reaffirm my commitment to action learning and suggest that the development options were emergent within the initial assessment centre research. To this extent, the resultant development or learning occurred as a combination of attending the event and being provided with a means to translate or interpret this experience. From the point at which the grids became developmental, it is no longer possible to identify or isolate the effects of the centre from the resultant research methods. As a result the ongoing development can only be considered as partially related to the assessment centre. On the other hand, without the intervention there is no evidence to suggest that any meaningful development would have taken place.

The grid technique went beyond straight forward investigation and enabled learning in a number of ways. Firstly, it allowed participants to review their needs in personally meaningful categories - their own constructs. Secondly, it allowed data to be used from the assessment centre in a form which related their assessment centre performance to those categories . It also provided a means to evaluate the assessment process from their individual perspective. Finally, and most importantly, it allowed participants to share their development with others and to exchange information about both constructs and performance - thus they were provided with a further ongoing source of feedback.

\subsubsection{Subsequent stages}

As the research progressed, so it became more difficult to identify development as a product of assessment and more obvious that development was occurring as a product of the research 
process itself. Stage 3 created an opportunity to examine development in a broader context, which, although linked to assessment, could also be used in other contexts. As the use of constructs was developed and extended, so the constructs themselves became a source for developmental activities. The exchange and review of constructs provided a link between the assessment centre, the person and their current context. The major factor influencing development derived from the use of these, with exchange being possible to a greater or lesser extent depending upon the individual and their line manager. The case studies developed as the use of the constructs increased and as a direct result of their use. The only case which shows no development was that in which the construct elicitation was flawed. As the cases developed, so the methodology used became more explicitly developmentalal. The exchange of constructs represented an opportunity to consider development and obtain useful feedback. This feedback in turn could be used as a source of information about both skills and development activities. Although the constructs were related back to the assessment process, thus enabling assessment centre feedback to be decoded, the development activities it supported were work based and essentially personally related. This move away from assessment based development and towards personal development represents the major achievement and focus of the later stages of the research process.

\subsubsection{Research Outcomes}

As for the initial questions about assessment centres, these can be answered relatively easily.

Did the assessment centre have any effects?

Were these learning outcomes?
Generally the answer must be yes.

Initially the answer is no.

The effects present were not helpful to the learning process. The impact of poor performance or negative decisions tended to undermine the person and reduced their ability to plan effectively. Assumptions were made about the candidates and their development process. These assumptions not only failed to match the candidates perceptions, but were at odds with 
the organisation's own stated purpose. The data available to the candidates from the assessment centre was not in itself developmental, what was required was a mechanism to make it relevant. This could have been an widely known and accepted public system but even so candidates would have needed the skills an experience to operate within this system - in particular they would have needed the ability to interpret this data and compare it to their own personal systems.

The use of personal learning systems proved effective because it provided these links and with them participants became able to managed their own learning. This is not to say that learning will always take place, or that the process of eliciting and defining constructs is necessarily developmental, for that to take place some consideration of the individual's purposes may also be required. Development does not take place in isolation and whilst learning may be intrinsically valued it normally has some relevance to other parts of one's life. Valuable learning is learning which is valued by the person themselves. Organisations which set a lesser or secondary value on development within an assessment process should not be surprised if candidates respond by treating the event as a hurdle to be overcome rather than an opportunity to learn. On the other hand, organisations who genuinely wish to support development and wish to use the assessment centre process need to consider how they go about the introduction and support of such measures. Listed below are some considerations for improving the quality of learning in organisations which are exploring the use of assessment centres for development.

\subsection{Defining the purpose of the process}

Perhaps the most obvious, but least considered, aspect of the assessment centre process is its purpose. Having been defined in terms of a series of operations, the purpose of an assessment centre is often implicit. As such candidates often enter into a process without understanding precisely how it will be used. An organisation which considers the purpose of the assessment centre has to examine the relationship between development as an outcome and simple 
selection. The design and subsequent operation of the centre will be structured by the extent to which the organisation genuinely wants to see personal development. A mixed or hybrid design, combining selection and development, may be possible in the eyes of some psychologists. The question which needs to be addressed is to the extent to which the relative weighting (as determined by the organisation) is reflected in how the candidates approach or respond to the event. Assessment centres which focus on promotion draw people who want to be promoted and for the most part regard non promotion as failure. Failure, as we have seen, has a very specific effect on development and may focus candidates on specific development outside or in opposition to the needs of the organisation. If, on the other hand, development is the main objective what sort of development is to be achieved and by whom?. The idea that the centre will automatically channel people into relevant development is not supported by the case studies. Is it beyond the capacity of an organisation which wishes to run an assessment centre to specify the sort of developmental activities or needs to which the centre is relevant. A basic training course would have objectives - how is it that a much more expensive and sophisticated process avoids the need? My answer is that it does so by espousing the implicit model of development which these cases have failed to support. Perhaps a more explicit statement of purpose may go some way to focus the organisation, if not the candidates themselves.

\subsection{Designing the process to support those purposes}

Having defined the purpose, and one assumes recognising the need to avoid or reduce possible selection problems, the next stage is to design the process itself. This is not simply a question of timetables and exercises, but considering how the different components will be used and what information will be gathered. This consideration should also include who will use or own the information and what role the candidates themselves fulfill. Having identified that candidates are not passive beings simply undertaking different experiments, the question arrises as to how to treat them and what actions need to be considered to ensure or engage their participation as learners. Perhaps the simplest, but most obvious flaw, in most centres has been to assume that the candidates enter with a single purpose - that being identical to the 
organisation. Candidates bring with then a vast wealth of experience which needs to be recognised and utilised. The assessment centre must be able to tap into this experience and, by way of a corollary, the candidates need to be able to use their experience to interpret the assessment process. The mechanism used in these case studies was a form of the repertory grid. This is time consuming and therefore expensive. On the other hand, such a tool enables the generation of underlying constructs which could be communicated, exchanged or even used to create a system of agreed constructs or competencies.

\subsection{Defining the requirements of the job - competencies}

Traditionally the task of defining the job itself has been the province of psychologists and, strangely, this is the field in which we most often find the use of the repertory grid Unfortunately, however, whilst the method may be employed consistently (even one might say religiously) the use of the technique lacks overall coherence. It is outside the realm of this research to comment on actual use of the grid technique to elicit competencies, however, the formula adopted by Stewart an Stewart, which seem to be the guiding text, suggests where the possibilities normally end and the problems begin. Sadly, many researchers use the grid to elicit constructs, but fail to recognise the nature of the data they have collected. Constructs are thus summed and amended on the basis of their written description without any real consideration of either context or purpose. Some constructs which may be relevant to the performance domain may not be developmental in the eyes of their holders. Some may actually be developmental but because of their similarity to others (in the eyes of the professional psychologist) are lost. The overall effect is to reduce complex system to simple lists of competencies.

A process which wished to engage the candidates fully would look to the grid technique as a means for extending understanding of the domain rather than reinforcing a given view. Such an approach would need to extend the involvement of the potential candidates and reconsider the role of the "professional scientist". In any construct system the task of elicitation is taken by the trained professional - the researcher. The task of the subject is simply to produce 
constructs - no comments are sought and often the data, or written description of a construct, is treated as more important than the way in which the person may actually use it. Most significantly, the part played by the scientist is seen as impersonal and objective. This is true both at the gathering stage and the subsequent analysis. No real consideration is given to the researcher as an active participant whose own views often shape the nature of the constructs (particularly where the research participants may struggle for words).

Time and again construct or competency systems emerge with a similar number (12) of similar headings, all of which seem to relate to some broad body of work on intelligence, or personality, or some other aspect of human performance. If the process is designed to produce a simple list and not to engage the participants, then it is effective. If, on the other hand, the organisation wishes to encourage development, greater attention needs to be played to the role of the participants and their ability to structure constructs collectively. The limited research in the case studies suggests that managers can exchange and refine constructs and that this process may lead not only to better descriptions of the skills and abilities required (better at least in the sense of more useable) but also more focused development by the managers involved in the exchange. Some constructs may not be assessable, others may not be obviously related to development - there is no need for all constructs to be used in an assessment centre. Those that can be used, however, are at least likely to be understood and be relevant to those that have provided them. Far too often, it seems that the assessment centre process simply assesses those things which can be assessed and makes the assumption (and sometimes the claim) that because it does so objectively no other valid criteria can exist. An assessment process based on shared constructs may not be broader but is likely to be less exclusive, in the sense that it will recognise those things which cannot be accurately measured but which may still exist.

A second outcome of the development of a shared competency system relates to its day to day usage. Far too often competency system exist only within the narrow definition of the assessment centre and its exercises. Real management is far too complex for the use of single dimensions. A shared competency framework can also be useful in defining the links to other 
processes and the day to day job. Having identified what can be assessed within the centre, there are also opportunities to assess, and more importantly, to develop, within the job. The availability of a clear linked to day-to-day, or normal, performance is important as it enables other data to be collected (to add to the assessment centre if necessary, but also to identify opportunities to develop skills). The assessment centre has hitherto been conceived of a single event (with possible effects later on). Such an approach fails to integrate assessment with performance and development. The availability of a shared competency framework makes these links and, because it is generated by the potential participants it can be used by them. Competency frameworks based on other's perceptions of the skills or the jobs tend to put forward development opportunities which should exist but may not actually do so in reality (self development being sometimes the most vacuous of these opportunities)

Having a shared framework means that designing the centre becomes a task of matching competencies to work samples or exercises - not necessarily easy, but certainly more straight forward than operating in a vacuum. The only real question this raises is, who assesses whom. Traditionally preference has been given to trained assessors - be they managers or psychologists. The reason behind this is objectivity. Whilst bias could be a problem, there is no evidence to suggest that self assessment and peer assessment in a developmental context is harmful. The case studies suggest that participants are capable of self assessment and that regardless of the organisational outcome will tend to use this more often, and more meaningfully, that the official view. Having two sets of data ones own or "Personal" and "Other" that of an observer, is useful, but there is no reason why this could not be provided by peers.

The key to providing feedback is making it relevant and useful to the individual. Hitherto this has been seen as a communication issue in which the sender's role as predominant. Such a view, whilst it might fulfill the needs of the sender, tends to overlook the needs of the recipient. Once again assumptions are made about candidates' purposes. Often it is assumed that, having entered the process, they are prepared for feedback to be provided. If we can assume that a candidate enters a process at least knowing the intentions of the organisation 
regarding its outcomes, we can perhaps assume that they have some common purpose with the organisation. The extent of this shared communality however is not apparent. The research studies present here suggested that some candidates may enter an assessment process but feel no further attachment to the organisation supporting the process. Candidates will have their own separate individual purposes, which need to be examined either before or in the context of feedback provision. It is not simply that the purposes are different, but that different purposes require different sorts of information. Making the link to the candidate's purpose dictates structure and not the other way around. If as in case $\mathrm{G}$ the candidate does not wish to participate further, then this must be respected as an unfortunate, but allowable, outcome. To pretend that the organisation can achieve anything meaningful in the face of such oppositions is arrogant and ultimately futile.

If events such as attending assessment centres are to be meaningful they need to integrated and supported. The early research in this study suggested that development was closely bound up with training courses. Whilst such provision may be valid, the absence of other suggestions indicates a lack of breadth in terms of ongoing support. Workplace development suggested above must also be supported and coaching and mentoring schemes may be necessary before candidates place faith in them. Once again, the plan must be agreed as the product of a meaningful conversation. Without the learning conversation the plan is of little use to either the candidate or the organisation.

\subsection{Organisational and personal learning.}

From many organisations personal learning is a sub set of organisational learning - it is one method within a vast array of techniques available. For the individual, however, organisational learning is a sub set of their own personal learning. Without personal learning there is no learning at all, or at least no sense of what is valid and useful. Organisations have come to personal learning having recognised the limitations of conventional training techniques. In turn assessment centres have been seen as a means of supporting personal 
learning. Having no clear objectives and no obvious relationship to learning theory has, together with vastly inflated claims, given rise to the development centre - a vehicle for personal development. If this research has any long term significance, then it is in the fact that organisations, no more or less than individuals, need to consider the purpose of their learning before commencing on strategy. The assessment process can lead to development if the necessary links are made and the necessary support provided. But even then only where the personal significance and value of such learning can be identified.

Often organisations fail to specific purposes which are implicit for fear of discouraging participants. This is a false and slightly unflattering view of learners. Personal learning cannot be so easily deceived. In the absence of specific explicit purposes, participants will identify purpose from what is implicit - how people are treated, what is assessed and what decisions are made. It is hardly likely that these partial understandings will be as well informed as a situation in which purpose was explicit and the process consistent with the explicit purpose. Perhaps too many organisation are unwilling to explain their purpose because it is simply or predominantly a matter of selection and development is simply seen as a "by-product" (or worse a convenient label). If this is the case they are certainly not fooling candidates, but may be deceiving themselves.

\subsection{A pragmatic view of assessment centres}

One cannot really argue with the suggestion that assessment centres can, in theory, provide useful information which may be used in self development. On the other hand, the notion of self managed development would require a very different sort of assessment process. Ideally one would like to see a more open process with specific developmental objectives based on a shared and amendable system of competencies supported by clear feedback and adequate developmental resources (not least in terms of line manager support). Such a framework, however, would be expensive and it is here that the major concerns are sure to arise. At present assessment centres are used primarily for selection and development remains a useful spin off. To the extent that selection does take place and can be validated, the rather spurious 
claims of development are admissible as additional benefits. An open framework oriented to self development may well employ techniques such as peer or self assessment which are seen (from a psychometric or equity viewpoint) as unsuitable to selection.

The reality is one in which assessment centres will continue to be dominated by concerns related to the valid selection of personnel and it is these rather than individual development which are used to justify the cost and resources required. Sadly, the title "Development entres" used for many of these processes will remain little more than window dressing for many organisations. This is not to suggest that improvements cannot be made to the assessment process. On the other hand it does indicate that the assessment and development processes will remain separate. To this extent my conclusions on assessment centres relate mainly to the provision of information in the form of feedback. Not only must this be timely, but it must be appropriate to the needs of the participants. Data on scores will be of value to those who wish to know how successful of unsuccessful they have been. Whilst this information may be useful in determining how much effort participants put into their own development, it provides very little useful information in terms of developing skills. In this context, direct observational data is of more use, and it is in this area that further development of the process needs to be directed.

This aproach may seen rather pessimistic but the division of assessment and development should not be seen as a negative step. Indeed a recognition that the latter may well be a separate process may be a hidden benefit. Rather than assume that development inevitably follows from assessment, the recognition that it does not and may therefore be predicated on a separate basis, enables the development process to focus on the individual learner and his or her own needs. A separate development process would enable the individual to bring forward his or her own objectives into which assessment centre data could be fed (preferably by the individual) and within which organisational and individual purposes could be explored. Clearly such a process would rely on similar resources to that of the ideal development centre, unlike the ideal development centre, however, such a process would focus on the individual and therefore (need to be) validated on the basis of individual development. Whilst 
assessment would not drive such a process, development could be related to the assessment centre outcomes through, for example, a competency framework 


\section{Chapter 7 Assessing Competence}

The assessment system used for determining job competence is that of the UK National Vocational Qualifications (NVQs). If it possible to argue that, the competency based system used in assessment centres places learning in a minor, or subordinate role, the NVQ system, by way of contrast, contains explicit references to the significance of the learning process. Before examining learning, however, it is useful to consider in some depth the overall assessment process and, in particular, its use in the management domain.

\subsection{What is being assessed.}

"An NVQ is defined as (1):

a statement of competence clearly related to work and intended to facilitate entry into or progression in, employment and further learning, issued to an individual by a recognised awarding body.

The statement of competence should incorporate the following specific standards in:

the ability to perform in a range of work related activities, and

the underpinning skills, knowledge and understanding for performance in employment"

(NCVQ 1988, p 15)

In broad terms the NVQ System concerns itself with the effective production of a series of job outcomes. Performance is assessed in terms of a group of related outcomes (or unit of competence) focused on a particular area. The Unit is composed of a set of component activities or elements of competence, each of which contains several performance criteria 
together with a specified range over which performance should be identified as competent (see appendix $\mathrm{C}$ forsample of standards). Competent performance is determined by satisfying all performance criteria across the range, as modified by the separate assessment guidance notes. Qualification is based on completion of a number of units at a given level. Awards are normally made on a unit by unit basis, each unit award representing successful completion of all the component elements. In addition to the performance standards, competences usually contain a separate reference to the skills of knowledge which may be required to produce the specified outcomes, these are referred to as underpinning skills and knowledge. These are not directly assessable as part of the NVQ, but serve as a guide to the type of information or the area of skill on which effective performance is likely to be based.

Early work by the Training Agency (2) outlined 12 key qualities of a competence statement

"Competence statements should have the following characteristics or qualities :

- be capable of being delivered within an organisation involve clearly identified skills or knowledge incorporate a range of work-based activities be based on outputs rather than inputs reflect the competencies required by a range of organisations be capable of being observed or demonstrated or reflected on be intelligible to educationalists, managers and others in their organisations be capable of standing alone be capable of being linked to an organisations appraisal system be flexible enough to allow for the cultural variations between organisations be capable of being used as the basis of management development as well as the assessment of competencies

- be applicable to all sizes of organisations" (Training Agency 1989, p 11)

NVQ competences are in effect a form of criterion measure based on specific occupational 
domains. The format of the standards is a product of the need to define criteria in such a way as to make their assessment reliable. In simple terms a criterion measure should be sufficiently well defined in terms of detail that all potential assessors should be able to recognise success and failure without further guidance or interpretation. The detail within the NVQ standards can be seen as a product of this type of measurement, as Wolf explains " the ever receding goal of total clarity derives not from bad luck or incompetence, but is actually inherent within the methodology adopted". This attempt to define domains in greater and greater degrees of precision is responsible for the detailed structure of NVQs. To the extent that the system predicates some agreed understanding of effective performance within the domain it could be argued that, in some ways, very detailed standards may suggest areas in which either there remain significant and allowable differences in outcomes, or perhaps that such an all embracing understanding of the domain is yet to develop. As indicated below, both of these possibilities exist within the development of any management standard.

The National Vocational Qualification or NVQ system envisages a set of 5 hierarchically related levels of competence each of which relates to a specific set of duties and responsibilities within a given occupation (see table below).

\begin{tabular}{|l|l|l|}
\hline NVQ & Occupational equivalent & Academic equivalent \\
\hline 5 & Professional (chartered) & Higher Degree/Diploma \\
\hline 4 & technician & First Degree \\
\hline 3 & craft status & B/TEC Higher/ a level \\
\hline 2 & semi skilled & B/TEC National \\
\hline 1 & manual worker & B/TEC First \\
\hline
\end{tabular}

In broad terms the level required by any given job is determined the amount of discretion which the job holder is given to perform effectively. This aspect of the system contrasts significantly with other educationally based hierarchies which derive their structure from 
perceived differences in skill or knowledge. One important feature of competences is their relationship (or perhaps lack of relationship) to given educational programmes or syllabuses, as Gilbert Jessup (3) points out "By specifying outcomes in the form of performance standards, independent of any course, programme or mode of learning, it becomes possible to create a framework of such standards which can be adopted by any course or programme" (Jessup 1991, p 11) Jessup contrasts the NVQ system with more formal academic assessment schemes "Assessment, whether through essay, examinations, or other means has been dominated by the psychometric model designed to discriminate between individuals. This model can be seen in its most sophisticated form in the measurement of intelligence and other psychological attributes. The questions chosen and the system of marking are designed to sort out and grade candidates from best to worst... If the candidates improve year by year the marking is adjusted to ensure that the same proportion fails. The NVQ system seeks to measure work outcomes rather than personal inputs and therefore determines the level of a particular NVQ by reference to the autonomy of the individual in a job context - lower level NVQs operate with a fairly well structured environment with a large number of decision making constraints, higher level NVQs operate where there is less constraint, where procedures and work systems are more complex and in which the individual is required to make decisions themselves" ( $p$ 46-7)

The significance of such a system for management qualifications is that rather than focus on discrete elements of knowledge (such as marketing, human resources etc) organised in terms of academic standards, the competence system sets out to identify different levels of manager based on their duties and responsibilities. This task - of identifying distinct levels of managers or managerial duties - proved more problematic than was initially conceived. As a result the three and a half levels of management identified by the Management Charter Initiative sit rather uneasily within the 5 band system designed by the National Council for Vocational Qualifications. Thus, whilst the assessment system, in terms of assessing outcomes and the format of the standards, remains the same for both NVQs and management standards, the management standards themselves contain four quite unique bandings 
As one might imagine, given the wide variety of managerial roles, this system represents a considerable reduction in the breadth of possible descriptions of the management domain. The compromises and negotiations required to obtain a limited consensus between employers, educationalists, managers own associations and government have created a system of "best fit" in which it is widely recognised that individuals managers or levels of manager within organisations may or may not actually perform all the activities specified by performance outcomes at a given level. This partiality of fit is of particular significance to some more bureaucratic organisations such as the LFCDA.

Alison Wolf (4) makes the point that this process of standards agreement is normative i.e. it is based on an agreement from within the occupation as to what constitutes the domain itself. "The documents do not in theory create the standards. Rather they articulate and clarify them to professionals who understand them because of their prior knowledge and implicit understanding of what competence in their own context means. This in turn rests on an assumption that there is such a single common understanding of effective performance within the domain." (Wolf 1996)

\subsection{Competence assessment}

As the standards refer to specific outcomes rather than assessable behaviours, assessment can take a variety of forms each based on a notional body of "evidence". In part, at least, the assessment process has been derived from work undertaken in the United States on the accreditation of prior learning (APL) Susan Simosko (5 )charts it $s$ history and direction

"the current APL Movement developed initially in the United states in the late 1960s and 
1970s.. there were three basic questions to be investigated..:

1. Is it possible to equate non-college learning with that offered in traditional college curricula?

2. If it is possible, can assessment techniques other than paper and pencil tests be used to evaluate the outcomes of the learning?

and

3. If such a system proves feasible, would it be possible to integrate the ensuing model in current educational programmes? " (Simosko, 1991. p 18)

The rationale of both APL and competences is to create a system which is both open (i.e. accessible) and capable of dealing with information from a range of sources and experiences.

\subsection{The Assessment model}

Jessup's emerging model consists of seven consequential stages of which APL is the first and sets the scene for subsequent processes:-

initial assessment/APL

Guidance

action planning

programmed learning

continuous assessment

accreditation (of units)

He also refers to two distinct processes " the collection of evidence" from various sources and " making judgements on whether the evidence meets the standard, which in NVQs means whether the performance criteria have been met." ( $p$ 49). In many cases these processes are lead by different participants, i.e. it is often the candidate who collects and presents evidence for the assessor to make judgements about. Hall (6) makes the point that whilst "the process 
[of evidence gathering and portfolio building] is individualised, self managed and requires self reliance... candidates need to take clear responsibility for their own learning.. this does not suit every candidate's learning style" (Hall, 1992, p 11-12).

\subsection{The qualities of assessment}

According to Simosko (7) "There are essentially five technical requirements that all APL assessments must meet. They include:

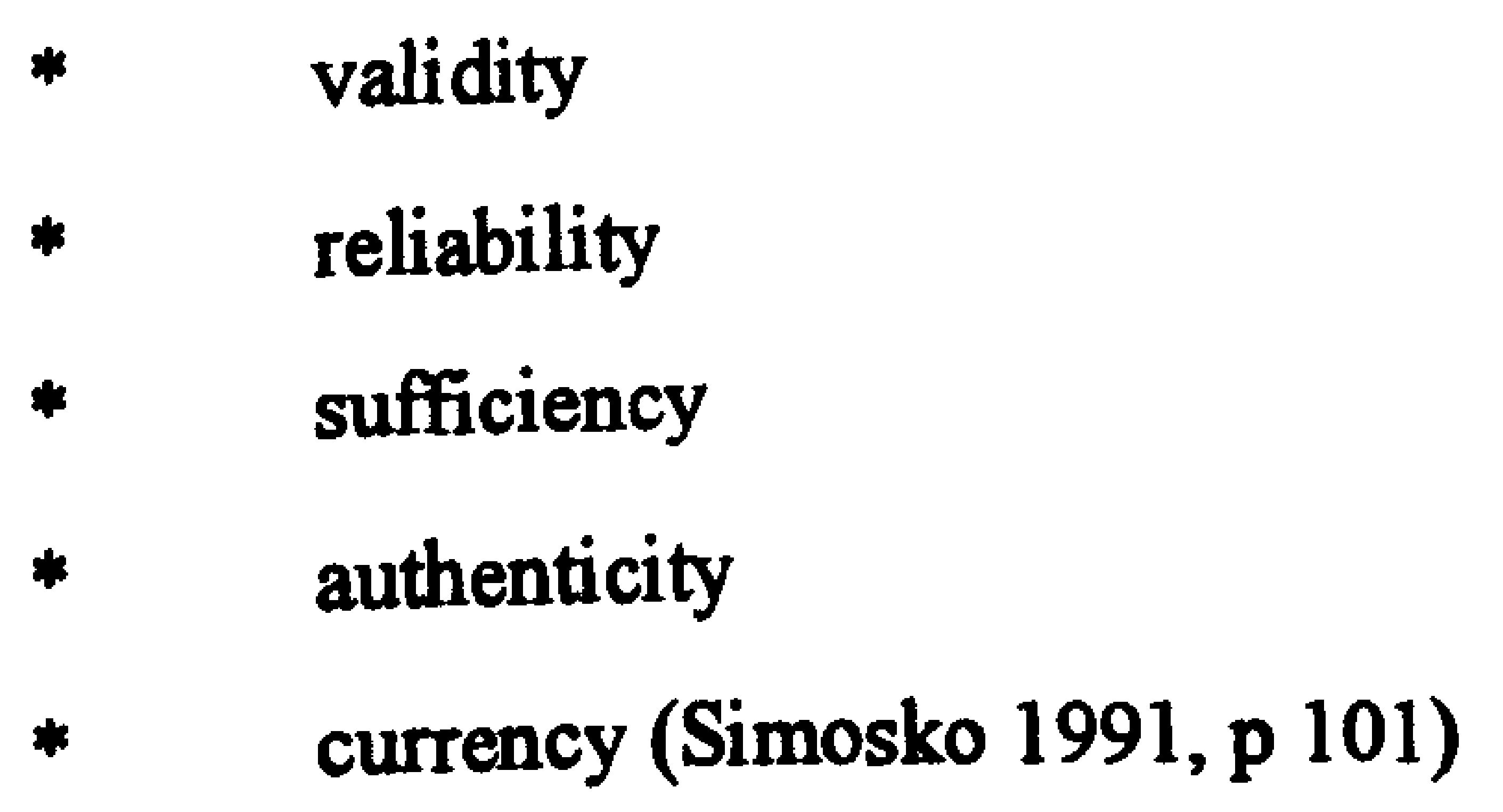

Walklin (8) defines validity in simple terms as the degree to which - "the assessment method must fit in with what is to be assessed" (Walkin, 1991, p 10). His formulation of reliability is not too dissimilar from that used in testing or assessment centre in that he defines it as "The extent to which an assessment of competence is consistently dependable and reliable when carried out by different assessors or by the same assessor with different candidates or at different times of day and in different places, is a measure of the reliability of the accreditation" (Walkin, 1991, p 10). Authenticity is a slightly more unusual facet and simply refers to the extent to which evidence performance evidence gathered is genuinely that of the candidate. Currency refers to the date on which performance took place and in the context of the MCI standards is normally considered within a two year time scale i.e. performance data over two years old is not considered sufficiently current to indicate current competence.

The idea of sufficiency is peculiar to NVQs and is related to the concept of range. Jessup remarks that "The argument, that assessment of performance is all that is required, would be sustainable if it was practicable to assess performance over the range to which an element of 
competence applies. In practice this is seldom possible, particularly at higher levels within the NVQ framework where the potential range of application is considerable" (Jessup , 1991, p 121). Herein lies a peculiar paradox of the relationship between actual or visible performance and underlying understanding. Once again according to Jessup, "there are two basic approaches to assessing transferability of competence, other than checking performance in every possible context. The first is to anticipate the main variations that are likely to occur and ensure individual know how to vary their performance according to the circumstances they meet. The second approach is to treat each new context as a problem which has to be diagnosed to determine what performance is required, drawing upon the individuals repertoire of skill and knowledge. The second approach assumes a knowledge of principles which underlie the activity in order to determine the most appropriate response. The two approaches are, of course not mutually exclusive but somewhat different ways of looking at the same problem" ( $p$ 122). This notion of sufficiency is problematic for assessors as it requires a judgement to be made about the extent to which performance data alone can be used and at what point, and to what extent, it may be supplemented with information about underpinning skills and knowledge. In assessing the latter, however, the assessor moves away from actual current performance into a tacit prediction of potential performance based on a combination of some prior performance and some assessment of knowledge or skill derived from a separate analysis or process.

The problem of assessing knowledge is further complicated by Jessup's insistence that it is job related knowledge , often of an informal type which should be assessed rather than a more formal syllabus. "An analysis of the knowledge that people actually draw upon, and need to draw upon to perform competently, may not appear as what is taught as the body of knowledge underpinning a profession or occupation or, if it is covered, may not be given the priority it deserves. Competent professionals tend to acquire a set of guiding principles, of which they are only partially conscious, derived from their own experience. These may build upon academic theories and knowledge or be only loosely related. whilst this is recognised in areas such as management, it also appears to be true in well established professions such as medicine" (Jessup 1991, p 127). There are therefore no specific written texts which should be 
understood but rather a vaguer and less precise set of underlying principles.

The problem of specifying knowledge illustrates a second issue for the NVQ system in terms of the role of the assessor. Initially it was envisaged that this responsibility would be fulfilled by the line manager, and that this person would be domain competent i.e. capable of understanding and recognising effective performance in the workplace on the basis of their own prior or current performance. Two issues have subsequently emerged which indicate that this is not always the case. Firstly, and most obviously, patterns of employment within organisations often give rise to situations in which a skilled specialist is managed by a general or non specialist manager - most employers recognise this as part of their structure and some have made attempts to overcome this by the use of other specialist assessors who are domain competent. This, however, seems to be a peripheral issue, in the sense that it is unusual for an employer to support NVQs in very specialist areas. More common by far, is the situation in which assessment is carried out by an external agent. The pre-existing system of education and training relied, and still relies, on educational providers - these include internal and external consultant trainers and a variety of colleges and universities. Since these latter groups are market driven and the market for assessment was moving from internal academic assessment to job related NVQ assessment it was only natural for them to provide an NVQ assessment service. Thus there exists the potential that the assessor will not necessarily be domain competent, or, alternatively, they carry with them a view of the domain which may be heavily academic in orientation and therefore significantly different from that of the candidate within an organisation. Wolf makes the point that this aspect of the assessment process is itself market driven. Organisations tend to view assessment as a fairly low priority activity and clearly secondary to their main business. For academic institutions, however, assessment in one form or another is part of their core business and as such they are more than willing and able to allocate resources to this task. Hence the prevalence of academic institutions as NVQ assessors particularly in the area of management.

\subsection{Competence and learning}


As indicated above the NVQ or competence based system contains an explicit commitment to learning. Perhaps the most coherent, and in some cases passionate support for the process is provided by Gilbert Jessup as Research Director of the NCVQ (9) As "Individuals differ in the way they prefer to learn and in the time and opportunity they have available" he believes that competences provide " a customer oriented system, in which the learner is the customer, who should determine what is provided. The model recognises that learning can pursue general objectives of self development, cultural development or intellectual development, or can pursue more specific goals and be clearly instrumental in achieving defined goals. the former is more associated with education and the latter with training. they are, of course, not mutually exclusive" (Jessup, G., 1985. p 4)

Simosko (10) comments on the actions of the assessor in developing learning. She refers to the role played by the assessor in assisting refection on past achievements and learning, and the importance of developing an active leamer by "giving the learner control" (Simosko 1991 p 55). According to her, this is achieved "By working with the standards and reflecting on their own understanding of them, candidates often come to see their own achievements in a new light. Things they may have forgotten are remembered: experiences that once seemed random suddenly fall into place as part of a previously unperceived learning pattern" ((Simosko 1991, p 86) She does not, however, distinguish this from other forms of performance feedback or relate this process specifically to the use of performance standards.

Walkin (11) refers to three types of assessment - informal, formative and summative. The implication here being that the former two have a learning oriented purpose and the last is more closely related to the achievement of a qualification. His proposal is that assessment operates in a series of stages, informal being the earliest at which evidence may or may not be used but which appears to be designed to acquaint the candidate with the standards themselves. This is followed by formative, which involves the use of real evidence against standards and comparing this to the requirements of the performance criteria. Walklin implies this process takes place only once, although there is no proscription of multiple formative assessment . Finally, when both the candidate and the assessor fell that sufficient evidence 
has been complied, a summative assessment is conducted the purpose of which is to confirm that the evidence meets the standard and thus enables the award of a unit. This latter process is also subject to further checks through a quality control system known as verification. Successful completion of a unit goes towards the completion of a qualification (based on a set number of specified units) and once awarded no further work is undertaken in that particular area of job performance (although the evidence may be used if it is relevant to another area e.g. evidence of work planning may be used in units related to managing people, developing people and managing operations). From a leaming perspective therefore the formative assessment seems to be aimed at enabling the learner to develop by the provision of feedback on their evidence i.e. the evidence that they provide of their performance. 


\section{Chapter 8 NVQ Programme.}

In 1992 a fatal accident resulted in detailed investigation of training and effectiveness by the Health and Safety Executive. As consequence of their investigation the HSE issued an improvement notice to the effect that the LFCDA was required to develop a system of competence based assessment for its operational personnel. Between 1992 and the present day the LFCDA has been working with the Home Office and external consultants to develop a competence based framework. The NVQ programme considered in this research came about at a point where the LFCDA competence system seemed to be strongly influenced by national management qualifications in the form of the Management Charter Initiative. A decision was made to move away from traditional academically based qualifications and pilot a small NVQ scheme as an alternative.

\subsection{Development context}

Prior to 1994 the London Fire Brigade had sponsored uniformed and non uniformed personnel to undertake relevant managerial qualifications offered by universities and colleges. These qualifications had included courses such as the DMS (Diploma in Management Studies) and the CMS (Certificate in Management Studies). Management views on this type of provision were mixed - some managers welcomed the development of staff and the new ideas which this type of training provided, others were more cynical and regarded them as simply a day a week off work. Generally, however, there was concern over direct relevance and the application of course material to specific jobs and tasks. Amongst sponsored staff the view of external courses was more positive. Even amongst this group, however, the issue of relevance was of concern because the course material could not always be applied (sometimes this related to the rather conservative and hierarchical nature of the organisation which found it difficult to deal with innovation or change)

\subsection{Assessment context}

D:ISUBMTTLAPRREV3.WPD. 2/6/98

168. 
The London Fire Brigade has no appraisal system, hence there is no systematic review of workplace performance. The existing appraisal scheme was abandoned in 1986 on the basis that it was unduly bureaucratic and it was creating work for managers without producing positive results. The absence of systematic assessment is not unusual amongst smaller organisations but for an organisation to abandon, rather than replace, appraisal is indicative of more significant underlying cultural issues. Between 1986 and 1992 three separate attempts were made to introduce an appraisal scheme, each scheme used a different approach. All three attempts were rejected by the Director of Personnel and the Management Board. For an organisation of the size and type of the LFCDA to avoid appraisal in such consistent way is at odds with its commitment to becoming a learning organisation as there remains no coherent or consistent assessment of learning needs.

Assessment for sponsorship of training normally consists of an application and interview, rejections from staff in suitable management positions are few and the impression amongst staff and their managers is that selection is a formality. No evaluation of the learning provided has been conducted with individuals or their managers. The idea of vocational qualifications, therefore, had two clear selling points. Firstly, relevance, which was as attractive to line managers as learners. Secondly, the apparent reduction in time of work, which was of interest to senior managers and some learners. At the same time, an NVQ based programme would give the organisation some experience and understanding of the assessment process before a full scale competence system was used.

The NVQ programme utilised two of the three then existing qualifications approved by the Management Charter Initiative , M1 standards for junior managers and M2 for middle managers. The standards themselves consists of a series of specific outcomes grouped around key management activities (see Appendix $\mathbf{C}$ for summary of standards). Learners are required to provide evidence of competence against each specific outcome in the form of a portfolio. Portfolios are assessed and competence determined on the basis of written evidence. Evidence can be obtained either from current activities or prior achievement. The accreditation of prior learning APL was of particular interest to the LFCDA since it offered the opportunity for 
managers to become qualified quickly (and apparently easily) on the basis of their existing skills i.e. with relatively little effort or expense on the part of the employer. The London Fire Brigade programme was designed to encourage managers to use the APL route in preference to creating new evidence or undertaking courses. In this the Brigade was supported by the university who would undertake the assessment process and whose experience would be relied upon in relation to managing the programme. To assist the APL process and provide some internal expertise, staff within the training department were identified as coaches people who could explain the assessment process and prepare candidates but who would not actually assess evidence. The programme would commence with an explanation of the standards and the assessment process, followed by a self assessment in relation to APL evidence availability. The candidates would then accumulate and present evidence prior to assessment by the university. No further university involvement was planned and no specific plans were provided to support the candidates - this was left to the coaches and candidates as individuals to manage themselves.

\subsection{The development of the research}

Initially, as a coach, I was allocated two candidates and my role was to help them prepare for assessment. My work with these individuals suggested that the approach used by the LFCDA, particularly in relation to APL, was misguided and that insufficient consideration had been given to the candidates own needs and purposes. From working specifically with two candidates, I extended the research, under the general heading of competence research to consider other participants, five of whom feature in the case studies. Having adopted a specific supportive role initially, it was difficult to abandon this completely. Whilst my relationship to other participants varied according to their needs, my main purpose was to assist them in their development inside (where possible) but also outside the NVQ system. The primary focus was the individual candidate and, as in the assessment centre studies, the problem of contamination is inevitable. 


\subsection{The Assessor Survey}

As the issue of assessment itself gave way to broader concerns over purpose and the candidates drew away from the assessment of competence as the "be all and end all", so it became necessary to examine the assessment in more detail. The candidate perception was very partial and often influenced by specific issues (such as specific underpinning knowledge). An opportunity presented itself to work with the assessors who were keen to produce a practitioners' handbook and thus the assessor survey came about. The assessor survey is a far from remarkable piece of research, but one which made concrete a number of concerns which assessors felt able to discuss openly, having some clear communality in their views. The survey itself is of considerably less value than the subsequent discussions of role and responsibilities in relation to candidates. 


\section{Chapter 9}

\subsection{Introduction.}

The following five case studies are taken from a group of LFCDA staff enrolled on an NVQ management programme offered and supported by a local University. The case studies share a common framework which is presented in a sequential order. Some differences occur in terms of data presentation, as participants chose to engage in or withdraw from assessment activities. Wherever possible the reasons for these decisions have been explored as part of the research, and hopefully, any omissions should be explained by the case studies themselves. The programme commenced in 1994 and for some candidates is still running i.e. they have yet to submit their final portfolio of evidence. To preserve anonymity participants names have been replaced by lower case letter a to e.

\subsection{Standardised Structure of the Case Studies}

To maintain consistency the case studies are presented, as far as possible, in a single format based on the structure indicated below. This is intended to provide greater coherence for the reader but should not be interpreted as a strict chronology since some aspects of some stages notably those of development and review - took place simultaneously. The purpose of standardised presentation is to enable comparison across cases.

\subsection{Description of the Research Data}

Data is presented in a six stage process as follows:-

\subsubsection{Stage 1}

Stage 1 of the research consisted of pre NVQ sponsorship interviews. These interviews formed part of the selection process to the programme and were conducted 
by staff in the LFCDA Personnel Department. Data here is derived from interview notes and presented in summary form. Stage 1 also contains some biographical data concerning the participant's current job or role and recent service history.

\subsubsection{Stage 2}

Stage 2 was undertaken as part of induction of the induction process to the programme offered by the university. Candidates were asked to identify possible areas for the Accreditation of Prior Learning (APL) i.e. to compare their perceived competence against the standards. Data here is derived from initial schedules of competence completed by each participant as part of an induction day run by the university. Participants were asked to examine in detail the management standards and to identify those areas in which they perceived themselves as having relevant skills and experience (competence) and, within the latter, those where they could provide information as evidence to support a claim. The data here is presented in tabular form against units and elements of competence (the number of elements varies according to the MCI standards used). It is intended to indicate the extent to which competence is perceived by the participant and the evidence of competence currently available to him. This was undertaken prior to any development or assessment and was designed to identify possible sources of evidence for APL. All such tables are numbered 1 prefixed by the participant's letter for example al, bl etc. 
Sample Table NVQ s1

\begin{tabular}{|c|c|c|c|}
\hline \multicolumn{2}{|c|}{ unit/element } & \multirow{2}{*}{ competent } & \multirow{2}{*}{$\begin{array}{l}\text { evidence available for APL } \\
\text { memos to area HQ }\end{array}$} \\
\hline 1.1 & $\begin{array}{l}\text { Identify opportunities for } \\
\text { improvements in service } \\
\text { delivery }\end{array}$ & & \\
\hline 1.2 & Evaluate proposed changes & yes & \\
\hline 1.3 & $\begin{array}{l}\text { Negotiate and agree } \\
\text { introduction of change }\end{array}$ & yes & memos to area $\mathrm{HQ}$ \\
\hline 1.4 & $\begin{array}{l}\text { implement and valuate } \\
\text { change }\end{array}$ & yes & memos to area $\mathrm{HQ}$ \\
\hline 1.5 & $\begin{array}{l}\text { Introduce develop and } \\
\text { evaluate quality assurance } \\
\text { systems }\end{array}$ & yes & memos to area $\mathrm{HQ}$ \\
\hline 2.1 & $\begin{array}{l}\text { establish and maintain } \\
\text { supply of resources }\end{array}$ & yes & requisitions \\
\hline 2.2 & $\begin{array}{l}\text { establish and agree } \\
\text { customer requirements }\end{array}$ & yes & memos to area $\mathrm{HQ}$ \\
\hline
\end{tabular}

\subsubsection{Stage 3}

Stage 3 came about as a result of difficulties experienced by candidates in relating the process of evidence collection and presentation to meaningful personal development. In particular the value of the APL process as genuine development was questioned, to the extent that one participant felt that he was not achieving anything meaningful. This suggested an investigation of his own values as a manager and this was undertaken in the form of a repertory grid.

If stages 1 and 2 represent parts of the development programme as designed by the LFCDA and the university, Stage 3 represents the first piece of the specific research into learning itself. It utilises the repertory grid technique to compare the standards (i.e. required competences) to specific job components as described in table 1 and, 
using these as elements, generates personal constructs relevant to performance in the management domain. Specific units and elements of competence were compared against specific job activities (as elements within the grid) and self oriented definitions of skills or qualities were elicited. Table s2 provides an example of the initial generation process including some indication of job tasks or broader job areas in which the qualities were seen as relevant.

\section{Sample Table s2}

\begin{tabular}{|l|l|l|}
\hline positive & negative & context \\
\hline sound judgement & impressionistic & selecting staff \\
\hline supportive & too busy & staff development \\
\hline $\begin{array}{l}\text { fair and } \\
\text { reasonable }\end{array}$ & $\begin{array}{l}\text { ignorant (of people's } \\
\text { needs) }\end{array}$ & $\begin{array}{l}\text { staff development } \\
\text { work planning }\end{array}$ \\
\hline
\end{tabular}

In addition to identifying constructs an attempt was made to identify possible development needs. The constructs from table 2 were represented back to the participant and he then prioritised these in terms of personal development. This process took two forms, one comparative or broadly normative the other exclusively self referent. In the former self perceptions of performance are compared to a nominal mean - that of other participants in the programme. In the latter a simpler three point scale was introduced to encourage self analysis of need. The difference between the two approaches and the reasons for modification are explained in case study 2 participant $b$. This data is presented in tabular form and once again a standard system of numbering has been used. Table $\mathbf{3}$ provides an example of the self analysis process (in its initial form). 
Sample Table s3

\begin{tabular}{|l|c|c|l|l|}
\hline \multicolumn{1}{|c|}{ positive } & self & average & \multicolumn{1}{c|}{ negative } & \multicolumn{1}{c|}{ diff } \\
\hline sound judgement & 7 & 6 & impressionistic & +1 \\
\hline supportive & 7 & 8 & too busy & -1 \\
\hline $\begin{array}{l}\text { fair and } \\
\text { reasonable }\end{array}$ & 8 & 7 & $\begin{array}{l}\text { ignorant (of } \\
\text { people's needs) }\end{array}$ & +1 \\
\hline leadership & 7 & 6 & $\begin{array}{l}\text { avoiding the } \\
\text { problem }\end{array}$ & +1 \\
\hline in charge & 7 & 5 & too friendly & +2 \\
\hline
\end{tabular}

The purpose of this analysis was to examine in greater detail the participants' view of their own development needs and to build from the rather retrospective approach of APL to a more prospective consideration of actual developmental activities.

\subsubsection{Stage 4}

Stage 4 consisted of a more formal development plan which identifies activities in relation to a self determined framework of skills/competencies (as identified above 3). Its intention was to help generate evidence and identify areas for skills development. It seeks to specify both learning activities against required skills and to indicate possible sources of evidence. The plan matched the skills or competency identified in terms of specific developmental activities and compared sources of evidence (as a review mechanism) to potential evidence for portfolio building. The plan(s) provided the basis for further negotiation, mainly, though not exclusively, with line managers concerning development and evidence provision

Stage 4 considers actual development activities rather than simply the gathering or presentation of evidence. For participants $b, c$ and $d$ it includes 
the mapping of constructs back onto the standards to illustrate how the latter were related to skills development and the extent to which skills underpinned different units (the table is presented as part of the stage 6 for participant a since it was developed after he had withdrawn from the programme - it was not possible to undertake this task for participant $e$ ). This was done at competence unit level and designed to identify the relationship between specific competence outcomes ( as both descriptors of the management domain and learning targets within the context of the development programme) and personal constructs (as potentially more meaningful learning descriptors). This mapping process was intended to extend the analysis of competences from APL - simply gaining or applying/presenting evidence - to actually undertaking specific developmental activities. Data derived from this process is presented in a tabular form using a standardised number 4 . Table 4 allows participants to identify the strength of relationship between their own personal constructs and each unit of competence (by this stage it was felt that most participant's had a good knowledge of the competence standards and it was not therefore necessary to consider them at the more detailed level of elements) Relationships between units and constructs are expressed as $\mathbf{S}$ strong, $M$ medium and W weak. Sample Table s 4 illustrates how this process is represented.

Sample table s4

\begin{tabular}{|l|l|l|l|l|l|l|l|l|l|l|}
\hline \multicolumn{1}{|r|}{ unit } & 1 & 2 & 3 & 4 & 5 & 6 & 7 & 8 & 9 & 10 \\
\hline Quality & & & & & & & & & & \\
\hline $\begin{array}{l}\text { sound } \\
\text { judgement }\end{array}$ & $\mathrm{s}$ & & $\mathrm{m}$ & & & & & & & \\
\hline supportive & & & & & & $\mathrm{m}$ & $\mathrm{s}$ & $\mathrm{m}$ & & \\
\hline $\begin{array}{l}\text { fair and } \\
\text { reasonable }\end{array}$ & & & $\mathrm{w}$ & & & $\mathrm{s}$ & $\mathrm{s}$ & & & \\
\hline
\end{tabular}




\subsubsection{Stage 5}

Stage 5 consists of a review of learning experiences and the development plan and considers the participants own criteria for reviewing the effectiveness of learning. It is undertaken post initial assessment and thus benefits from assessment feedback. This stage is designed to provide a reflective opportunity on the process of learning (just as stages 3 and 4 considered the potential focus or content of learning). Sources of qualitative evidence are considered as is an evaluation process using personal constructs. Stage 5 also uses material derived from the formal NVQ assessment process, as this review activity corresponds to the presentation of evidence of personal development or job competence.

\subsubsection{Stage 6}

"Final" interviews (stage 6) were conducted either as a result of a formal withdrawal from the programme or after approximately two years participation (active or otherwise). The participant reviews his progress within the programme and considers the benefits provided. Continued participation or a decision to withdraw from the programme are explained. Summaries in respect of each participant are included at the conclusion of each case study. These are intended to identify aspects of the case which illustrative of key learning issues. 


\subsection{Case study 1 participant a}

Stage 1 (summary of selection interview notes)

Participant a is a substantive Assistant Divisional Officer currently serving as Station Commander at a busy central London fire station. He has over 20 years service with the London Fire Brigade, approximately ten of which are as a manager (Station Officer and $\mathrm{ADO}$ ). His previous management training consisted of short (non qualification) courses undertaken on a residential basis at the Fire Service College. He is interested in the NVQ programme as a means of extending his management skills and obtaining a formal management qualification which reflects both his current experience and seniority within the Brigade. He has no previous experience of NVQs as either candidate or assessor but is looking for a programme which can accommodate his heavy workload. He is also interested in a programme which utilises job based leaming rather than one which would require him to take time away from his very busy job. He gave several examples of job components which suggested that M2 standards would be appropriate (i.e. he has a broad range of middle managerial duties and activities)

Stage 2 (initial analysis against standards)

Participants in the development programme were presented with the appropriate MCI management standards in some detail and asked to identify activities which they currently undertook which could provide evidence. Participants were asked to review their performance against the detailed performance criteria and identify

a. Whether they met the criteria (and could be described as competent) and, if so,

b. What sources of evidence existed. 
The purpose of the activity, besides offering a detailed examination of the standards, was to assess the scope for accreditation of prior learning and, thereby, identify the need for further development to take place. 
Table al

\begin{tabular}{|c|c|c|c|}
\hline \multicolumn{2}{|c|}{ unit/element } & \multirow{2}{*}{$\frac{\text { competent }}{\text { yes }}$} & \multirow{2}{*}{$\frac{\text { evidence available for APL }}{\text { memos to area HQ }}$} \\
\hline 1.1 & $\begin{array}{l}\text { identify opportunities for } \\
\text { improvements in service delivery }\end{array}$ & & \\
\hline 1.2 & evaluate proposed changes & yes & \\
\hline 1.3 & $\begin{array}{l}\text { negotiate and agree introduction of } \\
\text { change }\end{array}$ & yes & memos to area $\mathrm{HQ}$ \\
\hline 1.4 & implement and valuate change & yes & memos to area $\mathrm{HQ}$ \\
\hline 1.5 & $\begin{array}{l}\text { Introduce develop and evaluate } \\
\text { quality assurance systems }\end{array}$ & yes & memos to area $\mathrm{HQ}$ \\
\hline 2.1 & $\begin{array}{l}\text { establish and maintain supply of } \\
\text { resources }\end{array}$ & yes & requisitions \\
\hline 2.2 & $\begin{array}{l}\text { establish and agree customer } \\
\text { requirements }\end{array}$ & yes & memos to area HQ \\
\hline 2.3 & $\begin{array}{l}\text { maintain and improve operations } \\
\text { against quality and functional } \\
\text { specifications }\end{array}$ & & \\
\hline 2.4 & $\begin{array}{l}\text { create and maintain conditions for } \\
\text { productive work activity }\end{array}$ & & \\
\hline 3.1 & control costs and enhance value & yes & station financial records \\
\hline 3.2 & $\begin{array}{l}\text { monitor and control activities } \\
\text { against budgets }\end{array}$ & yes & station financial records \\
\hline 4.1 & justify proposals for expenditure & yes & memos to area $\mathrm{HQ}$ \\
\hline 4.2 & negotiate and agree budgets & yes & memos to area $\mathrm{HQ}$ \\
\hline 5.1 & $\begin{array}{l}\text { define future personnel } \\
\text { requirements }\end{array}$ & & \\
\hline 5.2 & $\begin{array}{l}\text { determine specifications to secure } \\
\text { quality people }\end{array}$ & yes & interview records \\
\hline 5.3 & $\begin{array}{l}\text { assess and select candidates against } \\
\text { team and organisational } \\
\text { requirements }\end{array}$ & yes & interview records \\
\hline 6.1 & develop and improve teams & yes & notes of meetings \\
\hline
\end{tabular}




\begin{tabular}{|c|c|c|c|}
\hline 6.2 & $\begin{array}{l}\text { identify review and improve } \\
\text { development activities for } \\
\text { individuals }\end{array}$ & yes & $\begin{array}{l}\text { support to people doing } \\
\text { statutory exams }\end{array}$ \\
\hline 6.3 & develop oneself within job role & yes & attending courses \\
\hline 6.4 & $\begin{array}{l}\text { evaluate and improve } \\
\text { developmental processes }\end{array}$ & & \\
\hline 7.1 & set and update work objectives & yes & station routines \\
\hline 7.2 & $\begin{array}{l}\text { plan activities and determine work } \\
\text { methods }\end{array}$ & yes & station routines \\
\hline 7.3 & $\begin{array}{l}\text { allocate work and evaluate teams } \\
\text { individuals and self against } \\
\text { objectives }\end{array}$ & yes & station routines \\
\hline 7.4 & $\begin{array}{l}\text { provide feedback to teams and } \\
\text { individuals }\end{array}$ & yes & station routines \\
\hline 8.1 & $\begin{array}{l}\text { establish and maintain trust and } \\
\text { support of subordinates }\end{array}$ & yes & \\
\hline 8.2 & $\begin{array}{l}\text { establish and maintain trust and } \\
\text { support of ones manager }\end{array}$ & yes & \\
\hline 8.3 & $\begin{array}{l}\text { establish and maintain relationships } \\
\text { with colleagues }\end{array}$ & yes & \\
\hline 8.4 & $\begin{array}{l}\text { identify and minimise interpersonal } \\
\text { conflict }\end{array}$ & yes & \\
\hline 8.5 & $\begin{array}{l}\text { implement disciplinary and } \\
\text { grievance procedures }\end{array}$ & yes & \\
\hline 8.6 & counsel staff & yes & \\
\hline 9.1 & $\begin{array}{l}\text { obtain and evaluate information to } \\
\text { aid decision making }\end{array}$ & yes & memos to area $\mathrm{HQ}$ \\
\hline 9.2 & $\begin{array}{l}\text { forecast trends and developments } \\
\text { which affect objectives }\end{array}$ & not yet & \\
\hline 9.3 & record and store information & yes & station records \\
\hline 10.1 & $\begin{array}{l}\text { lead meetings and group } \\
\text { discussions }\end{array}$ & yes & \\
\hline
\end{tabular}




\begin{tabular}{|ll|l|l|}
\hline 10.2 & $\begin{array}{l}\text { contribute to discussions to solve } \\
\text { problems and make decisions }\end{array}$ & yes & $\begin{array}{l}\text { area meetings } \\
\text { ops meetings }\end{array}$ \\
\hline $10.3 \quad$ advise and inform others & yes & memos to area HQ \\
\hline
\end{tabular}

Participant a's schedule suggested considerable scope for APL and on the basis of this analysis he was advised to consider making a submission of evidence for Unit 7 . Participant a agreed and began to assemble a portfolio for this purpose. Of all the participants present at the induction, Participant a seemed to have by far the greatest experience of management and appeared to have the least to undertake in terms of creating new evidence. At the time it was suggested to him by staff from the university that he might be able to obtain as much as $75 \%$ of the NVQ qualification on the basis of APL alone.

\section{Stage 3}

The stage 3 process or intervention came about directly as a result of problems identified by participant $a$ in the creation of a portfolio. The intervention was initially intended to assist participant $a$ in the identification of appropriate performance but reconfigured to assist in the identification of relevant underlying skills. The problem which presented itself was that of understanding and applying the standards to a particular job or role. As a result of this it was not clear to the participant as to where appropriate evidence could be located. On the basis of the units being considered and a previous job analysis of the role, I was able to locate a number of potential sources of evidence i.e. as a result of my expert knowledge of the generic Station Commander role and the associated administrative procedures I was able to identify a number of documentary sources which could yield evidence.

It soon became obvious that the problem was more than one of recognition (although this no doubt played a role) and that other factors were involved - most importantly a 
lack of conviction that the process of evidence gathering (and thus of APL and potentially the NVQ qualification itself) was of any real benefit.

Designing the process.

In examining the underlying causes of the problem it became clear that one avenue available could be the exploration or re-exploration of participant a's purpose in undertaking the qualification. In SOL terms this would have involved an examination of the significance of the qualification to participant a and any associated motives before moving on to consider the strategy being recommended. To the extent that participant a had already committed considerable time and effort to the creation of a portfolio I judged this to be a possibly retrogressive step. Rather than examine the broader considerations regarding participant a's choice of the NVQ programme, I offered the suggestion of investigating the skills which participant a thought might be relevant to the different units, how they might relate to his current job and, implicitly, how these could be developed to participant a's benefit.

The technique chosen was that of the repertory grid. The elements to generate the grid were provided by both NVQ elements of competence and distinct job activities and the constructs thus generated provided participant a's definitions of relevant skills or qualities. I have found the grid methodology useful in this context as a means of eliciting definitions of qualities for designing training or assessment activities, however, it can be rather cumbersome and time consuming. Rather than use the full method, a shortened version was adopted in which a restricted form of the card sort technique was used followed by a comparison between participant $a$ and the average performance of his peers (i.e. not a full analysis of al the individual referents). The purpose of this customisation was to help participant a to identify areas of self perceived strengths and potential weaknesses which could act as an indicator of developmental priorities. Because the skills were linked to both activities and NVQ units and elements it was also possible to identify potential activities in respect of 
skills and possible sources of evidence.

Table a2 construct grid

\begin{tabular}{|l|l|l|l|}
\hline & positive & negative & context \\
\hline a & sound judgement & impressionistic & selecting staff \\
\hline b & supportive & too busy & staff development \\
\hline c & fair and reasonable & $\begin{array}{l}\text { ignorant (of people's } \\
\text { needs) }\end{array}$ & $\begin{array}{l}\text { staff development } \\
\text { work planning }\end{array}$ \\
\hline d & leadership & avoiding the problem & $\begin{array}{l}\text { counselling } \\
\text { planning }\end{array}$ \\
\hline e & in charge & too friendly & $\begin{array}{l}\text { managing people } \\
\text { discipline and grievance }\end{array}$ \\
\hline f & active & passive & contributes to meetings \\
\hline g & station based & area based & $\begin{array}{l}\text { service improvement } \\
\text { budget control }\end{array}$ \\
\hline h & sets own standards & no standards & assesses performance \\
\hline I & encourages & shouts and screams & developing others \\
\hline j & practical & academic & managing others \\
\hline
\end{tabular}

The grid elicited constructs using different units of competence compared to different job activities. Constructs were not identified by title but simply by poles. The third column indicates those job areas in which the construct was most likely to be manifest. Constructs were then presented back to the participant and he was asked to compare his current performance to his perceptions of a peer group (i.e. to identify strengths and potential weaknesses or areas for development) in relation to a nominal referent group. Table a 3 was designed to highlight strengths and weaknesses using participant a's own construct system. 
Table a3 self assessment grid

\begin{tabular}{|l|c|c|l|l|}
\hline \multicolumn{1}{|c|}{ positive } & self & average & \multicolumn{1}{c|}{ negative } & \multicolumn{1}{c|}{ diff } \\
\hline sound judgement & 7 & 6 & impressionistic & +1 \\
\hline supportive & 7 & 8 & too busy & -1 \\
\hline fair and reasonable & 8 & 7 & $\begin{array}{l}\text { ignorant (of people's } \\
\text { needs) }\end{array}$ & +1 \\
\hline leadership & 7 & 6 & $\begin{array}{l}\text { avoiding the } \\
\text { problem }\end{array}$ & +1 \\
\hline in charge & 7 & 5 & too friendly & +2 \\
\hline active & 8 & 6 & passive & +2 \\
\hline station based & 7 & 6 & area based & +1 \\
\hline sets own standards & 7 & 6 & no standards & +1 \\
\hline encourages & 7 & 7 & shouts and screams & 0 \\
\hline practical & 7 & 7 & academic & 0 \\
\hline
\end{tabular}

The first construct grid provides an indication of participant a's own reference or assessment system and links his constructs to the appropriate job component or NVQ unit/element - its prima facie purpose was to examine sources of evidence for NVQ assessment. The second schedule utilises the constructs for self assessment (in relation to the mean of a peer group). Discussions on the latter suggested that there were few areas of exceptional need and participant a was asked to consider the significance of these criteria and self assessments for his own development.

\section{Stage 4}

The self assessment generated in stage 3 had been written up as in the format of the above schedule and was re-presented to participant a as a means of identifying specific personal development needs. The generally positive nature of the self assessment reflected participant a's view of his own experience and the extent to 
which his development needs had already been met. In terms of future development, it suggested that the participant was generally satisfied with his own abilities, particularly since he expressed bo interest in promotion.

The area of standard setting was discussed in general and in its particular relation to NVQs. Participant a saw himself as someone who sets standards by example and more specific encouragement. He contrasted his own approach, which could be directive, with those of colleagues, who tended to let watches manage themselves. He felt that watches and watch officers still needed direction and setting standards by example was a key part of his role. At the same time, he often found himself too busy to deal with some of the people issues presented to him and particularly mentioned his frustration at not being able to spend enough time developing his junior officers.

The development plan was therefore designed to explore the issue of staff development and looked towards providing a more structured approach to this issue (which could be used at fire stations generally). Maintaining records of staff development would contribute evidence towards unit 7 managing and developing people and also unit 6, managing the team.

The plan consisted of three steps or stages which were to be pursued with each of the three junior officer on each watch (a total of 12 individual development plans) with the watch officers taking personal responsibility for delivering development and monitoring officers on their own individual watch.

Phase 1 Reviewing current learning objectives and identifying needs through appraisal and discussion

Phase 2 Developing activities to meet objectives with line manager support and external training events where appropriate 


\section{Phase 3}

Reviewing progress against objectives and providing feedback to staff on their development and progress

At the same time it was agreed that participant a would identify some means of evaluating the quality of his own learning. This took two forms, firstly criteria for assessing the success of the activity as a contribution to the management of his station and secondly criteria against which he could assess his own self development. For the first review the participant was keen to look at the level of staff involvement in development, his own participation in terms of more time and greater coherence and also more control over officer development. For his own development he identified greater personal confidence in handling development issues (based on a broader range of techniques available for developing and monitoring staff) together with a better understanding of how individuals learned.

Evidence against NVQ units would be derived from individual development plans, review sessions and meetings with watch commanders. It would take the form of naturally occurring product and witness testimony, together with a personal account explaining the plans and their use on the station.

\section{Stage 5}

My initial intention in creating stage 5 was to allow participants to review their own development following assessment by the university. It was intended primarily as part of a participant-based evaluation of the NVQ programme building on the criteria they had developed as part of stage 4 (the development plan).

Participant a was generally satisfied with the outcome of the process he had initiated. All but three junior officers had created and reviewed personal development plans in accordance with their needs. Although the consideration of possible learning activities was rather limited, and course-focused, he felt that the approach had considerable 
benefits in encouraging personal responsibility for learning. Participant a expressed some disappointment at not being able to motivate the remaining three officers who he described as people who didn't want promotion or development. Generally, development and promotion were linked and he found most of the plans referred specifically to either statutory exams or preparation for specific aspects of further promotion. He was satisfied with the assessment process introduced and had tried to express the outcomes of the activity in terms of team building. He was less convinced that he had actually learned anything significant. The skills used were already in his possession and, whilst he could point to tangible work improvements, he could not identify any new or additional knowledge or techniques which had been used.

The contrast between job success and personal achievement is probably the most significant aspect of this stage. Although the experience of assessment cannot be seen particularly positively, the question of underpinning knowledge served to emphasise and perhaps bring into focus a distinction already present in the participant's mind. From the point of view of improving effectiveness or performance the development plan could only be viewed as a success. Similarly in terms of generating product evidence for units and elements of competence the process proved valuable (if rather time consuming). From a personal view however this success was limited. The activities in themselves lead to a better understanding of individual officers at the station but failed to provide any general principles which could be applied to others. The range of techniques derived for staff development were limited to those already in existence and, in terms of new knowledge, relatively little was identified. An attempt by the external assessor to identify underpinning knowledge, either gained or previously available, therefore faltered as the participant considered that no new knowledge had been developed or acquired. The experience or impact of the assessment process itself is considered in more detail in stage 6 (below), in terms of reviewing the learning plan, however, the assessment undertaken served to reinforce the distinctions between knowledge acquisition and outcome oriented measures of competence. For participant a the absence of the former represented a significant 
limitation of the process despite evidence gained (and confirmed) for the latter.

Stage 6

Perhaps the most difficult aspect of any development programme comes when the learner decides to withdraw. In many cases this is considered as a failure either of the candidate (often attributed to a lack of motivation) or of the programme (sometimes explained in terms of lack of direct relevance). In the case of participant a the decision to withdraw from the NVQ programme can be seen as a success of the research programme, in as much as, it can be attributed to a review of the participant's motivation and of the relevance of the programme. This lead to a recognition of what was needed on the part of the learner, what the programme provided and what could be achieved (or indeed had been achieved) within, and to some extent despite, the latter. Participant a had joined the programme to achieve some recognition for his own skills and experience, his formal needs in terms of management development were very limited and, by his own admission, academic study was not of interest to him. The development programme seemed to offer a quick and relatively simple way for his existing skills to be recognised.

In truth, however, the process required to demonstrate competence in NVQ terms offered only a very cumbersome and time intensive route to satisfying participant a's aims. The development of the construct grid, on the other hand, provided a simple and easy to use mechanism by which the development programme on offer could be evaluated. The decision to withdraw from the programme can be linked to aspects of the grids (particularly those related to the negative construct of academic) but also the distinction made between competence or a satisfactory level of (or personal satisfaction with) job performance and the collection and presentation of evidence of competence.

The decision to withdraw from the programme was not taken lightly, and a number of 
factors within the NVQ system and the approach taken by the LFCDA were highlighted as contributing to the outcome :-

The general problem of portfolio building was discussed in the context of relevance and of time spent. Participant a felt that the programme, particularly the APL element, had over emphasised the portfolio at the expense of genuine development. Because the portfolio represented a key component in the means by which competence would be assessed too much time had been spent acquiring skills on building a portfolio of evidence which was actually of very little use in his job. This criticism of the programme in general also related to the specific contents of his own portfolio. The time spent in collecting or generating materials, and subsequently organising them, was out of proportion to any time he had spent in considering the evidence or reflecting on his own performance. Whilst this could be taken as a criticism of the participant, he felt that the programme and the advisers from the university had concentrated on the administrative tasks associated with portfolio building and failed to encourage reflection. The time spent in the former activity had in many instances prevented anything other than a cursory review, to ensure that the evidence presented was linked to the performance criteria to be assessed. The issue of cross referencing was also identified as administratively cumbersome. Although the participant recognised that the nature of managerial work often operated across different units and elements, he felt that the cross referencing process tended to reinforce the structure of the units and elements within the standards, rather than the complexity of managerial work. (See below on standards)

The issue of underpinning knowledge was considered in the context of a practical and academic approach to learning. The advice provided by the university in terms of underpinning knowledge related to specific pieces of seemingly appropriate literature. Apart from the problem that the literature and "knowledge" suggested was actually inappropriate to the context, the participant expressed concern that the knowing which enabled him to fulfil the desired outcomes was not in a form normally recognised as 
knowledge in either an academic or organisational sense. Not only was his ability to perform underpinned by something that hadn't formed part of the conventional knowledge required by a taught Diploma in Management Studies (the source most used by the university). The knowledge he used was essentially tacit and implied. Not only had it not been referenced, it had not even been written down. By knowledge the NVQ system seemed to be suggesting something that was formally recorded, which could be referenced, and, by extension, tested. For participant a, knowledge was something he knew about which was seldom part of the academic field of management studies and often something that his understanding allowed him to predict on the basis of experience. His knowledge was practical and purposeful rather than organisational or academic. It served the purpose of enabling him to manage effectively and for this purpose it required no written expression. Not only did the NVQ system prefer written knowledge, it also seemed to prefer it to be in a form approved by writers on the subject of management. Since the participant was a practitioner, he saw little need to write down that which he already knew and even less to learn about things which were, in his view, completely irrelevant to his management context.

The status of assessors was examined in relation to recognition of competence and the potential uniqueness (or peculiarity) of the LFCDA. The use of external (academic) assessors was seen as problematic for two reasons. Firstly, the assessors were not fully aware of the context within which management took place and were therefore unaware of the reasons why evidence was put forward in certain ways. This had the result that the participant often found it necessary to explain the entire Brigade and its management procedures before he could provide evidence of competence for his role within it. To some extent this can be seen as a problem of contextual knowledge, the possession of which should have enabled assessors to consider evidence without detailed explanation. On the other hand, the way in which the standards themselves and the related assessment operate, suggests that the task of creating contextual understanding is part of the responsibility of the candidate. Should this task continue 
to be a part of the candidate's responsibilities within the assessment process some consideration may need to be given to allowing or encouraging the candidate to review or at least question organisational practice.

The standards themselves were reviewed as a tool for management learning. Participant a had no problem with the use of the management standards as indicators of performance and felt that they could be applied to a range of jobs within the Brigade. At the same time their use to assess performance would be limited by the assessment process (and the time required). There were clearly areas not covered adequately by the standards. He was also concerned that the adoption of a formal system requiring formal evidence overlooked the existence of an effective informal system which produced no paper records but which resulted in competent performance. This formality which, at first sight, would appeal to a formal bureaucratic organisation, such as a Fire Brigade, contrasted with a number of work activities in which the informal, and hence unofficial, systems operated. Key elements of competence, such as those relating to staff selection, were undertaken through both informal and formal means, the results of the formal methods being less significant to the day to day management of fire stations. Managers using the informal system were prevented from demonstrating competence externally, since to do so would reveal to scrutiny an effective but unrecognised system of contacts and perceptions. On the other hand, a learner seeking to demonstrate competence using the formal system would not be able to fully explain how certain aspects of staff were adequately assessed. This formality, expressed in the standards and the assessment process, is a direct product of the system of NVQs themselves and derives for the idea that formal systems can and do operate more effectively than informal approaches. This in turn derives from a model of management and implicitly of organisations themselves which is formal, bureaucratic and highly structured. Not only is such a model at odds with contemporary management theory, but also with the vast body of organisational behaviour literature which demonstrates the importance of informal systems, networks and values. 
Finally the approach used by the standards were described as piecemeal, in as much as they served to divide or disect management activities into manageable chunks. In reality management tasks and activities did not neatly fit into such discrete categories and the participant voiced the suspicion that the way in which the different components had been described was more to do with the assessment process, and hence for the benefit of assessors, than for the benefit of actual managers. When asked to compare the standards against his own constructs participant a found very few significant relationships. Table a4 below represents this lack of relevance.

Table a4 constructs against NVQ units

\begin{tabular}{|l|l|l|l|l|l|l|l|l|l|l|}
\hline \multicolumn{1}{|r|}{ unit } & l & 2 & 3 & 4 & 5 & 6 & 7 & 8 & 9 & 10 \\
\hline Quality & & & & & & & & & & \\
\hline a & s & & m & & & & & & & \\
\hline b & & & & & & $\mathrm{m}$ & $\mathrm{s}$ & $\mathrm{m}$ & & \\
\hline $\mathrm{c}$ & & & $\mathrm{w}$ & & & $\mathrm{s}$ & $\mathrm{s}$ & & & \\
\hline $\mathrm{d}$ & & & & & & $\mathrm{m}$ & $\mathrm{m}$ & $\mathrm{m}$ & & \\
\hline $\mathrm{e}$ & & & & & & & $\mathrm{m}$ & & & \\
\hline $\mathrm{f}$ & $\mathrm{w}$ & & & & & & & & & \\
\hline $\mathrm{g}$ & $\mathrm{w}$ & & & & & & & & & \\
\hline h & w & & & & & & & & & \\
\hline I & & & & & & & $\mathrm{w}$ & & & \\
\hline j & & & & & & & & & & \\
\hline
\end{tabular}

The table above was generated after the participant had withdrawn from the programme and serves to focus attention one the issue of relevance. As indicated above the relationship between personal constructs (as personally valid descriptors of the management domain) and units of competence (as publicly available descriptions) was very limited. In other, subsequent, cases this instrument was administered before 
selecting development options. In this particular case the administration of the instrument after withdrawal seems to confirm the participant's dissatisfactions with the specific NVQ units as they applied to him as an individual.

There would seem to be a number of related, but quite separate, skills required of candidates which are not fully reflected in the management standards themselves. These include the creation of portfolios (the assembly and presentation of evidence) the ability to review organisational practice and, almost coincidentally, some ability to reflect on personal achievement. In short these are the learning skills required of, but never quite expressed in, NVQs. 


\subsection{Case study 2 Participant b}

Participant $b$ is a substantive day duty Assistant Divisional Officer currently serving as Station Commander at a busy central London fire station. He has approximately 20 years service with the London Fire Brigade, just over three of which are as a manager (he was promoted from Station Officer to day duty ADO in the Fire Safety section and was at the time of interview temporarily posted to the role of Station Commander). His previous management training consisted of short (non qualification) courses undertaken on a residential basis at the Fire Service College. He is interested in the NVQ programme as a means of developing his management skills and obtaining a formal management qualification which will reflects his seniority within the Brigade. He has no previous experience of NVQs as either candidate or assessor but is looking for a programme which can provide access to nationally recognised qualifications. He is aware that the programme utilises job based learning rather than formal course attendance. He expressed no preference for NVQs over other methods of development, except to indicate that the former seemed to be indicative of future trends within the Authority and that, as such, he was happy to be part of the pilot programme. He gave several examples of job components which suggested that M2 standards would be appropriate (i.e. he has a broad range of middle managerial duties and activities) but was unable to provide clear indication of how they would be of use to him in his present role.

\section{Stage 2}

Participants in the development programme were presented with the appropriate MCI management standards in some detail and asked to identify activities which they currently undertook which could provide evidence. Participants were asked to review their performance against the detailed performance criteria and identify

a. Whether they met the criteria (and could be described as competent) and, if so, 
b. What sources of evidence existed.

The purpose of the activity, besides offering a detailed examination of the standards was to assess the scope for accreditation of prior learning and, thereby identify the need for further development to take place

Table bl (initial analysis against standards)

\begin{tabular}{|c|c|c|c|}
\hline \multicolumn{2}{|c|}{ unit/element } & \multirow{2}{*}{$\begin{array}{l}\text { competent } \\
\text { or not yet } \\
\text { competent }\end{array}$} & \multirow{2}{*}{$\begin{array}{l}\text { evidence available for APL } \\
\text { Meetings with Group } \\
\text { Divisional Officer }\end{array}$} \\
\hline & $\begin{array}{l}\text { identify opportunities for } \\
\text { improvements in service delivery }\end{array}$ & & \\
\hline 1.2 & evaluate proposed changes & yes & $\begin{array}{l}\text { Note to Group Divisional } \\
\text { Officer }\end{array}$ \\
\hline 1.3 & $\begin{array}{l}\text { negotiate and agree introduction of } \\
\text { change }\end{array}$ & yes & Meetings with watch officers \\
\hline 1.4 & implement and evaluate change & yes & \\
\hline & $\begin{array}{l}\text { Introduce develop and evaluate } \\
\text { quality assurance systems }\end{array}$ & yes & $\begin{array}{l}\text { Meetings with Group } \\
\text { Divisional Officer }\end{array}$ \\
\hline & $\begin{array}{l}\text { establish and maintain supply of } \\
\text { resources }\end{array}$ & yes & \\
\hline 2.2 & $\begin{array}{l}\text { establish and agree customer } \\
\text { requirements }\end{array}$ & yes & $\begin{array}{l}\text { Meetings with Group } \\
\text { Divisional Officer }\end{array}$ \\
\hline & $\begin{array}{l}\text { maintain and improve operations } \\
\text { against quality and functional } \\
\text { specifications }\end{array}$ & & $\begin{array}{l}\text { Meetings with Group } \\
\text { Divisional Officer }\end{array}$ \\
\hline & $\begin{array}{l}\text { create and maintain conditions for } \\
\text { productive work activity }\end{array}$ & & Meetings with watch \\
\hline & control costs and enhance value & yes & Finance returns \\
\hline & $\begin{array}{l}\text { monitor and control activities } \\
\text { against budgets }\end{array}$ & yes & Finance returns \\
\hline 4.1 & justify proposals for expenditure & yes & $\begin{array}{l}\text { Meetings with Group } \\
\text { Divisional Officer }\end{array}$ \\
\hline
\end{tabular}




\begin{tabular}{|c|c|c|c|}
\hline 4.2 & negotiate and agree budgets & yes & $\begin{array}{l}\text { Meetings with Group } \\
\text { Divisional Officer }\end{array}$ \\
\hline 5.1 & $\begin{array}{l}\text { define future personnel } \\
\text { requirements }\end{array}$ & & $\begin{array}{l}\text { discussions with area } \\
\text { personnel and staff office }\end{array}$ \\
\hline 5.2 & $\begin{array}{l}\text { determine specifications to secure } \\
\text { quality people }\end{array}$ & yes & $\begin{array}{l}\text { discussions with area } \\
\text { personnel and staff office }\end{array}$ \\
\hline 5.3 & $\begin{array}{l}\text { assess and select candidates against } \\
\text { team and organisational } \\
\text { requirements }\end{array}$ & yes & interviews \\
\hline 6.1 & develop and improve teams & not yet & \\
\hline 6.2 & $\begin{array}{l}\text { identify review and improve } \\
\text { development activities for } \\
\text { individuals }\end{array}$ & not yet & \\
\hline 6.3 & develop oneself within job role & not yet & \\
\hline 6.4 & $\begin{array}{l}\text { evaluate and improve } \\
\text { developmental processes }\end{array}$ & not yet & \\
\hline 7.1 & set and update work objectives & yes & station work routines \\
\hline 7.2 & $\begin{array}{l}\text { plan activities and determine work } \\
\text { methods }\end{array}$ & yes & station work routines \\
\hline 7.3 & $\begin{array}{l}\text { allocate work and evaluate teams } \\
\text { individuals and self against } \\
\text { objectives }\end{array}$ & yes & station work routines \\
\hline 7.4 & $\begin{array}{l}\text { provide feedback to teams and } \\
\text { individuals }\end{array}$ & not yet & \\
\hline 8.1 & $\begin{array}{l}\text { establish and maintain trust and } \\
\text { support of subordinates }\end{array}$ & not yet & Meetings with watch Officers \\
\hline 8.2 & $\begin{array}{l}\text { establish and maintain trust and } \\
\text { support of ones manager }\end{array}$ & yes & $\begin{array}{l}\text { Meetings with Group } \\
\text { Divisional Officer }\end{array}$ \\
\hline 8.3 & $\begin{array}{l}\text { establish and maintain relationships } \\
\text { with colleagues }\end{array}$ & yes & $\begin{array}{l}\text { Area station commander } \\
\text { meetings }\end{array}$ \\
\hline 8.4 & $\begin{array}{l}\text { identify and minimise interpersonal } \\
\text { conflict }\end{array}$ & yes & station meetings \\
\hline 8.5 & $\begin{array}{l}\text { implement disciplinary and } \\
\text { grievance procedures }\end{array}$ & yes & case records \\
\hline
\end{tabular}




\begin{tabular}{|ll|l|l|}
\hline $8.6 \quad$ counsel staff & yes & no written records kept \\
\hline $9.1 \quad \begin{array}{l}\text { obtain and evaluate information to } \\
\text { aid decision making }\end{array}$ & yes & $\begin{array}{l}\text { Meetings with Group } \\
\text { Divisional Officer }\end{array}$ \\
\hline $9.2 \quad \begin{array}{l}\text { forecast trends and developments } \\
\text { which affect objectives }\end{array}$ & yes & $\begin{array}{l}\text { Meetings with Group } \\
\text { Divisional Officer }\end{array}$ \\
\hline $9.3 \quad$ record and store information & yes & station filing system \\
\hline $10.1 \quad \begin{array}{l}\text { lead meetings and group } \\
\text { discussions }\end{array}$ & yes & Meetings with watch Officers \\
\hline $10.2 \quad \begin{array}{l}\text { contribute to discussions to solve } \\
\text { problems and make decisions }\end{array}$ & yes & $\begin{array}{l}\text { Meetings with Group } \\
\text { Divisional Officer }\end{array}$ \\
\hline $10.3 \quad$ advise and inform others & yes & Meetings with watch Officers \\
\hline
\end{tabular}

Participant b's schedule suggested some scope for APL. On the basis of this analysis he was advised to consider making a submission of evidence for Unit 7 using station routines as a basis for evidence. $b$ agreed and began to assemble a portfolio for this purpose. Participant b's experience seemed to be equivalent to, or typical of , most of the pilot group. The division of his workload between evidence collection and personal development seemed equally shared. Although there were current job activities which he could identify which would provide evidence, there were also areas in which he expressed an interest in undertaking more specific developmental activities. At the time it was suggested to him by university staff that he might be able to obtain as much as $50 \%$ of the NVQ qualification on the basis of APL and the remainder through guided development (mostly in his current role).

\section{Stage 3}

Stage 3 or the derivation of personal constructs came about as a result of participant b's general dissatisfaction with APL. Although evidence was available for some 
elements and against most performance criteria, some gaps still existed - mostly in relation to providing feedback to staff. At the same time, the process of developing a portfolio, extracting evidence and listing its relationship to criteria seemed unduly bureaucratic. Participant b was keen to examine his own development rather than simply reproduce material already in existence at the station.

The idea of a personal development plan was of interest to him and, in order to focus on his own personal development a reduced form of the repertory grid was administered.

Table b2

\begin{tabular}{|c|c|c|}
\hline quality & positive & negative \\
\hline cooperation & works with people & imposes things on people \\
\hline responsibility & gets things done & $\begin{array}{l}\text { blames others when things } \\
\text { go wrong }\end{array}$ \\
\hline independence 1 & knows own mind & $\begin{array}{l}\text { gets told what to do (and } \\
\text { always does it) }\end{array}$ \\
\hline independence 2 & takes initiative & works for others \\
\hline friendly or approachable & $\begin{array}{c}\text { discusses issues and } \\
\text { problems }\end{array}$ & confronts people \\
\hline independence 3 & sets realistic objectives & $\begin{array}{l}\text { relies on brigade rules and } \\
\text { systems }\end{array}$ \\
\hline
\end{tabular}

The grid suggested a tendency to value cooperation rather than confrontation with development needs located in the areas of proactivity, objective setting and achievement. Examining development needs was attempted using a peer group mean as an indicator (see case study 1 for details of this approach). However participant b found this approach unhelpful, since his knowledge of his peers was considerably less accurate than that he felt he had of himself. Consequently, the assessment of needs was undertaken on the basis of within person comparison of different needs based on 
constructs. The resulting table (b3) presents the results of this form of a needs analysis for this participant.

Table b3

\begin{tabular}{|c|c|c|c|}
\hline quality & positive & $\begin{array}{c}\text { self development } \\
\text { needs }\end{array}$ & negative \\
\hline cooperation & works with people & low & $\begin{array}{c}\text { imposes things on } \\
\text { people }\end{array}$ \\
\hline responsibility & gets things done & medium & $\begin{array}{c}\text { blames others when } \\
\text { things go wrong }\end{array}$ \\
\hline independence 1 & knows own mind & very low & $\begin{array}{c}\text { gets told what to do } \\
\text { (and always does it) }\end{array}$ \\
\hline independence 2 & takes initiative & medium & works for others \\
\hline $\begin{array}{c}\text { friendly or } \\
\text { approachable }\end{array}$ & $\begin{array}{c}\text { discusses issues and } \\
\text { problems }\end{array}$ & low & confronts people \\
\hline independence 3 & $\begin{array}{c}\text { sets realistic } \\
\text { objectives }\end{array}$ & medium & $\begin{array}{c}\text { relies on brigade } \\
\text { rules and systems }\end{array}$ \\
\hline
\end{tabular}

\section{Stage 4}

Having identified a system of personally relevant skills or qualities the next step was to identify how these could be related to the units of competence. This process was intended to examine how meeting development needs could also provide evidence for competence. The table below compares personal constructs to units and indicates the strength of the relationship. $S$ indicates a strong relationship as perceived by the participant, W a weak relationship, $\mathrm{m}$ a medium relationship and finally blank cells indicate no meaningful relationship. 
table b4

\begin{tabular}{|c|c|c|c|c|c|c|c|c|c|c|}
\hline unit & 1 & 2 & 3 & 4 & 5 & 6 & 7 & 8 & 9 & 10 \\
\hline quality & & & & & & & & & & \\
\hline cooperation & & & & & & $s$ & $\mathrm{~m}$ & $\mathrm{~s}$ & & \\
\hline responsibility & & & & & & $\mathrm{s}$ & $\mathrm{s}$ & $\mathrm{s}$ & & \\
\hline independence 1 & & & & & $\mathrm{s}$ & & & & & \\
\hline independence 2 & $\mathrm{s}$ & & & & & & & & & \\
\hline $\begin{array}{r}\text { friendly or } \\
\text { approachable }\end{array}$ & & & & & & $\mathrm{s}$ & & $\mathrm{s}$ & & \\
\hline $\begin{array}{r}\text { independence 3 } \\
\hline\end{array}$
\end{tabular}

The table enabled the participant to consider his perceived development needs within the framework of the available NVQ units thereby indicating both a context for development and, through the use of the specific performance criteria, the nature of the evidence to be collected. The identification of staff development or unit 6 as a context for self development was made on the basis of the above table and was to lead to a further extension of the system of constructs as participants $b$ and $c$ embarked on a process of joint development. Details of the joint development process are outlined in the next case study.

\section{Stage 5}

The decision to share constructs and development proposals described in case study c enabled both participants to reflect on their own development needs in relation to their respective roles. Although having common responsibilities and similar backgrounds, the construct systems were sufficiently different to encourage a broader and more detailed discussion of what constituted effective performance. Through this there emerged differences between their commonly understood positions and that of the organisation itself. As well as enabling the two participants to provide evidence about 
each other's development, the shared approach also created an alternative model of performance. Categories such as independence were mutually valued and set against a more prescriptive view which appeared to underpin both the organisation's view and to a lesser extent the system of NVQ units. Although the latter allowed greater breadth, both participant $b$ felt that it still offered a rather narrow and bureaucratic method of development.

This was reinforced by participant b's experience of the process of assessment. Evidence, having been collected and presented, was discussed in isolation from the person whose development it represented. Underpinning knowledge was considered as a purely impartial or objective set of principles derived from either literature or previous formal learning. Participant b's experiences in relation to providing training, his own feelings about the process and his concerns were thus relegated to the margin's whilst the assessor discussed the formal process of learning or course design.

\section{Stage 6}

The programme provided participant $b$ with a useful framework within which to structure his own development. Although bureaucratic and time consuming, it offered the opportunity to submit real work as evidence of competence. Personal development could be undertaken as part of his current job and the outcomes submitted as part of gaining a recognised qualification. At the same time, the system was not in itself developmental, and evidence could be produced from existing systems or activities without any real reflection. His early experience of APL, or preparing for APL, was not positive and he felt that this approach could be counter productive. Thus, whilst his view of the standards was supportive, his view of the programme, as initially designed, was that it offered far more than it actually delivered. His experience of assessment was that this tended to replicate the more mechanical aspects of the NVQ system and was heavily reliant upon the evidence presented in the portfolio. 


\subsection{Case study 3 participant c}

Stage 1

At the time of his application Participant c was a substantive Assistant Divisional Officer commanding a small station in South East London. He had previously worked as part of a specialist time in the Fire Safety Department and his recent move had come about as a result of a restructuring in which the work of his team was devolved to fire stations. Participant $\mathrm{c}$ felt that his professional expertise had not been fully recognised by the Brigade and was dismayed that, having spent considerable time acquiring specialist skills, the job he had performed ceased to exist. He felt that the level of expertise available to station personnel was very limited and, despite his involvement in the design of their training, that the result would be a poorer less professional service (and potentially a more dangerous for the people of London). He saw a management qualification as something which would be recognised and supported by the Brigade and as relevant to his new managerial position. The idea of individual study appealed to him, as he had recently completed an Open University degree course. Although NVQs were not familiar to him he considered the approach, involving APL, as more suitable to someone of his experience.

Stage 2

Participants in the development programme were presented with the appropriate MCI management standards in some detail and asked to identify activities which they currently undertook which could provide evidence. Participants were asked to review their performance against the detailed performance criteria and identify

a. Whether they met the criteria (and could be described as competent) and, if so,

b. What sources of evidence existed. 
The purpose of the activity, besides offering a detailed examination of the standards was to assess the scope for accreditation of prior learning and, thereby identify the need for further development to take place

Table c1

\begin{tabular}{|c|c|c|c|}
\hline \multicolumn{2}{|c|}{ unit/element } & \multirow{2}{*}{$\frac{\text { competent }}{\text { yes }}$} & \multirow{2}{*}{$\frac{\text { evidence available for APL }}{\text { previous role }}$} \\
\hline & $\begin{array}{l}\text { identify opportunities for } \\
\text { improvements in service delivery }\end{array}$ & & \\
\hline 1.2 & evaluate proposed changes & yes & previous role \\
\hline 1.3 & $\begin{array}{l}\text { negotiate and agree introduction of } \\
\text { change }\end{array}$ & yes & previous role \\
\hline 1.4 & implement and evaluate change & yes & previous role \\
\hline 1.5 & $\begin{array}{l}\text { Introduce develop and evaluate } \\
\text { quality assurance systems }\end{array}$ & yes & previous role \\
\hline 2.1 & $\begin{array}{l}\text { establish and maintain supply of } \\
\text { resources }\end{array}$ & yes & previous role \\
\hline 2.2 & $\begin{array}{l}\text { establish and agree customer } \\
\text { requirements }\end{array}$ & yes & previous role \\
\hline 2.3 & $\begin{array}{l}\text { maintain and improve operations } \\
\text { against quality and functional } \\
\text { specifications }\end{array}$ & & previous role \\
\hline 2.4 & $\begin{array}{l}\text { create and maintain conditions for } \\
\text { productive work activity }\end{array}$ & & previous role \\
\hline 3.1 & control costs and enhance value & yes & previous role \\
\hline & $\begin{array}{l}\text { monitor and control activities } \\
\text { against budgets }\end{array}$ & yes & current role \\
\hline 4.1 & justify proposals for expenditure & yes & current role \\
\hline 4.2 & negotiate and agree budgets & yes & current role \\
\hline & $\begin{array}{l}\text { define future personnel } \\
\text { requirements }\end{array}$ & & current role \\
\hline
\end{tabular}




\begin{tabular}{|ll|l|l|}
\hline 5.2 & $\begin{array}{l}\text { determine specifications to secure } \\
\text { quality people }\end{array}$ & yes & previous role \\
\hline 5.3 & $\begin{array}{l}\text { assess and select candidates against } \\
\text { team and organisational } \\
\text { requirements }\end{array}$ & yes & previous role \\
\hline 6.1 & develop and improve teams & yes & current role \\
\hline 6.2 & $\begin{array}{l}\text { identify review and improve } \\
\text { development activities for } \\
\text { individuals }\end{array}$ & yes & current role \\
\hline 6.3 & develop oneself within job role & yes & current role \\
\hline 6.4 & $\begin{array}{l}\text { evaluate and improve } \\
\text { developmental processes }\end{array}$ & current role \\
\hline 7.1 & set and update work objectives & yes & current role \\
\hline 7.2 & $\begin{array}{l}\text { plan activities and determine work } \\
\text { methods }\end{array}$ & yes & current role \\
\hline 7.3 & $\begin{array}{l}\text { allocate work and evaluate teams } \\
\text { individuals and self against } \\
\text { objectives }\end{array}$ & yes & current role \\
\hline 7.4 & $\begin{array}{l}\text { provide feedback to teams and } \\
\text { individuals }\end{array}$ & yes & current role \\
\hline 8.1 & $\begin{array}{l}\text { establish and maintain trust and } \\
\text { support of subordinates }\end{array}$ & yes & current role \\
\hline 8.2 & $\begin{array}{l}\text { establish and maintain trust and } \\
\text { support of ones manager }\end{array}$ & yes & current role \\
\hline 8.3 & $\begin{array}{l}\text { establish and maintain relationships } \\
\text { with colleagues }\end{array}$ & yes & previous role \\
\hline 8.4 & $\begin{array}{l}\text { identify and minimise interpersonal } \\
\text { conflict }\end{array}$ & yes & current role \\
\hline 8.5 & $\begin{array}{l}\text { implement disciplinary and } \\
\text { grievance procedures }\end{array}$ & yes & current role \\
\hline 8.6 & counsel staff & yes & current role \\
\hline 9.1 & $\begin{array}{l}\text { obtain and evaluate information to } \\
\text { aid making }\end{array}$ & yes & previous role \\
\hline
\end{tabular}




\begin{tabular}{|ll|l|l|}
\hline $9.2 \quad \begin{array}{l}\text { forecast trends and developments } \\
\text { which affect objectives }\end{array}$ & yes & previous role \\
\hline $9.3 \quad$ record and store information & yes & previous role \\
\hline $10.1 \quad \begin{array}{l}\text { lead meetings and group } \\
\text { discussions }\end{array}$ & yes & previous role \\
\hline $10.2 \quad \begin{array}{l}\text { contribute to discussions to solve } \\
\text { problems and make decisions }\end{array}$ & yes & previous role \\
\hline $10.3 \quad$ advise and inform others & yes & previous role \\
\hline
\end{tabular}

Rather than identify discrete areas of activity participant $\mathrm{c}$ chose to divide units and element between his current and previous role. In terms of APL this suggested areas which he had undertaken within his previous role as sources for evidence. In terms of development it pointed towards aspects of his new job which could provide evidence but which might also be utilised in relation to more specific developmental activities. Although participant c was advised about possible APL he chose to focus his attention on his current role and current needs.

Stage 3

Unlike participant's a and b, participant c preferred to avoid the APL route open to him. Although this might have reduced his overall efforts he preferred to submit new evidence based on specific developmental opportunities. He thus approached the development planning stage without any experiences of APL or of deriving/presenting evidence. The repertory grid process was thus administered as an addition to, rather a replacement for, the job/NVQ matching process detailed above and was intended to clarify development needs. Table c provides details of participant c' constructs regarding effective management performance. 
Table c2

\begin{tabular}{|l|l|l|}
\hline quality & positive & negative \\
\hline self confidence & confident & brash aggressive \\
\hline understanding & knowledgeable & ignorant \\
\hline realistic & balances & keen enthusiastic \\
\hline respected & respected by peers & excluded \\
\hline staff management & respected by staff & ignored \\
\hline coherence & planned & reactive \\
\hline sensitivity & humane & insensitive \\
\hline
\end{tabular}

It is interesting to note that participant $c$ chose not to identify discrete areas of work in relation to constructs but elected to retain them as an overall framework for the management domain. The constructs were presented back to participant $\mathrm{c}$ who was asked to prioritise his own needs according to the simple 3 point scale derived for participant b.

Table c3

\begin{tabular}{|l|l|l|l|}
\hline quality & positive & $\begin{array}{l}\text { self development } \\
\text { needs }\end{array}$ & negative \\
\hline self confidence & confident & medium & brash aggressive \\
\hline understanding & knowledgeable & low & ignorant \\
\hline realistic & balances & low & keen enthusiastic \\
\hline respected & respected by peers & medium & excluded \\
\hline staff management & respected by staff & medium/high & ignored \\
\hline coherence & planned & low & reactive \\
\hline sensitivity & humane & low & insensitive \\
\hline
\end{tabular}


Table $\mathrm{c} 2$ indicates the relevant personal constructs derived from participant $\mathrm{c}$ in relation to effective managerial performance in the rank of Assistant Divisional Officer. Table c3 indicates participant c's self perceived needs in relation to these constructs. Discussion of the constructs with the participant focused on issues around self confidence and respect and issues which he perceived in relation to his change of duties. Having been comfortable in a specialist headquarters, role the participant was keen to demonstrate his competence as a station commander. This demonstration was an important part of his motivation in undertaking and NVQ. At the same time, the view of his peers and subordinates was also important to him. Although not unduly sensitive, he felt that his effectiveness rested on the support of his staff and his peer group and that winning their confidence was a key element of being an effective Station Commander.

\section{Stage 4}

The selection of development activities was made on the basis of both needs and opportunities. Table $\mathrm{c} 4$ below indicates the relationship between perceived needs and competence units. It is clear that most of participant c's constructs relate to managing and interacting with people. In this respect his constructs are broadly similar to those of participants $a$ and $b$. Having recognised common needs, participants $c$ and $b$ independently contacted each other and agreed to examine common opportunities for development. As relatively new Station Commanders they had much in common in terms of role and responsibilities, cooperating seemed to offer further benefits in relation to their self development. 
Table c4

\begin{tabular}{|l|l|l|l|l|l|l|l|l|l|l|}
\hline unit & 1 & 2 & 3 & 4 & 5 & 6 & 7 & 8 & 9 & 10 \\
\hline quality & & & & & & & & & & \\
\hline self confidence & & & & & & $\mathrm{m}$ & $\mathrm{m}$ & $\mathrm{s}$ & & \\
\hline understanding & & & & & & $\mathrm{s}$ & & $\mathrm{s}$ & & \\
\hline realistic & $\mathrm{m}$ & & & & & $\mathrm{m}$ & & & & \\
\hline respected & & & & & & $\mathrm{s}$ & $\mathrm{s}$ & $\mathrm{s}$ & & \\
\hline staff management & & & & & & $\mathrm{s}$ & $\mathrm{s}$ & $\mathrm{s}$ & & \\
\hline coherence & & $\mathrm{s}$ & & & & $\mathrm{m}$ & & & & \\
\hline sensitivity & & & & & & $\mathrm{s}$ & $\mathrm{s}$ & & & \\
\hline
\end{tabular}

The decision to "join forces" with participant c came about as a result of their common job function. Although geographically separate, the two station commanders managed quite similar fire stations. Both had relatively small numbers of personnel and low rates of operational activity. This provided them with sufficient time to analyse the effectiveness of their stations as well as to consider issues like training in greater detail. The latter was extremely important to the two officers, as their personnel had relatively few operational incidents to maintain their skills, and therefore required, in the view of the two commanders, a very specific training programme. In addition, both participants had backgrounds in fire safety, and this provided an opportunity for further examination of training in relation to that area of work.

To specific pieces of development were undertaken with each participant playing a leading and supporting role in one. The two development activities were parallel to each other and involved the preparation of training programmes for station based personnel. Participant c selected an operational area for a station training programme, whilst participant $b$ selected a specific area of fire safety for a fire safety training programme. The two processes provided a range of evidence in relation to unit 6 
derived from both the actual product - the two training programmes designed and witness testimony i.e. the comments from one participant regarding the other's contributions.

The joint development programme also lead to the development of a provisional joint construct system in which the participants rated each other against their own and the other's constructs. In addition to providing feedback about the programme in relation to units and elements of competence, the participant's began, informally at first, to provide feedback about each others more general qualities. Following a request from participant $\mathrm{c}$ this became formalised in an agreed joint grid (see table $\mathrm{c} 5$ below)

Table c5

\begin{tabular}{|c|c|c|c|c|c|c|}
\hline quality & positive & b self & c self & $\mathrm{b}$ on $\mathrm{c}$ & $c$ on $b$ & negative \\
\hline self confidence & confident & 4 & 3 & 3 & 3 & brash aggressive \\
\hline understanding & knowledgeable & 3 & 4 & 4 & 4 & ignorant \\
\hline realistic & balances & 4 & 5 & 4 & 4 & $\begin{array}{c}\text { keen } \\
\text { enthusiastic }\end{array}$ \\
\hline respected & $\begin{array}{c}\text { respected by } \\
\text { peers }\end{array}$ & 4 & 3 & 3 & 4 & excluded \\
\hline staff management & $\begin{array}{l}\text { respected by } \\
\text { staff }\end{array}$ & 3 & 2 & 3 & 4 & ignored \\
\hline coherence & planned & 4 & 4 & 4 & 3 & reactive \\
\hline sensitivity & humane & 3 & 4 & 3 & 3 & insensitive \\
\hline cooperation & $\begin{array}{c}\text { works with } \\
\text { people }\end{array}$ & 4 & 4 & 3 & 4 & $\begin{array}{l}\text { imposes things } \\
\text { on people }\end{array}$ \\
\hline responsibility & $\begin{array}{l}\text { gets things } \\
\text { done }\end{array}$ & 3 & 4 & 3 & 3 & $\begin{array}{l}\text { blames others } \\
\text { when things go } \\
\text { wrong }\end{array}$ \\
\hline independence 1 & $\begin{array}{l}\text { knows own } \\
\text { mind }\end{array}$ & 5 & 4 & 4 & 4 & $\begin{array}{l}\text { gets told what to } \\
\text { do (and always } \\
\text { does it) }\end{array}$ \\
\hline
\end{tabular}




\begin{tabular}{|c|c|c|c|c|c|c|}
\hline independence 2 & takes initiative & 4 & 3 & 4 & 4 & works for others \\
\hline $\begin{array}{c}\text { friendly or } \\
\text { approachable }\end{array}$ & $\begin{array}{c}\text { discusses } \\
\text { issues and } \\
\text { problems }\end{array}$ & 5 & 5 & 4 & 4 & confronts people \\
\hline independence 3 & $\begin{array}{c}\text { sets realistic } \\
\text { objectives }\end{array}$ & 3 & 4 & 4 & 4 & $\begin{array}{c}\text { relies on brigade } \\
\text { rules and } \\
\text { systems }\end{array}$ \\
\hline
\end{tabular}

Key : Scores are based on a 1 to 5 scale with 5 most effective and 1 least effective in relation to the role of Station Commander

Stage 5

The availability of witness testimony removed many of the more cumbersome aspects of assessment. Athough still bureaucratic, the assessment process was eased by the wealth of evidence provided. The question of underpinning knowledge took two forms. Detailed operational knowledge was assumed, on the basis that the assessor could not realistically assess the validity of the training in terms of real requirements. Knowledge of training (or learning) was provided by reference to a previous taught course on systematic training. An attempt by the assessor to consider other learning approaches, such as learning styles, was rejected by the participant on the basis that this could not be dealt with within the training programme. Thus, although new knowledge was considered, the context effectively excluded it. Table c6 represents the two participant's views of each other following the initial development activities but prior to submission of portfolios for formal assessment. 
Table c6

\begin{tabular}{|c|c|c|c|c|c|c|}
\hline quality & positive & b self & c self & b on $c$ & $c$ on $b$ & negative \\
\hline self confidence & confident & 4 & 4 & 4 & 4 & $\begin{array}{c}\text { brash } \\
\text { aggressive }\end{array}$ \\
\hline understanding & $\begin{array}{c}\text { knowledg } \\
\text { eable }\end{array}$ & 4 & 4 & 4 & 4 & ignorant \\
\hline realistic & balances & 4 & 5 & 4 & 4 & $\begin{array}{l}\text { keen } \\
\text { enthusiastic }\end{array}$ \\
\hline respected & $\begin{array}{l}\text { respected } \\
\text { by peers }\end{array}$ & 4 & 4 & 4 & 4 & excluded \\
\hline staff management & $\begin{array}{l}\text { respected } \\
\text { by staff }\end{array}$ & 5 & 4 & 4 & 5 & ignored \\
\hline coherence & planned & 4 & 4 & 4 & 4 & reactive \\
\hline sensitivity & humane & 4 & 4 & 4 & 4 & insensitive \\
\hline cooperation & $\begin{array}{l}\text { works } \\
\text { with } \\
\text { people }\end{array}$ & 4 & 4 & 4 & 4 & $\begin{array}{l}\text { imposes } \\
\text { things on } \\
\text { people }\end{array}$ \\
\hline responsibility & $\begin{array}{c}\text { gets } \\
\text { things } \\
\text { done }\end{array}$ & 4 & 4 & 4 & 4 & $\begin{array}{l}\text { blames } \\
\text { others when } \\
\text { things go } \\
\text { wrong }\end{array}$ \\
\hline independence 1 & $\begin{array}{l}\text { knows } \\
\text { own } \\
\text { mind }\end{array}$ & 5 & 4 & 4 & 4 & $\begin{array}{l}\text { gets told } \\
\text { what to do } \\
\text { (and always } \\
\text { does it) }\end{array}$ \\
\hline independence 2 & $\begin{array}{c}\text { takes } \\
\text { initiative }\end{array}$ & 4 & 4 & 4 & 4 & $\begin{array}{c}\text { works for } \\
\text { others }\end{array}$ \\
\hline $\begin{array}{l}\text { friendly or } \\
\text { approachable }\end{array}$ & $\begin{array}{l}\text { discusses } \\
\text { issues } \\
\text { and } \\
\text { problems }\end{array}$ & 5 & 4 & 4 & 4 & $\begin{array}{l}\text { confronts } \\
\text { people }\end{array}$ \\
\hline independence 3 & $\begin{array}{l}\text { sets } \\
\text { realistic } \\
\text { objective } \\
\text { s }\end{array}$ & 4 & 4 & 4 & 4 & $\begin{array}{l}\text { relies on } \\
\text { brigade rules } \\
\text { and systems }\end{array}$ \\
\hline
\end{tabular}


Key : Scores are based on a 1 to 5 scale with 5 most effective and 1 least effective in relation to the role of Station Commander

The revised table shows a general improvement in relation to both self perception and perception of other's competence but no significant variation in the constructs. It suggests that the development process has given rise to an improved perception of effectiveness but interestingly has not modified the separate constructs. The system remains essentially a hybrid rather than a common approach to assessing performance.

\section{Stage 6}

The key to success for participants $b$ and $c$ was their ability to support each other. Both in terms of motivation and general support and, more specifically, in relation to development planning and providing evidence of competence (witness testimony) the two participants played a large part in each others success. The potentially problematic issue of authenticity was overcome by deciding in advance who would claim credit for work that had been produced jointly. Although they co-operated on two major pieces of work, each participant chose to submit evidence, in relation to their own competence through one piece of work and, therefore, to provide witness testimony only for the other. Theoretically, at least this could represent a breach of the competence based assessment procedure as neither participant could demonstrate unquestioned authenticity. On the other hand, such co-operation is normal amongst learners in other contexts and would normally take place during any management activity. To this extent, the breach of the rules represents the adoption of a more realistic approach to assessing complex managerial behaviour which is often dependant upon the efforts of others.

Participants $\mathrm{b}$ and $\mathrm{c}$ cited a number of advantages that collaboration had provided. 
Most significant to them was the existence of common interests and problems in station management. Coming from specialist backgrounds they were both keen to demonstrate management skills in a station context. They both felt the need to develop practical workable solutions to some of the problems that faced them at stations. Working together reduced the overall amount of time spent on developing approaches as they could share ideas and combine partial efforts at planning into more coherent and comprehensive plans.

Portfolio building was also assisted by the ability for each to provide witness testimony for the other, this obviated the need to introduce third party evidence for some areas and also speeded up the process of gathering evidence, since each knew precisely what evidence was required and how precisely to provide it. Both participants came to the programme with an implicit need to extend their underpinning knowledge in the area of operations and used the operational training project as an opportunity to do so. Their common experience in fire safety gave them an opportunity to experiment with a fire safety training programme and they were able to use this as a template for a review of operational training at each station.

In many ways the co-operative approach overcame the need to generate large amounts of new or artificial evidence for assessment. In addition to naturally occurring product, the two participants relied heavily on witness testimony from each other.

Participant $c$ was enthusiastic about the NVQ approach and found the collaboration to be of particular benefit. He was not convinced that he could have maintained this enthusiasm without his colleague. Partially, this was attributed to the sharing of tasks such as relating evidence to criteria, partially to the benefit of having a ready source of evidence. He was critical of the programme because it emphasised the individual nature of the approach and seemed, implicitly, to restrict natural cooperation. This quasi academic stance on the issue of assessment and authenticity was at odds both 
with his personal style of management and a number of the management activities in which he had been involved. He commented that other colleagues in his previous role would have found it very difficult to generate evidence which would have met the stipulations regarding authenticity as many pieces of work were the result of a group or team effort. To this extent, he was not convinced that such an individualistic approach was in keeping with the fire service, particularly in relation to operational fire fighting. He questioned the extent to which group or team activities could be assessed if each team member would be required to produce individual and separate evidence of their performance. 


\subsection{Case study 4 participant d}

\section{Stage 1}

Participant d was an operational Station Officer or watch commander at a busy central London station.Responsible for two appliances and 12 personnel. He had recently completed his statutory examinations and was looking for a first entry level qualification in management. Participant $d$ was not particularly aware of the NVQ approach but keen to participate in a trial within the Brigade. His interviewers found participant $d$ to be the most enthusiastic of the applicants and the keenest to obtain a formal management qualification. He was significantly younger than other applicants and had attained his rank at quite a young age, part of his enthusiasm was therefore attributed to a need to demonstrate his abilities to his colleagues, particularly his peers. At the same time participant d demonstrated a clear need to extend and develop management skills and saw the workplace as a supportive environment.

\section{Stage 2}

Participants in the development programme were presented with the appropriate MCI management standards in some detail and asked to identify activities which they currently undertook which could provide evidence. Participants were asked to review their performance against the detailed performance criteria and identify

a. Whether they met the criteria (and could be described as competent) and, if so,

b. What sources of evidence existed.

The purpose of the activity, besides offering a detailed examination of the standards was to assess the scope for accreditation of prior learning and, thereby identify the 
need for further development to take place.

Table d1

\begin{tabular}{|c|c|c|c|}
\hline \multicolumn{2}{|c|}{ unit/element } & \multirow{2}{*}{$\frac{\text { competent }}{\text { yes }}$} & \multirow{2}{*}{$\begin{array}{l}\text { evidence available for APL } \\
\text { meetings with Station } \\
\text { Commander }\end{array}$} \\
\hline 1.1 & $\begin{array}{l}\text { maintain operations to meet quality } \\
\text { standards }\end{array}$ & & \\
\hline 1.2 & $\begin{array}{l}\text { create and maintain the necessary } \\
\text { conditions for productive work. }\end{array}$ & yes & $\begin{array}{l}\text { meetings with Station } \\
\text { Commander }\end{array}$ \\
\hline 2.1 & $\begin{array}{l}\text { contribute to the evaluation of } \\
\text { proposed changes to services, } \\
\text { products and systems. }\end{array}$ & yes & $\begin{array}{l}\text { meetings with Station } \\
\text { Commander }\end{array}$ \\
\hline 2.2 & $\begin{array}{l}\text { implement and evaluate changes to } \\
\text { services, products and systems. }\end{array}$ & yes & $\begin{array}{l}\text { meetings with Station } \\
\text { Commander }\end{array}$ \\
\hline 3.1 & $\begin{array}{l}\text { make recommendations for } \\
\text { expenditure. }\end{array}$ & No & \\
\hline 3.2 & $\begin{array}{l}\text { monitor and control the use of } \\
\text { resources. }\end{array}$ & no & \\
\hline 41 & $\begin{array}{l}\text { define future personnel } \\
\text { requirements }\end{array}$ & no & \\
\hline 4.2 & $\begin{array}{l}\text { contribute to the assessment and } \\
\text { selection of candidates against } \\
\text { team and organisational } \\
\text { requirements }\end{array}$ & no & \\
\hline 5.1 & $\begin{array}{l}\text { develop and improve teams through } \\
\text { planning and activities. }\end{array}$ & yes & meetings with watch \\
\hline 5.2 & $\begin{array}{l}\text { identify review and improve } \\
\text { development activities for } \\
\text { individuals }\end{array}$ & yes & meetings with watch \\
\hline 5.3 & develop oneself within job role & yes & \\
\hline 6.1 & set and update work objectives & yes & station routines \\
\hline 6.2 & $\begin{array}{l}\text { plan activities and determine work } \\
\text { methods to achieve objectives }\end{array}$ & yes & station routines \\
\hline
\end{tabular}




\begin{tabular}{|c|c|c|c|}
\hline 6.3 & $\begin{array}{l}\text { allocate work and evaluate teams } \\
\text { individuals and self against } \\
\text { objectives }\end{array}$ & yes & meetings with watch \\
\hline 6.4 & $\begin{array}{l}\text { provide feedback to teams and } \\
\text { individuals }\end{array}$ & yes & meetings with watch \\
\hline 7.1 & $\begin{array}{l}\text { establish and maintain trust and } \\
\text { support of subordinates }\end{array}$ & yes & meetings with watch \\
\hline 7.2 & $\begin{array}{l}\text { establish and maintain trust and } \\
\text { support of ones manager }\end{array}$ & yes & $\begin{array}{l}\text { meetings with Station } \\
\text { Commander }\end{array}$ \\
\hline 7.3 & $\begin{array}{l}\text { establish and maintain relationships } \\
\text { with colleagues }\end{array}$ & yes & \\
\hline 7.4 & $\begin{array}{l}\text { identify and minimise interpersonal } \\
\text { conflict }\end{array}$ & yes & meetings with watch \\
\hline 7.5 & $\begin{array}{l}\text { implement disciplinary and } \\
\text { grievance procedures }\end{array}$ & yes & \\
\hline 7.6 & counsel staff & yes & \\
\hline 8.1 & $\begin{array}{l}\text { obtain and evaluate information to } \\
\text { aid decision making }\end{array}$ & yes & $\begin{array}{l}\text { meetings with Station } \\
\text { Commander }\end{array}$ \\
\hline 8.3 & record and store information & yes & station files \\
\hline 9.1 & $\begin{array}{l}\text { lead meetings and group } \\
\text { discussions }\end{array}$ & yes & meetings with watch \\
\hline 9.2 & $\begin{array}{l}\text { contribute to discussions to solve } \\
\text { problems and make decisions }\end{array}$ & yes & $\begin{array}{l}\text { meetings with Station } \\
\text { Commander }\end{array}$ \\
\hline 9.3 & advise and inform others & yes & $\begin{array}{l}\text { meetings with Station } \\
\text { Commander }\end{array}$ \\
\hline
\end{tabular}

Although station meetings were identified as a possible source of evidence for APL, the format and content of written records was not seen to be particularly helpful for assessment purposes. In contrast those activities which could provide more extensive and ostensibly objective data - such as managing finance - were areas in which it the participant acknowledged developmental needs. The choice which presented itself therefore seemed to be to "create" artificial records of meetings - for the purpose of 
NVQ assessment or to undertake new activities which would generate both evidence and signify additional competence. Participant $d$ opted for the latter and therefore chose to postpone consideration of APL in relation to units 6 and 7 .

\section{Stage 3}

The purpose of stage 3 was to assist participant $d$ in clarifying his needs and identifying priorities for his development. Personal constructs were derived from units and job components as per participants a to $\mathrm{c}$. Table $\mathrm{d} 2$ represents the personal constructs relevant to the role of Watch Commander and indicates both positive and negative poles together with a consideration of where the different constructs are likely to be visible.

Table d2

\begin{tabular}{|l|l|l|l|}
\hline quality & positive & negative & context \\
\hline clarity & clear & confusing & managing people \\
\hline objectivity & impartial & favouritism & managing people \\
\hline friendliness & open & hostile & managing people \\
\hline motivation & encouraging & indifferent & managing people \\
\hline decision making & considered & impatient & station management \\
\hline cogent & knows answers & guesses at things & brigade procedures \\
\hline structured & logical & immediate & major projects \\
\hline achievement & methodical & reactive & station management \\
\hline
\end{tabular}

Having elicited constructs, these were then represented back to the participant as a focus for assessing his developmental needs. Table $\mathrm{d} 3$ provides a summary of needs in a simple three point scale. 


\begin{tabular}{|l|l|l|l|}
\hline quality & positive & negative & development needs \\
\hline clarity & clear & confusing & medium \\
\hline objectivity & impartial & favouritism & low \\
\hline friendliness & open & hostile & low \\
\hline motivation & encouraging & indifferent & low \\
\hline decision making & considered & impatient & high \\
\hline cogent & knows answers & guesses at things & medium \\
\hline structured & logical & immediate & medium \\
\hline achievement & methodical & reactive & medium \\
\hline
\end{tabular}

\section{Stage 4}

The combination of self perceived needs and available evidence was used to examine possibilities for development in the workplace. The participant was keen to address those areas in which he perceived needs. Although he could have provided evidence for APL in relation to staff management (units 6 and \&) he preferred to focus an areas in which he had relatively little experience (see table d4).

At first the absence of current job evidence was seen as a barrier, particularly in relation to units 2 and 3. Following discussions with his line manager, however, the participant was provided with a specific project in relation to a building project at his station. The participant was asked to undertake duties normally associated with his line manager (the Station Commander) and to present papers and reports concerning a refurbishment proposal. Although this task was part of the manager's role, it was linked to more day to day maintenance issues, which were part of the participant's job. To this extent the development represented an extension of current duties, rather than completely new work. 
Table d4

\begin{tabular}{|l|l|l|l|l|l|l|l|l|l|}
\hline unit & $\mathrm{l}$ & $\mathrm{2}$ & 3 & 4 & 5 & 6 & 7 & 8 & 9 \\
\hline quality & & & & & & & & & \\
\hline clarity & $\mathrm{m}$ & $\mathrm{m}$ & $\mathrm{m}$ & $\mathrm{m}$ & & $\mathrm{m}$ & $\mathrm{m}$ & $\mathrm{s}$ & $\mathrm{s}$ \\
\hline objectivity & $\mathrm{m}$ & & & & & $\mathrm{m}$ & $\mathrm{m}$ & & \\
\hline friendliness & & & & & & $\mathrm{m}$ & $\mathrm{m}$ & $\mathrm{m}$ & \\
\hline motivation & & & & & & $\mathrm{m}$ & & & \\
\hline $\begin{array}{l}\text { decision } \\
\text { making }\end{array}$ & & & $\mathrm{m}$ & & & & & $\mathrm{m}$ & $\mathrm{m}$ \\
\hline cogent & & $\mathrm{s}$ & $\mathrm{m}$ & $\mathrm{s}$ & & & & & $\mathrm{m}$ \\
\hline structured & & & $\mathrm{m}$ & $\mathrm{m}$ & & & & $\mathrm{s}$ & \\
\hline achievement & $\mathrm{s}$ & $\mathrm{s}$ & $\mathrm{m}$ & & & & & & \\
\hline
\end{tabular}

The availability of a supportive line manager, who was prepared to share work with the participant, provided the opportunity for a more structured use of the NVQ standards and the personal constructs. Participant $\mathrm{d}$ felt comfortable with his own constructs and was prepared to share them with his manager. The line manager in turn, although not sharing constructs was prepared to comment and suggest modifications, so that a shared set of performance constructs could be used to assess evidence and development. The problem area, which had previoúsly been identified, could now be reconsidered as this formed part of the line manager's role and he was prepared to allow the participant to operate (with supervision) in order to obtain evidence.

\section{Stage 5}

In many ways participant d's experience of assessment was closest to that predicted by the literature on competences and NVQs. His portfolio was directly structured 
towards the individual unit. It was based on a specific developmental event or task not directly connected with his normal day to day duties and had been defined in such a way as to provide suitable evidence. The cooperation of his line manager had allowed events to be constructed which would generate relevant evidence and the manager also provided fulsome witness testimony. The question of underpinning knowledge was much less significant at this level that at level 2 and reference to general principles and brigade procedures was taken as sufficient for the purpose of this unit. Table d5

\begin{tabular}{|l|l|l|l|l|}
\hline quality & positive & negative & self & manager \\
\hline clarity & clear & confusing & 4 & 3 \\
\hline objectivity & impartial & favouritism & 4 & 4 \\
\hline friendliness & open & hostile & 4 & 4 \\
\hline motivation & encouraging & indifferent & 4 & 4 \\
\hline $\begin{array}{l}\text { decision } \\
\text { making }\end{array}$ & considered & impatient & 3 & 2 \\
\hline cogent & knows answers & guesses at things & 3 & 3 \\
\hline structured & logical & immediate & 3 & 2 \\
\hline achievement & methodical & reactive & 3 & 3 \\
\hline
\end{tabular}

Key : Scores are based on a 1 to 5 scale with 5 most effective and 1 least effective in relation to the role of Watch Commander

\section{Stage 6}

The success of participant d's approach can be traced back to his relationship with his line manager and the support the latter provided. In particular the evidence problem which was identified in stage 2 could only have been overcome with this support. The NVQ programme allowed the participant to learn what was effectively a new job, using the NVQ system as a structure. As a recognised or sponsored learner he was 
able to call upon the time and support of his manager. The programme thus fulfilled three aims, two explicit, those of the participant to learn about his job and to gain a qualification, the third, implicit, that of the manager to develop and be able to rely upon a competent subordinate. As a work based approach to qualification, the NVQ suited both the participant and his manager in a way that other participants could not attain. Substantive station commanders were already seen as middle managers an as such their competence was assumed. To undertake a qualification, albeit one based on work performance, was seen by many managers as superfluous and certainly not something which they should be asked to support. In contrast, as a newly appointed watch commander, in a new role, support was seen as relevant, as was learning. The qualification was seen by the line manager as a beneficial way to learn about managerial responsibilities on a station.

The table below represents the position in terms of constructs as seen by the participant and his line manager after eight months. It is additional to the evidence presented for NVQ assessment and is intended to provide feedback on progress in relation to personally meaningful categories. Although useful to the participant, it is not an essential component of his development which, for the present at least, is centred on completion of the NVQ. The scales used, and assessments provided, may, however, figure in a longer term approach towards a more senior position. 
Table d6

\begin{tabular}{|l|l|l|l|l|}
\hline quality & positive & negative & self & manager \\
\hline clarity & clear & confusing & 4 & 4 \\
\hline objectivity & impartial & favouritism & 4 & 4 \\
\hline friendliness & open & hostile & 4 & 4 \\
\hline motivation & encouraging & indifferent & 4 & 4 \\
\hline $\begin{array}{l}\text { decision } \\
\text { making }\end{array}$ & considered & impatient & 4 & 4 \\
\hline cogent & knows answers & guesses at things & 4 & 4 \\
\hline structured & logical & immediate & 4 & 3 \\
\hline achievement & methodical & reactive & 3 & 4 \\
\hline dynamic & gets things done & $\begin{array}{l}\text { waits for things to } \\
\text { happen }\end{array}$ & 3 & 3 \\
\hline resourceful & $\begin{array}{l}\text { finds out what is } \\
\text { needed }\end{array}$ & $\begin{array}{l}\text { maintains existing } \\
\text { positions }\end{array}$ & 3 & 3 \\
\hline confident & $\begin{array}{l}\text { seem to be comfortable } \\
\text { with responsibility }\end{array}$ & runs away from things & 3 & 4 \\
\hline
\end{tabular}

Key: Scores are based on a 1 to 5 scale with 5 most effective and 1 least effective in relation to the role of Watch Commander

The revised assessments (table e5) includes additional constructs proposed by the line manager. These relate directly to the specific tasks undertaken and implicitly to the units for which evidence was provided. They suggest a broader view of performance to which the manager subscribed and which the participant accepted as relevant to those areas of his role. The extension of the system in this way, although not strictly conversational in its genesis, indicates that the use of constructs can be significant without the requirement for repertory grids and that exchange, albeit in a limited form can extent the perceptions of performance in job roles. 


\subsection{Case study 5 participant e}

\section{Stage 1}

At the time of interview participant e was a non uniformed section head whose post was broadly equivalent to that of a Station Officer. He was one of only two nonuniformed personnel who applied for the NVQ programme and was a member of the Training Department. Like participant c participant e had also been redeployed from a previous role within the Authority. His change of jobs moved him from a specialist training research role into a front line management role with four direct subordinates. This was participant E's second redeployment and it brought him back into a field where he had considerable prior experience. Participant e was keen to undertake NVQs as his previous experience of academic related studies at a similar level had proved unsuccessful. He considered the NVQ approach more relevant to his role as a line manager and compared the NVQ approach to his previous failure at an economics paper which was unrelated to his job (or in his view his career as a personnel officer). Participant e discussed the previous failure and identified both the academic content and the lack of relevance as contributory factors and contrasted this with the clearly relevant, practical approach of the NVQ. He discussed his current role both as an opportunity to make a fresh start and also in terms of prior staff management experience. In many ways participant e provided his interviewers with a very full picture of the NVQ system and a clear and coherent reason behind his application.

\section{Stage 2}

Participants in the development programme were presented with the appropriate $\mathrm{MCI}$ management standards in some detail and asked to identify activities which they currently undertook which could provide evidence. Participants were asked to review their performance against the detailed performance criteria and identify 
a. Whether they met the criteria (and could be described as competent) and, if so,

b. What sources of evidence existed.

The purpose of the activity, besides offering a detailed examination of the standards was to assess the scope for accreditation of prior learning and, thereby identify the need for further development to take place

Table el

\begin{tabular}{|c|c|c|c|}
\hline \multicolumn{2}{|c|}{ unit/element } & competent & evidence available for APL \\
\hline 1.1 & $\begin{array}{l}\text { maintain operations to meet quality } \\
\text { standards }\end{array}$ & & discussions with line manager \\
\hline 1.2 & $\begin{array}{l}\text { create and maintain the necessary } \\
\text { conditions for productive work. }\end{array}$ & & discussions with line manager \\
\hline 2.1 & $\begin{array}{l}\text { contribute to the evaluation of } \\
\text { proposed changes to services, } \\
\text { products and systems. }\end{array}$ & & discussions with line manager \\
\hline 2.2 & $\begin{array}{l}\text { implement and evaluate changes to } \\
\text { services, products and systems. }\end{array}$ & competent & discussions with line manager \\
\hline 3.1 & $\begin{array}{l}\text { make recommendations for } \\
\text { expenditure. }\end{array}$ & & \\
\hline 3.2 & $\begin{array}{l}\text { monitor and control the use of } \\
\text { resources. }\end{array}$ & competent & Budget returns \\
\hline 41 & $\begin{array}{l}\text { define future personnel } \\
\text { requirements }\end{array}$ & & discussions with line manager \\
\hline 4.2 & $\begin{array}{l}\text { contribute to the assessment and } \\
\text { selection of candidates against } \\
\text { team and organisational } \\
\text { requirements }\end{array}$ & & discussions with line manager \\
\hline 5.1 & $\begin{array}{l}\text { develop and improve teams through } \\
\text { planning and activities. }\end{array}$ & competent & discussions with line manager \\
\hline
\end{tabular}




\begin{tabular}{|c|c|c|c|}
\hline \multicolumn{2}{|c|}{ unit/element } & \multirow{2}{*}{$\frac{\text { competent }}{\text { competent }}$} & \multirow{2}{*}{$\frac{\text { evidence available for APL }}{\text { discussions with line manager }}$} \\
\hline 5.2 & $\begin{array}{l}\text { identify review and improve } \\
\text { development activities for } \\
\text { individuals }\end{array}$ & & \\
\hline 5.3 & develop oneself within job role & competent & discussions with line manager \\
\hline 6.1 & set and update work objectives & competent & discussions with line manager \\
\hline 6.2 & $\begin{array}{l}\text { plan activities and determine work } \\
\text { methods to achieve objectives }\end{array}$ & competent & discussions with line manager \\
\hline 6.3 & $\begin{array}{l}\text { allocate work and evaluate teams } \\
\text { individuals and self against } \\
\text { objectives }\end{array}$ & competent & \\
\hline 6.4 & $\begin{array}{l}\text { provide feedback to teams and } \\
\text { individuals }\end{array}$ & not used & \\
\hline 7.1 & $\begin{array}{l}\text { establish and maintain trust and } \\
\text { support of subordinates }\end{array}$ & competent & $\begin{array}{l}\text { discussions with line manager } \\
\text { and staff }\end{array}$ \\
\hline 7.2 & $\begin{array}{l}\text { establish and maintain trust and } \\
\text { support of ones manager }\end{array}$ & competent & discussions with line manager \\
\hline 7.3 & $\begin{array}{l}\text { establish and maintain relationships } \\
\text { with colleagues }\end{array}$ & competent & discussions with line manager \\
\hline 7.4 & $\begin{array}{l}\text { identify and minimise interpersonal } \\
\text { conflict }\end{array}$ & unsure & \\
\hline 7.5 & $\begin{array}{l}\text { implement disciplinary and } \\
\text { grievance procedures }\end{array}$ & not used & \\
\hline 7.6 & counsel staff & not used & \\
\hline 8.1 & $\begin{array}{l}\text { obtain and evaluate information to } \\
\text { aid decision making }\end{array}$ & competent & \\
\hline 8.3 & record and store information & competent & files \\
\hline & $\begin{array}{l}\text { lead meetings and group } \\
\text { discussions }\end{array}$ & unsure & \\
\hline & $\begin{array}{l}\text { contribute to discussions to solve } \\
\text { problems and make decisions }\end{array}$ & competent & \\
\hline 9.3 & advise and inform others & competent & \\
\hline
\end{tabular}


On the basis of the table above participant e proposed to present evidence of competence in relation to units and 6 and 7 . He consulted his line manager regarding the provision of evidence for the APL process.

\section{Stage 3}

Unfortunately participant e's line manager was unable to provide clear evidence of competence across the relevant performance criteria. Discussions between the participant and his manager identified a number of areas in which further development proved necessary and it was agreed not to pursue APL. In its place, the line manager would devise discrete tasks and projects to derive evidence. On the job development was therefore focused on managing work allocation and staff development.

Constructs were not derived at this stage as both the participant and his line manager had agreed a development process baaed on the available NVQ units. Although an attempt was made to discuss relevant qualities of a manager, the participant expressed some anxieties over such an approach and, rather than add to the complexity of the process, a decision was made, with the participant's agreement, to focus on units of competence and specific performance criteria.

\section{Stage 4}

The choice of staff management had been made on the basis of previous experience in that role, together with an assumption based on effective performance. More detailed analysis of current performance against the standards did not confirm competent performance and, over time, began to suggest notable deficiencies. In order to minimise any possible contamination by previous performance, a discrete area of work was identified and specific objectives agreed. The result was the creation of a specific project designed to gather evidence of competence in a limited area. The management of the project was the responsibility of the participant with the line 
manager and myself taking responsibility for the management of the learning. Regular progress reviews were conducted by the line manager - in relation to task completion, and myself, in relation to learning and evidence. The line managers reports were also available as a sources of witness testimony.

It soon became obvious that the participant was experiencing problems managing staff and that these could not be identified in relation to specific performance criteria not being met. The performance problem, however, was not one of specific criteria (although this could be seen as evidence of under-performance) but a more general lack of confidence. The issue for NVQ assessment was not, therefore, about providing additional opportunities to gain evidence, but rather, providing support to improve or at least modify the underlying causes, without undermining the authenticity of the assessment.

The situation that thus presented itself contained two paradoxes:-

Firstly, that in attempting to provide the support necessary to create evidence of competence, the line manager was liable to undermine the authenticity of the evidence i.e. that the participant would be managing with her support and thus not actually making or communicating his decisions - this issue is about the level of moral or emotional support which can be provided to learners.

Secondly, in assessing performance generally the line manager had used the NVQ standards. This had highlighted areas of under performance but only at a symptomatic level i.e. they in themselves were not causal but simply products or outcomes of development needs elsewhere. In attempting to create or manufacture evidence the line manager could (subject to the limitation above) demonstrate competence without there being actual development.

The paradoxes present, together with the performance problems being highlighted 
suggested that further use of the competence based approach was limited either for development or general performance assessment.

\section{Stage 5}

No formal assessment of participant e was undertaken. His line managers witness testimony raised a number of performance issues and, in the context of a formative assessment, was considered as a potential negative indicator. The assessor raised issues of faimess and impartiality with both the participant and his line manager. The absence of any contradictory evidence and the admission by the participant that the report was accurate indicated that no evidence of competence was available for some performance criteria and formal assessment was postponed pending further development.

\section{Stage 6}

The problems experienced by participant e raise issues about the use of NVQs and the performance standards outside a development programme. The availability of general standards which are designed to apply to managerial posts brings with it the danger that such standards will be used in non-developmental contexts such as capability. Although the Authority's personnel procedures clearly indicate the need for remedial developmental action, prior to any formal or informal approach under capability, they fail to recognise the significance of the link. It was never intended that applying for or being accepted on a developmental programme could become a journey towards a disciplinary hearing. At the same time, having used and accepted NVQ standards for the purpose of development and demonstrating competence, it is very difficult to abandon them for other aspects of performance management. The failure of the NVQ development programme highlighted performance difficulties, and, having been unable to deal with these within a developmental context, other options were inevitable. 
On a slightly more positive note the programme did not fail through lack of effort by the individual or support from the line manager. In examining management performance across the different units, it clarified those areas in which the participant was not effective and which, despite support, he was to remain ineffective. This latter analysis was able to take place because there existed clear evidence of poor performance, rather than just the absence of evidence. The evidence also indicated areas of strength and used positively could suggests different types of work with fewer or more specialised managerial responsibilities. Some proponents of the NVQ system assume that all units are required for a qualification and overlooks the flexibility that a partial approach offers. Although the system may have penalised the participant by identifying areas of ineffectiveness, the NVQ approach could also be used to highlight areas of effectiveness and thereby identify jobs in which he could become competent.

The paradoxes identified between developing skills, or, more accurately, personal qualities (such as self confidence) and measuring outcomes (and outcomes alone) are a product of the NVQ approach. The presumption of a direct link between development and performance can be counter productive, particularly when it overlooks the need for skill or other more personal development prior to assessment. The development of skill may not be manifest in a performance outcome, nor by focusing on performance outcomes do we necessarily develop skills. This case illustrates the issue in stark contrast. The participant's needs were for support to develop skills, in providing that support the manager would have prevented the participant claiming that the outcomes were authentically their own. What was required was a different form of development, the products of which, would have been greater confidence. Whether this is considered as a prior or enabling process is a matter of debate. That it can exist, or that it should need to exist, forms no part of the current competence based system.

Participant e's formal withdrawal from the NVQ programme came about as a result of 
illness. Following his return to work a number of options were discussed in relation to his performance. It had become obvious to both the participant and his line manager that his current posting was not suitable and this was having an impact on overall work performance and also the participant's own health. To the extent that the development programme had focused attention on possible shortcomings, it could be said that the programme contributed to the problem. On the other hand, the programme also offered a more structured approach to the assessment of performance which allowed both the manager and the participant to examine problems in a positive way. Participant e had completed those units and element of the programme of which he felt himself capable and, whilst he was not able to obtain a formal qualification, he could recognise those areas of management in which he was best able to perform. The result of the discussions with him was to identify a posting based on his strengths and achievements, a job in which he could perform most, but not all, of the role of a line manager within the Authority.

With the benefit of hindsight, the failure to elicit relevant personal constructs may have contributed to the problems experienced by this participant. The rather narrow focus on performance criteria reinforced some of the difficulties he experienced as a manager. Perhaps a more useful approach may have been to elicit constructs around his perceived problems as a manager rather than qualities required. Although potentially more dangerous - in focusing on the negative - this may have revealed the participant's view of causality in relation to his expressed difficulties, which in turn may have suggested other development (or job) options. It is important to note that the failure to elicit constructs cannot be identified as the sole cause of the participant's problems and that his manager's initial assessment suggested longer term performance issues. In this context the use of standards as a developmental tool needs to be reexamined.

The literature suggests that responsibility for development (and in particular the presentation of evidence) rests with the individual learner. It is not clear as to the 
responsibility of the employer in relation to poor performance and it could be argued that a purely competence based system of self development is insufficient both in terms of a learning strategy. It is not clear that the system is capable of meeting deeper personal needs nor can one be sure that it fulfills the employer's legal and moral obligations for dealing positively with poor performance. The question, therefore, arises, had this person not applied for the programme, how would the employer have responded and would the use of standards be seen as either appropriate or beneficial. 


\section{Chapter 10 The Assessor Survey}

\subsection{Introduction}

The assessor survey was undertaken as a supplementary piece of research. It was used to obtain the views of assessors involved in MCI assessment systems. Because the LFCDA staff had very little direct experience of assessment, the assessor survey was designed to canvass the views of more experienced assessors.

\subsection{The Design}

The survey contents represented the result of a number of prior discussions about the role of the assessors. During these discussions a series of key steps or stages were identified. The aim of the survey was to examine the allocation of resources between these key stages and to consider the mechanism by which candidates moved from one stage to the next. The stages were represented as a sequence of steps that an assessor would go through with a candidate. Assessors were asked to identify the least, greatest and average time spent in each activity, together with the method by which they decided to move from one stage to the next. The use of time as an indicator of importance within the assessment process is significant in this context since all assessors are paid on an hourly basis and each candidate is given an allocation of assessor's time. There is therefore an incentive for the assessors to allocate time as efficiently as possible and to meet as much of the candidates needs in relation to the programme as time permits. The survey method was chosen as a simple and effective means of gaining information from a number of assessors. The survey was administered remotely over a period of approximately six weeks was followed up with a subsequent open meeting with assessors on the issue of assessment and quality. Preliminary findings were presented to the group for discussion on the agenda as a quality control item. 


\subsection{Research subjects}

Although some of the assessors were directly involved with the assessment of LFB candidates, others were not and the survey asked for information across the full range of assessment activities they had performed with candidates. The survey thus offers a broader perspective on the issue of assessment by assessors generally. The small size of the sample was determined by the then resources of the university and the need to ensure that all assessors were involved in a similar context (i.e. assessment outside normal course style delivery). This was important as the type and style of support provided to the LFB by the university differs in some respects from that offered by those institutions who have used MCI standards as a development of existing Diploma and Certificate courses (this type of provision necessarily has a much higher level of structure). The candidates with whom the assessors interacted came from a variety of organisations, mostly in the public sector, and were all being supported in some form by their employers.

\subsection{Results of Survey}

Table 1 shows the mean time spent in each activity by assessors together with the range (i.e. difference between assessors) The results of the survey clearly indicate a prevalence of standards oriented and advice and guidance. On average some $23 \%$ of the time allocated to the assessment process is spent in these activities. The first label consists of explaining the structure and wording of the standards themselves and the second comparing them to job components or work activities. This process of translation or "contextualisation" is seen by assessors as an essential introduction to the subsequent process of evidence gathering and portfolio building which together take up a further $25 \%$ of assessors time spent with the candidate. Interestingly some $15 \%$ of assessors time seems to spent on the formative assessment of materials and evidence without any active candidate involvement. 
The attempt to further elaborate the practitioners' model by eliciting a set of common procedures or protocols was less successful. Although the staged model was relatively easy to identify the precise determination of indicators was much less obvious. Some assessors felt that this was achieved when the candidate expressed a willingness to go on. Others looked for more tangible signs, such as the ability of the candidate to make links between standards and the job they did or to provide examples of evidence which could support their claim to be competent. One conclusion which could be drawn is that whilst assessors follow a common overall model they are all working with different sorts of indicators - some expert based and some candidate based which govern the movement from stage to stage of the process. The absence of clear rules or procedures at this level formed part of the discussion within the group (see below). At its extreme, however, it would also be possible to conceive of an assessment process which was purely expert lead i.e. that it consisted of explanation and advice without fully engaging or involving the candidate at all. This facet (expert lead assessment) is particularly noticeable in the early part of the assessment process in which the assessor is simply providing information concerning the standards themselves. Although candidate involvement increases over time, there could not be said to be a given identifiable point at which control of the process was actually being shared between the participants. 
Table 1

\begin{tabular}{|l|l|l|l|l|}
\hline stage & activity & mean time \% & minimum & maximum \\
\hline 1 & Explain standards & 23 & 10 & 40 \\
\hline 2 & Explain assessment process & 25 & 10 & 40 \\
\hline 3 & Collect evidence & 1 & 0 & 5 \\
\hline 3 & Present evidence & 0 & 0 & 0 \\
\hline 5 & Review written evidence & 8 & 5 & 20 \\
\hline 6 & Provide written feedback & 7 & 5 & 25 \\
\hline 7 & Discuss evidence with candidate & 9 & 5 & 20 \\
\hline 8 & Conduct summative assessment & 27 & 10 & 50 \\
\hline
\end{tabular}

Key- All figure are expressed as a percentage of the time spent by the assessor during the assessment process.

Mean time is the average time spent with each candidate averaged across all assessors Mimium is the minimum time spent with any one candidate by any one assessor on an activity

Maximum is the maximum time spent with any one candidate by any one assessor on an activity

\subsection{The Assessor Meeting}

The purpose of the meeting was three fold

i. It formed part of an ongoing process of support offered by the university in the hope of ensuring common standards and procedures (quality assurance) one potential outcome being an assessor's manual. 
ii. It provided an opportunity for individual assessors to meet and exchange views on, and experiences of, the assessment process, and to examine particular problems they had encountered (quality management)

iii. It provided me with the opportunity to elicit and develop a practitioners model which would be capable of assisting the university in $i$ above and of involving the assessors in a more structured version of ii.

\subsubsection{The process of assessment}

The notion of a practitioners' model broadly following accepted practice within the group, had been well received and the survey focused on key stages or activities. The survey results came as little surprise to the assessors and all had identified the issue of explanation of standards as a problem. Partially, this was attributed to the language used by MCI (in common with other awarding bodies). Partially, however, the assessors felt that this was an issue of structure. They considered that there was a specific need to explain how outcome based standards differed from skill or process based models. This distinction was to become more important for the assessment process in the evidence gathering stage. All expressed the view that early emphasis upon the assessment process and the portfolio were of value. Interestingly, when faced with an estimate the time spent in the process, some were in favour of providing a more formal induction course for MCI using large groups rather than individual session. This was seen as a more economic use of the available time. The suggestion, that formal teaching was as good as, if not better than, one to one contact is indicative of the type of support offered at this stage and is illustrative of the process used by assessors. Whilst having obvious benefits to the assessors (and potentially candidates) in terms of time management, the proposal was seen to reduce candidate involvement to that of an audience, suggesting that this stage may be little more than a knowledge based informing process with very low levels of candidate/assessor interaction. Assessors were aware of the nature of this and distinguished between this process 
(providing information about the standards) and later processes of identifying evidence and providing encouragement to candidates.

Most assessors felt that the survey results were typical of their own experiences and whilst this provided some relief (in that the problem was not an individual one) all expressed some level of disappointment or frustration about the amount of time spent in explaining basic terminology and convincing candidates of the relevance of the standards to their work. As well as identifying an alternative method for delivering information, assessors felt that the latter activity - "demonstrating relevance" was more fitted to the employer than the assessor. One difficulty identified here could be that, in the view of the assessors, many employers remained equally ignorant or sceptical as the candidates. Nevertheless, the idea that employers had a greater role to play, or that the assessors were being asked to play a role for which they were only partially suited, was expressed by all the group. Given the cost of assessment and the time factor used to determine cost, most assessors felt that actual individual advice and assessment of evidence were much better uses of their time and expertise. Assessors were spilt over the relative importance of these two activities, with some clearly preferring more candidate contact for guidance and support, whilst others accepted that providing written feedback on portfolios was seen by the awarding body to be more directly relevant to the provision of a qualification.

\subsubsection{The Contents of Assessment}

The perception that developing skills or understanding outside the MCI framework was not taking place proved to be an uncomfortable for many assessors, particularly those who had previously been teachers or who had management development backgrounds. Criticisms of this aspect of the process took two forms. Those of the educationalist which stressed the need to develop broader skills (such as the development learning skills) and those of management developers for whom the MCI represented a reductionist approach which (despite its benefits) could never fully 
reflect the breadth of the management domain. The more pragmatic conclusion reached here was that the MCI assessment process was necessarily narrow and that time constraints largely prevented any other form of development being supported by assessors. Responsibility for the skills development was transferred back to the candidate and their employer. The role of assessors was thus further restricted by the assessors themselves who saw the time constraint as an over-riding one. The development of skills seemed to be part of the old course-based approach into which the new competence based system clearly did not fit. This was recognised as a paradox and some assessors found comfort in the recognition that this restriction in role could account for some of their sense of loss self worth. As teachers or trainers they had a relatively clear mission - to deliver learning through courses. As assessors their responsibility for development was very much curtailed. The paradox was also evident in that they assumed that skills had been developed because they were measuring outcomes When challenged, few could identity examples were skills had actually been developed. To some extent, therefore, the MCI approach represented an attack on the traditional skills based approach to development. It provided no real substitute for more traditional methods of developing people's skills and abilities, though it could be seen as a useful supplement.

\subsubsection{Who controls the assessment}

The debate over use of indicators to determine when one stage was nearing completion and another about to begin, raised several useful questions over the control of the process. Whilst the group agreed that the model, as written, was both linear and rather mechanistic (it was agreed that different processes could take place simultaneously), the idea of control focused on who was making decisions over what approach to adopt and what evidence (this was the term used) was being utilised. All assessors felt responsibility for the success of the assessment, often in isolation, as the candidate sometimes failed to recognise this aspect of the process. Assessors felt it was their duty to decide on the agenda, even where this involved the candidate in 
providing some information or evidence. They felt uncomfortable about allowing the candidate to go away without a clear activity to perform (such as collect evidence of competence or submit part of a portfolio ). On occasions the actual timetable was negotiated with the candidate, but more often it was dictated by assessors availability. The agenda of meetings with candidates was almost universally set by the assessors. This combination of control of information (through knowledge of the standards) and control of the agenda and timetable are very much at odds with the notion of the candidate as an equal partner and much more in keeping with the traditional position of a student during other forms of assessment. Assessors were conscious of this issue, not least because several candidates had expressed their frustration with a system they were unable to control and over which they had little influence. Getting candidates "back on track" was seen as the second most serious problem for an assessors , after getting their involvement in the first place. It seemed as if having got the candidate prepared to accept responsibility for their own development process, the assessors then took away any opportunity for them to influence or control the pace or conduct of the assessment. Once again, assessors put themselves into the position of examiners, keen to retain control of the assessment process but anxious that the candidate should not fail ! Some assessors saw the position as untenable and suggested a further distinction between an adviser (who could interpret the assessment process and offer guidance) and the terminal assessor who simply evaluated outcomes or products. When it was suggested that the role of assessor spanned both sets of responsibilities it became clear that the university, and therefore the employers, were actually only paying for (and thus receiving) the latter, the implicit role of helper or partner having being overshadowed by the need to assess and qualify. 
System 7 (from Harri Augstein and Thomas)

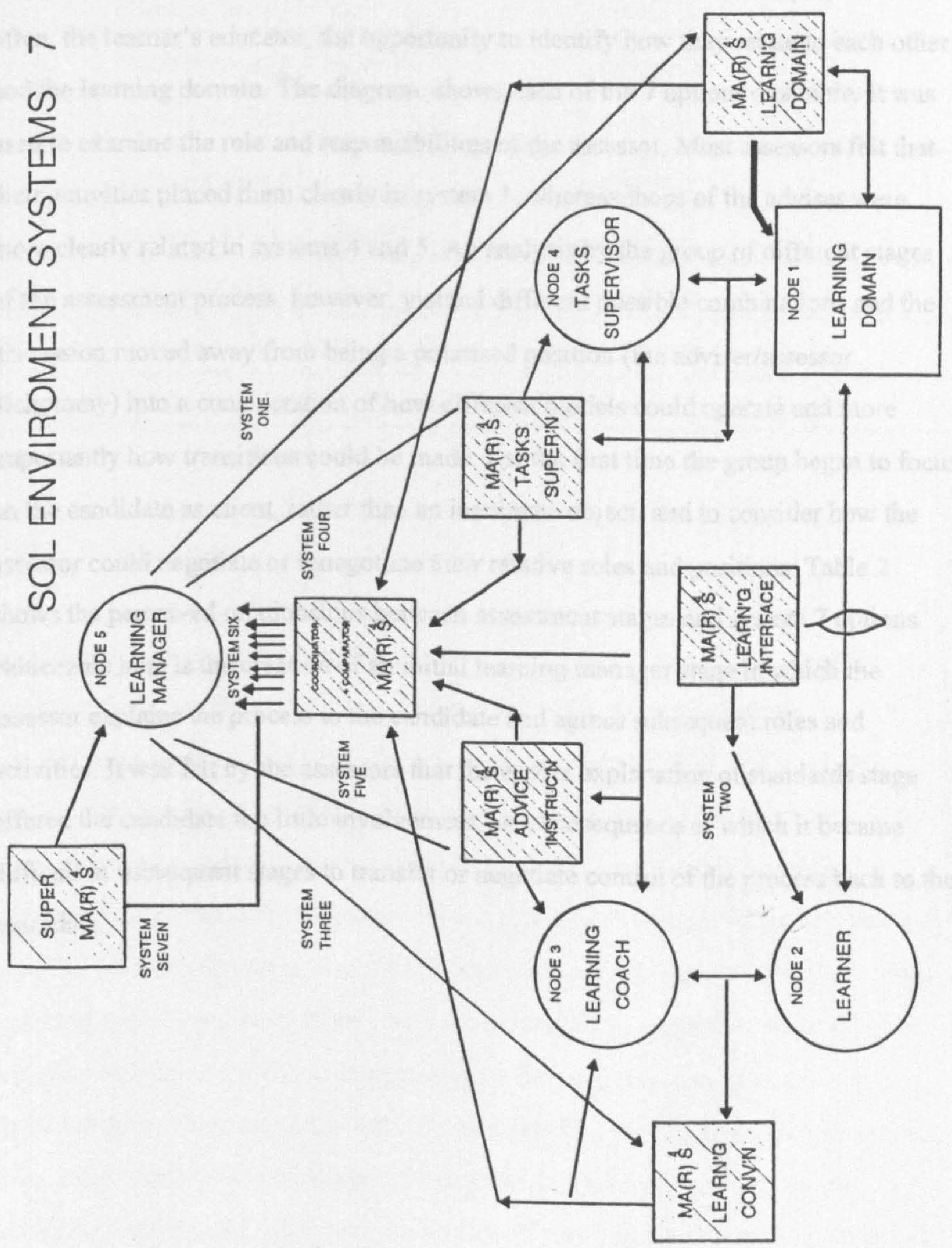


The system seven model has been used by Harri-Augstein and Thomas (1991) (1) as a method of identifying and explaining the different roles which a learner and another may perform in relation to each other. It is intended to offer the learner, or, more often, the learner's educator, the opportunity to identify how they relate to each other and the learning domain. The diagram shows each of the 7 options available. It was used to examine the role and responsibilities of the assessor. Most assessors felt that their activities placed them clearly in system 1 , whereas those of the adviser were more clearly related to systems 4 and 5 . An analysis by the group of different stages of the assessment process, however, yielded different possible combinations and the discussion moved away from being a polarised position (the adviser/assessor dichotomy) into a consideration of how different models could operate and more importantly how transitions could be made. For the first time the group began to focus on the candidate as client, rather than an inanimate object, and to consider how the assessor could negotiate or renegotiate their relative roles and positions. Table 2 shows the perceived relationships between assessment stages and system 7 options. Noticeable here is the creation of an initial learning manager stage in which the assessor explains the process to the candidate and agrees subsequent roles and activities. It was felt by the assessors that the earlier explanation of standards stage offered the candidate too little involvement, as a consequence of which it became difficult in subsequent stages to transfer or negotiate control of the process back to the candidate. 
Table 2

\begin{tabular}{|l|l|l|}
\hline stage & activity & system 7 \\
\hline new & explain process & system 6 \\
\hline 1 & Explain standards & system 2 \\
\hline 2 & Explain assessment process & stsytem 3 \\
\hline 3 & Collect evidence & system 4 \\
\hline 3 & Present evidence & system 4 \\
\hline 5 & Review written evidence & system 4 \\
\hline 6 & Provide written feedback & system 5 \\
\hline 7 & Discuss evidence with candidate & system 5 \\
\hline 8 & Conduct summative assessment & system 4 \\
\hline
\end{tabular}

\subsection{Conclusions}

The system 7 approach enabled the group to identify the changing nature of the assessment process in as much as it could now be seen as a series of role transformations rather than a set of mechanistic procedures. This changed the practitioners' model from being a chain of events in which the candidate and, to a lesser extent, the assessors, were passive figures, into a process managed by the assessors, but in which the respective roles and positions changed according to the needs of the task. The revised model allows the assessor to explain how the process is designed to work and enables both partners to identify the roles they fulfil. The new model moves beyond a set of interactions by offering a common basis of understanding, which is independent of, but related to, the actual assessment process. It formally identifies to the assessor those activities in which there is genuine candidate involvement and those which offer only information giving and receipt. It contains not only a "what", but also a "how" and to some extent a "why" in the sense that it identifies developmental opportunities as distinct from assessment of evidence. 
At the same time it recognises the significance of assessing evidence and assigns to it a given set of relationships.

The next stage in the development of the model is that of candidate involvement. Assessors are currently exploring methods to explain the assessment process using the system 7 metaphor and eliciting candidate views as to its helpfulness as a candidate map of the process. The intention is to create a guide to assessment which shows not simply what will happen, but what each participant should expect of the other and gives advice on how each needs to act and react to meet the others needs. The idea of an assessor manual has been transformed into an assessment manual which offers assessors and candidates a common view of the process and an understanding of each others parts within it.

\subsection{Reflective commentary}

The idea behind the survey was to gain the views of assessors as an alternative perspective on the assessment process. The decision on methodology was borne out of convenience rather than academic rigour. Often quantitative data as produced by the survey is seen as in some way superior to qualitative, or participatively generated, data, the latter sometimes being referred to as exploratory or preliminary studies. In this case the use of quantitative data was exploratory or preliminary, as it was designed to provide a context in which a subsequent discussion or conversation could take place. Whilst the early staged model served as a basis for quantitative data collection, the analysis was used for further qualitative data gathering through participation in a group setting. The addition of the system 7 model provided an alternative way of representing the assessment process - one which moved away from content and activities towards inter-related roles. The adoption of the system 7 approach lead to a further reconstruction of the assessment model into a series of transitions in which responsibility for learning could be shared. 
The main variable within the survey was that of time. Whilst significant from the point of view of time management, in itself, the variable provided little direct evidence of the quality of assessor/candidate interactions. As a means of generating debate or conversation, however, time spent in different activities helped assessors focus on what they saw as problem issues. The time variable was not in itself significant to the examination of assessor/candidate relationships, it became significant only when assessors chose to examine the implication of the time allocation in terms of implicit priorities within the process.

\subsection{Conclusions}

Data gains its significance not only from its manipulation, or its structure, but more importantly from the purpose to which it is put. The question of data format, or even data gathering, is not as significant as the uses or purposes of the research itself. This is not to say that methodology is not significant, but that the commonly heard arguments that quantitative data is somehow superior or that qualitative or participative studies are in some way implicitly inferior, ignore the fact that data gains meaning through interpretation. In this case quantitative data became significant through the interpretation of the assessors. They used it to initiate an examination of relationships. The subsequent model used (system 7) bore no relationship to either the quantitative data or the data gathering methodology. It served a separate purpose in exploring an apparent dichotomy of styles. It is neither the mechanisms used, or the models employed, which provide research with its significance it is the use to which they are put. The notion of inferior or inappropriate data, or inappropriate models, ignores the fact that research methodologies are the tools used. It is not the tool itself, but the job or outcome - of extending knowledge and understanding- which is of real benefit. Action research, as an approach, recognises the different potentials of different methodologies in the sense that it consider the purposes for which they can employed. It cannot be bound by a single method but is guided by the need to provide useful outcomes. 


\section{Chapter 11 Conclusions on NVQ research}

\subsection{Introduction}

The purpose of the NVQ research was to examine the issues involved and the resources required to introduce a competence based assessment and development system within the LFCDA. The choice of management competencies and the composition of the pilot group were seen to provide a useful indicator of future needs when compared to the practical and operational issues relating to assessing firefighting. Management as a domain was seen to be relatively straight forward. The implicit assumption of the pilot, therefore, was to examine the issue of competence based assessment in a relatively low pressure environment within which the cost of failure was seen as very low. In terms of assessment two issues were highlighted - the use of APL as a quick and easy way to recognise competence and to achieve qualifications, and the overall resources impact of the assessment process. The issue of development was largely tangential to the initial research brief.

\subsection{APL}

The combination of easily available evidence and a positive view of his own performance suggested that APL would provide fewest problems to participant a. His case, however, is indicative of much of the assumptive nature of $N V Q$ s when it refers to motivation. Although this participant chose the APL route as the simplest and most direct route to a qualification, even he found the evidence requirements excessive. Although portfolio building can be an exhaustive process, the issue highlighted in this case is not one of commitment, but rather of significance or relevance. The value of gaining a qualification was outweighed by the cost of presenting evidence, not because the latter was burdensome but because, in itself, it provided no real development. The claims made in relation to reflection were not substantiated in this case. Neither the collection or presentation of evidence encouraged reflection. It could 
be argued that the focus on collecting evidence drew attention (and time) away from considering experience as action and towards a consideration of experience only in the form of written records.

Because participant a had expressed an interest in APL it was assumed that he had no interests in development. The construct grid elicited tended to confirm this as he rated himself highly across all areas. The problems experienced in APL therefore did not come about as a result of a frustrated desire for development but rather an emergent lack of relevance or meaning in a qualification and assessment process. Participant a found the assessment process sterile and without relevance to his duties. Completing a portfolio, whilst it may have contributed towards a formal qualification, did little for his confidence as a manager, and certainly did nothing to add to his skills. Even where the APL route was the preferred choice, the system of assessment, with its inherent lack of developmental content, seems to be problematic.

\subsection{NVQ portfolios}

The problem of portfolio building is most obvious in APL because it represents an attempt to build from historic and often non developmental sources. The problem of portfolio building exists throughout the NVQ process and equates almost directly to the problem or issue of exam technique in traditional academic courses. Candidates are encouraged to consider evidence rather than experience and to develop skills in collection and presentation rather than experimentation and reflection. References to Kolb's learning cycle within the literature contrast sharply to the actual presentation and assessment process. Even where candidates were undertaking new activities the burden of evidence gathering was considerable. Partly because development does not always yield direct written evidence of a form suitable for NVQ portfolios.

The introduction of a partnership approach, whether it be with a peer or line manager, considerably reduced the problem of evidence. In creating a partnership, however, it 
was necessary to transform the development process and introduce a new explicitly developmental focus. The construct grids enabled participants to focus on their perceived needs in terms of meaningful personal descriptions. They were then able to exchange and extend the descriptions to provide a content for development. These constructs were related to performance standards in the sense that they had been derived from a consideration of performance standards and work components but they were not based on the standards. The availability of a second, personal, set of descriptors was particularly useful to the initial planing of development activities, it also allowed the manager (who had not received a briefing on the standards) to engage in the process.

The outcome of the partnerships in assessment terms was the availability of extensive additional evidence in the form of witness testimony. This, however, was in turn a product of mutually agreed development plans, themselves predicated on a shared understanding of development needs and related development activities. The standards thus represented an outcome towards which the development process was working but which were not in themselves the focus of development. As such the achievement of competence (the building of portfolios and the assessment process itself) were by products of a development process rather than vice versa. Development took place in a context dominated by shared, personally-meaningful criteria. The fulfilment of performance criteria was an outcome of the activities undertaken but not its sole purpose.

The effect of the introduction of personal constructs was not to replace standards completely but to relegate then to final outcomes i.e. by focusing on development needs identified by the participants, the programme offered the opportunity for local self managed development. The involvement of peers and line managers enhanced the effectiveness of these activities by providing access, support and, for the purposes of NVQs, evidence. The burden of portfolio production was thus reduced by the latter. The major contribution of the constructs, however, was not in relation to evidence, but 
in relation to development. The portfolios became an output or outcome of development rather than its sole focus. Evidence was produced as part of a naturally occurring development activity rather than simply an evidence gathering exercise. The key success of the research programme was in creating relevance for the participants and, in order to do so, it was necessary to reposition the standards, not as the focus of development, but simply as the indication of its achievement. The completion of units and elements of competence is an indication that development has taken place. It is not necessarily, or even usefully, the focus of the development and it is certainly no substitute for self managed developmental activity.

\subsection{The role of assessors}

The assessor survey was designed to increase evidence relating directly to the face to face contact referred to by NCVQ in their assessment guidance. This process remains one of the key elements in the learning process described in competence literature. The experience of LFCDA candidates was very limited. To the extent that some candidates found the process rather mechanistic, I canvassed the views of a number of full and part time assessors. The assessor group's responses, both as individuals and collectively in a meeting, suggested that the notion of formative assessment was rather optimistic.

Estimates of time spend in actual face to face contact with candidates văried from $10 \%$ as a low to $60 \%$ as a high with a mean of $29 \%$. Within this very limited time span the proportion of time spent on explaining standards and promoting portfolio development seemed to exclude any form of reflective conversation. The idea that, in discussing evidence, the candidate and the assessor would review how the achievement came about and what had been learned (or understood) was seen to be a fantasy on the part of the designers. Although the industry lead body referred to the use of reflective techniques, the emphasis of the assessors was linked directly to the completion of units and the skills required to produce and submit evidence. The self 
perceived role of the assessors contained very limited developmental activity. If we exclude explanation of the standards themselves and the portfolio building process, the assessors contributed very little to work based development. Some suggestions were made but often these were seen as inappropriate or unachievable. Examining the role of the line manager was not part of the assessor brief, to the extent that both learning opportunities and possible problems of obtaining evidence were religiously avoided.

An area of interest not fully explored in this research is the purpose of the assessor. Since use of the NVQ system has become more common in organisations there has been a tendency to shift away from external assessors to in house, often line manager, assessment. Whilst this research suggests that such a move may be a positive step for the assessment process, such a transfer may or may not concur with the purposes of the assessors. In particular, a line manager may be encouraged to focus on the assessment process to the neglect of any development activity. The national focus on outcomes and outcome based funding could simply be replicated in a system which encourages managers to assess rather than develop - indeed since the former is in some cases the only evidence of the latter is difficult to see how learning itself will actually be evaluated. These issues are beyond this study, the research presented, however, suggests that the purposes of the assessor as a participant in the process may well be as significant as those of the learner. The purpose and role of the assessor will considerably influence their relationship to the learner and the relative-importance given to assessment or development will clearly affect the success of the process as a development.

\subsection{The assessment process and development}

Within the overall assessment process the issue of underpinning skills or knowledge is problematic. The industry lead body remained deliberately vague on this point even when pressed by assessors. The awarding body within which the assessors operated 
was equally non-committal leaving the issue of what knowledge to require and how to assess it to individual choice. In some cases this choice rested on available course literature and tended to be prescriptive in terms of academic content. For other assessors the question of knowledge was reduced to that knowledge actually demonstrated by the candidate to produce the outcomes, and to this extent was assessed only as a secondary source of information.

Thus the combination of assessor comments and candidate experience suggest that the actual assessment process lacks any real developmental content, despite the written intentions of Gilbert Jessup. From a candidate perspective the preparation of a portfolio is equally non-developmental and, whilst the evidence may rely on developmental activity, the actual process of compilation (sorting and cataloguing experiences) provides no new insight or understanding. This is not to say that the standards cannot be used developmentally or that their availability prevents them being used in development activities . Rather it suggests that there is a significant difference between the use of the standards for development and their use for assessment. The latter being significantly different in both application and outcome. NVQ type standards could be of significant use in planning learning, either individually or for groups in training contexts, but when applied to the assessment of performance tend to operate in a very structured and mechanistic way. Like competencies in assessment centres, there is very little wrong with having a written description or roadmap of the domain. The problem seems to occur when one substitutes the road map for the territory and mistakes the assessment process for the development process.

\subsection{Suggestions for improving the learning process}

If we accept that the standards can be useful to learners the next stage consists of establishing ways in which learners can use the standards. This may sound obvious, but, like so much in assessment literature, stating the obvious is often ignored and 
assumptions made. If we recognise that public standards represent a form of otherorganised learning and, that to become useful to individuals, they need to access these for self organised learning, we need to design a mechanism for translation. Before we do this, however, we need to consider the purposes of the learner. The current system of NVQs sees the learner as self motivated towards achieving a qualification. Whilst this is true of some learners, this may not be the only, or over- riding purpose. The notion of a multiplicity of purposes suggests that a useful starting point may be to consider a possible hierarchy of purposes culminating in a qualification, but within which different needs and priorities could be addressed.

The NVQ research presented in these studies relied heavily on the use of personal constructs to make the standards relevant. Such a process certainly involves the person at a fundamental level but may not always be necessary, provided that the individual already has some earlier understanding of his leaming needs. Where this is not the case, and this may be particularly true of candidates whose prime interest is in the qualification, some consideration of developmental need is of benefit. The use of constructs for focusing on development simply makes explicit and personal the link between public standards, personal needs and the work domain.

Improving the actual assessment process is more problematic. Replacing formative assessment by other forms of coaching and support may be valid but these do not overcome the problems inherent in portfolio building. Whilst the coach or mentor may be more helpful in terms of explaining standards or event encouraging refection on achievements, the actual assessment will remain reliant upon evidence. The studies suggest that the involvement of the line manager as a learning coach may improve the availability of evidence since his or her views can be submitted in the from of witness testimony. This is also true of other forms of cooperation although, as indicated in the studies, the issue of authenticity may have to be considered. The notion of a collective approach to competence does not fit with the current NVQ methodology which remains individually focused. Nnevertheless, collective or group development may 
yield evidence which individuals can submit for assessment.

The problem of portfolio building has been the subject of almost continued criticism. The written nature of much of the evidence required has been questioned as has the sheer volume of material collected and presented. The former may be replaced by other forms of evidence, depending on the nature of the qualification. In the case of managers, however, written evidence reflects the largely written nature of some activities. Volume remains an issue for candidates and seems to be a result of the need to provide evidence across many different performance criteria and range statement. Unless a process of sampling is agreed nationally this problem will remain and even where assessors allow cross referencing (this seems to be dependent upon the assessor) the need to show competence across the range of activities remains the principal factor governing portfolio size or weight.

\subsection{The role of the research process}

It would be foolish to suggest that the research process used in these case studies was in any way neutral. Although beginning with a consideration of current competence against standards, it soon became apparent that there were significant differences between the purposes of the organisation and those of the individual participants. These differences were most obviously revealed by the use of personal constructs and the emergence of a possible assessment system outside NVQs. The use of personal constructs represent both an interpretation of national standards and simultaneously an attempt to go beyond them into the individual's own purposes and assessment system. My justification for the use of personal constructs rests not only on their apparent success as a focus and tool for development, but also on the relative poverty of the use of NVQ standards in isolation.

Stages 1 and 2 of the research project were intended to assist with APL. In reality, however, they seemed to point to the futility of APL as a developmental process. In 
prioritising APL the London Fire Brigade had misinterpreted the development process and had substituted qualification for development. The use of constructs in stages 3 and 4 enabled the candidates to focus back on their own development and where necessary align this to the standards and generate evidence for assessment. It was not the standards which generated evidence, however, but a separate set of development activities based on personal needs. As with the assessment centre case studies, the research promoted leaming by providing relevance and structure. Without the research, or more particularly without the constructs, there is little to show that participants would have pursued any sort of developmental activity. Whilst it may have been possible for some candidates to generate or collect evidence, there is nothing to suggest that this would have represented meaningful learning. 


\section{Chapter 12 Conclusions}

\subsection{Assessment or development ?}

The relationship between assessment and self development is far from obvious. The research studies suggest that the missing component appears to be the learner. The assessment processes operate effectively in their own right but focus on evidence rather than the person behind the evidence. Thus assessment centres reduce the learner to a set of indicative behaviours whilst the NVQ approach relies on the portfolio in place of the person. What is not made clear is the relationship between what is assessed and how it can be developed. In particular what is often missing, is how to engage or re-engage the person as a learner. Without a clear role for the learner, the focus of the development process can easily become the assessment rather than any necessary skills. In the same way that traditional academic courses tend to encourage students to learn exam techniques, attending assessment centres can easily lead to time being spent on "test busting". In the same way that certain forms of continuous assessment tend to encourage essay writing, so NVQs can turn attention towards portfolio building. Without a clear role for the learner the learners may simply decide to focus on improving their self presentation skills at the expense of other possible areas.

\subsection{Personal constructs as a means of re-engaging the individual.}

In itself, there is nothing wrong with a public system of standards or a set of organisational competencies. Problems arise when these are used as if they represent a superior (objective) form of knowledge and contrasted to personal or subjective understanding. Collective knowledge is something in which we can all share but which cannot replace our own personal knowledge and understanding, particularly our knowledge of ourselves. It may be possible to measure personality in 16 or 27 or just 5 dimensions, but to become meaningful the measure must be related to our everyday 
experiences. Reliability of measurement has tended to depersonalise psychological measures to the extent that their sensitivity and coverage are limited (sensitivity being limited most notably in respect of change). The use of personal constructs forms part of a link between personal and public knowledge. By making available our own categories - the ways in which we assess our own performance for example - we can either exchange information with others or interpret or decode public information into our own personal system. Assessment systems need to be interpreted before they can be properly applied. The personal construct approach provides a mechanism for this interpretation.

\subsection{A model of learning}

The concept of self organised learning, as created and developed by Harri Augstein and Thomas (1991) suggests a differentiation between that which is self organised and that which is other organised. At a practical level this serves to differentiate between external, often formal, systems of learning (which may have been imposed) and self generated or personal systems which are in the control of the individual. In a more abstract sense the dichotomy is perhaps less tenable, since, as both Harri Augstein and Thomas would admit, the process of self organisation is itself social or as they have termed it conversational. Thus whilst one measure of self organization is the creation and use of personal constructs, a more significant indicator is the ability to exchange constructs and maintain or even share control of the learning process. In this sense the notion of self organisation is close to that of Argyris' (2) duetero learning i.e. an awareness of and hence control over the process of learning (viz learning to learn). The case studies illustrate a possible hierarchy within this process beginning with the generation of constructs, moving towards the exchange of constructs through the interpretation of other systems within a personal construct framework.

Harri Augstein and Thomas (3) suggests three levels of conversation each based on an examination of purpose, strategy, outcomes and a review process. The three levels of 
learning refer to task or domain, life and learning itself. The conversations in this research are almost all task or domain based. There are no life conversations because the very specific domain focused conversations were part of the focus of both my research and the participants learning. The absence of learning to learn conversations is less straight forward. These could have emerged from any task conversation. On the other hand, the focus of all the conversation remained firmly rooted in the task domain of management. Attempts to consider broader purposes were slightly more successful in examining NVQ learning, as the APL process encouraged participants to think about their objectives in achieving a qualification. Nevertheless, subsequent considerations of purpose largely focused on completing the programme.

The need for ongoing support for management learning raised by the studies has not been fully considered within either NVQs or assessment centres. This is most obvious when we contrast a simple appraisal process and the role played by the line manager, with the absence of a place for him or her within the more formal assessment systems. The type of self development asssociated with assessment seems to be equated with a lack of support, whereas self management actually requires support. It is not isolation that distinguishes effective self managed leaning, but autonomy or control. Self managed learning is about making choices about development options, it is about creating options from resources but cannot be undertaken without resources.

A general criticism of assessment oriented learning lies in its lack of attention to the role or location of the learner and their day to day activity. This is not only true in respect of their relationship to the line manager but also peers. The underlying assumption appears to be that self managed learning is individualistic. This lack of attention to learning may in fact be counterproductive to the extent that the effect of the assessment process may be negative or at least not in an organisationally positive direction (e.g.fixated on part of the assessment process). This is particularly problematic in an organisation such as the LFCDA with its essentially internal labour market. Any reductions in the supply of skilled labour - either because people develop 
in non-productive ways or simply withdraw from the assessment and development cycle - can result in the loss of skilled and experienced personnel. A further unanswered question relates to the validation of assessment focused development. According to the assumptions in an assessment based learning system, such learning would be interpreted through improved scores or assessment results i.e. positively! If, however, such development is so exclusively focused that it has no relationship to the workplace performance, what actual return is made on the considerable personal and organisational investment?

\subsection{Conclusions}

In conclusion the task of developing learning may be assisted by assessment. To develop an effective learning programme, however, organisations need to consider the role of assessment within learning rather than the vague notion of learning as a product of assessment. It is the quality of the learning process which is important and not necessarily the quality of the assessment. Good technical or professional assessment may not necessarily be good personal development. Even where assessment systems remain "other oriented", and for many organisations the concept of self oriented assessment remains a distant prospect, the other orientation must recognise learning as its primary objective. There seems little to recommend to the learner a system which sees assessment as an end in itself. 


\section{Chapter 13 Personal Conclusions}

This research is about manager's learning but in undertaking it my own views and, to an extent, skills have changed. Indeed my purposes in conducting research have changed, as has the way in which I perceive knowledge to be generated. Initially my research was motivated by frustration about the absence of learning in literature about training. My search for learning focused on activities which did not rely upon external agents in the form of teachers or trainers. At first glance assessment systems seemed to offer real possibilities for self managed learning. As the research progressed through the literature review, I was disappointed by the lack of any specific consideration of the learning process amidst a wealth of assumptions and assertions. As the case studies progressed, so it became apparent that learning needed support and that information without some means of interpretation was of little value to the participants.

As a result of the absence of data I had to review my role as a researcher. The options appeared to be to report the lack of data as results or to consider what measures could be used to encourage learning. Since the ownership of the research was no longer related to my employer, this choice became one between helping the participants or simply allowing them to develop as best they could without any support. In choosing the former I was forced to reconsider my purposes in conducting research and the implications for writing up. Although I was keen to assist, and, therebý to generate data, the choice about the focus and pace of development now lay with the participants rather than myself. Having rejected the traditional researcher/subject relationship, I found myself having comparatively little control over the subsequent development activities which participants selected. In effect, the subjects had taken charge of large parts of the experiment leaving me the role of recorder as well as that of coach.

I am aware of the limitations to the research in terms of participation in the process. It 
is difficult for me to say whether this is attributable to a reluctance on the part of participants, or a lack of confidence by myself as researcher. The participants were comfortable working in the task domain and I was happy to continue helping them, provided that data was being generated about their learning. What else could have been done? The notion of learning to learn did not emerge from the conversations and to introduce it would have been a more deliberate and potentially intrusive act on my part. On the other hand, the limited nature of the conversations suggests that the research tended to operate at a very instrumental level and that the full person was not being engaged in the learning process. With hindsight, I consider that the learning can be supported but cannot be forced. If this is where the participants were most interested in working, what role, or what right, has the researcher to focus on new and possibly confusing concepts.

\subsection{Learning and training}

Traditional learning methods value the role of the teacher as either expert or guide. In doing so they create or maintain a power relationship between the learner and the person managing the learning (in SOL terms, the other). This relationship may be explicit in such cases as the apprentice master bond or implicit e.g. a great deal of distance or open learning in which the learner may manage aspects of the process (particularly pace) but in which key elements of control, mostly the learning process (and coincidentally domain content), remain in the hands of the teacher or learning designer. Self Organised Leaming (SOL) seeks to restructure this relationship, transferring power or control to the learner. This is not to say that there is no role for another to assist in the process, but rather that SOL seeks to create the conditions under which the transfer can take place. This is in itself a learning process - learning to leam through becoming more conscious of one's own learning process.

One of my initial concerns as a trainer was to examine how people learnt. One of my early frustrations was the extent to which studies of learning emphasised the role of 
the teacher or trainer at the expense of the learner or the learning process. My research aimed to examine how learning could take place without the presence of a formal trainer. What has emerged suggests that the physical presence of the trainer is less significant than the impact of the trainer, or assessor, as the designer of a learning process. Both NVQs and development centres put forward the idea that they can enable people to structure and manage their own learning. My review of the literature was unable to demonstrate how this process or processes actually operated. Despite the widespread belief that such activities could enable or support self managed learning, the research evidence was largely inconclusive. This absence of evidence provided the motivation for me to begin my own empiric research. The development of my research involved a change in my role as a researcher from that of an almost passive recorder to that of an active participant in the learning of others. Far from demonstrating that learning was not self managed, I intervened in the process to assist the development of self managed or self organised learning. What therefore distinguishes my role as researcher from the traditional role of the teacher or trainer?

In my view the two roles that of traditional trainer and that of learning coach differ in a number of distinct ways each of which is significant in terms of the relationship of the learner to his or her own learning. Firstly, the learner develops or identifies the outcomes of their own learning through defining the learning domain. Secondly, the learner as a participant in the research process is encouraged to share these outcomes with the research manager (myself) in the same way as the learner can exchange constructs about the domain with others outside the research.Thirdly and finally, the outcomes of the process are evaulated by the learner, rather than the trainer and its is the learners' own values which dictate the process of evaluation.

\subsection{Research process and research outcomes}

The main idea behind my research was to discover something about learning. My initial hypotheses were content based and related, to the extent to which a given 
activity or treatment would effect or impact of individual self development. As the research progressed, and the lack of appropriate "effects" emerged, so it became necessary to vary my research techniques and renegotiate my role. As this took place, so a second more important set of hypotheses began to emerge. These methodological hypothesis related to the extent to which any significant learning could be identified using experimental type techniques. At first, this hypothesis was expressed in a negative way, on the basis that experimental types of approach had yielded little evidence of learning. Later this hypothesis came to be expressed more positively, in relation to participation and conversation. In simple terms, the methodological hypothesis consists of a statement to the effect that personally significant learning can only be examined through an approach which recognises and engages (conversationally) with the learner and his or her own meanings and sense making systems. To the extent that leaming is conceived of as a separate entity, distinct from the leamer, we will continue to be trapped in a positivist framework within which positivist research supports, or at least fails to recognise alternatives to, positivist or non conversational approaches to learning.

In considering my work retrospectively, I do not consider that the research in relation to assessment processes is by any means complete. Although conclusions are reached here, there is a great deal more to be understood about assessment and learning and the relationship between ad hoc events and day to day management activities. On the other hand, the techniques currently available in educational research, tend to focus on the treatment rather than the consequences and on the means by which learning is to be achieved (training assessment etc) rather than the people who may or may not learn. This work has explored an alternative approach, which treats the individual learners as significant. Rather than examine changes in behaviour (outcomes), it focuses on changes in understanding and in particular self understanding. Proceeding from the simple, but often omitted, assumption that learning is a reflective process, it examines the reflector rather than the effects. If learning were a simple mechanistic process, akin to say blinking or salivating, then perhaps the experimental approach 
would be valid, to the extent that it might identify contributory factors of which the individual would not normally be aware. In the case of learning, however, and self development in particular, the awareness of the learner is a key component. The involvement of the learner is essential to any consideration of learning. This research supports the hypothesis that meaningful learning can only be examined by means which encourage the learner to identify and reflect of his or her own meanings.

With the benefit of hindsight, I am much clearer that it is the methodology and not just the outcomes which make my work personally significant (and hopefully useful to others). It is the process of research that is significant, as well as the results themselves, and it is the interrelationship of process and results which make both valid. If the achievement of the learners is primarily their achievement with my assistance, then the corollary of this is that, my achievement in terms of methodology, was only possible with their assistance and cooperation. Whereas the writing up (particularly the misuse of clauses and strangulated English) are mine, the methodology I describe only came about through the participation of other learners.

In terms of hypothesis testing, my first hypothesis relating to the effect of assessment on learning remains unfulfilled. Certainly assessment has some effects on individual's learning, but these are neither of the magnitude, nor necessarily in the direction, intended or predicted. They are no more positive than any other work activity and may, in some cases, be detrimental to both the person and the organisation. The notion of assessment based leaming as a positive or healthy phenomenon is yet to be established.

My second hypothesis related to the methodology or research techniques appropriate to learning and, to the extent that conversational research has enabled learning, it has also provided relevant information on the process. This is an important outcome, even though, at first, I was more concerned to explain the process in the form of an apology for creating, or in some way fixing, the data to meet my requirement. Leaving aside 
the rather cynical view that all research methods in some way provide the data required in the format preferred (for the appropriate conclusions to be made) - the idea that methodology is significant and potentially as significant as the results is of some note. Traditionally researchers have sought to quantify learning and to describe it in terms given by the researcher. My research examines the quality of the learning and uses a framework specified by the interests of the learner. In crude terms, the former approach failed to yield any significant data, only when exploring why there were no obvious effects of assessment did it become possible to consider the actual value of the learning to the individual. Subsequently, this consideration of value and purpose enabled significant learning to take place.

If one considers assessment as a treatment and treats learning as a commodity to be measured extemally, results of an investigation can, as in this, case prove elusive and somewhat intangible. If, on the other hand, one abandons the notion of measurement of commodities as a data collection process and considers the explanations and understandings of the learner, one discovers a range of useful data. This process of discovery is not, however, without its own "effects". The most signifcant of the effects is to allow the learner to consider his or her purposes and interpret the treatment (as one might term the assessment activity). Unlike the effects implicit in the more traditional model, the effects of conversational research are not expressed in terms of an impact on learning, but rather they evidence themselves in the quality and direction of the learning itself. The outcome of conversational research is not simply data about learning, but a move towards more coherent self managed learning i.e. an improvement in the quality of learning. The relationship between research, as a process, and results, as outcomes, is,,therefore, both causal and interdependent - one providing impetus for the next.. At first, I conceived this is terms of a problem It is, however, an inevitable and unavoidable component of conversational research. As one studies someone else's understanding of something, so both understandings are changed and as the new understandings are explored and exchanged so these give rise to new and different understanding. The process is the product and vice versa. 
In this sense the evidence, or data, provided by research is inseparable from the research methods used. Just as the evidence of learning is learning itself, so the method of providing evidence must be in some way developmental. It may not be possible (even were it to be desirable) to undertake conversational research without development. The key question seems to be - in whose interest and under whose control the learning or development takes place? To the extent that this is my research, I must admit that control, has, on many occasions, rested with me as the researcher. I have not offered to share control equally with my research participants and, with hindsight, this represents a limitation to my work. In seeking to retain control over a process which, by its very nature, needed to be shared, I may have limited its usefulness. The focus on immediate job oriented development (rather than broader life or learning to learn conversations) may not relate solely to the limited nature of participants objectives, but also perhaps a failure on my part to allow them full access to the research process

Research in a conversational environment is, by necessity, a learning process. It involves not merely the use of existing research tools, but the development of research techniques which enable others to learn. Action research in this context is as much about learning from the process of research and from research participants as it is from formal supervision or training in research methods. The development of the methodology took place largely in response to the needs of the leamers; rather any needs I had identified as a researcher. Research is a conversational process and what is presented now emerged through several conversations over a period of years. At the same time I was also engaged in a conversational process with my supervisors. Part of my own development, therefore, was the recognition that learning research cannot escape or be separated from learning itself. One cannot expect to understand learning from the perspective of one who either has or is not learning but only from the viewpoint of one who is also learning. This is the essence of conversational research. It informs the researcher no less than the research participant, and does so to the extent that either or both are prepared to recognise and value the learning provided. 


\subsection{Conversational research}

The limitations of this research are my own limitations as a researcher, and I must emphasise that the results achieved in relation to the research participants may well have been shaped by both my skills and these limitations. The ideas behind the concept of conversational science suggests greater possibilities for exploring and enhancing human understanding based on conscious, scientific, and, therefore, rational exploration of our subjective understandings of ourselves and the world around us. These ideas do not stand in opposition to traditional rationalist or positivist understandings of the world, but rather see existing science as collective subjectivity. The dangers inherent in traditional forms of scientific enquiry are not necessarily the methods used or the conclusions reached, but lie in the notion that they can be objective and as objective they carry value. This reification of science is at odds with our normal human existence. It creates and maintains the notion of professional scientists as separate and different from normal humanity and seeks to drive a wedge between day to day existence and knowledge. The notion of a conversational science has clear antecedents in the work of Kelley and the idea of the personal scientist. It has utilised and created tools to extend that possibility and now seeks to mechanisms to realise that potential.

Because traditional science rests on its "objectivity" it is often hostile to any form of subjective or personal knowledge, particularly so when it sees such phenomena as threatening its own position. Because it is hostile to subjectivity, many apparently scientific disciplines seek to disguise or disown the human origins of their activities. Applied psychology - the discipline which created assessment centres- is a good example of such an area. As a discipline it uses tools such as the repertory grid in a way that is much less rigorous (and hence more unconsciously subjective) than any personal scientist would be comfortable with. Yet, simultaneously and partially because of its infatuation with statistics, it sees itself and its products as objective. A conversational approach to this apparent paradox cannot be to stand aside and 
criticise. Implicit within the conversational methodology must be the notion of exchange or conversation. My purpose is not to ridicule or necessarily undermine applied psychology, but, by suggesting other ways of achieving understanding, to indicate the limitations that perceived objectivity places on its adherents. By indicating what sort of learning could be achieved, suggesting different ways of approaching the problem of development in organisations, and by offering different research techniques, I am proposing that impartiality or objectivity is an increasingly inconvenient or limiting factor in examining human behaviour. If we really want to understand ourselves, we must listen to ourselves and recognise that neither objectivity or pure subjectivity exist but only different forms of collective or shared understanding. A conversational science recognises the significance of shared knowledge and seeks to add to the mechanisms available to us to share in each other's understanding.

\subsection{Endings}

I have described my research as a journey. This journey is not over. My research has caused me to re-examine my role in relation to learning both my own learning and that of others. Paradoxically, it has served to remove constraints regarding training or teaching. It is not the technology or even the power relationships which govern learning - it is the commitment to learning which makes the difference. The way in which I attempt to structure or manage learning is governed by the purposes and strategies of the learner as an individual. I learn how to help them from working with them rather than standing apart. Participation is the key to understanding learning just as it is the secret of how to make learning work. My journey is far from over but it will not be undertaken alone. It is a journey which will be undertaken with other learners in other contexts. Assessment and training are simply contexts for learning, they may represent opportunities to learn, but they are not learning tools. Learning is about participation in the process of creating meaning. 


\section{References}

Chapter 1

1. Harri-Augstein, S. and Thomas, L. "Learning Conversations". Routledge. London. 1991.

2. Argyris, C. “On Organisational learning.”. Blackwell. Oxford 1994

3. Harri-Augstein, S. and Thomas, L (ibid)

4. Reason, P. and Rowan P. (Eds) foreword to "Human Enquiry". John Wiley 1981.

5. Reason, P. and Rowan P. (Eds) (ibid.)

6. Kuhn, T. "The Theory of Scientific Revolutions" University of Chicago.

Chicago. 1962

7. Harri-Augstein, S. and Thomas, L (ibid)

8. Kelly, G.A. The Psychology of Personal Constructs" Norton. New York. 1955

9. Harre, R and Gillet G "The Discursive Mind". Sage. 1994

10. Lewin,K. "Action Research and Minority Problems" Journal of Social Issues 2 $(33-46) 1946$

Chapter 2

1. Pedlar, M. Burgoyne, J. and Boydell, T. “A managers guide to self development" McGraw Hill. 1995

2. National Forum for Management Education and Development "First Line Management Standards" and "Middle Management Standards". National Forum for Management Education and Development. 1992. 


\section{Chapter 3}

1. Moses, J.L. "The assessment centre method". in Moses, J.L. \& Byham W.C. (Eds) "Applying the assessment centre method" Pergammon, New York. 1977.

2. Vernon, P.E. "Personality assessment: a critical survey". London, 1963. Tavistock.

3. Stewart, V. \& Stewart, A. "Tomorrow's managers Today". (2nd Ed) Institute of Personnel Management. 1981.

4. Hunter, J.E and Hunter, R.F "Validity and Utility of alternative predictors of job performance" Psychology Bulletin. 1984,

5. Dodd, W.E. "Attitudes towards assessment center programs". in Moses, J.L. \& Byham W.C. (Eds) "Applying the assessment centre method" Pergammon, New York. 1977.

6. Schmitt, N, Groding, R.Z., Noe, R.A., \& Kirsch, M... "Metanalysis of validity studies published between 1964 and 1982 and the investigation of study characteristics". Personnel Psychology , 37, 407-22, 1984

7. Blinkhorn, S. "Centres of excellence". Training Officer, June 1989.

8. Mayo, A. "Managing careers: strategies for organisations" London, IPM. 1991.

9. Stewart, V. \& Stewart, A. Ibid. 1981.

10. Klimoski; R. \& Brickner, M. "Why do assessment centers work ? the puzzle of assessment center validity". Personnel Psychology 40, 243-60, 1987.

11. Boyatzis, D.E. "The competent manager". John Wiley. 1982

12. Hoogheimstra, T. "Integrated management of human resources". in Mitriani, A. , Dalziel, M. \& Fitt, D. (Eds), "Competency based human resource management". Hay. 1994.

13. Bray, D.W. "Fifty years of assessment centres: a retrospective and prospective view". Journal of management development, 4, no 4, 4-11. 1985.

14. Moses, J.1. ibid

15. Robertson, I. T., Gratton, L. \& Sharpley, D. "The psychometric properties and 
design of managerial assessment centres: dimensions into exercises won't go". Journal of Occupational Psychology. 60, 187-195, 1987

16. Klimoski, R. \& Brickner, M. (Ibid)

17. Hinrichs, J.R. \& Haanpera, S. "Reliability of measurement in situational exercises : an assessment of the assessment center method". Personnel Psychology, 1976, 29, 31-40

18. Lewis, C. "Employee selection" 1985. London, Huthchinson.

19. Slivinski, W.L. \& Bourgeois, R.P. "Feedback of asessment centre results". in Moses, J.L. \& Byham W.C. (Eds) "Applying the assessment centre method" Pergammon, New York. 1977.

20. Feltham, R "Validity of police assessment centres: a 1-9 year follow up". Journal of Occupational Psychology, 61, part 2, p 129-144. 1988.

21. Byham, W. Ibid

22. Boehm, V.R \& Hoyle, D.F "Assessment and management development". in Moses, J.L. \& Byham W.C. (Eds) "Applying the assessment centre method" Pergammon, New York. 1977.

23. Gill, R.A. "A traininability concept for management potential and an empirical studv of its relationship with intelligence for two managerial skills" Journal of Occupational Psychology, 1982, 55, 139-148.

24. Hoogheimstra, T. Ibid

25. Boehm \& Hoyle ibid

26. Byham, W.C. "Dimensions of managerial competence: what they are, how they differ between levels, how they are changing" Pittsburg. Development Dimensions International. 1982.

27 Storey, J \& Sisson, K. "Making Mangers in Britain: a progress report". Public Money and Management, Spring 1990.

28 Boehm, V. " Using assessment centres for management development -five applications". Journal of management development, vol 4, no 4, 40-53. 1985

29 Greatrex, J \& Philips, P. "Oiling the wheels of competence" Personnel Management, 21, 36-9, August 1989. 
30 Robertson, I.T. \& Makin, P.J. "Management selection in Britain: a survey and critique". Journal of occupational Psychology, 59, p 49-58. 1986.

31. Boyatzis, D. (ibid)

32 Imada, A.S , Van Slyke, M.D., \& Hendrick, H.W.."Applications of assessment centers multi nationally: the state of the art obstacles and cross cultural implications". Journal of Management Development, 4, 54-67. 1985.,

33. Glaze, A. "Cadburys dictionary of competence". Personnel Management, 21, 44-8, July 1989.

34. Byham, W.C. "Assessor selection and training".in Moses, J.L. \& Byham W.C. (Eds) "Applying the assessment centre method" Pergammon, New York. 1977.

35. Byham, W.C. \&. Thoreson, J" Effectiveness of assessor training techniques" Pittsburg, DDI. June 1976

36 Byham (ibid)

37. Mayer, H.H. "Self appraisal of Job Perfromance". Personnel Psychology, p 291-295. 1980

38. Fletcher, C. "Candidates reactions to assessment centres and their outconmes: a logitudinal study". Journal of Occupational Psychology 64, p 117-12. 1991.

39 Jacobs, R. "getting the measure of managerial competence". Personnel management. p 32-7. October 1989.

40. Schmitt, N. , Ford, J. \& Stults, D.M. "Changes in self-perceived ability as a function of performance in an assessment centre". Journal of Occupational Psychology, 59, 327-35, 1986.

41. George, D.I. \& Smith. M.C. "An empircal comparisson of self assessment and organisational assessment in personnel selection". Public Personnel management, 19, 2, p 175-90.

42. Robertson, I.T., Iles, P.A., Grafton, L. \& Sharpley, D. "The impact of personnel selection and assesment measures". human relations, 44, 9, p 963983. 1991.

43. Huck, J.R. "Assessment centers: a review of the external and internal validities".. Personnel Psychology, 1973, 26, 191-212. 
44. Wexley, K.W. "Characteristsics of effective interviews". in Berk, R.A. (ed). "Performance assessment methods and applications". The John Hopkins University Press. 1986

45. Landy, F.J. \& Farr, J.L. "The Measurement of work Performance - Methods, theories and applications". London,Academic Press 1983

46 Pedler, M. , Burgoyne, J. \& Boydell, T.(ibid)

47 Schein, E.H. "Career Theory and Research - some issues for the future". in Brooklyn Derr (ed) "Work, family and career". Mit Press. 1980.

48 Nemerroff, W.F \& Wexley, K.W. "An exploration of the relationships between perfromance feedback interview characteristics and interview outcomnes as perceived by managers and suboredinates". Journal of

Chapter 7

1 National Council for Vocational Qualifications, "NVO Criteria and procedures". London 1989

2. Training Agency / CNAA Development Services. "Towards a new certificate in management". (Part of the series "Investors in people") Training Agency. 1989

3. Jessup, G. "Outcomes: NVOs and the emerging model of education and training". London. Falmer Press. 1991.

4. Wolf, A "Assessing Competence" Open University press. 1995

5. Simosko, S. "APL: A practical guide for professionals". London. Kogan Page. 1991.

6. Hall, J. "Crediting competence - a portfolio development technique for managers". Training and development. June 1992

7. Simosko, S. (Ibid)

8. Walkin, L. "The assessment of performance and competence". Stanley Thomes 1991.

9. Jessup, G. "Technical note on the new training initiative: Implications for 
standards assessment procedures and accreditation". MSC. 1985.

10 Simosko, S. (Ibid)

11 Walklin, L. (Tbid)

\section{Chapter 12}

1. Harri-Augstein, S. and Thomas, L. "Learning Conversations". Routledge. London. 1991.

2. Argyris, C. “On Organisational leaming.". Blackwell. Oxford 1994

3. Harri-Augstein, S. and Thomas, L (ibid) 


\section{Bibliography}

Adams, D. "Assessment centres: bespoke or ready to wear". Guidance and Assessment Review. 3, 1, 6-7. 1987.

Advisory, Conciliation and Arbitration Services. "Employee Appraisal" London, ACAS. 1988

Alon, A. "Assessment and Organisational Development". in Moses, J.L. \& Byham W.C. (Eds) "Applying the assessment centre method" Pergammon, New York. 1977.

Anastasi, A. "Psychological testing". (4th ed). New York. date

Anderson, G.C. "Performance appraisal" London, HMSO. 1986.

Anon. "Civil Service assessment centres - selecting high fliers". Industrial Relations Review and Report: Recruitment and Development Review, no 460, radr 4-6. March 1990.

Anon. "Assessing management competencies: pioneering work by NEBSM". Training Officer, 28, 1, p 12-3. Jan/Feb 1992

Anon. "Qualifications for managers: the quiet revolution". Industrial Relations Review and Report: Recruitment and Development Review, 498, p 2-9. October 1991.

Anon. " Managerial capabilities and self development at Brooke Bond.Industrial Relations Review and Report: Recruitment and Development Review, 500, 6-9. November 1991.

Anon. "Guidelines and ethical considerations for assessment centre operations". Public Personnel Management, 18, 4, p 457-70. Winter 1989.

Anon. "Recruiting for competency in the Employment Service". Industrial Relations Review and Report: Recruitment and Development Review, 504, p 2-5. January 1992.

Anstey, E., Fletcher, C. \& Walker, K. "Staff appraisal and development". Allen \& Unwin. London. 1976.

Appelbaum, S.H., Kay, F. \& Shapiro, B.T. " The assessment centre is not dead: how to keep it alive and well". Personnel Management, 8, 5, p 51-65. 1989.

Argyris, C. "Interpersonal competence and organisational effectiveness". The Dorsey press. 1962 
Argyris, C. "Some limitations of the case method: experiences in a management development programme". Academy of Management Review, 5, p 291-8. 1980.

Argyris, C. "Double loop learning in organisations". in Kolb, D.A, Rubin, I.M. \& McIntyre, J.M. "Organisational Psychology: An Experiential Approach". Prentice Hall. 1984. (4th Edn).

Argyris, C. “On Organisational learning.". Blackwell. Oxford 1994

Arkin, A. "Turning managers into assessors". Personnel Management, 23. 11, p 49-51. November 1991.

Automobile Association. "Personal performance review: you and your job". Automobile Association. 1991.

Barlow, G. "Deficiencies and the perpetuation of power: latent functions in management appraisal". Journal of Management Studies, 26, 5, p499-517, September 1989.

Bass, B.M. "The leaderless group discussion". Psychological Bulletin. 51, 456-92. 1954

Beard, D. "Leaming to change organisations". Personnel Management. p 36-39. January 1993.

Beck, J. \& Cox, C. (eds) " Advances in management". Wiley 1980.

Bedford, T. " New developments in assessment centre design". Guidance and Assessment Review. 3, 3, 2-3. 1987.

Bees, M. \& Swords, M. "National Vocational Qualifications and Further Education". London. Kogan Page \& NCVQ. 1990.

Bender, J.M. "What is typical of assessment centers". Personnel 50, 50-57. (1973).

Bennis, W.G. "Leadership Theory and administrative behaviour". Administrative Science Quarterly, 4,3, Dec 1959.

Berk, R.A. (ed). "Performance assessment methods and applications". The John Hopkins University Press. 1986

Bernard, A. "Managing motivation for performance improvement". in Mitriani, A. , Dalziel, M. \& Fitt, D. (Eds), "Competency based human resource management". Hay. 1992 
Bernardin, J.H. \& Bownas, D.A. "Personality assessment in organisations". New York, Praeger. 1985.

Binsted, D. "The design of learning events for management". Management Education and Development, 2, II. 1980.

Black, H. \& Wolf, A. (Eds) "Knowledge and Competence: current issues in training and education" Sheffield. Training Agency 1990.

Blinkhorn, S. "Centres of excellence". Training Officer, June 1989.

Boak, G. \& Stephenson, M. "management learning contracts: from theory to practice" Journal of European Industrial Training, 11,4, 6. 1987

Boak, G., Thompson, D. \& Mitchell, L. "Developing managerial competencies : the management learning contract approach". London. Pitman. 1991.

Boam, R. \& Sparrow, P. "Designing and achieving competency: a competency based approach to developing people and organisations". Maidenhead, Berks. McGraw Hill. 1992.

Boehm, V. " Using assessment centres for management development -five applications". Journal of Management Development, vol 4, no 4, 40-53. 1985.

Boehm, V.R. \& Hoyle, D.F "Assessment and management development". in Moses, J.L. \& Byham W.C. (Eds) "Applying the assessment centre method" Pergammon, New York. 1977.

Bowers, D.G. \& Seashore, S.E. " Predicting organisational effectiveness with a four factor theory of leadership". Administrative Science Quarterly, 1, 11, p 238-263. 1966.

Boyatzis, D.. "The competent manager". John Wiley. 1982

Boydell, T. \& Pedler, M.J. (Eds). "Management self-development - Concepts and Practices". Gower. 1981.

Bramshill. "Career Development Centre". Bramshill Staff College . undated

Brass, D.J. \& Oldham, G.R. "Validating an in-basket test using an alternative set of leadership scoring dimensions". Journal of Occupational Psychology, 61, 652-657. 1976. 
Bray, D.W. "Current trends and future possibilities". in Moses, J.L. \& Byham W.C. (Eds) "Applying the assessment centre method" Pergammon, New York. 1977.

Bray, D.W. "Fifty years of assessment centres : a retrospective and prospective view". Journal of Management Development, 4, no 4, 4-11. 1985.

Brodie, M. "Evaluation and predictability in management development". Journal of Management Development.2, 4, p 42-56. 1983.

Burgoyne, J.G. \& Stuart, R. "The nature, use and acquisition of managerial skills and other attributes". Personnel Review 5(4) 19-29, 1976.

Burke, J. W. (ed)."Competency based education and Training". London, Falmer Press. 1989.

Burke, J.W. "The implementation of NVQs". in Burke, J. W. (ed). "Competency based Education and Training". London, Falmer Press. 1989.

Burnaska, R.F. "The effects of modelling training upon manager's behaviours and employees' perceptions". Personnel Psychology 29, 329-335. (1976).

Byham, W.C. \& Thoreson, J. " Effectiveness of assessor training techniques" Pittsburgh, DDI. June 1976.

Byham, W.C. \& Thornton G.C III. "Assessment centers" in Berk, R.A. (ed). "Performance assessment methods and applications". The John Hopkins University Press. 1986

Byham, W.C. "Assessor selection and training".in Moses, J.L. \& Byham W.C. (Eds) "Applying the assessment centre method" Pergammon, New York. 1977.

Byham, W.C. "Dimensions of managerial competence: what they are, how they differ between levels, how they are changing" Pittsburgh. Development Dimensions International. 1982.

Byham, W.C. \& Thornton G.C III. "Assessment centers and management performance". NY. Academic press. 1982.

Campbell, J.P., Dunnette, M.D., Lawler, E.E. III \& Weick, K.E. "Management behaviour, performance and effectiveness". New York. McGraw-Hill. 1970.

Carlton, I. \& Sloman, M. "Performance appraisal in practice". Human Resource Management Journal, p 80-94. Spring 1992. 
Carrigan, P.M. "Assessor's on the job performance affected by assessment center training" Assessment and Development, 3, 2, p 6-11. 1976.

Cassidy, T. \& Lynn, R. "a multifactorial approach to achievement motivation: the development of a comprehensive measure". Journal of Occupational Psychology, 62, p 310-12. 1989.

City and Guilds. "NVQs giving credit where credit is due." City and Guilds, London. undated.

City and Guilds. "Direct Trainers and assessors award assessment handbook, 1990." City and Guilds, London. 1990.

Cockerill, T. "Two kinds of competence for rapid change". Personnel Management. p 52-6. September 1989.

Cohen, B.M., Moses, J.l. \& Byham, W.C. "The validity of assessment centres: a literature review. (Monograph II). Pittsburgh Development Dimensions International. 1982.

Collin, R. "Managers' competence: rhetoric, reality and research". Personnel Review, 18, 6, p20-5. 1989.

Confederation of British Industry. "Business success through competence: investors in people". CBI with City and Guilds. 1991.

Confederation of British Industry and . "National targets and the implications for NVQ levels". CBI \& NCVQ. 1991.

Confederation of British Industry. "Towards a skill revolution". report of the vocational education and training task force. CBI. 1989.

Constable, J. \& McCormick, R. "The making of the British manager". BIM/CBI. London. 1987.

Cooke, J. \& Knibbs, J. "The managers's role in staff development". Journal of European Industrial Training, vol 11, 1, p 5-9. 1984.

Council for National Academic Awards (and B/TEC and ED). "The assessment of management competencies: project report December 1990". London. Council for National Academic Awards. 1990.

Council for National Academic Awards (and B/TEC). "The assessment of management competencies: guidelines December 1990". London. Council for 
National Academic Awards.1990.

Council for National Academic Awards. "The assessment of management competencies". London. Council for National Academic Awards.

Crabb, S. "Certified competence". Personnel Management, 23, 5, p 57-8. May 1991.

Cronbach, J. L. \& Glesser, G. C. "Psychological tests and personnel decisions". (2nd Ed.) Urbana Ill. University of Illinois press. 1965.

Cunningham, R,J. \& Olshfski, D. "Evaluating task leadership: a problem for assessment centres" Public Personnel management, 14, 3, p 293-299. Fall 1985.

Dale, M. \& Iles, P "Assessing management skills: a guide to competencies and evaluation techniques". London, Kogan Page. 1992

Dobson, P. \& Williams, A. "The validation of the selection of British male army officers". Journal of Occupational Psychology, 62,4. Dec. 1989.

Dodd, W.E. "Attitudes towards assessment center programs". in Moses, J.L. \& Byham W.C. (Eds) "Applying the assessment centre method" Pergammon, New York. 1977.

Drucker, P.F. "The practice of management". New York. Harper Row, 1954

Drucker, P.F. "Management tasks, responsibilities and practices".Harper \& row 1974.

Dugan, B. "Effects of assessor training on information use". Journal of Applied Psychology vol 73, no 4, 743-8, 1988.

Dulewicz, V. "Assessment centres as the route to competencé", Personnel Management Vol 21, no 11, 56-9. November 1989.

Dulewicz, V. \& Herbert, P. "Personality, competences, Leadership style and managerial effectiveness" . Henley Management College working papers HWP 14?92. 1992.

Dulewicz, V. " Improving assessment centres". Personnel Management Vol 23, no 6, 50-5. June 1991.

Dulewicz, S.V. \& Fletcher, C. "The relationship between previous experience, intelligence and background characteristics of participants and their performance in an assessment centre". Joumal of Occupational Psychology, 55, 197-208. 1982. 
Dulewicz, S.V. \& Fletcher, C. "The context and dynamics of performance appraisal" in Herriot, P. ( Ed) "Assessment and selection in organisations" John Wiley, London. 1989

Dunnette, M.D. \& Fleishman, E.A. "Human Performance and productivity". Hilsdale N.J. Erlbaum. 1982.

Dunnette, M.D. "Multiple assessment procedures in identifying and developing managerial talent" In McReynolds, P. "Advances in psychological assessment. Vol II" Science and Behaviour Books. 1971.

Edmonds, T. \& The, M. "Personal competence: where does it fit in ?". Competence and Assessment, Issue 13, p 6-8. 1990.

Elkin, G. "Competency based HRD". Training and Development (UK), 9, 3, p 17-18. 1991.

Elkin, G. "Competency based Human Resource Development".Training and Development (UK), Industrial and Commercial Training, 22, 4, p 20-25. 1990.

Equal Employment Opportunity Coordinating Council. "Uniform guidelines on employee selection procedure" Federal Register, 38290-315, 1978.

Feltham, $\mathbf{R}$ "Assessment centre decision making: judgemental vs mechanical" . Journal of Occupational Psychology, 61, part 3, p 237-241. 1988.

Feltham, R. "Validity of police assessment centres: a 1-9 year follow up". Journal of Occupational Psychology, 61, part 2, p 129-144. 1988.

Finkle, R.B. "Managerial assessment centers" in Dunnette, M.D. (ed) "Handbook of industrial and organisational psychology". Chicago. Rand Mcnally. 1976. (862-888)

Fletcher, C. \& Williams, R. "Performance appraisal and career development" London. Hutchinson. 1985.

Fletcher, C. "Appraisal: routes to improved performance". IPM, London. 1993.

Fletcher, C. \& Williams, R. "The influence of performance feedback in appraisal interviews". Journal of Occupational Psychology, 49, p 75-83. 1976.

Fletcher, C. "Should the test score be kept secret". Personnel Management, 18, 4, p 44-46. 1986. 
Fletcher, C. "Candidates reactions to assessment centres and their outcomes: a longitudinal study". Journal of Occupational Psychology 64, p 117-12. 1991.

Fletcher, C. "Quality indicators in the use of psychometric tests". Selection and development Review. 8, 1-3, 1992.

Fletcher, C. \& Williams, R. "The influence of performance feedback in appraisal interviews". Journal of Occupational Psychology, 49, p 75-83. 1976.

Fletcher, C \& Dulewicz, V. "An empirical study of a UK based assessment centre". Joumal of Management Studies. 21, p 83-97. 1984.

Fletcher, C. \& Kerslake, C. "Candidates anxiety level and assessment centres performance". Journal of Managerial Psychology 9, 1993.

Fletcher, S. (1991). "NVQs, standards and competence". London. Kogan Page. 1991.

Fletcher, S. (1992). "Competence based assessment techniques". London. Kogan Page. 1992.

Fowler, A. "Plan an assessment centre". PM plus, 3, 12, p 21-4. December 1992.

Fransella, F. \& Bannister, D."A manual for repertory grid technique. "London, Academic Press. 1977

Furguson, J. "When is an assessment centre a development centre ?". Guidance and Assessment Review, 7, 6, p 1-3. December 1991.

Furnham, D. "A question of competency". Personnel Management, vol 22, 6, p 37, June 1990.

Gaugler, B. \& Thomton, G. C. "Number of assessment centre dimensions as a determinant of assessor accuracy". Journal of Applied Psychology, 74, 445-52, 1989.

Gaugler B.,Rosenthal, D.B., Thornton, G.C. \& Bentson, C. "Meta analysis of assessment center validity". Journal of applied psychology, 72, 493-511, 1987.

George, D.I. \& Smith. M.C. "An empirical comparison of self assessment and organisational assessment in personnel selection". Public Personnel management, 19, 2, p 175-90. Summer 1990.

Ghiselli. E.E. "The validity of aptitude tests in personnel selection" Personnel Psychology 1973, 26, 461-467. 
Gratton, L. "Counselling the assessed". Training and Development (UK), 3, 10, feb 1985.

Gill, D. , Unperson, B. \& Thakur, M. " Performance appraisal in perspective: a survey of current practice". London. IPM. 1973,

Gill, R.A. "A trainability concept for management potential and an empirical study of its relationship with intelligence for two managerial skills" Journal of Occupational Psychology, 1982, 55, 139-148.

Glaze, A. "Cadburys dictionary of competence". Personnel Management, 21, 44-8, July 1989.

Goodge, P. "Giving feedback: a guide for managers". Training Officer, 25, 6, p 16870. June 1989.

Goodge, P. "Assessment centres: what the text books do not tell you". Training and Development (UK),4, 4, p 708. 1985.

Goodworth, C. "The secrets of successful appraisal and staff counselling". Oxford. Heinemann. 1989.

Gratton, L. "Assessment centres: theory research and practice". Human Resource Management (Australia). 23, 3, p 10-14, 1985.

Greatrex, J \& Philips, P. "Oiling the wheels of competence" Personnel Management, 21, 36-9, August 1989.

Greller, M.M. "The nature of subordinate participation in the appraisal interview". Academy of Management Joumal 21, 646-658. (1978).

Griffin, J, Butler, L. \& Weightman, J. "A spoonful of competence makes the medicine go down". Health Services Management. 86, 6, p266-9. December 1990.

Griffiths, P. \& Allen, B. "Assessment centre breaking with tradition". Journal of Management Development. 6, 1, p 18-29. 1987.

Guerrier, Y. \& Riley, M. "Management assessment centres as a focus for change". Personnel Review, 21, 7, p 24-31. 1992

Guion.R. "Personnel Testing". McGraw Hill. 1965.

Gunz, H.P."Careers and corporate cultures: managerial mobility in large organisations". Basil Blackwell. Oxford.1989. 
Haffenden, I. \& Brown, A. "Towards the implementation of competence based curricula in FE. ". in Burke, J. W. (ed). "Competency based education and Training". London, Falmer Press. 1989.

Hall, J. "Crediting competence - a portfolio development technique for managers". Training and Development. June 1992

Handy, C. "The making of managers". MSC/NEDC/BMM, Nedo, London, 1987.

Harre, R and Gillet G ."The Discursive Mind". Sage. 1994

Hartle, F. "Performance management - where is it going". in Mitriani, A. , Dalziel, M. \& Fitt, D. (Eds), "Competency based human resource management". Hay. 1992

Hay, J. "Managerial competences or management characteristics". Management Education and Development, 21, 4. p 305-15. Winter 1991.

Hayes, J.L. "A new look at managerial competencies: the AMA model of worthy performance". Management Review, 1979.

Herriot, P. "Managerial assessment: the research evidence". in Hirsch, W and Bevan, S. "What Makes a Manager".Brighton, Institute of Manpower Studies. 1988

Herriot, P. ( Ed) "The Careers management Challenge". John Wiley, London. 1992

Herriot, P. ( Ed) "Assessment and selection in organisations." John Wiley, London. 1989

Herriot, P. "The selection Interview" in Warr, P.B. (ed) Psychology at Work, (3rd edn) 1986, Harmondsworth. Penguin.

Hicks, N. \& London, M. "Career decision making". in Morrison, R-F. \& Adams, J. (Eds). "Contemporary career development issues". Laurence Erlbaum, Hilsdale NJ. 1991.

Hinrichs, J.R. "Comparisons with real life assessments of management potential with situational exercises, paper and pencil ability tests and personality inventories". Journal of Applied Psychology 53, 425-433. (1969).

Hinrichs, J.R. \& Haanpera, S. "Reliability of measurement in situational exercises : an assessment of the assessment center method". Personnel Psychology, 1976, 29, 31-40.

Hrsch, W and Bevan, S. "What Makes a Manager".Brighton, Institute of Manpower Studies. 1988 
Hirsh, W. "Defining Managerial skills". Brighton, IMS (reports 185. Employment brief 18) 1989.

Holdwsorth, R. "Appraisal". in Neale, F. "The handbook of Performance management". London, IPM. 1991

Hoogheimstra, T. "Integrated management of human resources". in Mitriani, A. , Dalziel, M. \& Fitt, D. (Eds), "Competency based human resource management". Hay. 1992

Hormby, D. \& Thomas, R. "Towards a better standard of management" Personnel Management, 21, 52-5. January 1989.

Huck, J.R. " Assessment centers: a review of the external and internal validities. Personnel Psychology, 1973, 26, 191-212.

Hutchinson, D. "Students with special needs" in Bees, M. \& Swords, M. "National Vocational Qualifications and Further Education". London. Kogan Page \& NCVQ. 1990.

Iles, P. \& Robertson, I. "Unintended consequences and undesired outcomes in managerial selection and assessment". Guidance and Assessment Review, 5, (2), P 45. 1989.

Iles, P.A., Robertson, I.T. \& Rost, V. "Assessment based development centres". Journal of Managerial Psychology, 4, p 11-16. 1989.

Iles, P. \& Blanksby, M. "Assessing skills at work". London. Kogan Page. 1991.

Imada, A.S , Van Slyke, M.D., \& Hendrick, H.W.."Applications of assessment centers multi nationally: the state of the art, obstacles and cross cultural implications". Journal of Management Development, 4, 54-67. 1985.

Jackson, D. \& Rothstein, M. "Evaluating personality testing in personnel selection". The Psychologist, 6, p 8-11. 1993.

Jackson, T. "Measuring management performance: a developmental approach for trainers and consultants". Kogan Page. London. 1991.

Jackson, D. \& Rothstein, M. "Evaluating personality testing in personnel selection". the Psychologist, 6, p 8-11. 1993.

Jackson, L. "Achieving change in business culture through competence based management development". Industrial and Commercial Training, 23, 4, p 9-16. 1991. 
Jacobs, R. "Getting the measure of managerial competence". Personnel Management. p 32-7. October 1989.

Jaffee, C.L. "Effective management selection: the analysis of behaviour by simulation techniques" London. Addison Wiley. 1971.

James, G. "Performance appraisal". London, Work Research Unit. 1988.

Jessup. G. "Accreditation of prior learning in the context of national vocational qualifications" NCVQ, R\&D Report No 7. London, NVCQ. 1990.

Jessup, G. "Outcomes: NVQs and the emerging model of education and training". London. Falmer Press. 1991.

Jessup, G. "Technical note on the new training initiative: Implications for standards assessment procedures and accreditation". MSC. 1985.

Jessup, G. "The emerging model of vocational education and training". in Burke, J. W. (ed)."Competency based education and Training". London, Falmer Press. 1989.

Katx, D., Khan, R.L. \& Adams, J.S. (Eds) "The study of organisations". New York, Jossey Bass, 1980.

Keeton, M. \& Pottinger, P. (eds). "Competence:, the concept, its measurability and implications for licensing, certification and education". San Francisco, Jossey Bass. 1979

Keil, E.C. "Assessment centres: a guide for human resource management". London. Addison Wiley. 1981.

Kelly, G.A. The Psychology of Personal Constructs" Norton. New York. 1955

Kerr, S. \& Davenport, H. "AC or DC: A wolf in sheep's clothing". Guidance and Assessment Review, 5, (5), P 1-3. 1989.

Key, E., Meyer, H.H. \& French, J.P.R. "Effects of threat in a performance appraisal interview". Journal of Applied Psychology, 49, p 311-317. 1965.

Khan, R.L. "Skills of an effective business administrator". Harvard Business Review, (Jan-Feb 1955) p33-42.

Klemp, G.O. Jr. \& Spencer, L.M. Jr. "Job competence assessment". Addison Wesley. 1982. 
Klemp, G.O. Jr. "On the identification, measurement, and integration of competence". In Keeton, M. \& Pottinger, P. (eds). "Competence:, the concept, its measurability and implications for licensing, certification and education". San Francisco, Jossey Bass. 1979

Klimoski, R. \& Brickner, M. "Why do assessment centers work ? the puzzle of assessment center validity". Personnel Psychology 40, 243-60, 1987.

Knowles, M. "The adult learner: a neglected species". Houston. Gulf Publishing. 1978

Knowles, M.S. "The modern practice of adult education: Andragogy versus pedagogy". association Press. New York. 1978.

Kolb, D.A. \& Boyatzis, R.E. "Goal setting and self directed behaviour change". Human relations, 23 (5), p 439-57. 1970.

Kolb, D.A., Lublin. S., Spoth, J. \& Baker, R. "Strategic management development: experiential learning theory to assess and develop managerial competencies". Journal of Management Development. 5(3), 13-24, 1986.

Koontz, H. "Appraising managers as managers". McGraw Hill. 1971.

Kotter, J.P. "What effective general managers really do". Harvard Business Review 157-157. (1982).

Landy, F.J. \& Farr, J.L. "The Measurement of work Performance - Methods, theories and applications". London, Academic Press. 1983

Landy, F.J., Barnes-Farrell, J. \& Cleveland J.N. "Perceived faimess and accuracy of performance evaluation". Journal of Applied Psychology 65, 355-356. (1980).

Lane, J. \& Heriot, P. " Self ratings, supervisor ratings, pösitions and performance" Journal Of Occupational Psychology, 63. part 1, p 77-88. 1990.

Latham, G.P. \& Wexley, K.W. "Increased productivity through performance appraisal". Reading MA. Addison Welsey. 1981.

Laumayer, L. \& Teebe, T. "Employees and their appraisal". Personnel Administrator, 12, p 76-80. 1988.

Lawson, I. "Appraisal and appraisal interviewing".(3rd Ed.) London, Industrial society. 1989.

Lee. A.M. " Do assessment centres work ?". Training and Development (UK), 6, 12, p 
47. 1988.

Leigh, A. "The assessment of vocational and academic competence". Competence and Assessment 17, p 18-20. 1992.

Lewin,K. "Action Research and Minority Problems" Journal of Social Issues 2 . (33. 46)

118. Lewis, C. "Employee selection" 1985. London, Huthchinson.

Local Government Management Board. "Towards a quality workforce: NVQs and Local Government. LGMB. undated.

Local Government Management Board." Best practice in management selection: a guide to the use of assessment centres in Local Government" Local Government Management Board. Luton. 1992.

London, M. \& Mone, E.M. (Eds). " Career growth and human resources strategies". Quorum. 1988.

London, M. (Ed.) "Assessment centres and management development". Journal of Management Development. 4, 4. 1985.

Long, P. "Performance appraisal revisited". IPM. London. 1986.

Mabey, W. "The growth of test use". Selection and Development Review, 8, pt 3, p 68,. 1992

Mackay, I. \& Worsfold, P. "Unblocking your thinking: peoples performance".

Training and Development (UK), 9, 9, p 39-40. September 1991.

Mackenzie Davey, D, \& Harris, M. (eds). "Judging people: á guide to orthodox and unorthodox methods of assessment". Maidenhead. McGraw Hill. 1983.

Mackinnon, D.W. "An overview of assessment centres". Greensboro, N. Car. Centre for Creative Leadership. 1975.

Maier, N.R.F. "the appraisal interview". Wiley. 1956.

Management Charter Initiative." Crediting competence: a guide to APL for employers". London. Management Charter Initiative. 1991.

Management Charter Initiative." Guidelines for Action". London. Management Charter Initiative. 1991. 
Management Charter Initiative." management standards: Implementation Pack". London. Management Charter Initiative. 1991.

Manpower Services Commission. "Management training and development: a case of good practice - ICI Organic division". Investing in people 7. MSC, Sheffield. 1987

Manpower Services Commission . "People and Work". MSC, Training Services Division, London. 1979.

Manpower Services Commission and DES. "Review of vocational qualifications in England and wales" London, HMSO. 1986.

Mansell, J. "The assessment of prior learning and experience - the role of expert systems" FEU, Coombe Lodge. 1990.

Mansfield, B. \& Mathews, D. "Job competence - a description for use in vocational educational and training" work based learning project. Blagdon, FESC. 1985.

Mayer, H.H. "Self appraisal of Job Performance. Personnel Psychology, p 291-295. 1980

Mayo, A. "Managing careers: strategies for organisations". IPM. London. 1991 .

McClelland, D.C. \& Boyatzis, R.E. "Leadership motive pattern and long term success in management". Journal of applied psychology, 67, (6), p737-43. 1982.

McClelland, D.C. "Testing for competence rather than for 'intelligence'". American Psychologist, 28, 1, p 1-4. 1973.

Miles, $R$. "Feedback to extended interview candidates". Guidance and Assessment Review, 3, 2, p 1-3. 1987.

Miller, C. "Assessment in the workplace - Quality issues". Competence and Assessment, 9, p 19. Summer 1989.

Miller, C, Hogan, J., Pringle, S. \& West, G. "credit where credit is due". SCOTVEC, Glasgow. 1988.

Miller, M. "The integration of psychometric test results within guidance counselling". Guidance and Assessment Review, 7, (2), P 5-7. 1991.

Mintzberg. H. "The managers job: folklore and fact". Harvard Business Review. 4961. (1975). 
Mitchell, L. \& Cuthbert, T. "Insufficient evidence, the final report of the competency testing project". SCOTVEC, Glasgow. 1989.

Mitriani, A. , Dalziel, M. \& Fitt, D. (Eds), "Competency based human resource management". Hay. 1992

Moran, D. "The role of knowledge in competence based measurement". Education, 115, p 8-9. September 1991.

Moses, J.L. "Assessment center performance and management progress". Studies in Personnel Psychology 4, 7-12.(1972).

Moses, J.L. "The assessment centre method". in Moses, J.L. \& Byham W.C. (Eds) "Applying the assessment centre method" Pergammon, New York. 1977.

Moses, J.L. \& Byham W.C. (Eds) "Applying the assessment centre method" Pergammon, New York. 1977.

Napier, N.K. \& Latham , g. P. "Outcome expectancies of people who conduct performance appraisals". Personnel Psychology, 34, p352-369. 1986.

NCVQ. "Establishing the NVQ framework: critical path to 1992". unpublished NCVQ. 1990.

NCVQ. "Assessment in vocational qualification . Information Note 4" NCVQ. 1988.

NCVQ. "NVQ framework: progress to date". NCVQ. 1990.

NCVQ. "An introduction to the National record". NVCQ, London. 1990

NCVQ. "A procedures guide to the National record". NVCQ, Londón. 1990

NCVQ. " Accreditation Procedures". NCVQ, London. January 1988.

NCVQ. "Core skills in NVQs a response to the Secretary of State". NCVQ, London. 1990.

NCVQ \& Training Agency. "Developing NVQs, National Vocational Qualifications. Information and Guidance note No 1". London. NCVQ/TA. 1990.

NCVQ. "Assessment in NVQs : Use of evidence from prior leaning (APL). Information Note 5" NCVQ. 1989. 
NCVQ. "The NVQ criteria and related guidance" NCVQ. London. January 1989.

NCVQ (1989) "Guide to National Vocational Qualifications". London. NCVQ. 1989.

NCVQ (1991). "The NCVQ Framework" London. NCVQ. 1991.

Nemerroff, W.F \& Wexley, K.W. "An exploration of the relationships between perfromance feedback interview characteristics and interview outcomnes as perceived by managers and suboredinates". Journal of Occupational Psychology 52, 25-34 (1979).

Newman, J \& Llewellyn, N. "The accreditation of prior learning (APL)". in Bees, M. \& Swords, M. "National Vocational Qualifications and Further education". London. Kogan Page \& NCVQ. 1990.

Niedig, R.D. \& Niedig, P.J. " Multiple assessment centre exercises and job relatedness". Journal of Applied psychology. 1984, 69, 182-186.

Norton, S. "The empirical and content validity of assessment centers". Academy of Management Review 6, p 561-6. 1977.

Open University. " APL: An open learning pack for advisors and assessors". Open university, Milton Keynes 1990

Parker, L. "Personal competence: developing a model for general use". Competence and Assessment, 17, p 5-7. 1992.

Pedler, M. , Burgoyne, J. \& Boydell, T. "A managers guide to self-development". London, McGraw Hill 1986. (2nd Ed)

Plummer, R. "A guide for advisors". London. Management Charter Initiative. 1991.

Povah, N. "Using assessment centres as a means for self development". Industrial and Commercial Training, 18, 2, p 22-25. March/April 1986.

Rea, P. , Rea, J. \& Modhmaw, C. "use assessment centres in skill development" Personnel Journal, 69, 4, p 126-131. April 1990.

Reilly, R.R. \& Chao, G.T. "Validity and faimess of some altemative employee selection procedures". Personnel Psychology. 1982, 35, 1-62.

Robertson, I.T. \& Makin, P.J. "Management selection in Britain: a survey and critique". Journal of Occupational Psychology, 59, p 49-58. 1986. 
Robertson, I. T. , Gratton, L. \& Sharpley, D. "The psychometric properties and design of managerial assessment centres: dimensions into exercises won't go". Journal of Occupational Psychology. 60, 187-195, 1987

Robertson, I. T. \& Downs, S. "Learning and the prediction of performance: development of trainability testing in the United Kingdom" Journal of Applied Psychology, 1979, 64, 42-50.

Robertson, I.T., Iles, P.A., Grafton, L. \& Sharpley, D. "The impact of personnel selection and assessment measures". Human Relations, 44, 9, p 963-983. 1991.

Robinson, G. "Nothin new in management development". International Journal of Public Sector Management, 1, 3. 1988

Rodger, D. \& Mabey, C. "BTs leap forward from assessment centres". Personnel Management, 19, 7, p 32-35. July 1987.

Rowland, D. "The Competency Debate". Personnel Management, 23,10, p27. October 1991.

Sacket, P.R. \& Wilson, M.A. " Factors affecting consensus judgement in managerial assessment centres". Journal of Applied psychology. 1982, 67 (1), p 10-18.

Sacket, P.R. \& Dreher, G.F. " Constructs and assessment centre dimensions some troubled empirical findings". Journal of Applied psychology. 1982, 67, 401-410.

Sacket, P.R. \& Dreher, G.F. " Situational specificity of behaviour and assessment centre validation strategies: a rejoinder to Niedig and Niedig". Journal of Applied Psychology. 1984, 69, 401-410.

Sacket, P.R \& Ryan, A.M. "A review of recent assessment centre research" Journal of Management Development, 4, 13-27. 1985.

Saunders, M., Fuller, A. \& Lobley, D. "Emerging issues in the utilisation of NVQs, R\&D Report No 5". NCVQ, London. 1990.

Schein, E.E. Career dynamics". Addison Wesley, 1978.

Schein, E.H. "Career Theory and Research - some issues for the future". in Brooklyn Derr (ed) "Work, family and career". MIT Press. 1980.

Schmitt, N , Groding, R.Z., Noe, R.A., \& Kirsch, M... "Metanalysis of validity studies published between 1964 and 1982 and the investigation of study characteristics".

Personnel Psychology , 37, 407-22, 1984 
Schmitt, N. , Ford, J. \& Stults, D.M. "Changes in self-perceived ability as a function of performance in an assessment centre". Journal of occupational psychology, 59, 327-35, 1986.

Schroder, H.M. "Managerial competence the key to excellence" Kendall/Hunt Iowa. 1989.

Shackleton, V.J. \& Newall, S."Management selection : a comparative survey of methods used in top British and French companies". Journal of Occupational Psychology, 64, p 23-36. 1991.

Shrauger, J.S. \& Osberg, T.M. "The relative accuracy of self prediction and judgements by others in psychological assessments" Psychological Bulletin. 90, p 322-351. 1981

Simosko, S. "A Guide for assessors".London. Management Charter Initiative. 1991.

Simosko, S. "APL: A practical guide for professionals". London. Kogan Page. 1991.

Slivinski, W.L. \& Bourgeois, R.P. "Feedback of assessment centre results". in Moses, J.L. \& Byham W.C. (Eds) "Applying the assessment centre method" Pergammon, New York. 1977.

Smith, d. \& Blachman, B. "The Assessment of managerial abilities in an assessment centre". Personnel Review, 17, 4, p 15-21. 1988.

Sokol, M. \& Oresick, R. "Managerial Performance Appraisal". in Berk, R.A. (ed). "Performance assessment methods and applications". The John Hopkins University Press. 1986

Spencer, L.M. Jr., McClelland, D.C. \& Spencer, S.M. "Competence assessment methods: History and State of the are" Hay/McBER Research press. 1990. "

Stamp, G. \& Macdonald, I " Assessing and developing candidates for leadership development". Brunel Institute for Organisational and Social Studies. December 1986.

Stewart, V. \& Stewart, A. "Business applications of the repertory grid". McGraw Hill. 1981.

Stewart, V. \& Stewart, A. "Tomorrow's managers Today". (2nd Ed) Institute of Personnel Management. 1981.

Storey, J \& Sisson, K. "Making mangers in Britain: a progress report". Public Money and Management, spring 1990. 
Strombach, M. "Potential analysis in management development" in Mitriani, A. , Dalziel, M. \& Fitt, D. (Eds), "Competency based human resource management". Hay. 1992

Task force on assessment center standards. "Standards and ethical considerations for assessment center operation". Personnel Administrator, 25, 35-8. 1980.

Toplis, J., Dulewicz, V. \& Fletcher, C. " Psychological testing: a managers guide". (2nd ed) IPM, London. 1989.

Training Agency. "Issues in assessment. Development of standards for national certification - Guidance note 5". Employment Department. Sheffield. 1989.

Training Agency. "Developing standards by reference to functions - Guidance note 2". Employment Department. Sheffield. 1989.

Training Agency. "The definition of competences and performance criteria. Development of standards for national certification - Guidance note 3". Employment Department. Sheffield. 1989.

Training and Development Lead Body (1992b). "National Standards for Training and Development - An executive summary". Nottingham, TDLB. 1992

Training Agency / CNAA Development Services."Towards a new certificate in management". (Part of the series "Investors in people") Training Agency. 1989

Tuxworth, E. "Competency based education : background and origins" in Burke, J. W. (ed)."Competency based education and Training". London, Falmer Press. 1989.

Vernon, P.E. "Personality assessment: a critical survey". London, 1963. Tavistock.

Vroom, V.H. "Some personality determinants of the effects of participation". Englewood Cliffs N.J. Prentice Hall. 1966.

Vroom, V.H. " Leadership" in Dunnette, M.D. (ed) "Handbook of industrial and organisational psychology". Chicago. Rand Mcnally. 1976.

Walkin, L. "The assessment of performance and competence". Stanley Thornes 1991.

Warr, P.B. (ed) "Psychology at Work”, (3rd edn) 1986, Harmondsworth. Penguin.

Wexley, K.W. \& Yukl, G.A. "Organisational behaviour and personnel psychology". Homewood Ill. Irwin. 1984 (revised edition). 
Wexley, K.W. "Characteristics of effective interviews". in Berk, R.A. (ed).

"Performance assessment methods and applications". The John Hopkins University Press. 1986

Willis-Lee, R. "Climbing ladders: development of future leaders and managers". paper delivered to ACC conference 26.1.93. Fire Service College.

Wolf, A “Assessing competence” Open University Press. 1995

Woodruffe,C. "Assessment centres: Identifying and developing competence". IPM. London. 1990

Woodruffe, C. "Competent by any other name". Personnel Management, 23, 9, p 30-3 September 1991.

Woolowick, H.B. \& McNamara W.J. "Relationship of the components of an assessment centre to management success". Joumal of Applied Psychology 53, (5), 348-352. (1969).

Yeager, S.J. "The use of assessment centers by metropolitan fire departments in North America" Public Personnel Management, 15, 1, p 51-64. Spring 1986.

Zannisza, E. "Standards and management competence". Guidance and Assessment Review, 6, (2), P 1-4. 1990. 


\section{Appendix A}

Appendix A1 LFCDA rank structure

$\begin{array}{ll}\text { Appendix A2 } & \begin{array}{l}\text { Extract from the LFCDA } \\ \text { "Operational Training } \\ \text { Strategy" }\end{array}\end{array}$

$\begin{array}{ll}\text { Appendix A3 } & \text { Extract from "Towards } \\ & \text { 2000" LFCDA and } \\ & \text { Culture Change }\end{array}$ 
Appendix A1

LFCDA rank structure 


\section{Appendix A1 London Fire Brigade Uniformed Rank structure}

\begin{tabular}{|l|l|l|l|}
\hline rank & status & role & number \\
\hline Chief Fire Officer & Principal Officer & Brigade Commander & 1 \\
\hline Deputy Chief Fire Officer & Principal Officer & none specified & 1 \\
\hline Assistant Chief Fire Officer & Principal Officer & Area Commander & 5 \\
\hline $\begin{array}{l}\text { Deputy Assistant Chief Fire } \\
\text { Officer }\end{array}$ & Principal Officer & none specified & 1 \\
\hline Senior Divisional Officer & Principal Officer & $\begin{array}{l}\text { Divisional } \\
\text { Commander }\end{array}$ & 18 \\
\hline Divisional Officer & Senior Officer & Group Commander & 100 \\
\hline Assistant Divisional Officer & Senior Officer & Station commander & 250 \\
\hline Station Officer & Junior Officer & Watch Commander & 600 \\
\hline Sub Officer & Junior Officer & Watch Commander & 450 \\
\hline Leading Firefighter & Junior Officer & Crew Commander & 900 \\
\hline Firefighter & Firefighter & Firefighter & 3000 \\
\hline
\end{tabular}




\section{Appendix A2}

\section{Extract from the LFCDA}

"Operational

Training Strategy" 
10.3. In order that the quality of training is improved, it is necessary to attract and retain some the most able senior officers into training. To do this, the training function must be recognised as a mainstream route to promotion and not a specialist backwater. It is also essential to ensure that the terms and conditions of employment for senior officers in the training function are sufficiently attractive to recruit and retain them. This is not currently the case as officers employed in training in the rank of ADO are on day duties. This duty system is unpopular in comparison to the shift and flexible duty system (the latter which also attracts a 20\% additional allowance) worked by the majority of operational staff. It is therefore recommended that ADOs employed on training are conditioned to the flexible duty system on a weekday biased rota with less standby requirement than flexible duty rotas

\section{ASSESSMENT}

11.1 If operational training is to be effective then its results must be assessed. The principle of post-training assessment of trainees attending internal operational training courses will be introduced. This will ensure that the training has met the objectives set for it and that, on completion of it, trainees will be qualified and competent to undertake the activities in which they have been trained. Such an assessment is an essential component of the quality and safety audit and review system required by the Improvement Notices.

11.2. It is equally important that officers conducting ongoing continuation training at station level should assess that the training they are providing is effective and learning is taking place by those being trained. At the end of each drill or training session, the officer conducting it must record the training undertaken and for practical training, the level of competence displayed by those participating. This will assist in the planning of future training and will form part of the level 1 safety audit process referred to in the accompanying paper on safety strategy.

11.3. It is also essential that both officers and lower ranks should undergo a periodic structured assessment measured against known and understood criteria to demonstrate that they are competent in the range of operational skills which they are required to possess. The standards against which competence will be assessed will be set centrally by the Deputy Chief Officer but it will be a function of line management to conduct the assessments. This assessment of competence will form part of the level 2 safety audit.

11.4. Personnel who cannot demonstrate that they are competent will undergo further training in those areas where weaknesses are identified. This may be undertaken as part of the routine continuation training process or if it is appropriate, through attendance at structured refresher training at a designated training centre. 
12.1. There is a current requirement by the Home Office and First Aid at Work Regulations respectively to provide formal refresher training in the use of breathing apparatus and first aid. This requirement will continue. In regard to BA refresher training, this will increasingly be provided at station level as the Brigade introduces mobile heat and smoke facilities. It is also proposed to reintroduce more general refresher training for staff who are unable to demonstrate that they are competent. As stated in para. 3.1. the Chief Officer is developing a culture where staff can learn and develop in a supportive environment. Those who cannot initially meet the competence standards required will be given further time, support and training to assist them. There may be a very small number who, having been given additional assistance cannot meet the standards required. In such cases it may be necessary as a last resort to use the Capability Procedure.

13. LINKAGE WITH NATIONAL VOCATIONAL QUALIFICATIONS AND PROMOTION EXAMINATIONS

13.1. The service through a Lead Body/Joint Training Committee is currently progressing the development of National Vocational Qualifications (NVQs) derived from an analysis of the competencies required to undertake Brigade jobs at various levels. It is estimated that it may take between 2 and 4 years to identify such competencies. Regrettably the Improvement: Notices and the operational demands upon us do not allow us to await the outcome of these developments but ultimately operational training provided through our strategy will contribute towards attainment of NVQs. As our strategy is designed to base training on defined training needs and competency standards, any changes to our training eventually required to satisfy NVQs should be adjustments rather than fundamental changes. There will of course be substantial advantages in fire service operational qualifications being recognised nationally and being comparable with vocational qualifications in other industries. There may also be assistance to the furtherance of our equality policies by the development of competencies which are measurable by criterion testing. Competence can then be measured by objective assessment rather than subjective opinion.

13.2. NVQ development may also require changes to existing fire service promotion examinations. These currently require candidates to demonstrate some competence in training. Whilst this requirement has developed in recent years from competence in running a straightforward drill to running a broader training scenario, the competence in training required of London junior officers to meet the demands of this training strategy will be more extensive. Supplementary training may therefore be required unless national promotion examinations are altered further. 
13.3. The Brigade is currently experiencing considerable problems in finding sufficient qualified candidates to fill sub officer and station officer vacancies, most of which are located at fire stations. In an attempt to alleviate this, further action has been taken in this financial year to focus training sponsorship on staff sitting for statutory promotion examinations for these ranks. The problem is particularly marked at station officer level where vacancies outstrip qualified candidates. Only 47 London carididates (26\% of those sitting) have been successful in passing the recent station officer examination. This is better than the national average but nevertheless only 111 qualified candidates exist for 112 vacancies and not all of these will be suitable for promotion by reason of lack of experience or competence.

13.4 Clear evidence exists that insufficient staff are being recruited at firefighter level with the motivation and/or ability to take and pass promotion examinations to the sub officer and station officer ranks. Developments in the job e.g. increasing fire prevention work and broader management responsibilities, are also making it more complex. It is therefore necessary to take active steps to recruit more staff with the potential to progress to station officer level and beyond. Whilst it is not necessary that all staff have the ability to gain promotion, 2101 of the Brigade's 6387 operational staff are in the ranks of leading firefighter and above. One in three recruits must therefore progress to at least the rank of LFf and therefore an even higher ratio must be capable of passing promotion examinations if a reasonable field of candidates for promotion is to be available. The HSE Guide "Successful Health and Safety Management" emphasises the importance of ensuring that employees have the necessary physical and mental abilities for their jobs.

13.5. It is therefore essential that detailed consideration is given to :-

13.5.1.actively seeking to recruit more candidates with GCSE, equivalent or higher level qualifications without making this an absolute condition of employment; and

13.5.2. developing schemes to ensure that able staff are promoted to station officer as quickly as the Fire Service Appointment and Promotion Regulations allow i.e. 5 years.

13.6. The operational training strategy must provide for the structured development of knowledge, skills, attitudes and personal attributes which individuals can build upon as they progress. There are a number of core competencies which exist at each level in the Brigade but which must be exercised at increasing levels of complexity as seniority increases. It is therefore necessary to assess detailed competency requirements in each job role in the relevant operational training components set out in Section 5 of this paper. 
14.1. To meet the objectives of both the Brigade and the Health and Safety Executive, the operational training strategy and the requirements of the Improvement Notice LFB / 1 must be consistent. The Improvement Notice requires the Brigade to develop a programme having due regard to the principles set out earlier in this paper. Six stages are required in progressing the strategy which are consistent with the requirements of the Improvement Notices, viz:-

14.2.1.Stage 1 - Identify occupational training needs. It is proposed that these needs are defined largely by role i.e. firefighter, appliance commander, watch commander, station commander, sector commander, major incident commander. The analysis should cover both core operational training needs and specialist operational training needs of each role e.g. $\mathrm{HP} / \mathrm{TL}$ and FRU. In order to achieve this it will be necessary to undertake a detailed analysis of:-

14.2.1.1. the operational tasks required of the role i.e. a very detailed job description;

14.2.1.2. the level of attainment/competence in each of those tasks;

14.2.1.3. the knowledge, skills and personal attributes necessary to perform the tasks to the level of competence required.

14.2.2. Stage 2 - Validate the degree to which existing training will achieve the development of the knowledge, skills and personal attributes required. This requires all training inputs to the role in each of the relevant components identified in Section 4 to be examined in detail for content, realism and method of delivery and for a structured assessment of their effectiveness to be made.

14.2.3. Stage 3 - Develop and introduce changes to training required. Having identified any additions or improvements to the training required for each role, the necessary revisions to training provision must be developed and introduced. This may require the design of new syllabi, practical training programmes and training aids, the training of the trainers required to deliver it and/or and improvement to the facilities for the delivery of training.

14.2.4. Stage 4 - Identify individual training needs. Having identified the level of competence required in each task which is to be performed, it is necessary to identify the gap which exists between this and each individual's level of competence. This will be measured against the levels of knowledge and skills etc., defined in the first stage of the analysis set out in 12.2.1. It will be necessary to develop methods of 
assessment of competence which will include formal appraisal systems and criterion-based testing where this is appropriate. It will take some time to audit competence levels throughout the organisation and the full range of individual training needs will be defined progressively.

14.2.5. Stage 5 - Provide training. The training needs identified will be met from a range of provision i.e. internal off-the-job training, continuation training, on-the-job training, Fire Service College. For station personnel, the emphasis will be on providing training at the station wherever this is practicable. The needs identified will form the basis of programme planning and resource allocation for training at station, Area and Brigade levels. Priorities in training must be assessed using sound risk assessment principles.

14.2.6. Stage 6 - Evaluate and validate effectiveness of revised training. If the concept of continuous performance improvement to maximise quality is to be applied to training, it is necessary to ensure that revised provision is both evaluated and validated.

(N.B. evaluation is the process of assessing whether the training has achieved the learning objectives set; validation is the process of ensuring that the knowledge and skills learnt are valid for the job for which an individual is being trained.)

The results of evaluation and validation must continuously be fed back into the planning of training to ensure its efficiency and effectiveness. Equally, the training consequences of any operational service development e.g. the introduction of new appliances, equipment, procedures etc must be taken into account at the planning stage to enable training provision to be amended accordingly.

14.3. Three major options exist to undertake the work necessary:-

14.3.1. To employ consultants. A number of specialist training consultants exist who specialise in the identification of training needs and the planning of training to meet those needs. The CPO and ACO(P\&T) have had prelimiary discussions with Sudbury Consultants who undertook some extensive consultancy on leadership training for the Fire Service College and EDMC Consultants who have done initial outline work on NVQ development for the Fire Service. Both would charge a minimum of $£ 500$ per day per consultant. Bearing in mind the scope of the work required, even using consultants with some knowledge of the fire service to undertake only stages 1 and 2 of the project would be prohibitively expensive. Substantial in-house assistance would also be necessary as their levels of knowledge of operational matters are insufficient for them to work unaided. 
14.3.2. Undertake work in Personnel and Training Department. Whilst section 5 of this paper identifies much of the work required as falling within the role of P\&T Department, the scale of work and timescale for the initial analysis (which is set principally by the Improvement Notices) makes this impossible without substantial supplementation of existing resources. It is therefore proposed that whilst the $\mathrm{DCO}, \mathrm{CPO}$ and $A C O(P \& T)$ should direct and co-ordinate the exercise, project groups should be established in each Area working to a common brief and methodology.

14.3.3. Establish a network of project teams. It is therefore proposed that a project team is established in each Area Command and in the Personnel and Training Department to be directed by a project board chaired by the DCO and comprising the CPO, ACO (P\&T) and ACO (O). Initially each of the project teams in the Areas would be allocated the task of completing stages 1 and 2 of the project for one job role identified in para 14.2.1. The Personnel and Training Department would complete the same stages of work for the rank of major incident commander. To take account of recent analysis of the quality of operational performance, a member of the Operations and Training Performance Inspectorate would be included in each team. It is unlikely that, initially, the necessary job analysis skills will exist in team members and the leader and one member of each team will be given the necessary training. Some consultancy may also be necessary to supplement team skills. The use of Area based project teams will not only spread the initial workload but should bring ownership and commitment to the project from line managers.

14.4. No proposals are currently being made for stages 3 to 6 of the project as, until the analysis of the first two stages is completed, the workload to deliver the required changes to training is unknown. It may be that the project teams can continue the development work or some other project management structure may be required.

14.5. Other work required to deliver this strategy will also have to proceed in parallel with the work of the project teams. This work relates to training policy and will be undertaken largely in the Personnel and Training Department. This work will comprise:-

14.5.1. The development of methods to evaluate and validate the effectiveness of all aspects of operational training;

14.5.2. A review of current measures to assist personnel to prepare for promotion examinations to ensure an improved supply of promotion candidates particularly at sub officer and station officer levels; 


\section{Appendix A3}

\section{Extract from}

"Towards 2000"

\section{LFCDA and Culture Change}




\section{The Culture}

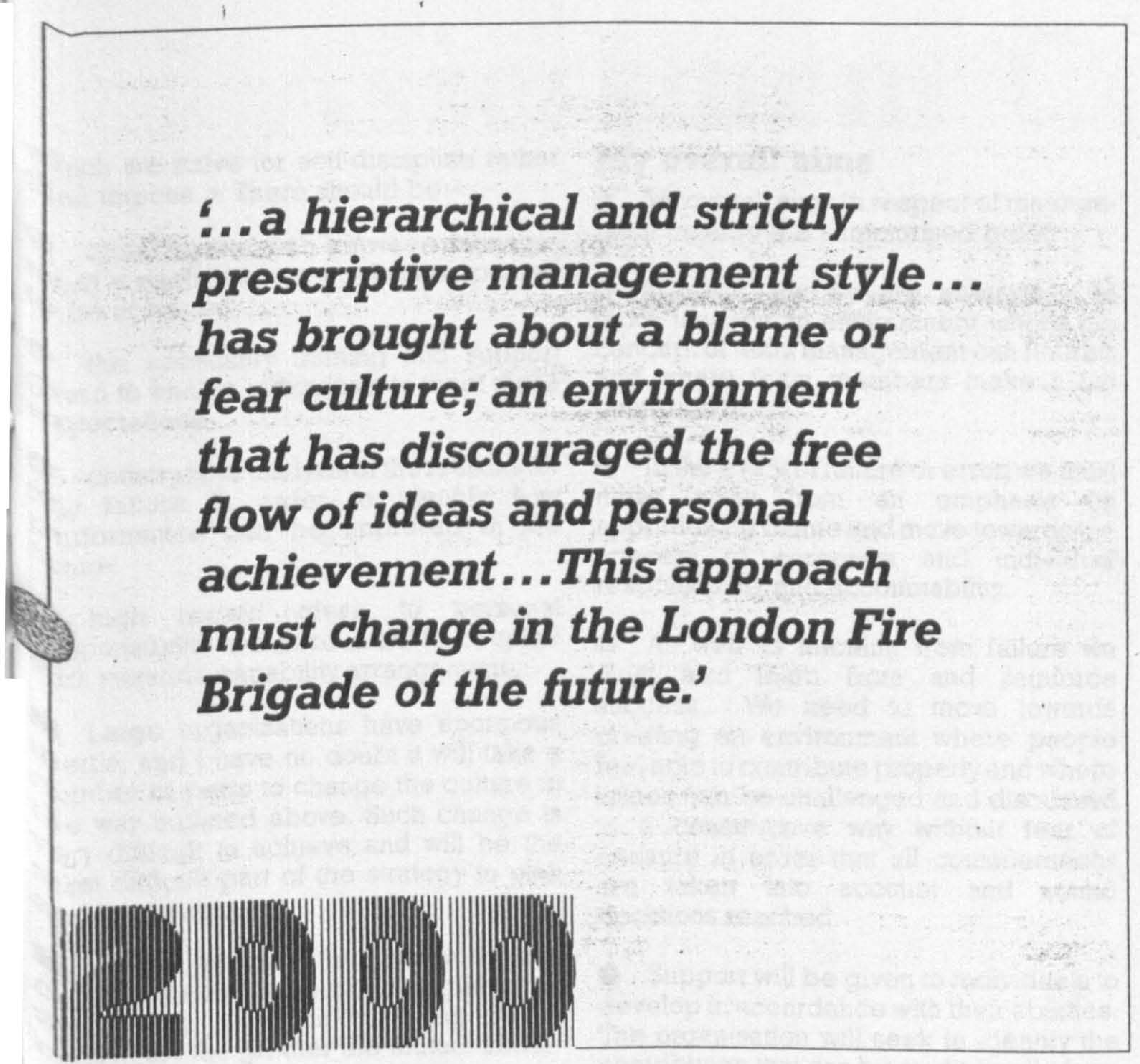

The LFCDA is a 'people business' with over $80 \%$ of the revenue budget spent on staff costs. Most of our services are not provided on Brigade premises and we must respond to emergency calls wherever they occur within London.

Accordingly the pursuit of quality in this organisation must be firmly based on the skills, knowledge and abilities of each one of you and will require changes in the way in which you are expected to carry out your job.

The London Fire Brigade is steeped in a hierarchical and strictly prescriptive management style and this has, as in many organisations, brought about a blame or fear culture; an environment that has discouraged the free flow of ideas and personal achievement.

The Brigade has in the past worked in this prescriptive manner, issuing instructions and orders with minimal training, supervising their implementation and resorting to discipline procedures when failures arise. This approach must change in the London Fire Brigade of the-future.

\section{My vision}

- Myvision is of a London Fire Brigade in 


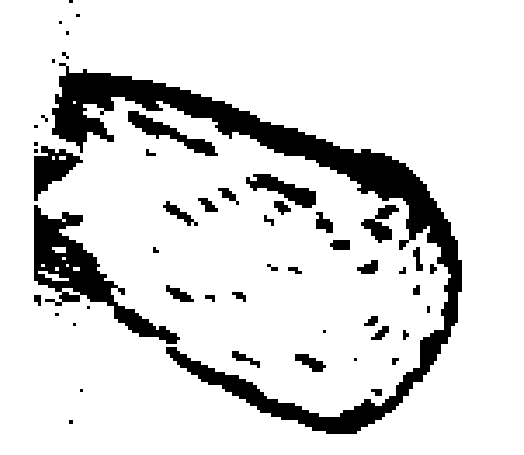

which we strive for self-discipline rather than impose it. There should be:-

clear agreement between manageinent at each level about what is expected to be achieved

the necessary training and support $\checkmark$ iven to enable individuals to meet those Expectations

constructive analysis of the reasons for any failure in order to identify how performance can be improved in the Suture

high regard given to personal ponsibility and accountability coupled with sensible capability arrangements.

Large organisations have enormous inertia, and I have no doubt it will take a number of years to change the culture in the way outlined above. Such change is very difficult to achieve and will be the most difficult part of the strategy to plan and implement.

A key element in promoting this cultural change is personal expectation which has a significant impact on behaviour; the greater the mutual understanding between staff and management at all levels of each other's expectations the more effective we can be in shaping behaviour and improving service quality.

\section{My overall aims}

My overall aims in respect of management change are summarised below:-

Managerially we are attempting to move towards an environment where the concept of team management can flourish and where team members make a full contribution.

In the event of failure or error, we must move away from an emphasis on apportioning blame and move towards the concept of corporate and individual responsibility and accountability.

As well as learning from failure we must also learn from and reinforce success. We need to move towards creating an environment where people feel able to contribute properly and where issues can be challenged and discussed in a constructive way without fear of censure in order that all considerations are taken into account and sound decisions reached.

Support will be given to individuals to develop in accordance with their abilities. The organisation will seek to identify the contribution that can be made by all of you and develop systems to assist you to meet your potential. An important part of this process will be self development.
An environment should be created where opportunity is open to all who have the ability and will to succeed with all staff working towards the agreed corporate goals of the organisation. Promotion will be based on merit and we will continue to develop objective methods of assessing ability.

Information about the approach, concepts, policies, practices and standards of the organisation will be disseminated as widely as possible, always backed with the reasoning behind each approach. This, will foster understanding amongst you, enabling you to further the ideals of the organisation without having to constantly refer upwards.

\section{My expectations}

To support my overall expectations for managerial change I have more specific expectations of Area Commanders, Heads of Departments and of Area and Departmental Management Boards, of Station Commanders and Branch or Section Heads.

I also think it is reasonable for those people to have certain expectations of me as Chief Fire Officer. I have shared these expectations with those directly concerned. 


\section{Appendix B}

Assessment Centre Materials.

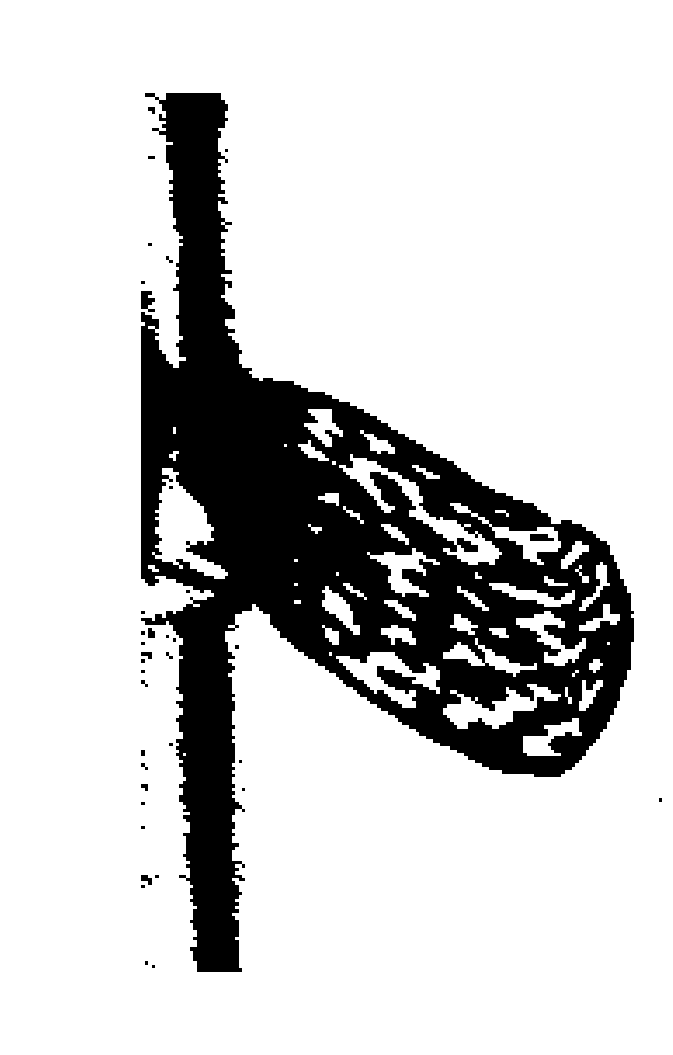




\author{
Eugene Burke C. Psychol. AFBPsS \\ London Fire Brigade \\ Personnel \& Training Department \\ 21 Albert Embankment \\ London SE1 7SD \\ Tel: $0171-587-6314 / 6312$ \\ Fax: $0171-587-6321$
}

\title{
7 November 1995
}

\section{Overview of the Divisional Commander Development Centre (DCDC) and Guidance for the Presentation and Written Brief.}

\section{Dear Candidate,}

First let me apologise for writing to you anonymously, but I hope that you will appreciate the workload involved in personalising all of these letters and my concern that you get this information early enough to allow you adequate time to prepare for the DCDC.

Information put together by the Occupational Psychology Unit concerning the psychometric tests was distributed to you last week (i.e. the materials on verbal and numerical ability tests, and the booklet outlining the types of questions in the specific tests you will be sitting). It was my view that the letter you are reading now be held back for at least another week to allow you to time to concentrate on these tests as they constitute the first component of the DCDC process. It is my hope that you have digested the information regarding the tests and that your preparation for them is already underway.

In addition to preparing for the tests, you will also need to prepare materials in advance of the DCDC which will allow us to assess your written and oral communication skills. I will go into these in the course of giving you an overview of the full DCDC process as shown in the figure on the next page.

\section{DCDC MORNING}

The DCDC will commence at 08.30 with coffee and with your personal schedule for the day. The day proper will begin with a general brief at 08.45 followed at 09.00 with the instructions for the In-tray Exercise. During the morning you will also engage in a Committee and a Presentation Exercise. The following provides a brief outline of these exercises:

- In-tray. This consists of a set of papers relating to the pros and cons of three options. Your task is to read through the documents and to recommend action on a preferred option. This exercise has been designed to tap your skills in analysing information and in making judgements. It will run throughout the day which is why you see it listed for the afternoon as well. You will leave and return to the in-tray and engage in other exercises during the day. So, in the morning, your work on the in-tray will be interrupted by the Committee Exercise, at the conclusion of which you will either begin the 
Presentation Exercise or return to the In-tray depending on your personal schedule. I am conscious that following the Assistant Chief Development Centre (ACDC) you may have heard various rumours and comments regarding this exercise. Please note that the score on this exercise is not simply about choosing an option. Rather, it is based on your analysis of the information regarding all three options and the evidence that you provide in support of your chosen option.

- Committee Exercise. You will be provided with a set of briefing papers as if you are a divisional manager within a department. You will then work with the other candidates in your assigned group to resolve the issues facing each department and develop an organisation (corporate) wide strategy. One hour has been scheduled for the committee meeting itself.

\section{DCDC}

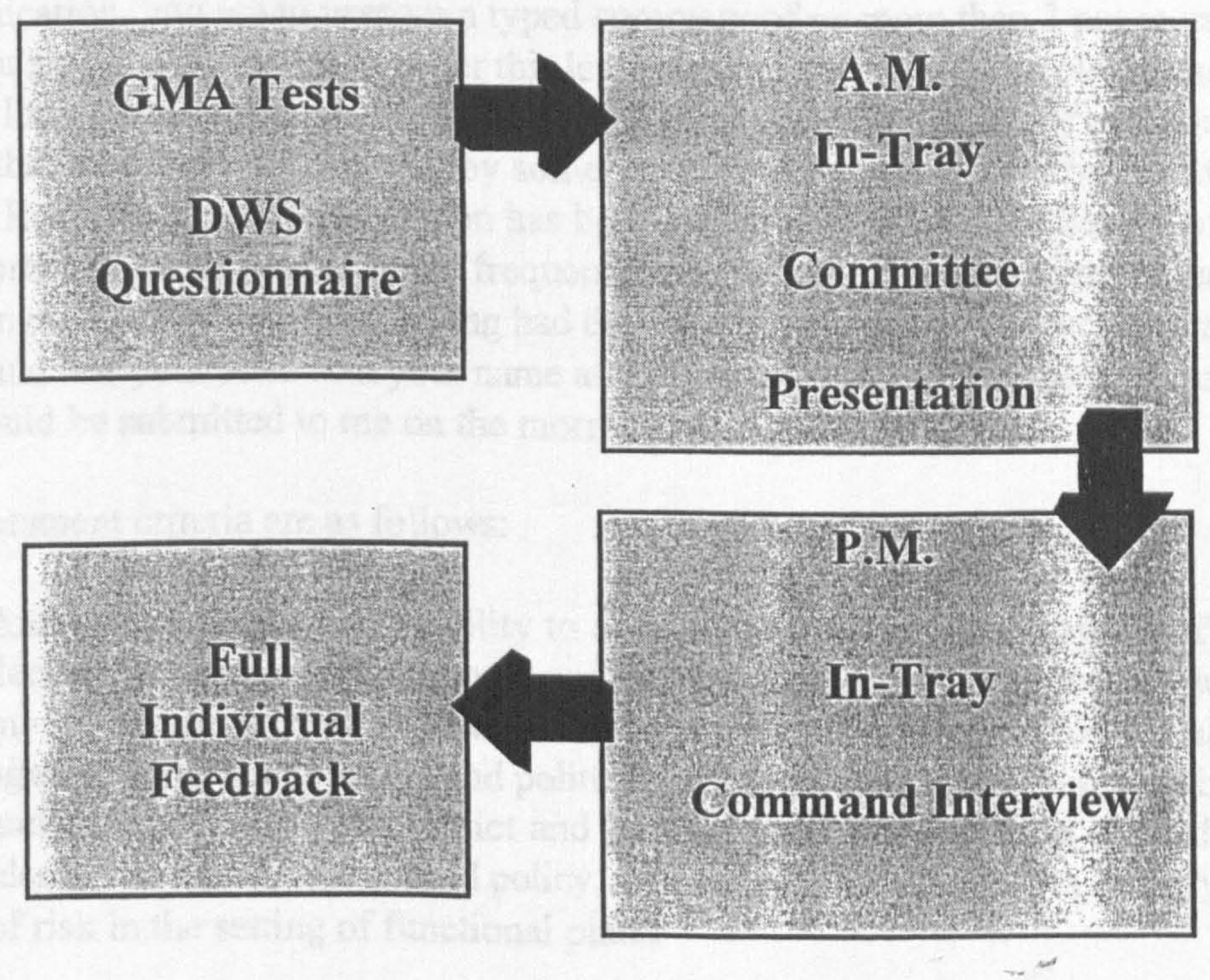

- Presentation. This exercise will form the basis for an assessment of your written and oral presentation skills, and this is where the assessment criteria given below are important. To provide you with the opportunity to demonstrate your strengths, choose one of these criteria as the basis for your presentation. This should describe a project and/or position through which you feel that you have demonstrated the qualities contained in the assessment criteria that you have chosen. An overhead projector, screen and flip chart will be provided for the presentation which should last for no more than 20 minutes. It should address the following questions though not necessarily in the order in which they are given (this is up to you): 
- What was the background to the position/project?

- What were the problems that were addressed and how were they identified?

- What was your role and how was this role established?

- What actions did you take and why?

- How successful were these actions and how was success demonstrated/measured?

- How has the experience that you gained contributed to your own personal development?

To supplement the presentation and facilitate the assessment of your written communication, you are to prepare a typed summary of no more than 3 pages using 12 point font size (i.e. size of letter as per this letter) and, preferably, Times New Roman (as per this letter; check your word processor for these characteristics). You should not assume that your brief will be read by someone at your presentation or by a uniformed officer. Remember, this organisation has both uniformed and non-uniformed officers, and reports and correspondence are frequently sent to non-uniformed committees who will often read material without having had the chance to discuss it with you beforehand. You should title your brief with your name and the assessment criteria you have selected. This should be submitted to me on the morning of your DCDC.

The assessment criteria are as follows:

Analytical Ability. The ability to comprehend the full implications of policy decisions within the department and for the department's relationship to other internal departments and external organisations; to balance departmental needs against resources, financial and political factors; to understand potential internal and external causes of conflict and propose proactive solutions to conflict; to identify problems in proposed policy, their causes and solutions; to identify levels of risk in the setting of functional plans.

- Decision Making. The ability to focus on key issues in the formulation and implementation of policies and proposals; to bring together relevant information from internal and external sources; to guide, support and lead others in decision making; to demonstrate personal responsibility for decision making; to translate decisions into clear and achievable plans.

- Management of Change. To anticipate and respond effectively to internal and external change; to adapt plans and priorities in response to changes in functional goals; to maintain effective performance of subordinates in responding to change; to recognise and exploit the opportunities for organisational development that are created by change. 
- Effective Communication. To communicate clearly to others orally and in writing; to promote understanding of functional issues to those within and external to the department; to develop effective relationships with colleagues and subordinates; to develop networks with members of other departments; to negotiate with others within and outside the department.

- Leadership. To demonstrate a clear appreciation of the department's mission as a whole and personal contribution to achieving that mission; to demonstrate personal responsibility for leading and managing others; to set examples of integrity and commitment in behaviour towards others; to motivate others in setting clear objectives and standards of performance.

- Personnel Development. To identify the skills and development needs of subordinates; to provide clear feedback on performance and encourage the selfdevelopment of others; to encourage contributions by subordinates and commitment to departmental goals; to acknowledge the contributions of colleagues and subordinates.

\section{DCDC Afternoon}

You will continue with the in-tray through the afternoon during which you will also engage in one other exercise:

Command Interview. This is a structured interview with two principal uniformed officers in which you will be presented with information on a potential incident. You will be asked what other information you would seek, what options you would consider for action, and how you would monitor the effectiveness of decisions made. This will last for 30 minutes. This is a stand alone component within the overall process and will be scored on a pass or fail basis.

\section{DCDC Outcomes}

Following the DCDC, data from all of your assessments less the Command Interview will be collated by the Occupational Psychology Unit to give an overall DCDC score. This score is a weighted sum of scores on each individual DCDC component (e.g. tests, committee exercise), and it will reflect the balance of strengths that you have demonstrated across all of the components. So, it is not a case of passing or failing individual DCDC components (except the Command Interview), but how you performed overall. It is also not the case that the DCDC is an IQ test as I hope you will appreciate from the breadth of the exercises summarised in this letter.

Once all of the DCDC scores have been collated for all candidates, these will be reviewed by an ACFO assessor panel and a short list of candidates will be drawn up. Those short listed will then be invited to attend interviews according to the schedule given to you by Veronica Beesley. 
You will be given full and detailed feedback on your performance on all of the individual components and on the DCDC overall.

I hope that the information provided above is clear, but please contact me (6314), Laurence Solkin (6329) or Sarah Buchanan (6312) if you have any questions regarding the DCDC. See you on the day.
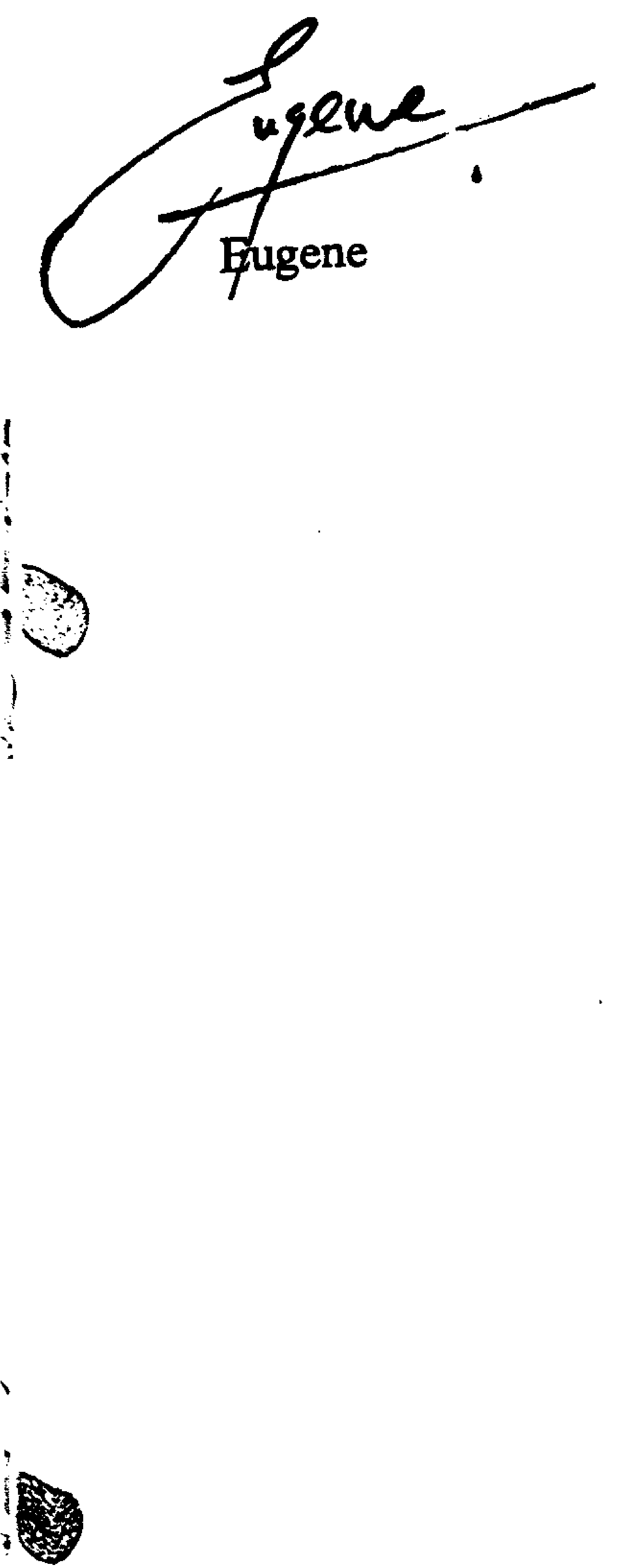


\section{In-tray Exercise}

Instructions. Attached you will find various documents relating to options for replacing a library. Each of the three options have both favourable and unfavourable factors associated with them, and your task is to consider these factors and to recommend a preferred option based on your analysis. This exercise comprises two actions for you to complete:

Options Appraisal. Attached is a separate sheet for you to record information relevant to each specific option. These are the sheets headed by the box labelled Option and their purpose is to allow us to assess your analysis of each option. These can be completed as follows:

- As you read through a document, identify which option an item of information contained on the document relates to. A document might relate to only one of the options, two options or all three.

- Using the rough paper provided, note whether the item of information is a factor that is favourable or unfavourable in relation to an option Also note any general factors that you feel are significant.

- Once you have read the documents, complete the Option Appraisal sheet for each of the three options. This requires you to identify the document from which an item or factor was identified.

- Recommendation. Once you have completed your analysis of the documents, the final action is to make a recommendation regarding a preferred option. A Recommendation sheet is also attached for this purpose. Your recommendation should be based on the information provided on the documents, and should summarise your analysis as recorded. on the Option Appraisal sheets. You should also include any general factors or items mentioned in the document that contribute to your decision. We will not be assessing your written style through this exercise, so you should focus your effort on providing a clear summary of the factors that led you to your recommendation.

The Problem. This concerns the replacement of the existing central library on one of three possible sites:

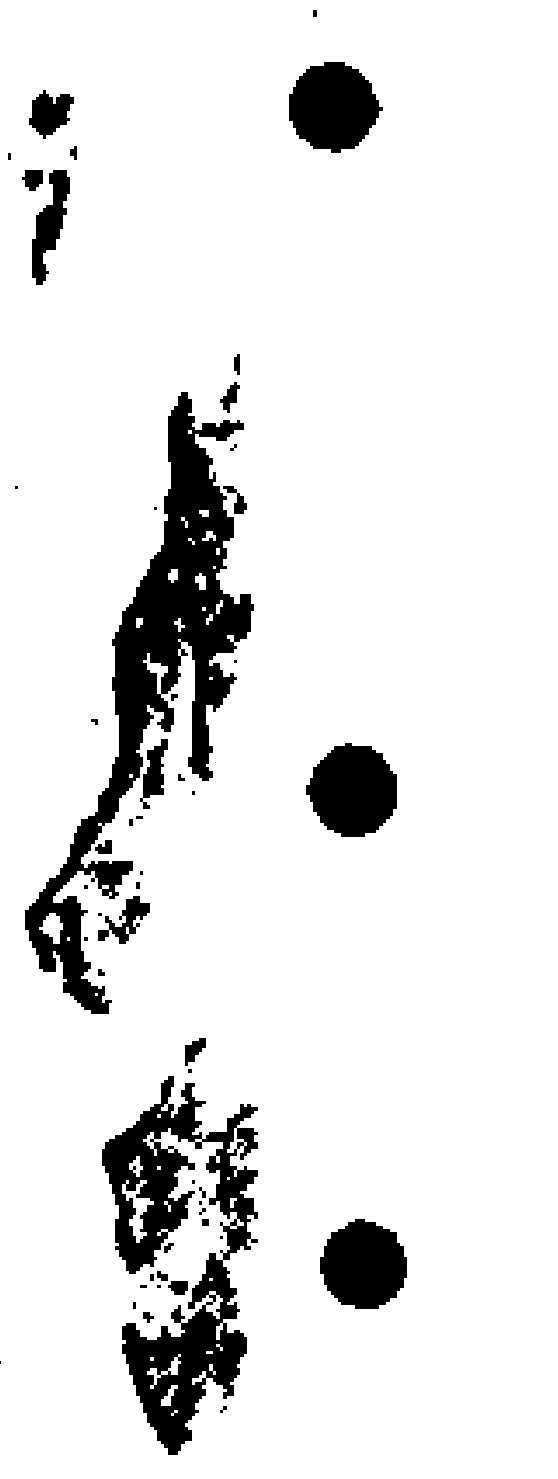

High Street which provides a new library as part of a new shopping and office complex close to the present site.

Hargreaves which offers a new library and a purpose built recreation centre.

Ring Road a more recent option proposed by the High Street developer which involves moving the current library site to the edge of a housing development. 


\section{In-tray Exercise}

\section{Overview of Exercise}

This exercise is about the analysis of information and about judgements regarding possible options for action. You are asked in the exercise to weigh factors for and against each of three options and to recommend one option only. This is to make the exercise manageable in the time available for it. In making your analysis and evaluation, keep in mind the following:

- The general context in which the problem is set. Why has the problem come about? What background information and what general factors are given that would influence decisions regarding all three options?

What are the shorter-term and longer-term needs and priorities? How do these compare in their likely impact and in ensuring a satisfactory outcome?

- Are there immediate actions that should be taken with respect to your decision? Staying within the limits set for the exercise, are there actions that you would suggest that would help the implementation of your recommendation?

Please remember to keep your analysis and recommendation within the information provided for the exercise. You may think of other actions that you would like to take but are not included within the papers provided to you. You will not gain extra points by stepping outside the brief of the exercise.

Finally, your recommendation should bring together the items you have identified through your analysis, and should give us a clear sense of why you arrived at your decision. While a simple summary is all that is required, this should state how you weighed the information, which factors you felt were most critical, and how you consider your reeommended option best meets organisational needs and the constraints of the situation.

You will be leaving and returning to this exercise throughout the day. Using your schedule for the day, you should begin by planning how you will tackle the exercise throughout the day. You will not be allowed any extra time to finish the exercise other than that shown on your schedule, and the exercise must be completed by the end of the day's events. While all candidates have been allotted the same time for the in-tray, for some of you the day will finish with other events (interview or feedback). So, you should take stock of when you, individually, must complete the exercise as shown on the schedule.

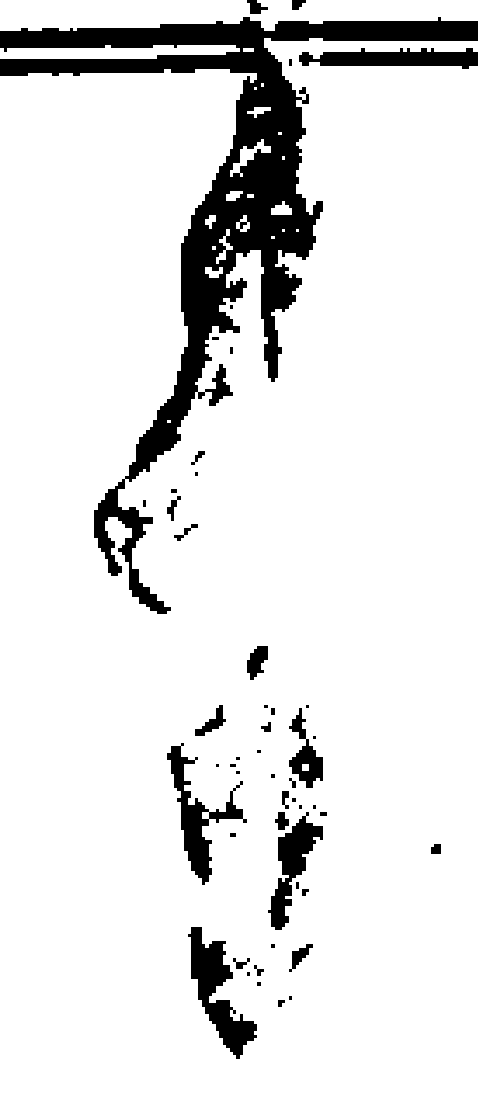




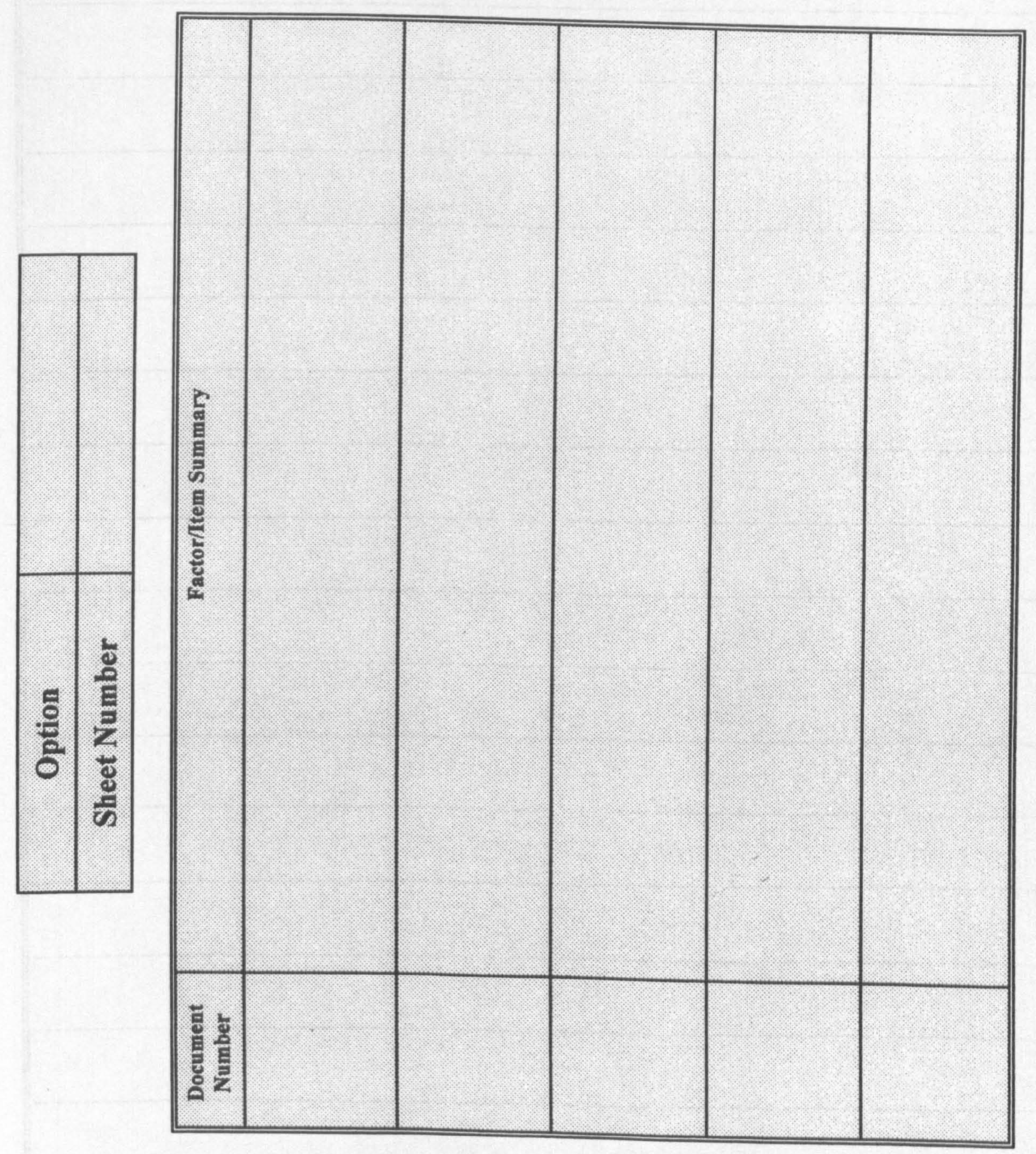




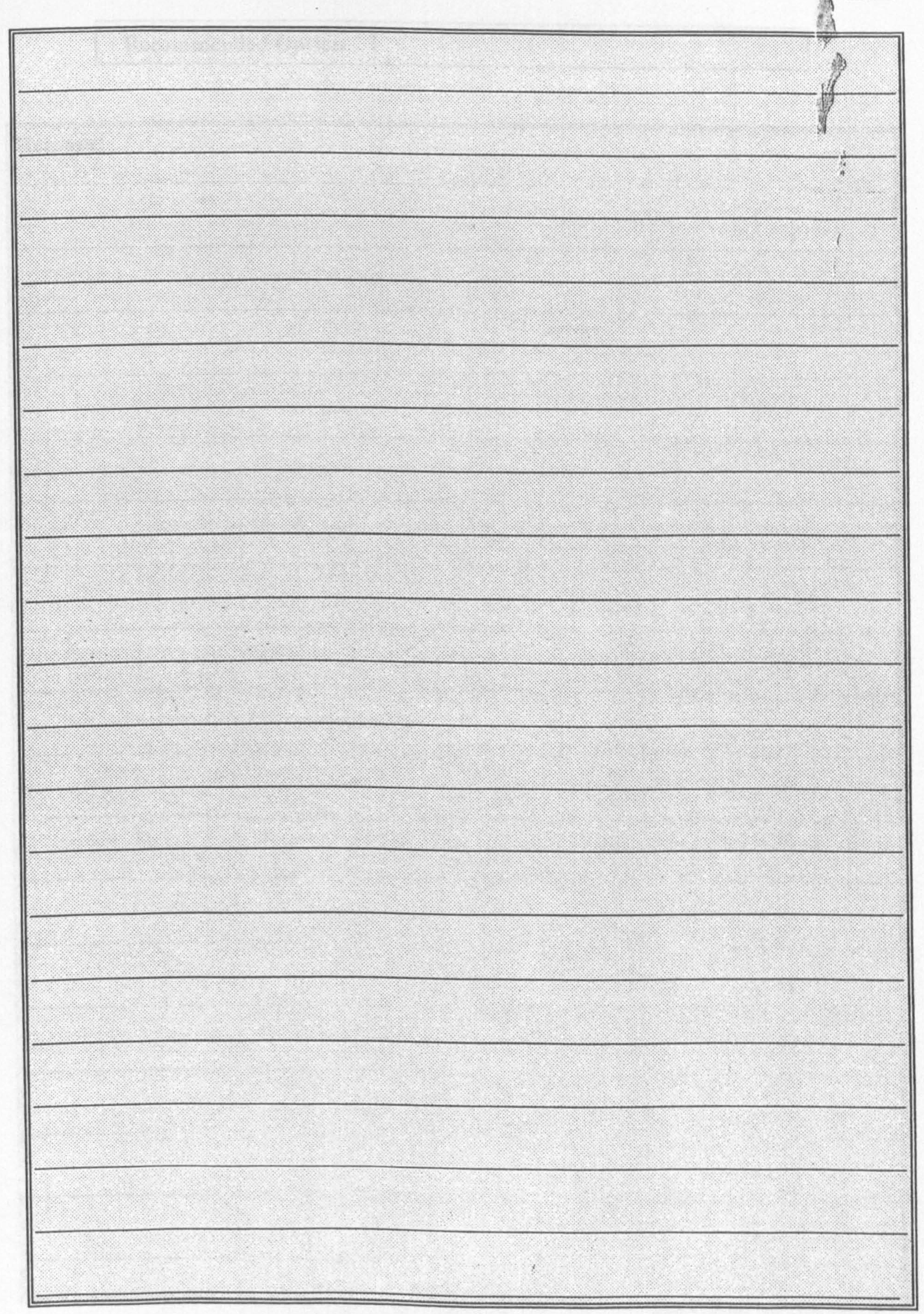




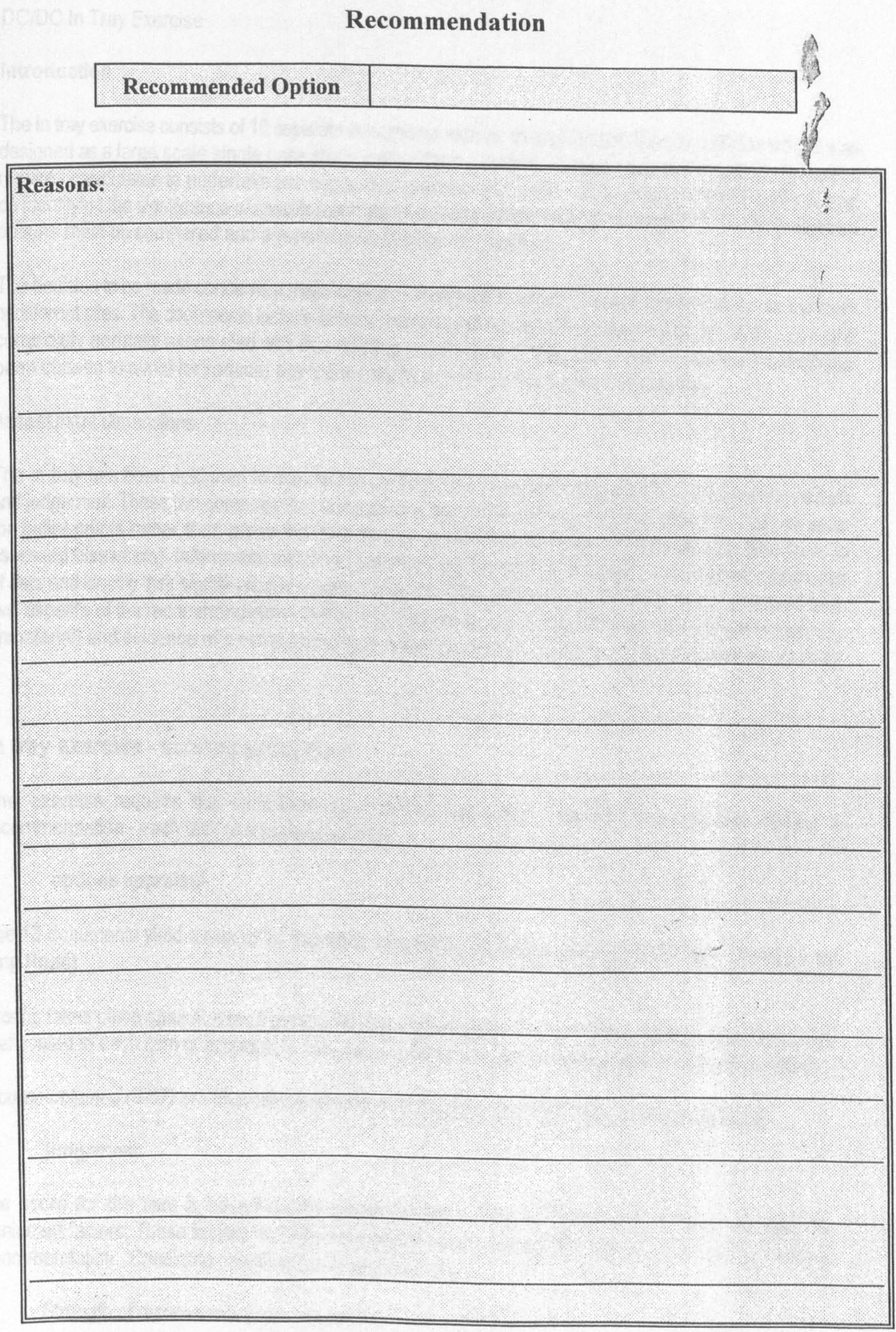


DC/DC In Tray Exercise

Introduction

The in tray exercise consists of 18 separate documents with an overall length of some 5,000 words it was designed as a large scale single case study (rather than a number of responses to be made). As such it requires candidates to undertake two separate but associated tasks - an appraisal of each option based on identifying the significance of specific items from each document, and an evaluation or in which all three options must be compared and a recommendation for one justified.

The decision to be made concerns a major capital investment for which there are three options in the form of different sites. The documents include letters, memos and extracts from reports and are of the type and complexity normally associated with files relating to decisions of this sort. A non-fire service context has been chosen to avoid (or reduce) any influences from prior (direct service) knowledge.

Assessment dimensions

The in tray has been designed to assess two strategic management competencies - information search and judgement. These two components are refiected in the tow tasks required. Because the exercise asks for bullet points rather than prose the assessment avoids testing literacy or writing skills (the latter is assessed elsewhere). Information search is assessed on the basis of the ability to recognise key pieces of data and identify their significance to a particular option. The assessment of "Judgement" is derived from two aspects of the recommendation - the overall support for the preferred option (the choice of option is immaterial) and evidence of a comparative (pair wise) process in evaluating options against each other.

\section{In tray exercise - scoring procedure}

The exercise requires the candidates to complete two tasks - options appraisal and making a recommendation - each task is scored separately.

\section{a. options appraisal}

The 18 documents yield a total of 57 separate data items ( 21 for Hargreaves, 15 for High Street, 21 for Ring Road)

Scoring takes place against a marking grid for each option using the candidates option notes. One mark is allocated to each item of information correctly identified (i.e. with its significance to the option noted).

(Scores obtained (0-57) are then translated into a percentage score for this part of the exercise)

\section{b. judgement}

The score for this item is based on the recommendation. The 57 items referred to above yield 15 significant factors. These factors must be considered against the options presented in order to reach a recommendation. Candidate scripts are scored in two ways :- 
Is based on the number of separate factors $(0-15)$ used to support the recommended option, marks are awarded for identifying each item (e.g. training facilities) and how it supports the recommendation pade.

ii. Comparative process (total C)

Signifies the extent to which options have been compared or weighed using the 11 factors. To scisre on this dimension candidates must compare at least two of the options against each other on a single factor (e.g. compare the cost of two options) each factor having a comparison scores one point (range 0 -15).

The two raw scores ( $R$ and $C$ ) are summed and translated into a percentage score (out of 30 )

\section{c. Weighting}

The two percentage scores are multiplied by a weighting factor of $30 \%$ for options appraisal and $70 \%$ for judgement to achieve a total score for this exercise. The weighting system used is designed to give greater importance to the final outcome recommendation, which is linked to judgement, over " option appraisal" which is more closely associated with information use. 
DCDC Summary Sheet

Candidate Number

1. Options appraisal

\begin{tabular}{|l|l|}
\hline Option & Score \\
\hline Hargreaves & \\
\hline High st & \\
\hline Ring road & \\
\hline Total score & \\
\hline
\end{tabular}

2. Judgement

\begin{tabular}{|l|l|}
\hline Recommendation & \\
\hline Comparison & \\
\hline Total score & \\
\hline
\end{tabular}

first assessor

second assessor 
GROUP EXERCISE (assessor copy)

You are a divisional manager working for the education department of your local authority.

Recently, central government, through the Department for Education, reexamined the budgetary provision for inner city authorities including your own. As a result, an additional sum of up to (one of)

4 candidates $£ 150,000$

5 candidates $£ 200,000$

6 candidates $£ 240,000$

7 candidates $£ 280,000$

may become available in the current financial year.

The Chief Education Officer has asked you and your colleagues for proposals for using this money and a meeting has been called to agree a list of projects for submission to elected members.

At this stage the precise sum available has not been determined and members have asked for a listing in priority order.

The Education Officer has been called to a meeting with the Chief Executive and has asked you as a group to produce a priority list.

Details of the proposal to be submitted by your division are enclosed, together with the corporate mission and values of the education department.

You have 30 minutes to prepare for the meeting. 
Thamesmead Education Department

Our aim is .. to provide a truly comprehensive education service which is open to all

to do this we will

1. provide access to education for all regardless of race, sex, age or ability

2. provide as broad as possible a range of educational services to meet the needs of as many people as we can

3. provide services which are efficient and offective in meeting those needs

4. communicate and cooperate with the local community

5. respeet the needs and wishes of pupils, teachers, parents, governors and all those who contribute to, or may benefit from. the education service 


\section{Background}

At present the council owns and operates a fleet of some 60 buses. These are used for transporting children between different school sites and to and from sports facilities. In addition to these relatively short journeys the buses are aiso used for a number of school outings (trips to zoos, theatres etc)

\section{Problem}

Concerns have been expressed by both parents and teachers' organisations at the risks involved in not having fitted seat belts. They point to a number of serious accidents involving buses on motorways which have resulted in loss of life and which seat belts may have prevented. A neighbouring borough has just announced that from next term all its school buses will be fitted with seat belts.

\section{Proposal}

The proposal is to use the additional resources to start the process of fitting seat belts to all school buses. The overall cost of the exercise is estimated at $£ 1,500$ per bus (i.e. $£ 90,000$ in total) and the proposal is to undertake this on a phased basis over two years, at a cost of $£ 45,000$ in the current year.

\section{Other options}

One alternative to fitting such seat belts may be to limit the use of council owned buses to short non-motorway journeys and to hire in other transport (with fitted seat belts) for the small number of longer journeys. This option would have the effect of increasing the price of such special journeys (making it difficult for some parents to afford). Headteachers are divided on this option with some preferring to pay for additional safety features (if necessary by hiring coaches themselves) while others are unable to do so.

\section{Other factors}

A further factor to consider is the cost of employing additional part-time staff to accompany infants. At present there is a staff to pupil ratio of $1: 8$ (or 5 adults per bus). Were seat belts to be introduced there would be a need for an additional member of staff - to strap children into and release them from their belts (this would be particularly important in an emergency). The cost of such additional staffing has not yet been finalised. This problem does not affect older children and it is estimated that no more than $10 \%$ of journeys will require additional staff, indeed it may be possible for parents to undertake these duties on a voluntary basis. 


\section{Background}

The council has a statutory duty to provide education to pupils who are unable to attend school for a significant period. Traditionally this has been achieved by the use of "home tutors" for those with long term sickness problems. More recently, however, the majority of work in this area stems from pupils who have been excluded from school. Most home tutors are experienced, often retired, teachers who work on a part-time basis with pupil's in the pupil's home.

Problem

Although home tutors are not particularly costly (compared to other teachers in the borough) they are only able to teach a single individual. The service itself is therefore very expensive. At the same time an increasing number of pupils are being excluded for a variety of reasons. One argument suggests that as schools struggle to improve their performance, the continued presence of disruptive elements is seen as an unnecessary burden on teaching resources and this actually encourages Head teachers to exclude more pupils. Whatever the reasons behind the increase, the position is that more pupils are excluded, which means that more children need to be taught at home.

\section{Proposal}

The proposal is to replace the current use of part-time staff with 5 full-time posts and to recruit staff who will specialise in this type of support. The total cost of the new team will be $£ 120,000$ per year which can be jointly funded from Education and Social Services Departments - with a contribution of $£ 50,000$ from the education budget. This proposal involves an increase in capacity of some $75 \%$ over present resources.

\section{Other options}

At the present rate of increase the number of pupils being excluded will exceed the resources of the new team in approximately three years. At that stage, and subject to national policy, it may be necessary to create a special unit for excluded pupils in which teaching can take place with smaller classes - as opposed to individual one to one home tuition. While this would represent a more cost effective form of teaching, the total cost (circa $£ 100,000$ per year) could not be justified at present.

Other factors

By replacing part-time staff with full-time devoted teachers the proposal sacrifices flexibility for a higher standard of education, particularly in relation to special needs. The issue of staff security and safety however remains a potential problem. It must be remembered that a percentage of the pupils taught by home tutors have been excluded by schools on the basis of drug abuse and violence. Whilst specialised staff may become more effective in dealing with some of these emotional/behavioural difficulties, there remains the risk that teaching staff may be attacked or assaulted. 


\section{OPTION C}

\section{Background}

The council has a policy of integrating physically disabled pupils where possible. Unless there are valid educational reasons the pupils disability has not been used to segregate them from mainstream education. Although there remain a number of places for pupils in special schools. the majority of mobility impaired children now attend normal schools with very few difficulties.

Problem

The policy has worked well for some years, particularly at primary school level. This has been achieved mostly by moving classes to ground floor rooms thus requiring very few physical adaptations. At secondary level, however, there is a need to provide access to specialist facilities such as science laboratories etc and, as these schools tend to be larger and on more than one floor, the problem of access by mechanical means (lifts/stair lifts etc) has to be faced.

Proposal

At present there are 5 pupils who are unable to attend chemistry classes at the Manor secondary school and a further 3 at St. Teresa's who cannot use the lecture theatre. The total cost of adapting these two premises is estimated at $£ 60,000$. This would involve the installation of a lift at the Manor and a stair lift at St. Teresa's.

Other options

The only alternative to providing access within our own schools would be to fund places in schools outside the borough. Although this is possible, either on a full-time or part-time basis for specialist lessons, this would create severe disruption to the lives of the disabled pupils (transport being not the least of their problems) and do little to fulfill our policy of full integration.

Other factors

As more pupils with mobility problems leave primary school it is likely that they will need access to our secondary schools. At present we have identified two (St. Teresa's and the Manor) of the council's five schools for adaptation. I believe that similar sums would be required for two of the remaining schools as and when the need arises (at a cost of approx $\{60,000$ ). The County High School, on the other hand, is much older and work to bring this up to the required standard may cost as much as $£ 100,000$. 


\section{Background}

The council currently provides school meals to some 4,500 children each day. This represents approximately $35 \%$ of children attending schools. Meals are prepared locally at each school, although food purchasing and menus are centrally controlled. Since 1990 catering has been a direct service organisation (DSO) with a requirement to make a return on capital invested.

Problem

As the proportion of children taking meals decreases so the cost of meals (based on items such as maintaining staff and kitchens) rises. Each fall in demand triggers rises in costs and we become trapped in a spiral of falling demand and increasing cost. At the heart of the problem is the fact that too many kitchens exist to supply far too few meals. Although take up in some schools is as high as $70 \%$ this cannot overcome the fact that many kitchens were designed for more meals than they serve and in some cases cannot operate without a minimum number of staff for safety reasons.

\section{Proposal}

The proposal is to replace existing school based kitchens with a number of strategically located food processing sites from which meals are chilled and distributed to be heated up locally. The total cost of the project is just under $£ 200,000$ against which there would be savings (based on reduced staffing) of some $£ 40,000$ per year.. Rather than replace all kitchens at once a phased proposal has been developed with a pilot stage involving one "cook/chill" site and six local schools. The total cost of the pilot scheme is $£ 60,000$ (net of $£ 8,000$ staff savings)

\section{Other options}

Unless a way can be found to reduce costs, the alternative is to close kitchens at some schools. This would mean either abandoning meal provision at those sites or making arrangements for meals to be transported "hot" from school to school with the health risks that this may involve. An alternativel is to buy pre-chilled food from another contractor (at higher prices) This would provide very little in the way of savings as any reduction in staff costs (at the school kitchen end of the service) would be more than taken up by higher food costs from our supplier.

\section{Other factors}

Cook/chill technology has developed rapidly in the past three years and many of the problems associated with earlier products has disappeared. The health risks associated with earlier systems now seem to have been overcome. Although there is general satisfaction within the catering trade, the public have yet to be convinced that meals provided in this way are as safe (or as pleasing) as more traditional methods. It must also be remembered that this proposal includes staff savings which can only be achieved by redundancy. 


\section{Background}

The council supports a number of schools swimming pools as a means of helping teach children to swim. Earlier this year the council were forced to close one of its remaining school swimming pools. The pool which was built over 20 years ago had suffered from vandalism and general misuse The options to the council at that stage consisted of redevelopment at a cost of $£ 300,000$ and closure. Unable to fund the redevelopment the council closed the pool thus saving $£ 5,000$ per year maintenance costs

\section{Problem}

The initial closure was based on falling numbers of children and the assumption that, as schools use of facilities was reducing (by $20 \%$ each year) over a period of about three years there would be little need for a third pool. In fact school's use of these facilities is now increasing (by $25 \%$ per year) under parental pressure to teach children to swim. A recent tragic drowning incident has added to the concern over the teaching of basic water safety in schools.

\section{Proposal}

A new sealing technique has now been offered to the council which would effectively re-seal the current pool for as little as $£ 50,000$. The new system which creates a thin plastic coating over existing tiling can be applied in a matter of days. A number of pools have been treated across the country and the system is guaranteed for five years. The re-opening would reduce public concern at water safety and reduce pressure on the two existing pools.

\section{Other options}

A second option to deal with the increase in demand would be to fund the use of pools in other boroughs - this is estimated to cost approx $£ 12,000$ per year at the current rate of use. Any proposal to use external resources would need to take some account of possible further increases, in both price and volume, over time.

Other factors

One of the two current pools may have to close for minor redecorating work in the next few weeks. This would be during the peak period. It is estimated that with only one operational pool, swimming and water safety classes will be cut by up to $50 \%$. 


\section{Background}

The Council has a policy of encouraging people who are under-represented in the workforce to apply for and train for council jobs. At present there is a significant mis-match between teaching staff, who are predominantly White Europeans, and school pupils (of whom only $25 \%$ are white and some $45 \%$ are Afro-Caribbeans). Although Afro-Caribbeans make up a half of the education department staff they tend to be employed in more junior posts in administration or as classroom helpers. Classroom helpers, although employed within classrooms, tend to work with smaller groups of pupils under the supervision of a qualified teacher.

\section{Problem}

A number of parent's organisations have expressed concern at the small number of black teachers working in the borough. A variety of recruitment proposals have been discussed including bringing in teachers from overseas. The parent's groups together with their local MP feel that there should be enough suitably qualified people within the borough who could be trained as teachers.

Unfortunately teacher training has traditionally involved long ( 2 years) residential courses and it is recognised that many of those who may be interested also have significant domestic responsibilities.

\section{Proposal}

With funding from the EC (European Community) it would be possible to design a locally based teachers course (practice teachers certificate) for staff currently employed as classroom helpers. The borough would need to meet the costs of tuition, which would be provided by the local Further Ed college (circa $£ 50,000$ ) The EC would then meet any additional salary costs for up to 20 staff. The scheme would operate by taking helpers out of the classroom for one day per week over a two year period and be followed up by a six month "trial" period as a practice teacher. The immediate advantage of the scheme, apart from providing qualified staff, would be that the helpers would continue to work in their current schools and would have their training as teachers fitted around their availability.

\section{Other options}

The only realistic option other than providing full- time training would be to offer incentives for qualified ethnic minority teaching staff to come to the borough. This could include low cost housing or higher rates of pay (special supplements). Although this would probably encourage more ethnic minority teachers to apply, any payments would need to be made to all new teachers regardless of race and would probably need to be matched by some payment to existing teachers.

\section{Other factors}

There is widespread concern over the reputation of practice teacher training and there has been notable opposition from one of the teacher's Trade unions. Many working within the field of education would see the project as providing "second class" teachers. Although the local FE college have promised that they will adhere to current standards for teacher training, they have also expressed reservations about the needs of some people who may apply for the scheme. 


\section{OPTION G}

\section{Background}

The Adult Education Institute provides a range of non-vocational courses directed at members of the locat community. II is funded jointly by the council and by fees from people attending courses. A wide Wanety of subjects are taught and the institute is a major provider of education to young unemployed adults, particularly those who may have missed out at secondany school.

\section{Problem}

Over the past three years the institute has sought to expand its services and to broaden the range of courses available. New courses were offered on the basis of a customer survey. Having been well supported mitially, it now apoears that a significant proportion of these courses are no longer attracting students. This means that the institute is faced either With rumning courses at a loss: (because there are too few people paying tees) or restricting courses to those that can actually inance themselves, it has been estimated that, at present fake up rates, as much as $35 \%$ of the curent course programine may be under threat. It these courses are closed this will have severe effects on staffing levels at the institute and may even threaten closure.

Proposal

The proposal is to launch an advertising campangh aimed at certain areas of the borough which have not traditonally been involved in education. This is seen as a dellberate attempt to target areas with high ethnic poptilations and to encourage take up by these groups. The total cost of the campaigh has been estimated at f 75000 . One third of this cost can be met from current funds by using students work (in areas strch as art and desigh). The additional cost of advertising campaign Will therefore be 250,000 .

Other options

The proposal looks to extend tire market tor extsting courses. An alternatvo would be to undartake a new survay in the berough to laentify other needs. Such a suvey would not only update the existing inrormation but also idenitify possible new course / tople areas. A survey would cost silghtly more that the proposed advertising campaign $(f \quad 60.000)$ and Would take slightly longer to complate (possibfy as much as 6 months) The results of the survey would not be avallable tor use in generating new. customers in the forthcoming acadernic year.

Other factors

The current programme of courses was extended by Vittre of the survey undertaken three years ago in which residents from all parts of the borough took part. Despite this, there is a noticeable bias (in course provision) in favour of more leistrely" pursuits such as ar and horticulure rather than more. practical courses such as car maintenance or computing. Tho institute is aware of this problem and is seeking to extend the course programme in the area of practical skills this will be one of the elenrents which they will seek to market in the advertising campaign. 


\section{OPTION H}

Background

At present the Education Department operates from several sites including the town hall, the neighbouring annexe and a number of old schoof buildings spread around the borough. Different sections are located etther because they serve a particufar geographical area, or, more usually because accommodation became available as a particular section or group needed it. Recently, a number of other Council Departments ( $\mathrm{such}$ as Social Services) have recently been centralised. Unfortunately no single site can accommodate the entire Education Department and there are insurficient funds to build or lease surch an appropniate building

Problem

Parents from a number of schools have complained that they can never find out who is responsible for key services such as special needs and that they are constantly being asked to go to different sites to see different people. In one particular case it was reported in the local press that the parents of a disabled child were asked to go to six different offices across the borough. This complaint is echoed by people applying for student maintenance grants who have to deal not only with three sections of the Education Departnent but also the Borough Treasurer.

Proposal

The proposal is to set up an information centre at the Town thall where all education queries could be handied by a decicated team. This group of staff would act as a focus for requests (and complaints) from the public and be abte to direct them to the appropriate section. In cases of need (such as those involving people with disabilities) there would alsa be a private interview room in which confidential interviews with appropriate specialist staft could be anranged . i.e. the member of staff couid travel in to the information centre rather than sending hie member of the public to another site. The cost of setting up the centre is estimated at 655.000 . This estimate includes the purchase new funiture, the conversion of existing offices at the Town itall and most significantly the development a computer database system which would provide information on all education senvices in the borough. The centre would be staffed by cierical and administrative staft who currently provide office support to the Edurcation Department in the Town Hall.

\section{Othat options}

A less sophisticated and less expensive option Would be lo provide better information and publicity by other means. This could be via the local press or through leatlets at other councll buldings 0.9 . Education Deparment ofíces, librartes and swimming pools. This information could be supplemented by a telephone based information service (possibly using the computer database system ) Which would direct the public to the appropriate office. Such an approach has worked for the lousing Bepartment who use notice boards in lifts and staimells on its housing estates. On the other hand such an approacts Would not provide the public lace lo tace contact with staft:

\section{Other factors}

Although the centre would provide a first point of contact, certain specialist services - such as special needs require sophisticated assessment facilities. Since these facilities cannot be made available at the centre, there would still be a need for someone to advise parents on their needs, and for parents and children to visit other sites. In addition, doubts have been expressed by some professional groups as to the benefit of making "overworked and under skilled" clerical and receptionist staff undertake an initial advisory role. 


\section{Committee Exercise Assessment Sheet}

\section{Candidate}

\begin{tabular}{|c|c|c|c|c|}
\hline $\begin{array}{c}\text { Stronger } \\
\text { Tendency } \\
\text { To }\end{array}$ & & $\begin{array}{l}\text { No Strong } \\
\text { Tendency } \\
\text { Either } \\
\text { Way }\end{array}$ & & $\begin{array}{l}\text { Stronger } \\
\text { Tendency } \\
\text { To }\end{array}$ \\
\hline & $\begin{array}{l}\text { Generates ideas, options, goals - } \\
\text { active/proposer }\end{array}$ & & $\begin{array}{l}\text { Accepts other's ideas and suggestions } \\
\text { - passive/acknowledger }\end{array}$ & \\
\hline & Oral contributions clear, concise & & Oral contributions unclear, verbose & \\
\hline & $\begin{array}{l}\text { Clarifies ideas, issues and options - } \\
\text { focusing }\end{array}$ & & $\begin{array}{c}\text { Confuses/clouds ideas, issues and } \\
\text { options - obscuring }\end{array}$ & \\
\hline & $\begin{array}{l}\text { Encourages others to contribute - } \\
\text { including }\end{array}$ & & $\begin{array}{l}\text { Discourages/blocks others from } \\
\text { contributing - excluding }\end{array}$ & \\
\hline & $\begin{array}{l}\text { Explores and develops contributions } \\
\text { of others }\end{array}$ & & $\begin{array}{l}\text { Neglects or dismisses contributions of } \\
\text { others }\end{array}$ & \\
\hline & $\begin{array}{l}\text { Posture and gesture positive - } \\
\text { attentive, supportive, patient }\end{array}$ & & $\begin{array}{l}\text { Posture and gesture negative - } \\
\text { detached, antagonistic, impatient }\end{array}$ & \\
\hline & $\begin{array}{l}\text { Encourages shared ownership of } \\
\text { proposals and solutions }\end{array}$ & & $\begin{array}{l}\text { Pushes own ideas and suggestions at } \\
\text { the expense of group ownership }\end{array}$ & \\
\hline & $\begin{array}{l}\text { Aids positive closure - coordinating, } \\
\text { achieving }\end{array}$ & & $\begin{array}{l}\text { Impedes positive closure - } \\
\text { fragmenting, delaying }\end{array}$ & \\
\hline
\end{tabular}

\section{Comments.}




\section{Candidate}

\begin{tabular}{|c|c|c|c|c|}
\hline $\begin{array}{l}\text { Stronger } \\
\text { Tendeney } \\
\text { To }\end{array}$ & & $\begin{array}{l}\text { No Strong } \\
\text { Tendency } \\
\text { Either } \\
\text { Way }\end{array}$ & & $\begin{array}{c}\text { Stronger } \\
\text { Tendency } \\
\text { To }\end{array}$ \\
\hline & $\begin{array}{l}\text { Organised with clear introduction, } \\
\text { middle and conclusion; easy to follow } \\
\text { major points and overall direction. }\end{array}$ & & $\begin{array}{l}\text { Structure complex or confusing; } \\
\text { difficult to follow direction and } \\
\text { general message. }\end{array}$ & \\
\hline & $\begin{array}{l}\text { Use of visual aids adds interest and } \\
\text { contributes to understanding of } \\
\text { presentation. }\end{array}$ & & $\begin{array}{l}\text { Use of visual aids detracts from } \\
\text { interest in and understanding of } \\
\text { presentation. }\end{array}$ & \\
\hline & $\begin{array}{l}\text { Oral expression clear and fluent; use } \\
\text { of words easy to understand. }\end{array}$ & & $\begin{array}{l}\text { Oral expression unclear and lacks } \\
\text { fluency; use of jargon or obscure } \\
\text { words impedes understanding. }\end{array}$ & \\
\hline & $\begin{array}{l}\text { Voice projection strong; varied use of } \\
\text { tone and modulation (e.g. for } \\
\text { emphasis). }\end{array}$ & & $\begin{array}{l}\text { Voice lacks strength of projection; } \\
\text { dull, monotone. }\end{array}$ & \\
\hline & $\begin{array}{l}\text { Posture and gesture controlled, } \\
\text { confident, relaxed. }\end{array}$ & & $\begin{array}{l}\text { Posture and gesture nervous, halting, } \\
\text { agitated. }\end{array}$ & \\
\hline & $\begin{array}{l}\text { Style of presentation expressive; } \\
\text { enthusiastic, humorous, lively. }\end{array}$ & & $\begin{array}{c}\text { Style of presentation static, laboured, } \\
\text { quiet. }\end{array}$ & \\
\hline & $\begin{array}{l}\text { Presentation directed to audience; } \\
\text { faces and talks to audience; maintains } \\
\text { eye contact. }\end{array}$ & & $\begin{array}{l}\text { Contact with audience intermittent or } \\
\text { inconsistent; faces away; little eye } \\
\text { contact; talks to screen. }\end{array}$ & \\
\hline
\end{tabular}

\section{Comments.}




\section{Written Brief Assessment Sheet}

\section{Candidate}

\begin{tabular}{|c|c|c|c|c|}
\hline $\begin{array}{l}\text { Stronger } \\
\text { Tendency } \\
\text { To }\end{array}$ & & $\begin{array}{l}\text { No Strong } \\
\text { Tendency } \\
\text { Either } \\
\text { Way }\end{array}$ & & $\begin{array}{l}\text { Stronger } \\
\text { Tendency } \\
\text { To }\end{array}$ \\
\hline & $\begin{array}{l}\text { Structured with clear introduction, } \\
\text { middle and conclusion; easy to follow } \\
\text { overall direction. }\end{array}$ & & $\begin{array}{l}\text { Structure poor; difficult to follow } \\
\text { points and overall direction. }\end{array}$ & \\
\hline 6 & $\begin{array}{l}\text { Use of words clear; terms, } \\
\text { expressions, acronyms clearly } \\
\text { explained. }\end{array}$ & & $\begin{array}{l}\text { Use of words inappropriate, } \\
\text { redundant, wordy; use of expressions, } \\
\text { jargon confusing/not explained. }\end{array}$ & \\
\hline & $\begin{array}{l}\text { Sentence/paragraph structures and } \\
\text { punctuation straightforward, clear; } \\
\text { easy to follow text. }\end{array}$ & & $\begin{array}{l}\text { Sentence/paragraph structures and/or } \\
\text { punctuation complex, over-elaborate; } \\
\text { difficult to follow text. }\end{array}$ & \\
\hline & $\begin{array}{l}\text { Page layout and use of graphics adds } \\
\text { to interest and understanding. }\end{array}$ & & $\begin{array}{l}\text { Page layout and use of graphics } \\
\text { detracts from interest and } \\
\text { understanding. }\end{array}$ & \\
\hline & $\begin{array}{l}\text { Addresses the brief given for the } \\
\text { exercise. }\end{array}$ & & Brief for exercise not addressed. & \\
\hline
\end{tabular}

\section{Comments.}




\section{Command Interview}

Divisional Commander

\section{Interviewer's Pack}




\section{Introduction}

This pack contains the information required by interviewer's to conduct Command Interviews (CIs) for Divisional Commander (DC) candidates.

Contained in the pack are the following:

- Overview of the structure of the command interview and assessment.

- Descriptions of each stage of the interview and the incident that it simulates.

- Injects, Questions and Target Answers that form the content of the interview.

- Assessment Sheets for interviewer's to record their assessment of the candidate's responses to the simulated incident.

The remainder of this section will briefly go over some general points about interviewing and assessment before going into the pack proper. The $\mathrm{CI}$ is broadly modelled on the Incident Management Implementation Group (IMIG) model of command. This has two general processes of Deciding and Acting under which there are several more detailed elements that focus on the specifics of gathering information, assessing resources, communicating, controlling and evaluating the implementation of an incident plan.

Given that assessment is to be through an interview, the $\mathrm{CI}$ will tend to focus more on Deciding (formulating a plan) than with Acting (implementing the plan). However, the CI has been constructed in such a way that sufficient evidence will be provided for interviewers to judge a candidate's operational competence. Indeed, this process is a valid method for competence assessment.

Please note that the focus is on the candidate's role within the function of command. That is, interviewers should concentrate on competence rather than personality. It is inevitable that personality may influence your assessment, but you should guard against this as much as possible (it could be that a candidate isn't sparkling because he was out on a job the night before). It may seem a bit pie in the sky, but just try to be aware of your personal biases and try to guard against them. It is these very biases that are the reason that the interview (and the whole assessment centre) is based on multiple assessments. What you will be doing is gathering evidence regarding a candidate's competence to operate as an incident commander (IC) at the rank of SDO. So, please frame your assessments within the context of that rank and not some abstract notion of an operational officer.

The quality of the evidence will depend on the quality of the interview. So, please also ensure that the information that you give and your questions are put clearly. You should also allow the candidate the opportunity to raise questions before and after the interview. Your job does not finish when the last question has been asked by you or your fellow interviewer. Some time should be spent at the end to close the interview down with a few comments or a word of encouragement regarding the rest of the assessment centre process. 


\section{Overview}

The scenario for the interview is that the candidate has been called to an 8 pump fire at 31-33 Northwick Terrace at 01.30. From that point on, the interview follows the initial stages of attendance at the incident. This is shown in Figure F1 below. Your job as the interviewers acting in pairs is to walk the candidate through the interview, feeding him with information at certain points, and asking him questions about his responses as he assumes command of the incident.

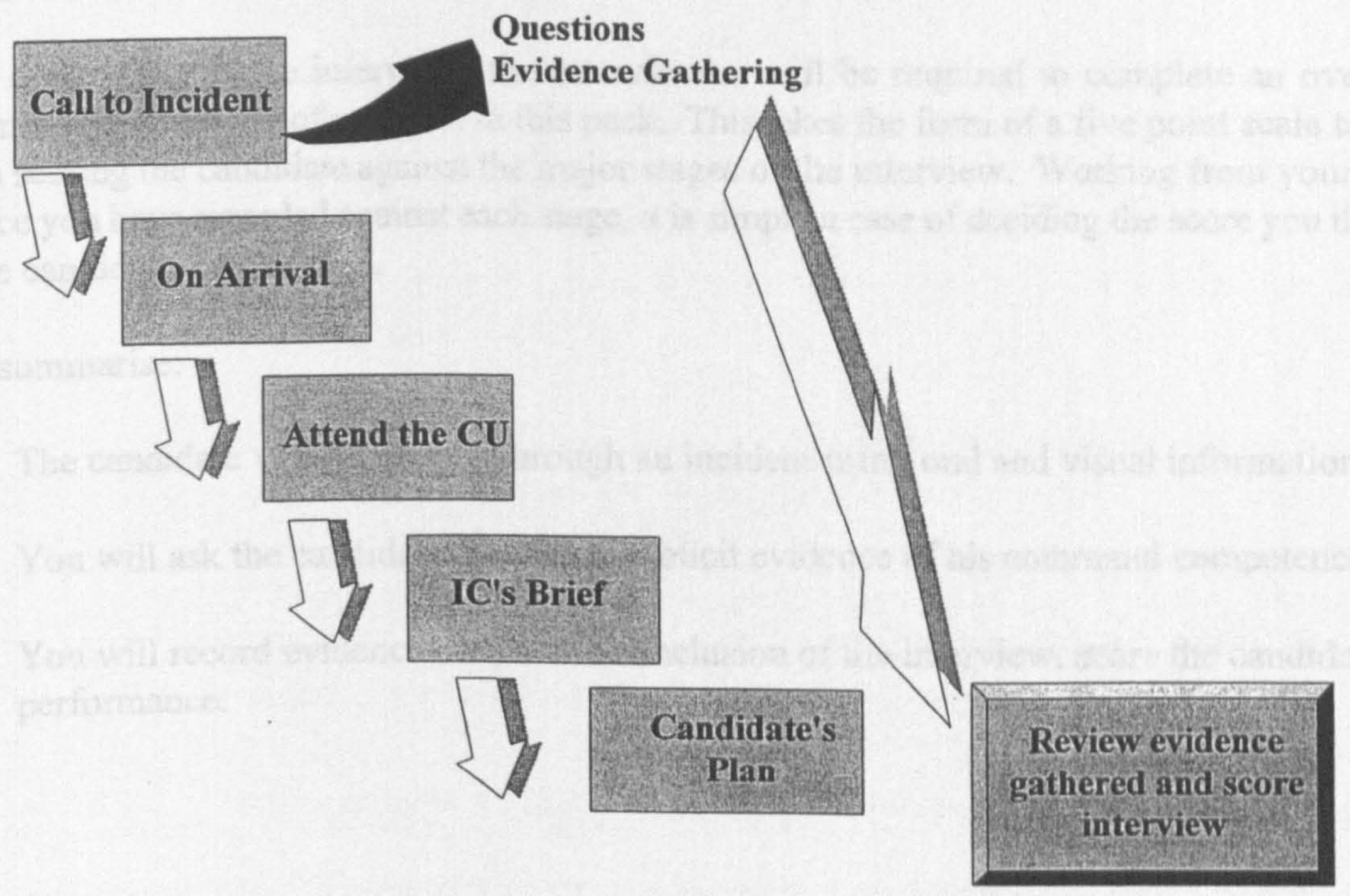

Figure F1: Overview of CI Structure

This will obviously require some division of labour. You may choose to split the roles of questioner and scribe between you for the whole of the interview (i.e. one does scribing and one does interviewing for the entirety of the interview). I would suggest that it will look more professional, be more interesting for you, and help to overcome biases if you switch jobs at certain points in the interview. So, one might act as scribe for the first stage and then swap to become interviewer for the second stage, and so on.

The candidate will receive information in two forms. Orally from the interviewers in setting up the scenario and inputting information as the scenario unfolds. Visually from a flip chart or white board which will give a rough sketch of the incident as you would find on a Command Unit (CU).

This style of structured interbview is referred to as a situational interview since it is based around a simulation of an incident. However, there are limits to the degree of fidelity that can be achieved in such an interview. I would therefore suggest that, while we may well be expanding 
the time normally allowed on the fireground (where things tend to happen much more quickly and far less clearly), we do have an opportunity to get a little way into the candidate's mind and see how it ticks operationally.

We have designed some sheets to help with the evidence gathering you will have to do during the interview. We need this evidence for two reasons; to provide feedback to all candidates and to defend no-go decisions that may arise (i.e. when a candidate has been shown to have considerable development needs as a SDO IC). Sheets for recording this evidence are contained in this pack.

At the conclusion of the interview, the interviewers will be required to complete an overall assessment sheet, a copy of which is in this pack. This takes the form of a five point scale to be used in scoring the candidate against the major stages of the interview. Working from your the evidence you have recorded against each stage, it is simply a case of deciding the score you think that the candidate has merited.

So, to summarise:

- The candidate will be walked through an incident using oral and visual information.

- You will ask the candidate questions to elicit evidence of his command competence.

- You will record evidence and, at the conclusion of the interview, score the candidate's performance. 


\section{The Simulated Incident and Questions.}

This section will take you through the incident, give the oral and visual information that the candidate will receive, the questions through which evidence is to be elicited, and examples of effective and less effective responses.

Introduction:

This interview may be a little different to those that you have sat before.

What we will do is to walk you through an incident that is typical of those attended by SDO's.

We will give you information at different stages of the interview and ask you questions.

What we are looking for are clear and straightforward answers to those questions that tell us how you would deal with the incident.

We are less concerned with your knowledge about procedures, and would like you to concentrate on telling us what you would do to help resolve the incident effectively and efficiently.

Do you have any questions about the interview before we begin?

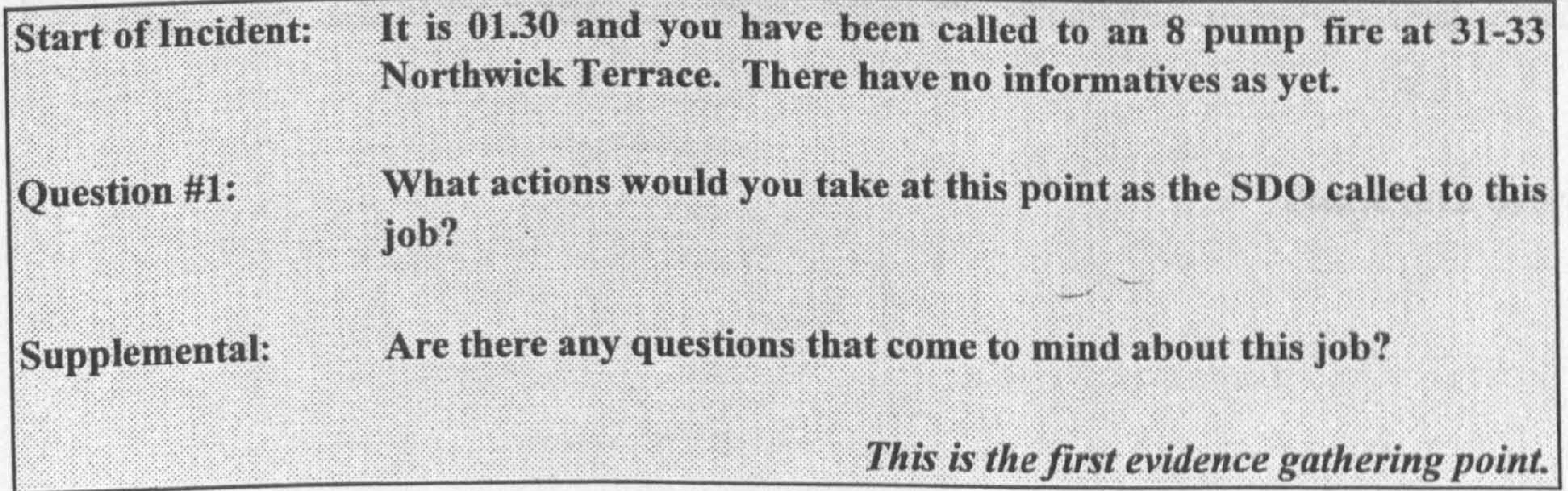

Please turn over 
Arrival:

You arrive at the incident to find the street full of smoke. The job appears to be in a 4 storey Edwardian building with scaffolding in the front. It looks like a 60 metre frontage.

As you walk past the building to the Command Unit, you see a sign for the Northwick Hotel. You see two $45 \mathrm{~mm}$ jets going into two doorways, and an ECO at one of the doors with a pile of tallies at his feet.

Through the doorway you can also see that there is a significant ground floor fire on the left of the building.

Please turn over 


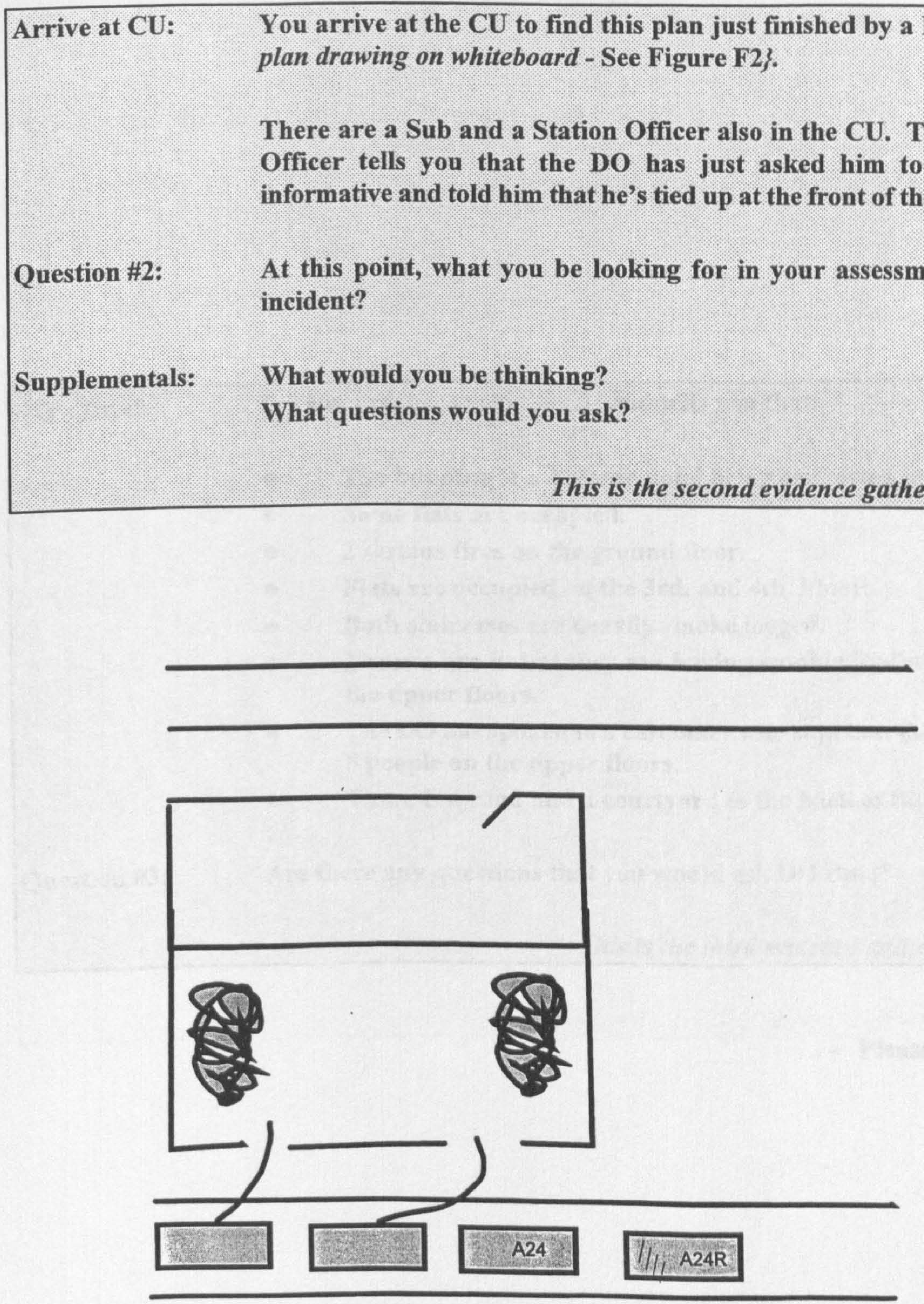

Figure F2: CU Sketch of Incident 
DO's Brief: DO Burt rushes up to the CU and tells you that:

- The building is a 4 storey hotel being converted into flats.

- Some flats are occupied.

- 2 serious fires on the ground floor.

- Flats are occupied on the 3rd. and 4th. Floors.

- Both staircases are heavily smoke logged.

- 2 crews are in but they are having trouble finding access to the upper floors.

- The DO has spoken to a caretaker who says that there may be 8 people on the upper floors.

- There is a road and a courtyard to the back of the building.

Question \#3: Are there any questions that you would ask DO Burt?

This is the third evidence gathering point.

- Please turn over 
Priorities:

Question \#4: With the information that you now have, what do you think are the key priorities in resolving this incident?

This is the fourth evidence gathering point.

If the candidate has not yet assumed command:

Inject: You receive information from a crew that the fire appears to be spreading

\section{Candidate's Plan:}

Question \#5: What would be the outline of your plan for this incident and how would you set about achieving your objectives?

This is the fifth evidence gathering point.

Acting on the Plan: Having set up your plan, what would you be looking for to make sure that the job is going right?

Supplemental: What other considerations would you take into account on a job like this one?

This is the sixth and last evidence gathering point. 


\section{Evidence Gathering}

What you will find in this section is a series of tables to guide you in your collection of evidence at each of the six assessment points during the interview. Recording of evidence can be done by simply checking against an item or noting other information given by the candidate.

Assessment Point 1: Action/questions at first call from CMC.

\begin{tabular}{|c|c|}
\hline Effective & Less Effective \\
\hline $\begin{array}{c}\text { Call control to find out history of makes } \\
\text { pump 8: }\end{array}$ & \\
Who made pumps - LF or higher? \\
Sequential or not? \\
Who is in charge? \\
Time of call (how long has the job been \\
going)? \\
Time of make up? \\
Monitor channels on the way.
\end{tabular} \mid


Assessment Point 2: Arrival at CU.

\begin{tabular}{|c|c|}
\hline Effective & Less Effective \\
\hline $\begin{array}{c}\text { How can we contact the IC? } \\
\text { Have any other messages/make ups been } \\
\text { sent? }\end{array}$ & Leave the CU to see job for self. \\
How many pumps are there? & Begin to formulate a plan immediately. \\
Any specials? & \\
How many of the 8 pumps have arrived? \\
Where are they? \\
Get Do back to CU. \\
Get somebody out to check the CU \\
sketch.
\end{tabular}


Assessment Point 3: Questions following DO Burt's brief?

\begin{tabular}{|c|c|}
\hline Effective & Less Effective \\
\hline $\begin{array}{c}\text { What is your plan?' } \\
\text { What are your resources? } \\
\text { Where are they? } \\
\text { Do you have enough? } \\
\text { Special hazards? } \\
\text { CRR? }\end{array}$ & Criticisms: \\
What is your next step? & procedures? \\
How deep is the building? & Why haven't you sent any messages yet? \\
How wide is the road? & General descent into detail. \\
& \\
Other: & \\
&
\end{tabular}

1 Response to this question raised by candidate: Get 2 jets through front doors, knock down the fire, send BA crews in to gain access to upper floors and search.

2 Response to this question raised by candidate: 20 metres.

3 Response to this question raised by candidate: 5 metres. 
Assessment Point 4: Priorities.

\begin{tabular}{|c|c|}
\hline Effective & Less Effective \\
\hline $\begin{array}{c}\text { What have I got? } \\
\text { Resources for rescues. } \\
\text { Officers resources - sector commanders } \\
\text { \& safety officers. }\end{array}$ & $\begin{array}{c}\text { Set up sectors straight away. } \\
\text { briefed and without further questions. }\end{array}$ \\
$\begin{array}{c}\text { Communication network - Is it working? } \\
\text { Who can I speak to? } \\
\text { Who has been around the back? Is it } \\
\text { clear? }\end{array}$ & $\begin{array}{c}\text { Implement a plan without clear } \\
\text { knowledge of resources. }\end{array}$ \\
& \\
\end{tabular}

4 Response to these questions is that the back has been checked and is clear. 
Assessment Point 5: Plan.

\begin{tabular}{|c|c|}
\hline Effective & Less Effective \\
\hline $\begin{array}{c}\text { Sector commanders. } \\
\text { to upper floors by ladders, protect those } \\
\text { routes, check fire spread to adjacent } \\
\text { buildings, and maintain an effective } \\
\text { attack on the fires on the ground floor. } \\
\text { Search \& rescues by BA crews and } \\
\text { report back. } \\
\text { Secure fireground communications. } \\
\text { BA resources and BA main control. } \\
\text { Support officers. } \\
\text { Maintain close liaison with previous IC. }\end{array}$ & \\
Make up - 12, possible 15. & \\
\end{tabular}


Assessment Point 6: Checking the Plan and Other Considerations.

\begin{tabular}{|c|c|}
\hline Effective & Less Effective \\
\hline Get information from BA crews through \\
sector commanders. & Keep making up. \\
Check actions against the plan. & \\
Considerations: \\
Interservice liaison \\
Press \\
Casualty handling \& clearance \\
Fire safety for fire investigation $\&$ \\
legislation \\
Salvage \& ventilation: Damage control \\
Lighting \\
Reliefs \\
Messages
\end{tabular}

-14- 


\section{Overall CI Assessment}

The sheet shown below is the scoring system for the interview.

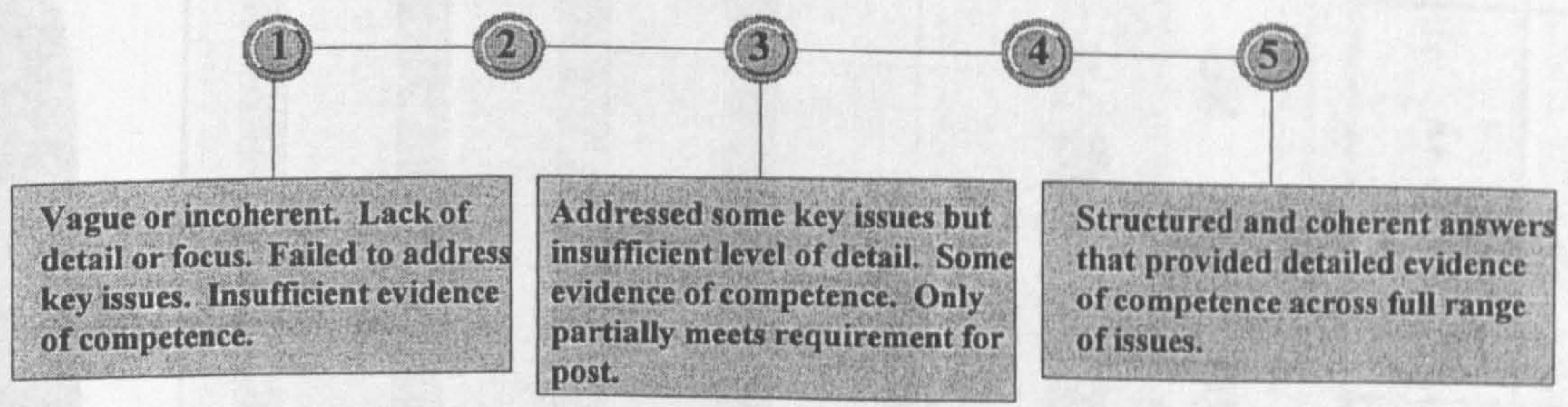

Candidate's Name:

\begin{tabular}{|l|l|}
\hline \multicolumn{1}{|c|}{ Assessment Point } & Candidate's Score \\
\hline $\begin{array}{l}\text { Assessment Point 1: Initial questions and } \\
\text { actions on receipt of call. }\end{array}$ & \\
\hline $\begin{array}{l}\text { Assessment Point 2: Assessment of } \\
\text { incident at CU. }\end{array}$ & \\
\hline $\begin{array}{l}\text { Assessment Point 3: Questions following } \\
\text { Do Burt's brief. }\end{array}$ & \\
\hline \begin{tabular}{l} 
Assessment Point 4: Priorities. \\
\hline Assessment Point 5: Plan.
\end{tabular} & \\
\hline $\begin{array}{l}\text { Assessment Point 5: Acting on the plan } \\
\text { and further considerations. }\end{array}$ & \\
\hline Candidate's Overall Score & \\
\hline
\end{tabular}

Comments: 


\title{
Performance Feedback: Guidance Notes Divisional Commander Development Centre (DCDC)
}

\author{
Prepared by Eugene Burke
}

1. Attached you will find a feedback sheet giving details of your performance on individual components of the DCDC and on the DCDC overall. The chart given in the upper half of this sheet displays the spread of scores for all DCDC candidates in terms of the lowest, average (arithmetic mean as shown by the vertical line) and highest scores. Your scores are shown in red in the table given in the lower half of the page.

2. The purpose of these notes is to remind you of the exercises and to explain how the scores shown on the feedback sheet were constructed. In some cases, such the DWS score, the scoring process is quite complex. However, I will be happy to discuss these scores with you personally, and, as noted at the end of these notes, you will be invited to a development feedback interview at which these scores will be explained in more detail. Should you with to arrange an appointment with me then please call either 6314 or 6312 .

3. The scores on individual components of the DCDC are as follows:

Dealing With Information (DWI). This score is your average percentile across the three ability tests (verbal, numerical and general reasoning). A percentile score tells you where in a given norm (comparison) population your score places you. It is not the percentage of questions that you answered correctly. So, a percentile of 50 would put someone in the middle of a norm population; i.e. having scored higher than or obtained the same score as $50 \%$ of that population. The norm population used for the tests that you sat was 2,000 UK male middle and senior managers working in both the private and public sectors with an age range of 20 through to 64 . As yet, we do not have a large enough sample of scores for LFB personnel to generate an in-house set of percentiles for these tests, so an external UK population norm was used.

Dealing With Situations (DWS). This was the questionnaire that asked you how you would typically approach or respond to a variety of situations (hence our working title for it). This questionnaire is based on a published questionnaire that has been adapted in consultation with the authors for use in the LFB. The score given on the feedback sheet is a percentage score which has been derived as follows:

- The questions in the DWS questionnaire relate to several different scales and your responses were first scored on these scales. Each scale score was then translated to a percentile score using a norm group we built up of 178 LFB uniformed personnel. So, for the DWS questionnaire, we have applied an in-house norm group.

Last summer I conducted a job analysis that examined the links between the DWS scales and performance on key activities at the principal officer level within the LFB. The sample for the job analysis comprised existing uniformed and non-uniformed principal officers. 
- The percentile score on each scale is translated into a performance expectancy score using a scoring procedure based on the job analysis results. Your score derived from this method is then divided by the maximum possible score to give the percentage DWS score shown on the feedback sheet.

- What this score represents is not a preferred principal officer profile, but an indication of adjustment or match to expectations of LFB principal officers.

Committee. This is a percentage score based on the maximum score possible for this exercise. You were independently assessed on this exercise by two assessors and their scores have been summed to give an overall exercise score for you. Please note that our analysis of the data gathered through the Assistant Chief Development Centre (ACDC) and the Director of Property and Technical Services Assessment Centre (DPTSAC) shows that committee scores are not dependant on particular options for either individual candidates or groups of candidates.

Communication. This score is also a percentage of the maximum score possible and represents the average of two exercises; the oral presentation and the written brief. As per the presentation, your written brief was also assessed by three assessors. However, the brief was assessed blind (your name was removed from the copies assessed) and by assessors who did not observe your presentation. This therefore gives two independent contributions to the assessment of your overall communication skills.

In Tray. This exercise comprised two parts; an analysis of information on each of three options and a justification for the choice of one option for further action. The scoring of this exercise represents a combination of the number of critical items identified in the analysis phase of the exercise, and the number of critical items and their evaluation in comparison to the alternative rejected options presented in the recommendation phase of the exercise. Again, your score is a percentage of the maximum possible on this exercise.

DCDC. This is a weighted combination of scores on the individual components just described (DWI through to In Tray). The weights were decided by the short listing panel and allow for a balance of strengths across all DCDC components. Thus, a lower score on any single component can be compensated for by higher scores on one or more other components. That is, there is no pass or fail on any individual component, and the DCDC score gives an overall index of personal development at the level of principal officer.

4. The feedback sheet serves one simple purpose - to give you a straightforward summary $;$ of your performance and to allow you to compare your performance against the full group of DCDC candidates. It is therefore a performance feedback sheet and not a fersonal development plan as a discussion with you is necessary before such a plan can be drawn up. It is the intention that this information will be used as a basis to discuss f with you your personal development needs. An interview for this purpose will be

arranged by the Management Development Manager. 
5. This feedback sheet is also confidential to you. While your scores have been discussed in the course of short listing candidates for the interview stage of the SDO promotion round, all papers containing scores are kept by me and will not be released to a third party without your consent. As I have said earlier in this note, I will be happy to meet with you if you have any questions regarding the feedback sheet and the DCDC process.

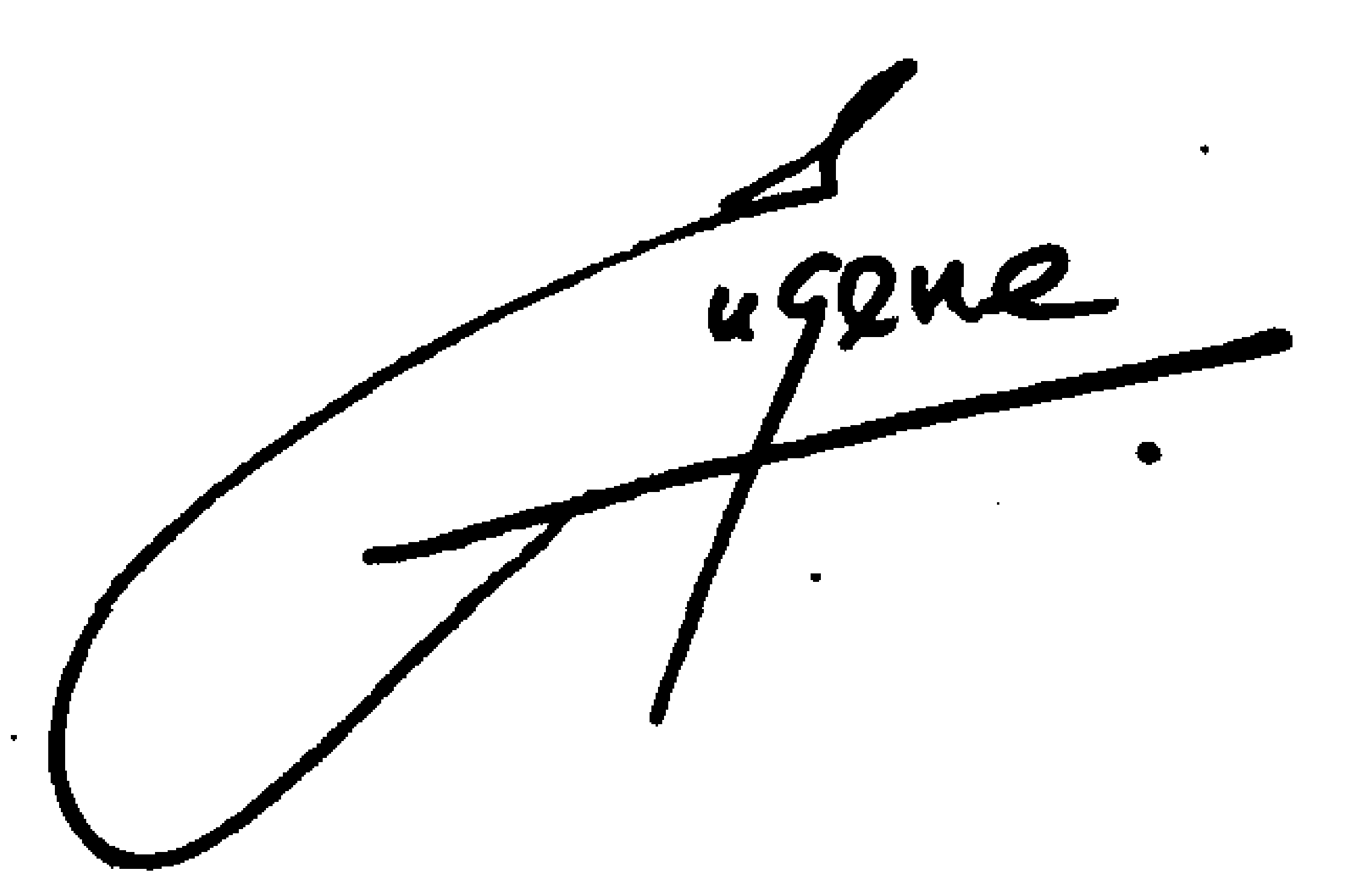




\section{Appendix C}

Extracts from

MCI Standards

M1 and M2
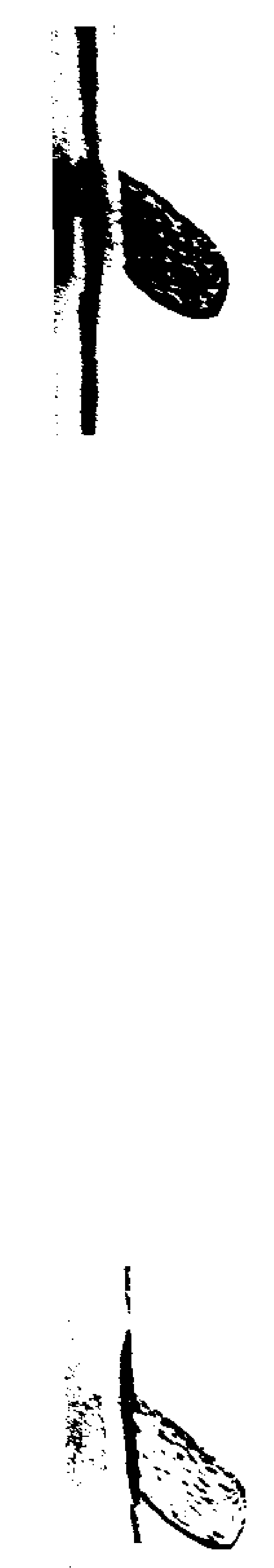


\section{Structure of the Management Standards}

The Management Standards define what a manager should be able to do. They Qescribe the results and outcomes a Competent manager should be able to Droduce. This section describes the structure of a Management Standard.

The Management Standards are set out in a hierarchy of:

- key purposes

- key roles

- units of competence

- elements of competence.

\section{Key purpose}

At the top of the structure is the key purpose of managers. This has been expressed as:

To achieve the organisation's objectives and continuously improve its performance.

\section{Key roles}

These represent the different areas in which managers are expected to operate. There are four key roles, representing the areas of:

- operations

- finance

- people

- information.

\section{Units of competence}

Each key role is made up of a number of units of competence. These describe in broad terms what is expected of a competent manager in particular aspects of the job.

\section{Elements of competence}

Each unit consists of a number of elements of competence. These reflect the skills, knowledge and abilities that managers are expected to possess. Elements are the basis for assessment.

\section{Performance criteria}

Each element is described by performance criteria which specify the outcomes which a manager has to achieve in order to demonstrate competent performance. These are the basis upon which evidence of competence is judged by the assessor.

\section{Range indicators}

For each element there is a set of range indicators which describe the range of instances and situations in which the element is applied.

\section{Evidence required}

In order to facilitate the development of evidence to meet the requirements of NVQs and SVQs, MCI has developed evidence specifications for each element of the Management Standards. These outline the source and form of evidence required to ensure that competent performance is achieved.

\section{Unit summaries}

To help employers, managers, management developers and educational providers understand the Management Standards, short descriptions of the skills, knowledge and abilities covered by each unit - clusters of elements - are shown on pages 13 to 18. It maybe be useful for the reader to familiarise themselves with these summaries before examining the elements in detail.
First Line

Management

Standards 
First Line

Management

Standards

\section{Overview of the First Line Management Standards}

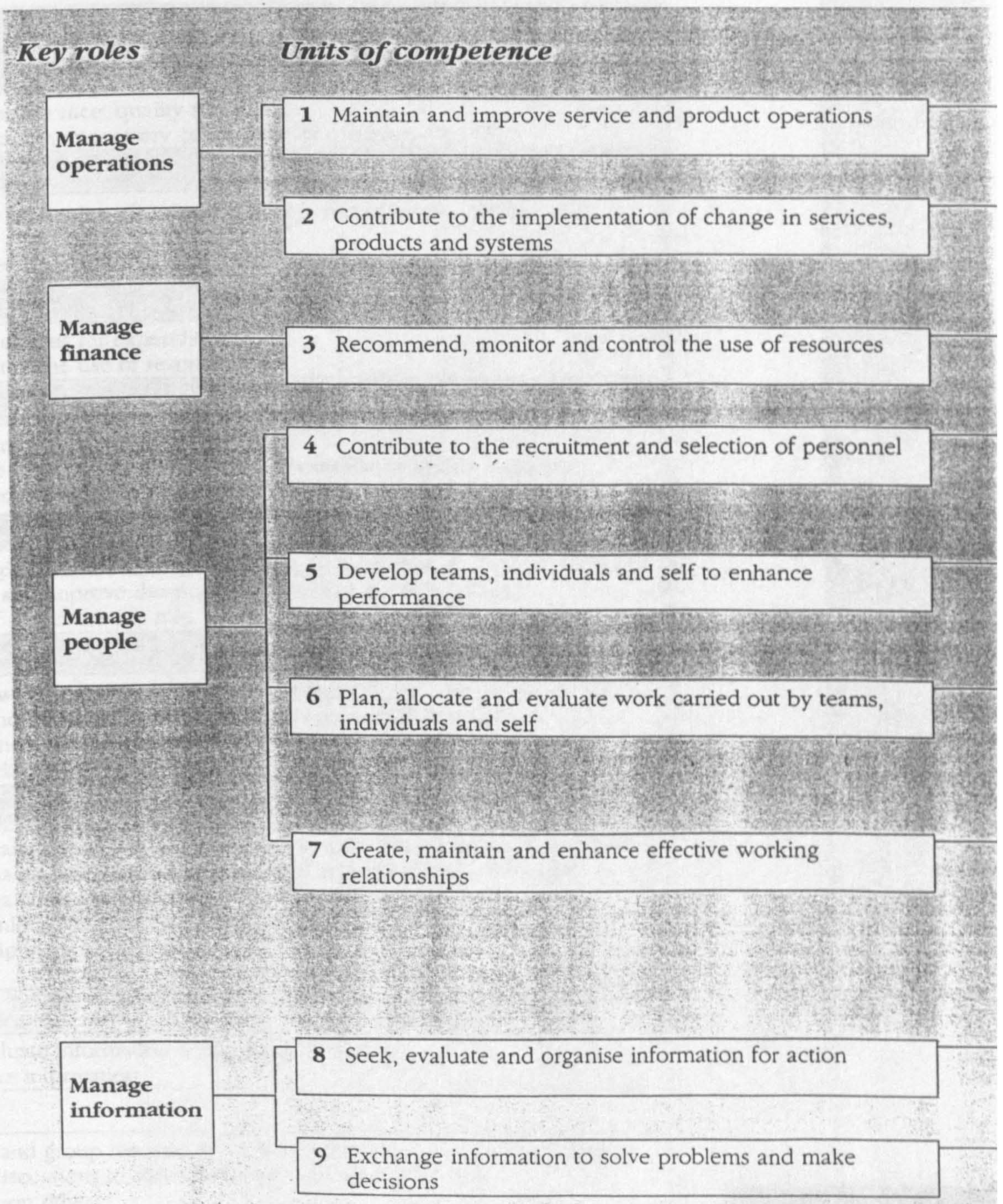




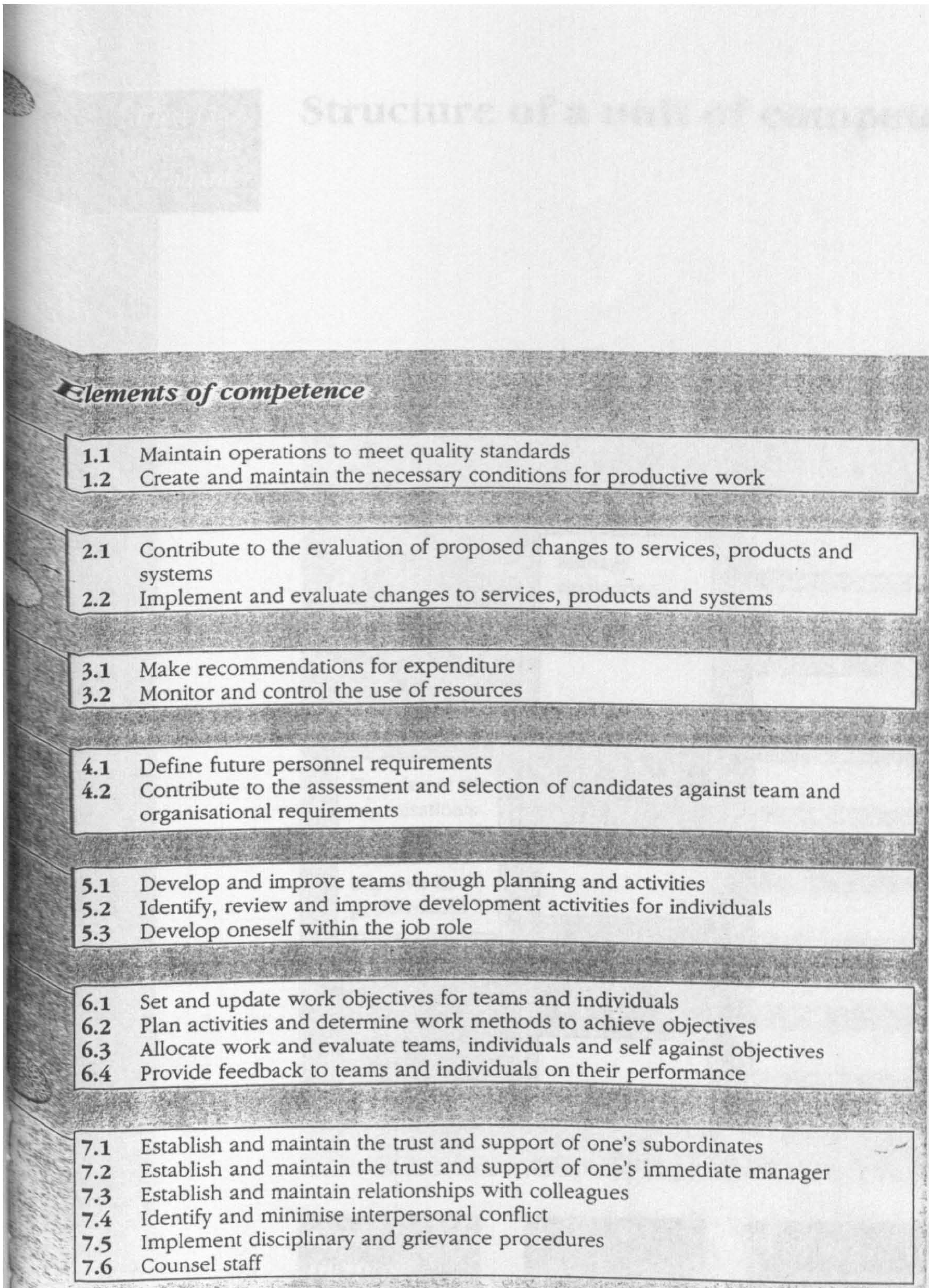

\section{lements of competence}

1.1 Maintain operations to meet quality standards

1.2 Create and maintain the necessary conditions for productive work

2.1 Contribute to the evaluation of proposed changes to services, products and systems

2.2 Implement and evaluate changes to services, products and systems

3.1 Make recommendations for expenditure

3.2 Monitor and control the use of resources

4.1 Define future personnel requirements

4.2 Contribute to the assessment and selection of candidates against team and organisational requirements

5.1 Develop and improve teams through planning and activities

5.2 Identify, review and improve development activities for individuals

5.3 Develop oneself within the job role

6.1 Set and update work objectives for teams and individuals

6.2 Plan activities and determine work methods to achieve objectives

6.3 Allocate work and evaluate teams, individuals and self against objectives

6.4 Provide feedback to teams and individuals on their performance

7.1 Establish and maintain the trust and support of one's subordinates

7.2 Establish and maintain the trust and support of one's immediate manager

7.3 Establish and maintain relationships with colleagues

7.4 Identify and minimise interpersonal conflic

7.6 Counsel staff

8.1 Obtain and evaluate information to aid decision making

8.2 Record and store information

9.1 Lead meetings and group discussions to solve problems and make decisions

9.2 Contribute to discussions to solve problems and make decisions

9.3 Advise and inform others 
First Line

Management

Standards

\section{Structure of a unit of competence}

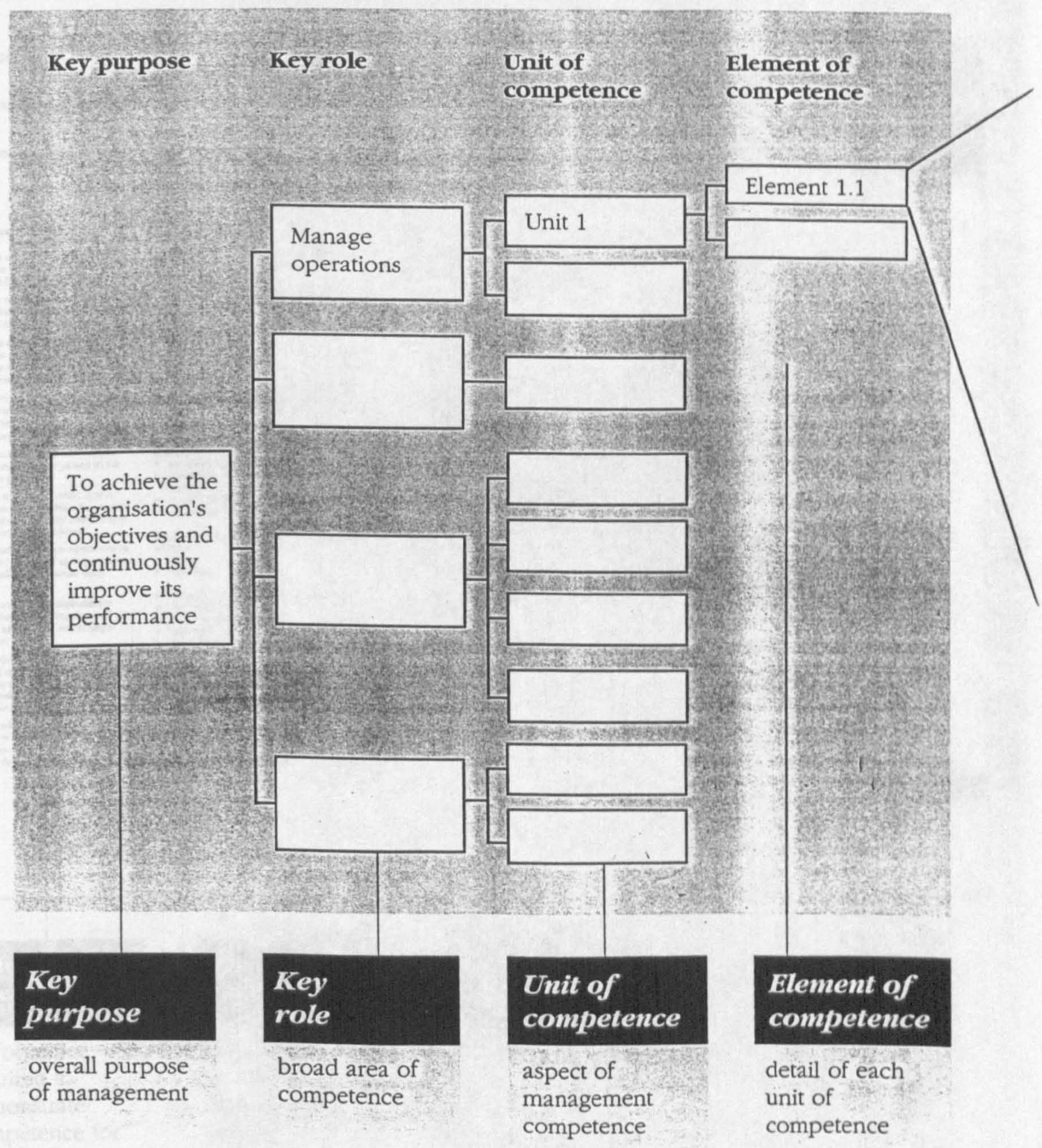




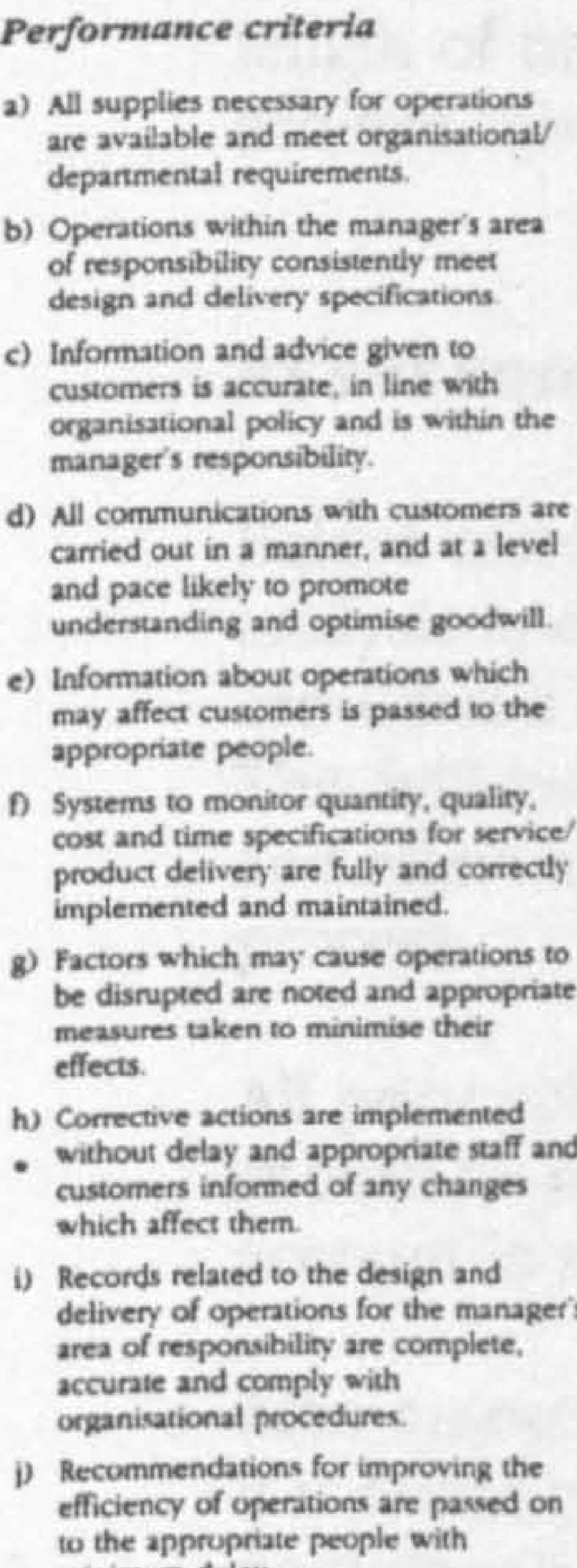

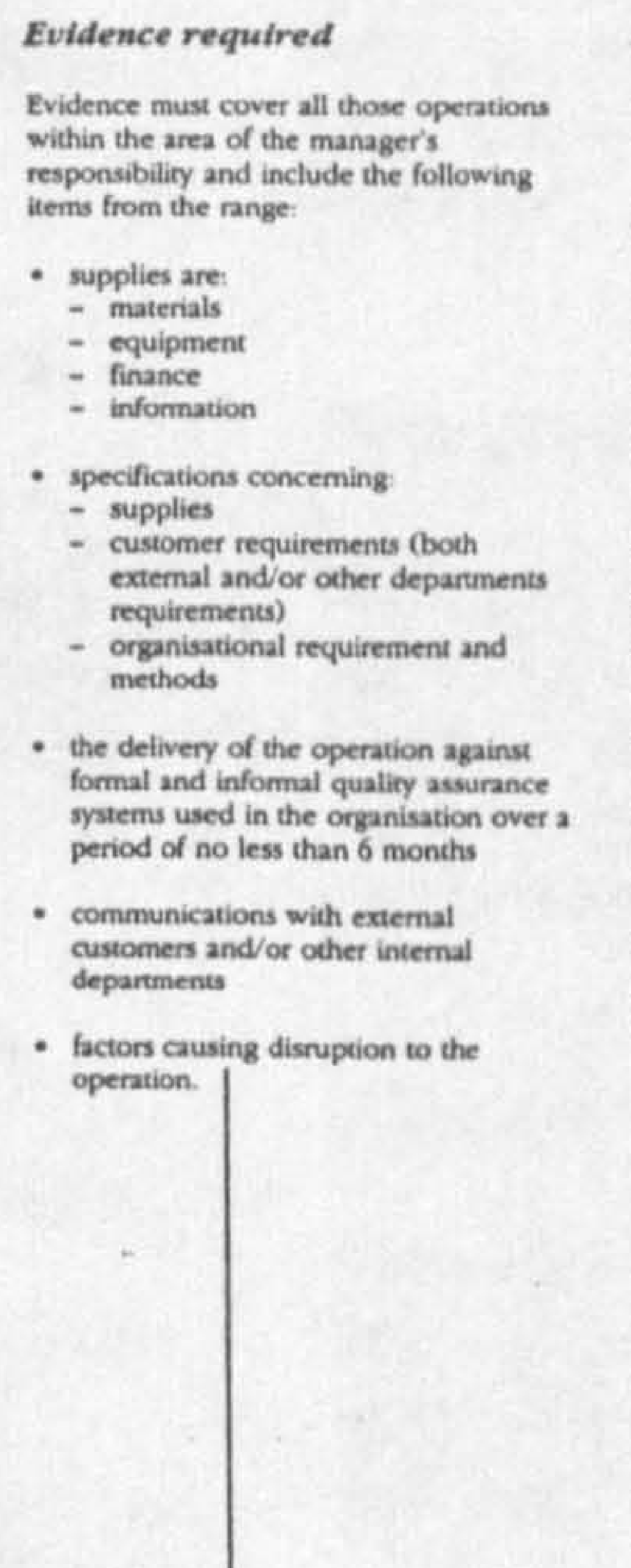

\section{Source of evidence}

The manager's performance in the
workplace over a period of time

Forms of evidence

Evidence should take the form of outputs and products of performance, dired form of witness testimony, quertioning and a penonal repon on actions that have or would be undertaken to achieve the

Some aspects of the range and the contingencies implied in the performance criteria may not be sufficiently demonstrated from performance and its ourpus alone. Additional evidence of therefore be required.

This should include knowledge of the factors which may cause disnuption and whe appropriate contingency measures to basic principles and methods relating to resource untilisation and control and qualioy assurance should also be demonstrated.
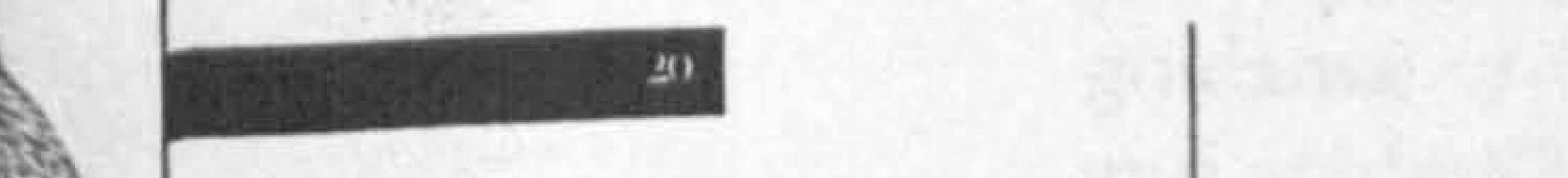

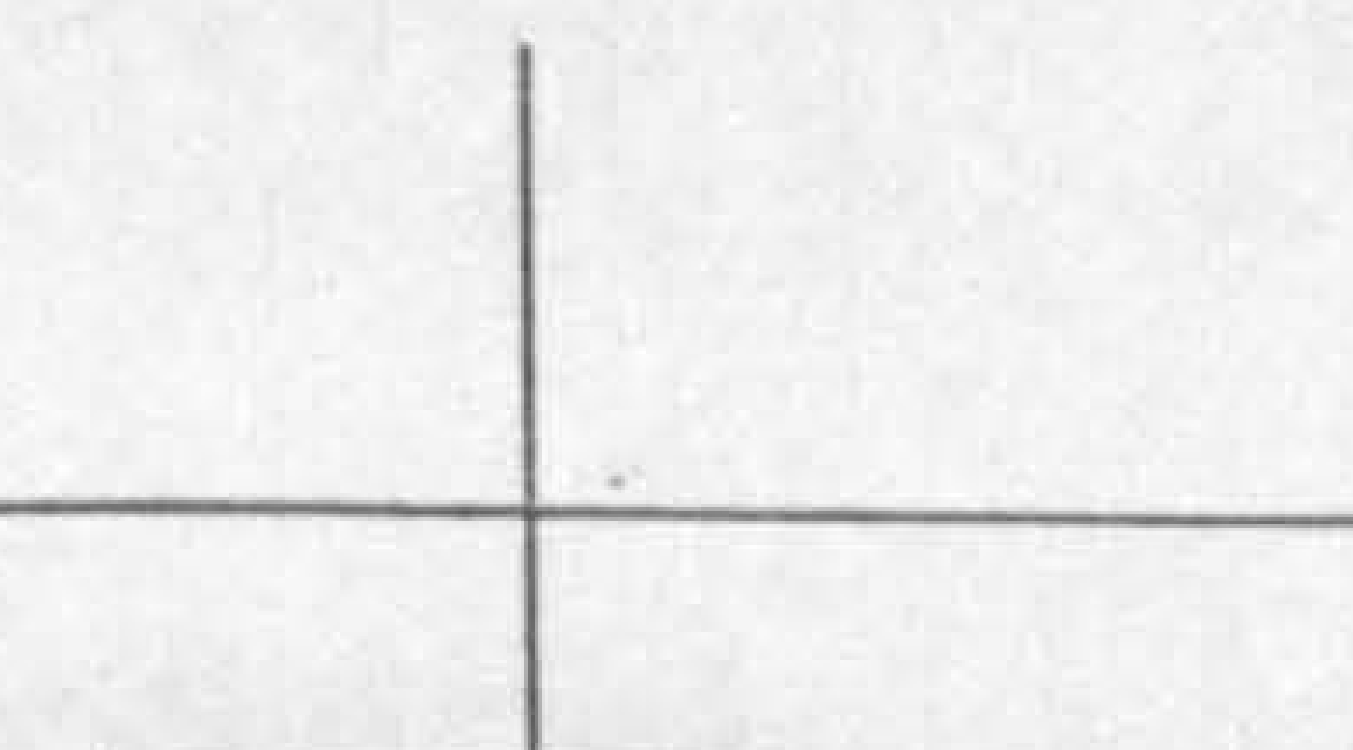

\section{Range}

Performance criteria

performance required to demonstrate competence for each element

\section{indicators}

circumstances

in which competence needs to be demonstrated
Evidence
required
sources and
forms of
evidence that
may be used to
demonstrate
competent
performance 


\section{$x_{n=2}$ \\ Aim of assessment}

The aim of assessment procedures against the Management Standards is to establish whether or not a manager is competent at their job.

There should be no constraints on the length of time required for an individual to achieve this competence.

\section{Assessment of previous work}

Before assessment can begin, a brief analysis is essential in order to establish a candidate's existing level of achievement. This will help in devising an economical and relevant learning programme or process.

All prior achievement and experience should be recognised and taken into account in the overall assessment process.

After assessment of existing achievements, it is recommended that prospective participants are given counselling and guidance to establish an agreed relevant and achievable action plan. This could take the form of a learning contract.

\section{Range of assessment}

Assessment for the Management Standards must only cover performance of the activities described in the Standards.

A candidate must display background knowledge to indicate understanding of how to apply actions in differing situations.
If evidence from performance is insufficient, assessment should include questions to elicit the candidate's knowledge and understanding of the basic principles directly relating to the competent performance of elements and performance criteria. An assessment interview may be useful for obtaining this, and for ascertaining understanding of the implications of performing in different contexts.

\section{Acceptable assessment systems}

Assessment systems and processes should be free from overt or covert discriminatory practices with regard to gender, race and/or creed, and pay due regard to the special needs of candidates.

They must be clear and credible to the candidates and employers.

Assessment systems should also be effective, economic and sufficiently rigorous to ensure the validity of the decisions made.

\section{Conditions for valid assessment}

Assessment must be made against the elements of competence in the First Line Management Standards. All performance criteria must be satisfied and the required evidence provided in the forms specified.

Over a period of time, every element must be assessed to ensure that competence is firmly established. Consistency of performance should be a prime consideration. 
All methods used for assessment must be appropriate to the performance being Zssessed. In practice this will call for a variety of modes of assessment and forms of evidence (see Assessment Guidelines for further information).

Assessment must allow for credit accumulation and transfer, and individuals should be able to obtain a record of a chievement for each unit of competence obtained. The full NVQ/SVQ is based on achievement of all the units of competence.

All assessment must be based on evidence of performance in the workplace. Where this is not possible, evidence from other sources must be sufficient to convince the assessor that the candidate is competent.

\section{Evidence needed for assessment}

Assessment should be based on the collection and weighing of evidence. The evidence must:

- clearly relate to the First Line Management Standards, with specific links made to the units and elements of competence and their associated performance criteria

- cover all the performance criteria for achievement of an element if it is to be credited

- cover those aspects of the range described in the evidence requirements detailed against each element

- be sufficient to enable the assessor to make an informed judgement about competent performance

- be based on current performance. In the absence of sufficient evidence from this source, additional evidence based on previous performance in differing contexts may be used

- be drawn from more than one source, since one item of evidence without corroboration would not be regarded as sufficient for a candidate to be deemed competent

- be provided from a reliable source and be firmly based on the outcome described in the elements and performance criteria

- describe the activities required by the occupational role as a whole rather than a fragmented and over-detailed list of tasks

- be presented in a manner to facilitate decision making on competent performance by the assessor

- allow assessors to distinguish between those who meet the First Line Management Standards and those who do not

- be based on the candidate's own work. In some elements this may be based on . activities undertaken in non-managerial. roles and in other contexts such as non-paid employment.

Evidence from the past must be assessed for its suitability and applicability in making judgements about current competence.

If the evidence presented describes team activity, assessment should be confined to the role played by the individual. 


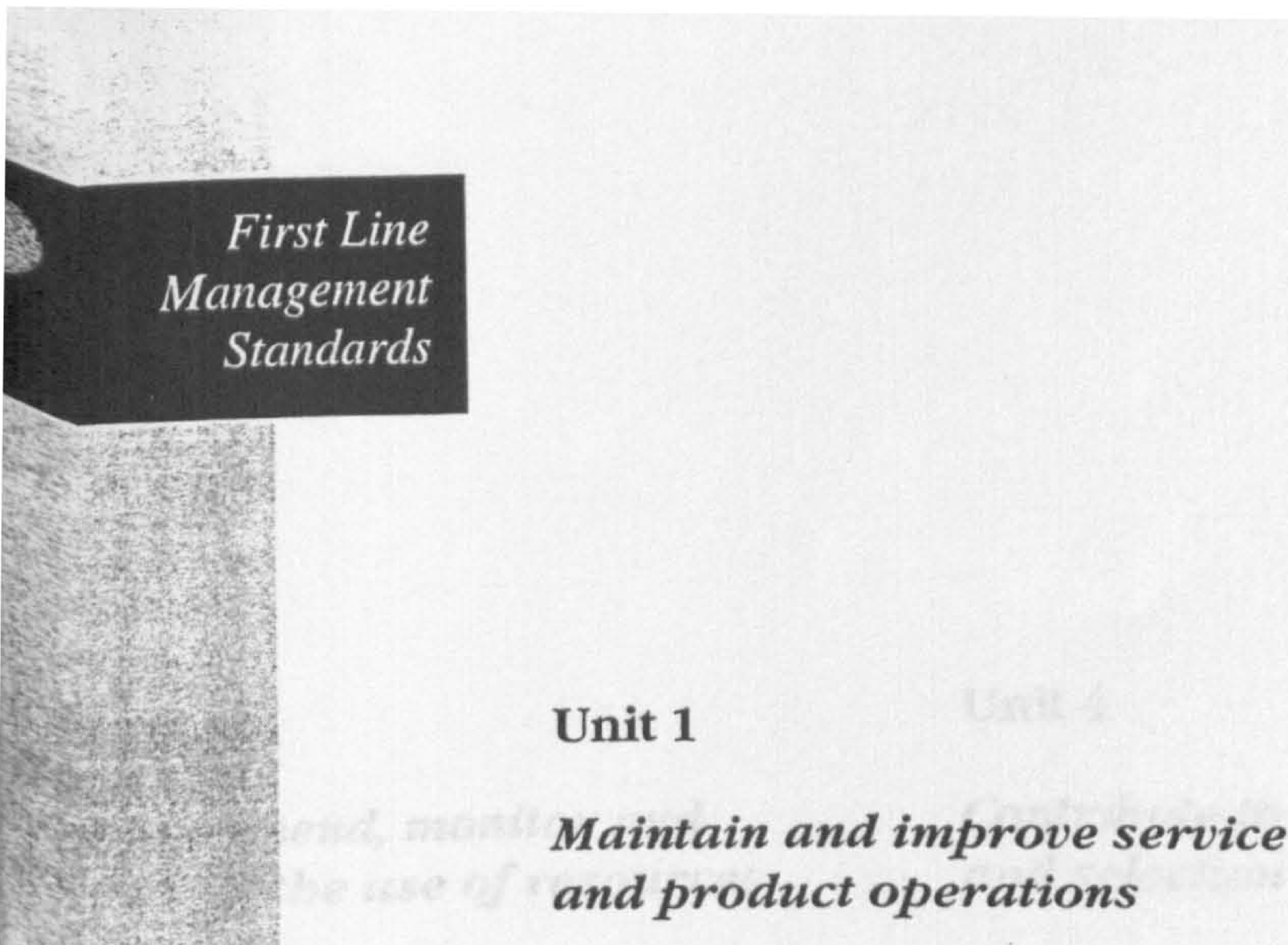

Key words

- Operations maintenance, control and improvement of quality

- Health and safety

- Progress monitoring and reporting

- Resource control and allocations

- External and internal communications

\section{General description}

This unit covers operations maintenance, the application of quality control systems, and health and safety legislation. It includes:

- dealing with factors causing disruption to operations.

- maintaining resources

- actions taken to ensure that necessary supplies are available

- communications with customers (both internal and external), staff and specialists

- giving and receiving feedback

- progress reporting to senior managers.

\section{Unit 2}

Contribute to the

implementation of change in services, products and systems

\section{Key words}

- Managing change

- Analysing suggestions and options

- Presenting recommendations

- Implementing new methods of working

- Monitoring and evaluating results

- Making modifications

\section{General description}

This unit covers the review and analysis of feedback on proposed changes to services, products and systems within the manager's control. It includes:

- making recommendations to senior managers and specialists on their potential implications

-_implementing, monitoring and evaluating agreed changes

- making necessary modifications. 


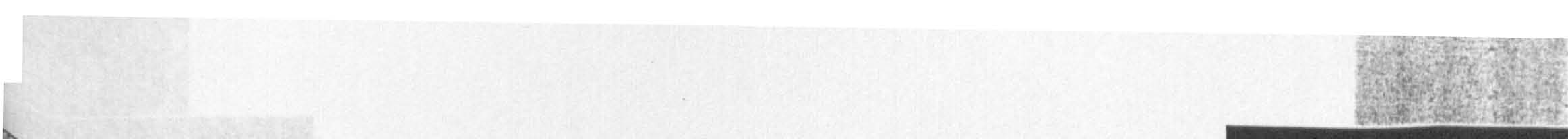

First Line

Management

Standards

\section{Unit 3}

\section{Recommend, monitor and control the use of resources}

\section{Key words}

- Requesting resources and items of expenditure

- Resource control

- Authorising and certifying expenditure

- Reporting financial performance

\section{General description}

This unit covers requesting items of new and existing expenditure needed to meet operational demands. It includes:

- monitoring and controlling the use of resources

- procedures for authorising expenditure

- analysis and recording of information

- making recommendations on resource utilisation and control.

\section{Unit 4}

\section{Contribute to the recruitment and selection of personnel}

\section{Key words}

- Defining personnel requirements

- Developing job specifications

- Assessing job applications

- Assisting in selection procedures

\section{General description}

This unit covers the manager's informal and formal role in defining future personnel requirements and assisting in the assessment and selection of suitable candidates. It includes:

- analysis of personnel requirements

- developing job specifications

- involvement in setting selection criteria.

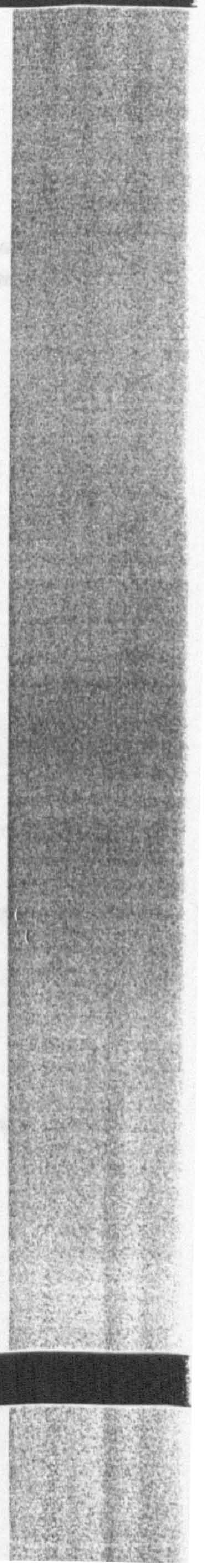




\section{Unit 5}

\section{Develop teams, individuals and self to enbance performance}

\section{Key words}

- Assessing current competence

- Self and team development

- Identifying training and development needs

- Reviewing progress

\section{General description}

This unit covers self development and actions undertaken by the manager to develop teams and individuals to improve their performance. It involves:

- self development

- assessment of current competence

- analysing learning and development needs

- planning

- ensuring that appropriate development takes place

- reviewing progress.

\section{Unit 6}

\section{Plan, allocate and evaluate work carried out by teams, individuals and self}

\section{Key words}

- Setting work objectives

- Defining work methods

- Performance targets

- Work allocation

- Providing feedback

\section{General description}

This unit covers the setting and updating of work objectives and managing work flows. It includes:

- planning and defining work methods

- allocating tasks

- reviewing progress against agreed objectives

- applying legal and organisational requirements

- working within constraints

- communications

- giving feedback on performance. 


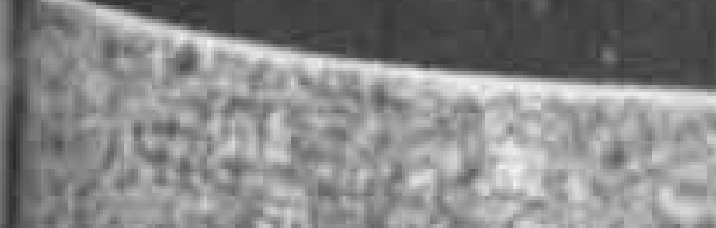 \\ Unit 9 \\ Exchange information to solve problems and make decisions}

\section{Key words}

- Chairing and participating in meetings

- Preparing papers

- Presenting proposals

\section{General description}

This unit covers leading and taking part in formal and informal meetings and discussion groups with colleagues, suppliers, customers, specialists and staff. It includes:

- arranging meetings

- preparing agendas and papers

- presenting clear arguments and information in a suitable manner and format

- managing discussions

- handling disagreements and conflicting views

- clarifying and summarising points made

- follow up action. 


\section{Unit 7}

\section{Create, maintain and enbance effective working relationships}

\section{Key words}

- Inter-personal relationships

- Conflict management

- Diciplinary and grievance procedures

- Counselling staff

\section{General description}

This unit covers establishing and maintaining effective working relationships with colleagues, staff and one's immediate manager. It includes:

- identifying and minimising potential conflict

- applying grievance and disciplinary procedures

- counselling staff on problems affecting their work

- networking with colleagues and external contacts

- actions taken to secure line manager support and confidence.

\section{Unit 8}

\section{Seek, evaluate and organise information for action}

\section{Key words}

- Analysis and evaluation

- Information management

- Storage and retrieval

- Computerised information management

\section{General description}

This unit covers gathering, assessing, recording and storing relevant information to assist in decision making on issues concerning the manager's team. It includes:

- applying legal and organisational requirements relating to confidential material

- use of computerised systems.
First Line

Management

Standards 


\section{Middle \\ Management Standards \\ Overview of the Middle Management Standards}

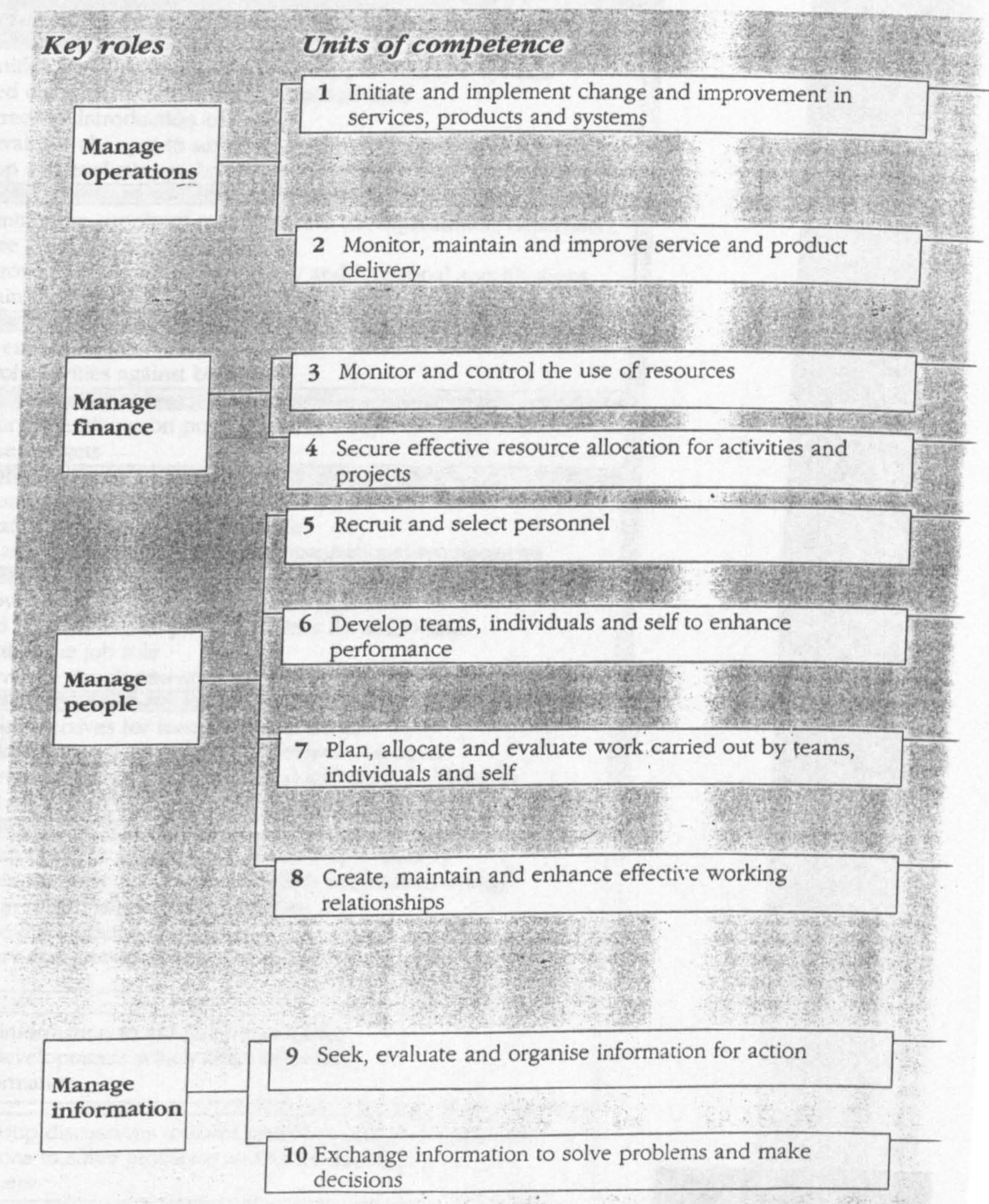




\section{Elements of competence}

1.1 Identify opportunities for improvement in services, products and systems

1.2 Evaluate proposed changes for benefits and disadvantages

1.3 Negotiate and agree the introduction of change

1.4 Implement and evaluate changes to services, products and systems

1.5 Introduce, develop and evaluate quality assurance systems

2.1 Establish and maintain the supply of resources into the organisation/department

2.2 Establish and agree customer requirements

2.3 Maintain and improve operations against quality and functional specifications

2.4 Create and maintain the necessary conditions for productive work activity

3.1 Control costs and enhance value

3.2 Monitor and control activities against budgets

1 Justify proposals for expendiure on projects

4.1 Justify proposals for expenditure on projects

4.2 Negotiate and agree budgets

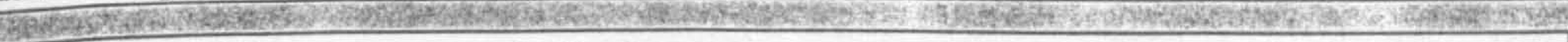

5.1 Define future personnel requirements

5.2 Determine specifications to secure quality people

5.3 Assess and select candidates against team and organisational requirements

6.1 Develop and improve teams through planning and activities

6.1 Identify, review and improve development activities for individuals

6.3 Develop oneself within the job role

6.4 Evaluate and improve the development processes used

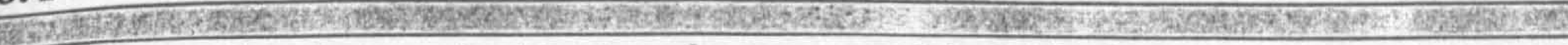

7.1 Set and update work objectives for teams and individuals

7.2 Plan activities and determine work methods to achieve objectives

7.3 Allocate work and evaluate teams, individuals and self against objectives

7.4 Provide feedback to teams and individuals on their performance

8.1 Establish and maintain the trust and support of one's subordinates

8.2 Establish and maintain the trust and support of one's immediate manager

8.3 Establish and maintain relationships with colleagues

8.4 Identify and minimise interpersonal conflict

8.5 Implement disciplinary and grievance procedures

8.6 Counsel staff

9.1 Obtain and evaluate information to aid decision making

9.2 Forecast trends and developments which affect objectives

9.3 Record and store information

10.1 Lead meetings and group discussions to solve problems and make decisions

10.2 Contribute to discussions to solve problems and make decisions

10.3 Advise and inform others 